\title{
Conflict, Security and the Reshaping of Society
}

The civilization of war

Edited by

Alessandro Dal Lago and Salvatore Palidda

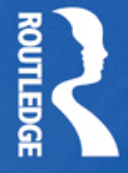

Routledge Studies in Liberty and Security 


\section{Conflict, Security and the Reshaping of Society}

This book is an examination of the effect of contemporary wars (such as the 'War on Terror') on civil life at a global level.

Contemporary literature on war is mainly devoted to recent changes in the theory and practice of warfare, particularly those in which terrorists or insurgents are involved (for example, the 'revolution in military affairs', 'small wars', and so on). On the other hand, today's research on security is focused, among other themes, on the effects of the war on terrorism, and on civil liberties and social control. This volume connects these two fields of research, showing how 'war' and 'security' tend to exchange targets and forms of action as well as personnel (for instance, the spreading use of private contractors in wars and of military experts in the 'struggle for security') in modern society. This shows how, contrary to Clausewitz's belief that war should be conceived of as a 'continuation of politics by other means', the opposite statement is also true: that politics, insofar as it concerns security, can be defined as the 'continuation of war by other means'.

This book will be of much interest to students of critical security studies, war and conflict studies, terrorism studies, sociology and international relations in general.

Alessandro Dal Lago is Professor of Sociology of Culture and Communication at the University of Genoa. Salvatore Palidda is Professor of Sociology in the Faculty of Education at the University of Genoa. 


\section{Routledge studies in liberty and security}

Series editors: Didier Bigo, Elspeth Guild and R.B.J. Walker

This book series will establish connections between critical security studies and international relations, surveillance studies, criminology, law and human rights, political sociology and political theory. To analyse the boundaries of the concepts of liberty and security, the practices which are enacted in their name (often the same practices), will be at the heart of the series. These investigations address contemporary questions informed by history, political theory and a sense of what constitutes the contemporary international order.

Terror, Insecurity and Liberty

Illiberal practices of liberal regimes after $9 / 11$

Edited by Didier Bigo and Anastassia Tsoukala

Exceptionalism and the Politics of Counter-Terrorism

Liberty, security and the War on Terror

Andrew W. Neal

Muslims in the West after $\mathbf{9 / 1 1}$

Religion, politics and law

Edited by Jocelyne Cesari

Mapping Transatlantic Security Relations

The EU, Canada and the War on Terror

Edited by Mark B. Salter

Conflict, Security and the Reshaping of Society

The civilization of war

Edited by Alessandro Dal Lago and Salvatore Palidda 


\section{Conflict, Security and the Reshaping of Society \\ The civilization of war}

Edited by Alessandro Dal Lago and Salvatore Palidda 
First published 2010

by Routledge

2 Park Square, Milton Park, Abingdon, Oxon OX14 4RN

Simultaneously published in the USA and Canada

by Routledge

270 Madison Avenue, New York, NY 10016

Routledge is an imprint of the Taylor \& Francis Group, an informa business

This edition published in the Taylor \& Francis e-Library, 2010.

To purchase your own copy of this or any of Taylor \& Francis or Routledge's collection of thousands of eBooks please go to www.eBookstore.tandf.co.uk.

C) 2010 Selection and editorial matter, Alessandro Dal Lago and Salvatore Palidda; individual contributors, their contributions

All rights reserved. No part of this book may be reprinted or reproduced or utilized in any form or by any electronic, mechanical, or other means, now known or hereafter invented, including photocopying and recording, or in any information storage or retrieval system, without permission in writing from the publishers.

British Library Cataloguing in Publication Data

A catalogue record for this book is available from the British Library

Library of Congress Cataloging-in-Publication Data

A catalog record has been requested for this book

ISBN 0-203-84631-1 Master e-book ISBN

ISBN10: 0-415-57034-4 (hbk)

ISBN10: 0-203-84631-1 (ebk)

ISBN13: 978-0-415-57034-3 (hbk)

ISBN13: 978-0-203-84631-5 (ebk) 


\section{Contents}

Notes on contributors

vii

Acknowledgements

Introduction

ALESSANDRO DAL LAGO AND SALVATORE PALIDDA

\section{PART I}

The constituent role of armed conflicts

1 Fields without honour: contemporary war as global enforcement

ALESSANDRO DAL LAGO

2 The barbarization of peace: the neo-conservative transformation of war and perspectives

ALAIN JOXE

3 Norm/exception: exceptionalism and governmental prospects in the shadow of political theology

ROBERTO CICCARELLI

4 Reversing Clausewitz? War and politics in Foucault, Deleuze-Guattari and Aron 
vi Contents

PART II

Securization

614 September 2001: the regression to the habitus DIDIER BIGO

7 Revolution in police affairs

SALVATORE PALIDDA

8 Surveillance: from resistance to support

ERIC HEILMANN

9 Enemies-criminals: the law and courts against global terrorism

GABRIELLA PETTI

PART III

The reshaping of global society

10 Peacetime war discourse: the political economy of bellicose metaphors

MARCELLO MANERI

11 Global bureaucracy: irresponsible but not indifferent MARIELLA PANDOLFI AND LAURENCE MCFALLS

12 The space of camps: towards a genealogy of places of internment in the present

FEDERICO RAHOLA

Bibliography 200

Index 


\section{Contributors}

Didier Bigo is Professor of International Relations at Sciences-Po, Paris, Researcher at the Centre for International Studies and Research/ National Foundation of Political Science (CERI/FNSP) and Director of the journal Cultures \& Conflits. He is the scientific coordinator of the CHALLENGE 6PCRD and editor of many publications, including Policing Insecurity Today: Defense and Internal Security and Terror, Insecurity and Liberty: Illiberal Practices of Liberal Regimes After 9/11.

Roberto Ciccarelli is a post-doctoral Research Fellow in Political Philosophy and Teaching Assistant at the School of Law, University of Salerno, Italy. His dissertation was 'Michel Foucault. The Subject as political experience and ethical game'. Among his books are Potenza e Beatitudine. Il diritto nel pensiero di Baruch Spinoza; Governance, società civile, movimenti sociali. Rivendicare il comune (with M. Blecher and G. Bronzini); Immanenza. Filosofia, Diritto e politica della vita dal XIX al XX Secolo; and Immanenza e politica in Spinoza.

Alessandro Dal Lago is Professor of Sociology of Culture. He has been Dean of the Faculty of Education at the University of Genoa and Director of many European research projects. His main publications are Non-persons: The Exclusion of Migrants in a Global Society; Mercanti d'aura. Logiche dell'arte contemporanea and Fuori cornice. L'arte al di là dell'arte (with Serena Giordano); and Le nostre guerre. Filosofia e sociologia dei conflitti armati (forthcoming).

Massimiliano Guareschi has a Ph.D. in Medieval History and is Researcher of Sociology of Cultural Processes at the University of Genoa, where he is working on French theory of war. He has published several essays, a book on Deleuze's philosophy (Gilles Deleuze popfilosofo) and a critical study on the thought of Raymond Aron. He is co-editor of a special issue of the journal Conflitti globali on 'Israele come paradigma'.

Luca Guzzetti is Assistant Professor of Sociology of Culture at the University of Genoa. He is the author of A Brief History of European Union Research Policy and La frode scientifica. Normatività e devianza nella 
scienza. Among his several essays are 'Refugees or Illegal Aliens? The War in Kosovo and Its Aftermath' and 'La télévision italienne berlusconisée'. He has also been the editor of 'Global Conflicts: A Special Section' in Ephemera. Theory and Politics in Organization.

Eric Heilmann is Full Professor at the University of Burgundy. He has published 'Le policier, l'ordinateur et le citoyen' (1990); 'Sorvegliare (a distanza) e prevenire. Verso una nuova economia della visibilità' (2007); and 'La vidéosurveillance, un mirage technologique et politique', in L. Mucchielli (ed.) La frénésie sécuritaire (2008).

Alain Joxe is Director of Research at the École des Hautes Études en Sciences Sociales of Paris. He is the foremost French specialist in strategic affairs and contemporary wars and President of the Interdisciplinary Centre for Research on Peace (www.ehess.fr/cirpes/). He has published many books and essays, including Le Rempart social; Voyage aux sources de la guerre; Le cycle de la dissuasion: essai de stratégie critique; L'Amérique mercenaire; and Empire of Disorder.

Marcello Maneri is Assistant Professor of Sociology at the University of Milano-Bicocca. He has published 'Media discourse on immigration. Control practices and the language we live by', in S. Palidda (ed.) Racial Criminalisation of Migrants in the 21st Century; 'Lo straniero consensuale. La devianza degli immigrati come circolarità di pratiche e discorsi', in A. Dal Lago (ed.) Lo straniero e il nemico. Materiali per l'etnografia contemporanea; 'The criminalisation of ethnic groups. An issue for media analysis', in Forum: Qualitative Social Research; and 'La construction d'un sens commun sur l'immigration en Italie. Les "gens" dans le discours médiatique et politique', in La revue internationale et stratégique.

Laurence McFalls is Full Professor of political science at Universite de Montréal, where he also directs the Canadian Centre for German and European Studies. He holds a Ph.D. from Harvard University and is a graduate of the University of California at Los Angeles. His research has included work on the collapse of communism, on German reunification, on Max Weber's methodology and sociology of domination, and on humanitarian interventions. He recently published Max Weber's 'Objectivity' Reconsidered (2007) and Construire le politique (2006).

Salvatore Palidda is Professor of Sociology at the Faculty of Education at the University of Genoa. He has a Ph.D. in Sociology and European Studies from École des Hautes Études en Sciences Sociales of Paris and has been Director of several European research projects. His books include Polizia postmoderna. Etnografia del nuovo controllo sociale (2000) and Mobilità umane (2008); and, as editor, Délit d'immigration (1996) and Racial Criminalisation of Migrants in the 21st Century (forthcoming, printed also in Italian, Spanish and French). 
Mariella Pandolfi is Professor of Anthropology at Université de Montréal. She holds a Ph.D. in Anthropology from École des Hautes Études en Sciences Sociales in Paris. Her work in the post-communist Balkan territories (Albania, Bosnia and Kosovo) has sought to penetrate a field that is marked by the breakdown of former communist regimes and international military and humanitarian presence. She recently published Passions Politiques (ed. with Vincent Crapanzano, 2008); Post Colonial Disorder (CUP, 2008); Sovranitete te levizshme (2009); and Contemporary States of Emergency (ed. with Didier Fassin, 2010).

Gabriella Petti teaches Sociology of Deviance and Social Control at the University of Genoa. Her main topics of research include the labelling of juvenile deviance and judiciary practices. She has published several essays and two books: Il male minore and Nemici di comodo. Pratiche di esclusione nei processi per terrorismo internazionale.

Federico Rahola is Assistant Professor of Sociology of Cultural Processes at the University of Genoa, where he teaches Sociology of Global Processes. He is in the editorial board of REMHU (Brasilia), 'Etnografia e ricerca sociale' and Conflitti globali. He is the author of, among others, Zone definitivamente temporanee, I luoghi dell'umanità in eccesso (2003); 'La forme-camp. Pour une généalogie des lieux de transit at d'internement du present' (Culture et Conflits, 68, 2007); and, with Massimilano Guareschi, Fanstasmi dell'eccezione. Conflitti, frontiere e politiche di sicurezza nello spazio globale (forthcoming). 


\section{Acknowledgements}

This volume brings together material from two EU-funded research projects that the Department of Anthropological Sciences at the University of Genoa has conducted in collaboration with other European universities and research centres: ELISE ('European Liberty and Security: Security Issues, Social Cohesion and Institutional Development of the European Union'), which was composed of a seven-team consortium under the Fifth Framework Research Programme of the European Commission; and CHALLENGE ('The Changing Landscape of European Liberty and Security'), consisting of fourteen teams under the Sixth Framework Research Programme of the European Commission.

We would like to thank all the authors of the essays in this book as well as the colleagues and friends who participated in workshops and debates organized in various European countries during the course of the two research projects. Our thanks in particular go to Roberto Bergalli (University of Barcelona), Fabienne Brion (University of Louvain), Roberto Escobar (University of Milan), Maurizio Guerri (University of Milan), Bernard E. Harcourt (University of Chicago), Jef Huysmans (Open University of London), Gary T. Marx (Massachusetts Institute of Technology), Michel Peraldi (Centre Jacques Berque, Rabat), Iñaki Rivera Beiras (University of Barcelona), Lorenza Sebesta (University of Bologna), Trutz von Trotha (University of Siegen), Jussi Vähämäki (University of Joensuu), Danilo Zolo (University of Florence), and Rob J. Walker (University of British Columbia). 


\title{
Introduction
}

\section{Alessandro Dal Lago and Salvatore Palidda}

\begin{abstract}
Who came up with the idea that the civil order is an order of battle? Who saw war just beneath the surface of peace; who sought in the noise and confusion of war, in the mud of battles, the principle that allows us to understand order, the State, the institutions, and its history?
\end{abstract}

(M. Foucault, Society Must Be Defended)

\section{War and the changing face of the enemy}

Barack Obama's speech during the awards ceremony for the Nobel Peace Prize on 10 December 2009 confirmed, without a shadow of a doubt, that the Democratic administration's foreign policy would not stray too far from the course already set by its Republican predecessor. As a noted commentator on military affairs observed, Obama tried to show public opinion that 'even a Nobel Peace Prize winner is capable of using force, albeit differently to Bush' (Hanson, 2009). ${ }^{1}$ The US president's reference to the theory and necessity of 'just wars' (Walzer, 2006) during his acceptance speech in Oslo simply implies that violence will remain a normal resource in US foreign policy, just as it was before. Apparently, and in actual fact, there is not much that is new. ${ }^{2}$ In contrast to the age of Clausewitz, the first to pronounce the principle of a logical continuity between foreign policy and war, in today's globalized society the resort to arms is no longer a solemn and ritualized moment of rupture with the civil order, but merely a question of opportunity. ${ }^{3}$ The decision to fight a war is taken without any declaration, reasons are invented that nobody believes (as with Iraq in 2003, Lebanon in 2006 and Gaza in 2008), public opinion is outrageously manipulated, and proclamations are made about striving for peace at the same time as more troops are sent into the battlefield. In short, periodic organized violence is a characteristic and constituent element of globalization, particularly during the period of aggressive neo-liberalism that has followed the end of the bipolar system. ${ }^{4}$

If, at the end of the first decade of the twenty-first century, a world order based on diplomacy and negotiations seems a utopia, then it is indispensable that we examine the effects of permanent armed conflict upon 


\section{A. Dal Lago and S. Palidda}

global society. A first step consists of defining the most widespread type of war. The slogan 'Global War on Terror', coined by the Bush administration after 11 September, identifies 'terrorism' as the principal enemy at a global scale. As a result, the era of war as an interstate conflict seems, at least in principle, to have declined. Even when a sovereign country is invaded, the stated goal is the elimination of terrorists (as in Afghanistan after 11 September 2001 and Lebanon in 2006) or the removal of a regime that controls a rogue state (Iraq in 2003), while any recognition or legitimacy to the enemy is denied (as illustrated in Alain Joxe's chapter). This means that war has lost its formal features, which gives rise to ambiguous and paradoxical situations. For example, war had not been declared when NATO bombed the Federal Republic of Yugoslavia in 1999, and so Yugoslavian ambassadors were able to appear on television in Atlantic Alliance countries to put forward their side; something which would have been unthinkable at the time of 'traditional wars'. The resort to arms can therefore be understood as a sort of 'occasional global police force', in which alliances of variable geometry (albeit until now always US-led) intervene to rid entire regions of regimes, armed groups, insurgents or terrorists, as and when they are singled out as enemies of peace and civilization (Dal Lago, 2008, 2010).

Directly connected to the operational method of resorting to arms is an emphasis on the political-moral objectives of the US-led alliances: exporting or building democracy, defending human rights, protecting minorities and so on. For around two decades, we have seen the proliferation of what could be called 'postmodern oxymorons': 'humanitarian war', limitations placed on freedoms in the name of security, detention centres placed beyond the jurisdiction of the laws of war, physical restraints (in other words, torture) in the name of democratic justice, and the deprivation of any legitimate status for enemies (as captured in the very broad definition of 'enemy combatants'). It is in this context that embedded NGOs find their legitimacy and that it becomes increasingly difficult to distinguish between the mass of organizations and individual civilians (contractors, administrators, entrepreneurs, journalists and even anthropologists) who participate in various ways in foreign military missions (Fassin and Pandolfi, 2009).

Over the last two decades or so, 'terrorism' has taken on the role of principle enemy of the Western world. ${ }^{5}$ Although not located to a particular country or region, but coinciding in each case with the social, religious and political inclinations of the 'Arab world' and 'Islam' (be this Sunni or Shiite), the enemy is by definition ubiquitous and yet in hiding; active in their own social environment - in other words, countries defined as Arab or Islamic - but also, and above all, 'among us' in Western or developed societies. This kind of enemy transcends the traditional geopolitical imagination, which still provided, to a certain extent, the frame for Huntington's famous essay on the 'clash of civilizations' (1996). In contrast to the 
other 'civilizations' that were destined - according to Huntingdon - to clash with the democratic and liberal West (first and foremost 'Islamic', but also 'orthodox', 'Chinese', 'South American', 'African' and other civilizations), ${ }^{6}$ the current enemy does not represent any civilization in the eyes of the liberal West but, if anything, the perversion of a religion that is easily able to penetrate the defences of 'our world'.

The process of defining radical Islam as a global enemy dates back to decisive events in the early 1990s: the Gulf War of February 1991 and the coup d'état in Algeria on 11 January 1992. The expulsion of the Iraqis from Kuwait represents the first war waged by Westerners against an Arab country since the Suez crisis of 1956. The elimination of FIS (the party which regularly won the elections in Algeria) by the pro-Western regime in Algiers is the event that sparked a full-blown war between the Algerian state, supported by the West, and armed Islamic groups. It should be noted that the social construction of the enemy at a global level was a relatively sudden process: between the 1970s and 1980s, the anti-Soviet guerrillas in Afghanistan, financed and supplied by the United States, were presented in popular culture as real freedom fighters (for example, in the film Rambo III), and it was only after the Soviet retreat from Afghanistan that the 'Islamic' guerrillas acquired the status of absolute enemies of the West. As Robin Cook, former British foreign minister who resigned from the Cabinet in protest at the Anglo-American invasion of Iraq in 2003, wrote:

Bin Laden was [...] a product of a monumental miscalculation by Western security agencies. Throughout the 80 s he was armed by the CIA and funded by the Saudis to wage jihad against the Russian occupation of Afghanistan. Al-Qaida, literally "the database", was originally the computer file of the thousands of mujahideen who were recruited and trained with help from the CIA to defeat the Russians. Inexplicably, and with disastrous consequences, it never appears to have occurred to Washington that once Russia was out of the way, Bin Laden's organisation would turn its attention to the West.

(Cook, 2005)

In any case, as a result of these developments, over the last two decades the dominant enemy of the West has changed face, not only from an ideological point of view (by shifting from communism to Islam), but also from a strictly military perspective. In place of the regular armies like those of the Iraqis in 1991 or the Serbs in $1999,{ }^{7}$ a physiognomically variable enemy has emerged, able to exploit the techniques of guerrilla and urban warfare together with those of suicide terrorism. The West's dread of $a l-q \bar{a} ' i d a$ (and similar or affiliated groups) consists exactly in its character - culturally constructed for the most part in the $\mathrm{West}^{8}$ - as the global interconnection between armed groups. This is not only because terrorists and enemies in general prove themselves adept in the use of the Internet, but 
because their network is, from a symbolic point of view, the opposite of the web. While the Internet appears as an instrument of freedom, economic development, creativity and democracy, the enemy represents the dark side, destruction, blind opposition and terror. ${ }^{9}$

Since this enemy operates on a global scale, combating it cannot be limited to the internal or external use of traditional military instruments. At the beginning of the 1980s, the United States had already initiated a 'turn' in strategy: identifying the global 'South' (and no longer just the Communist East) as the front of the new enemy, and 'low intensity' wars and operations that ignored international law on the conduct of war as the principal forms of combat. ${ }^{10}$ However, it was not until the end of the 1980s that Western, and in particular US, strategic culture began to formulate a concept of war geared to the emergence of new global threats. Expressions such as 'fourth generation warfare' and 'asymmetric warfare' allude to the existence of an enemy that no longer fights in the Clausewitzian sense, but in a total way, even if its resources are limited. ${ }^{11}$ An explicit variant of this transformation is the so-called 'Revolution in Military Affairs' (RMA) which, developing from the mid-1990s onwards, essentially steered neo-conservative political and military strategy during the two terms of George W. Bush. The principal tenets of RMA consist in absolute military supremacy, the most advanced technology and a limited use of ground troops. Although its strategic failures were exposed during the war in Iraq, ${ }^{12}$ RMA has nevertheless produced a lasting effect, namely the growing integration between the military industrial production and applied and fundamental scientific research (see Guzzetti in this book).

During this process of militarization, the fight against a global enemy has extended to the inside of our societies. A 'generalized fifth column' has visibly become the object of security practices that today tend to transform the social life of the Western and developed world (as Didier Bigo demonstrates in this volume). For ten years or so, non-European Union or Muslim citizens have become increasingly implicated in control practices. Migrants originating from Muslim countries in Africa and Asia are considered in the reports of various security agencies as a fertile terrain for fundamentalism and therefore terrorism (National Intelligence Council, 2004; Palidda, 2010). Naturally, fighting the enemy inside complex urbanized societies with sophisticated infrastructures entails both innovative tactics and a redefinition of those liberal standards that represent the very foundation of Western societies. It is for this reason that present-day international politics, in a much more radical way than during the Cold War, are reflected in the internal order of developed countries (Walker, 1993). In other terms, it might very well be argued that a continuum has been created between global war on terrorism, war on migration and war for the internal security in 'democratic' countries (Palidda, 1998, 2000, 2009). 


\section{The role of war in the transformation of global society}

By the expression 'civilization of war' that appears in the sub-title of this book, we allude precisely to the culture - at the same time, civilian and military - that has been produced by Western countries in just under two decades in relation to the conflicts with those who threaten (or are presumed to threaten) Western security. In particular, we have in mind the ambiguous connotations - halfway between war in the narrow sense and armed repression - that have been assumed by contemporary conflict, both inside and outside our societies. ${ }^{13}$ It is an intentionally paradoxical definition that has nothing to do with either the stereotypical ideology of Western civilization ${ }^{14}$ or the so-called 'clash of civilizations' theorized by Huntingdon. For us, the expression 'civilization of war' refers above all to the Western world's presumption of asserting its material, political and economic culture on a global scale through the use of arms (Fisk, 2006). It is precisely due to this presumption that the armed interventions of the last twenty years have assumed both a military and a civilian nature, as highlighted by the prevalent definitions ('humanitarian wars', peace keeping and so on) and slogans such as 'War on Terror', 'Enduring Freedom' and 'Iraqi Freedom'.

From a general political point of view, war has undergone a spectacular metamorphosis. We no longer fight against an enemy state in order to impose our will on a set of questions (as in the classic war à la Clausewitz), but we intervene in another country or society in order to topple its regime, to control its resources and to transform its economic system. The widespread rhetoric of multiculturalism in the USA and Europe cannot hide the reality of global standardization, which is first and foremost economic and military, but which also extends to political structures and lifestyles. The most concise expression of this culture can be found in the ideas of 'exporting democracy' and 'nation-building', both dear to the conservative radicalism of the George W. Bush era. ${ }^{15}$ This should not be strictly defined as imperialist because, in contrast to classic imperialism, it aspires to basically Americanize the world without the direct and territorial rule of other countries being decisive. As an exponent of the US Republican right has written:

Contrary to the exploitative purposes of the British, the American intentions of spreading democracy and individual rights are incompatible with the notion of an empire. The genius of American power is expressed in the movie The Godfather II, where, like Hyman Roth, the United States has always made money for its partners. America has not turned countries in which it intervened into deserts; it enriched them. Even the Russians knew they could surrender after the Cold War without being subjected to occupation. ${ }^{16}$

The imposition of the Western way of life on other worlds passes today through a combination of economic, financial, political and obviously 
military practices that can no longer be adequately explained with the labels of 'imperialism' or 'colonialism'. It would be more accurate to instead speak of a 'political-economic hegemony' that not only is shaped by a variable geometry - which shifts according to different occasions, expediencies and alliances - but is also extremely flexible in its methods. The fate of Iraq over the last thirty years perfectly reflects how a strategic objective - which first and foremost consists in the direct and indirect control of oil resources - can be pursued through apparently divergent policies: support for Saddam Hussein when the Iraqis were losing the war against Iran (1980-1988), the war of 1991 and the subsequent embargo against Iraq (1991-2003), and the invasion of 2003, which involved the elimination of Saddam and the imposition of democracy in Iraq. If, up to 2003, the West's relations with Iraq followed the traditional path of diplomacy and war, following its invasion the country has literally been 'reconstructed' by the developed world. The economy, law, police and education have all literally been reinvented from a Western perspective after the end of the dictatorship.

The integration of military rule and economic and cultural hegemony entails a 'civilizing' of the mix of activities connected with war and, in particular, with the arms trade (Dal Lago and Rahola, 2009). This process concerns a series of aspects both inside and outside our societies. With regards the outside, the most conspicuous aspect is by far the huge proliferation of contractors, namely the civil operators, armed or otherwise, who now complement Western troops in Afghanistan, Iraq and other theatres of war. It is calculated that their number today surpasses the total figure of US troops in both countries (Singer, 2004). While in the 1991 war in Kuwait, they represented 10 per cent of the force, by the start of the war in Iraq in 2003 they had reached 20 per cent (about 40,000 units). According to some observers, today they are more numerous than regular troops. ${ }^{17}$ Contractors not only deal with logistics, supplies (including those to the battlefield), the personal protection of diplomats, civil functionaries and high-ranking officers and the training of local troops, but they are also increasingly involved in operations on the ground (which has given rise to talk of 'corporate warriors') (Traynor, 2003; Singer, 2004). Besides the involvement of civilians in military operations, attention also needs to be paid to the set of activities that fall under the title of 'humanitarian intervention': ${ }^{18}$ the presence of NGOs in the protectorates established by NATO in the Balkans after 1999, the 'reconstruction' of civil, administrative and judicial infrastructures in Afghanistan and Iraq, as well as, clearly, economic colonization and the exploitation of natural and energy resources. If the various practices emerging in recent conflicts are examined, we can begin to talk of a true global hybridization of the 'military' and 'civilian' elements of Western hegemony in the areas of crisis. 
In regards to the internal transformations of societies involved in global conflicts, the decisive aspect has been the full-blown institution and normalization of the 'war discourse' in its various declinations. With the concept of 'discourse', Michel Foucault (1981) essentially alluded to the textual formations, principally written, that organize knowledge and communication in society. In contrast to the classic idea of ideology, the 'discourse' privileges structures of implicit, indirect, self-referential and procedural meanings, which subsequently tend to present themselves as 'objective', 'shared', 'necessary', 'indisputable' and so on. In the 1970s, Foucault's attention was repeatedly drawn to the role of war in 'governmentality' (the range of practices, not necessarily linked to the state but to intellectual, scientific, cultural and other dimensions, which ensure the government of society) (Senellart, 1995). For Foucault, war is a regulative instrument of power relations both inside and outside society. In developed societies, the discourse of war is articulated through extremely complex practices that end up making the militarization of social relations appear 'obvious', 'customary' and 'normal'. As already explained, after 11 September 2001, the discourse of war inside our societies has been inflected in terms of security: the control of foreigners, the exclusion of certain categories of 'enemies' from legal guarantees as well as limits on the freedoms of citizens. These are just the most conspicuous consequences. On a closer look, the intrusiveness of military discourse in society is much more pervasive, thorough and 'microphysical', as Foucault would have said.

A revealing, and at the same time strategic, example of this process is provided by the research policies of the European Union. Their interest lies in the ways in which the various drafting processes, procedures and discursive strategies reveal the positions of powerful bodies and pressure groups within the European Union. Put another way, research policies express the aspired model of society of European elites, including those lesser-known ones operating in EU think tanks and bureaucratic apparatuses. An analysis of the documents in question allows us to lay bare the ways in which the 'war discourse' operates in sectors of society that are apparently and officially distant from the 'military'. Let us consider, for example, the 'Seventh Framework Programme for Research (FP7) 2007-2013'. ${ }^{19}$ This programme starts by defining the wide-ranging objectives set by the European Union:

The programme has a total budget of over $€ 50$ billion. [...] The Framework Programmes for Research have two main strategic objectives: to strengthen the scientific and technological base of European industry; [and] to encourage its international competitiveness, while promoting research that supports EU policies.

We therefore find ourselves in the common situation whereby research is subject to industrial goals that minimize fundamental or basic theoretical 
and scientific work. This burden is made all the more explicit in the part of the presentation that identifies the suitable participants for a partnership:

research groups at universities or research institutes, companies intending to innovate, small or medium-sized enterprises (SMEs), SME associations or groupings, public or governmental administration (local, regional or national), early-stage researchers (postgraduate students), experienced researchers, institutions running research infrastructures of transnational interest, organisations and researchers from third countries, international organisations, civil society organisations.

The strategic objectives laid out in the programme could be compatible with the military and control logic embodied in RMA and the practical concepts illustrated above. In other words, whether the theme is health, the environment, social exclusion, migration or technological innovation and experimentation (especially in the fields of communication, information and transport), the military framework of the strategic discourse steering research policy remains evident. This, of course, is even clearer in the programme on the specific theme of security. ${ }^{20}$ The title of the brochure that presents the programme's first results is eloquent: 'Towards a more secure society and increased industrial competitiveness'. ${ }^{21}$ Here it is possible to read, among other things:

Making Europe more secure for its citizens while increasing its industrial competitiveness, is the goal of European Security Research. Europe has never been so peacefully consolidated, so prosperous and secure, yet at the same time so vulnerable against threats like terrorism, organised crime and natural disasters.

[...]

In order to protect our fundamental rights and freedom, technological preparedness and response of society to potential or actual threats are essential. At the same time, the overall societal dimension and preparedness is of highest importance at all stages, including prevention, crisis and after crisis management.

The theme of security is not only legitimated by its 'popularity' (inevitable following 11 September 2001 and the attacks in Madrid and London), but also by the broad and consensual objectives of economic competitiveness and the 'rights' of citizens. In other words, military and security technologies become the vector of the economic and civil development of Europe:

Moreover, the relationship between defence technologies on the one hand, and security technologies on the other, is particularly noticeable in the field of $\mathrm{R} \& \mathrm{D}$, with technologies that show potential 
developments in both areas (Dual Use). At both research and industrial development levels, synergies are possible and desirable.

It is not simply the subordination of scientific research to industrial and military goals that is at stake here. It is also that the security industry aims to literally open an internal market for its increasingly far-reaching services. Starting with the fight against 'external threats' in the name of citizen 'rights', the security industry extends its interests to the control of 'abnormal behaviour' and ends up placing the whole population under surveillance, denying or limiting its right to expression and demonstration of political ideas. This reflects, in essence, the aims of one of the funded research projects. It is worth quoting its objectives in full:

ADABTS (Automatic Detection of Abnormal Behaviour and Threats in crowded Spaces) aims to facilitate the protection of EU citizens, property and infrastructure against threats of terrorism, crime and riots, by the automatic detection of abnormal human behaviour. ADABTS aims to develop models for abnormal and threat behaviours and algorithms for automatic detection of such behaviours as well as deviations from normal behaviour in surveillance data. ADABTS aims to develop a real-time evaluation platform based on commercially available hardware, in order to enable high-performance low-cost surveillance systems.

ADABTS will gather experts in human factors, signal processing, computer vision, and surveillance technology. In a first stage, focus will be on human factors in order to define and model behaviours. Then, the focus will be shifted towards automatic analysis of surveillance data (video and audio). Finally, a demonstration system will be implemented. ADABTS will create models of behaviour that can be used to describe behaviours to be detected and how they can be observed. [...] ADABTS will develop new and adapt existing sensor processing methods and algorithms for detecting and tracking people in complex environments, involving groups of people or crowds. Extracted sensor data features (e.g. tracks, voice pitches, body articulations) need to be related to the behaviour primitives, and, moreover, to be dynamic and adapt to the context. [...] ADABTS will communicate results to the various kinds of identified actors: Security stakeholders like European and national authorities, police organisations or event organizers; Security system operators and security service companies; Security system integrators; Technology developers; the Research communities for psychology, human factors, and signal processing communities. ADABTS will involve all these actors, either as principal contractors, as subcontractors, or in an associated stakeholder group. 
Given such objectives, one wonders, first of all, what the definitions and protocols are for identifying 'abnormal behaviour'. Perusing the different research projects that are either completed or still in progress, ${ }^{22}$ it would not be too far-fetched to argue that we are faced with a process that aspires to a sort of surveillance of a sizeable part, if not all, of the European population.

It is seen as necessary to protect the citizens from dangerous groups such as terrorists, criminals, or political subversives, or all other risks $[\ldots]$ the social control is then justified as 'protection', as a necessary sacrifice of liberties and privacy and which necessarily involves high costs for a kind of 'Electronic Police State'. 23

It is evident that this spread of surveillance involves the direct funding of social control agencies (i.e. public and private police) and the security industry, rightly defined as one of the principal businesses of the twentyfirst century (Glassner, 1999). In fact, the partners of this project, similar to others already funded, include university researchers, structures of interior ministries of different countries, the military industry and private corporations specialized in so-called 'postmodern' controls (Palidda, 2000, 2007a). Furthermore, many of these public and private research centres, as well as the participating public and private companies which have benefited from European funding, have already completed or are currently conducting similar projects in joint venture with North American firms. Thus, the research funds actually end up 'indirectly' supporting forms of international cooperation that the European Union ignores or claims to ignore.

A decisive aspect of these projects regards their definition of 'military', and, in turn, their particularly narrow and ideological definition of 'security'. As Davis (1990) and Bauman (2006) have observed, this definition has acquired an almost mythological meaning because not only does it amount to a veritable passe-partout of social control, but it also functions as a label that allows any other discourse or action on security, especially of a social kind, to be marginalized or excluded. In its dominant or military meaning, 'security' implies the exclusion of structural problems of the weakest individuals, namely the poor, workers in underground or informal economies, precarious workers, nomads, migrants and marginalized people in general, who are a part of the European population or who at least live in Europe. ${ }^{24}$

The causes of insecurity of the partially included and excluded are not just questions about income, housing and health, but also include the risk of enduring violence at the hands of more powerful social actors, public and private police forces and organized crime (Palidda, 2010). Moreover, workplace injuries and illnesses affecting the least-protected social actors, such as those working in the informal economy, are ignored in dominant definitions of security. And yet it is a well-known fact that workplace 
injuries and illnesses are often closely linked to economic activities that produce harmful goods and environmental pollution, in other words insecurity for both the immediate victims and society in general (Palidda, 2009). But the FP7 (concerning security issues) does not contemplate research projects on these matters. ${ }^{25}$

\section{The contents of this book}

Research policies are just one, albeit significant and revealing, aspect of the increasing domination of the 'military discourse' over other influential forms of rhetoric in our culture. But they demonstrate - precisely in virtue of their strategic objectives - how civil life is largely conditioned and remodelled by the ascendancy of the fight against external threats and by the practical rhetoric of security. It is precisely these conditions that are at the centre of attention of the contributions to this volume. Renouncing the temptation of 'big brother' theories, but bearing in mind the objective capacity of the 'military' (and those who command it) to give form and purpose to the action of public and private actors, the research collected in this volume analyses different aspects of the militarization of society during peacetime. The first part sets out the historical and theoretical premises of the strategic changes that are currently in progress. The second part analyses the rise of the 'securitization' paradigm in crucial fields of global communication strategy, surveillance and justice. The third part investigates the restructuring of society on a global scale in relation to media rhetoric, the logic of humanitarian interventions and new forms of detention and social control.

The essays collected in this volume reflect a decade of theoretical and empirical research, conducted at the University of Genoa in collaboration with various European universities and research centres, on the links between armed conflict and society. From an epistemological point of view, our goal has been to integrate social science and the analysis of conflicts on a global scale. Indeed, we believe that sociology, in particular, cannot limit its range of action to the level of national societies, but must examine the relationship between the global and local dimensions of social phenomena. As such, armed conflicts take on crucial meaning because, as we try to demonstrate here, they are able to influence and mould contemporary societies. Never before as in this present historic period have social life and global conflicts constituted such a continuous dimension.

In the first chapter, Alessandro Dal Lago argues that a theoretical framework structured around the centrality of warfare in the current world system has yet to emerge in the social sciences. On the one hand, there is a lack of any real awareness about the role that war has played, and continues to play, in the rise and advance of Western hegemony across the planet. It has become common to define this logic as 'exceptionalism', which makes reference to the German debate of the 1930s about the 'state 
of exception'. However, this definition conceals a misinterpretation. Violence and war are not a violation of rules or an exception to some kind of international order, but rather the conditions for the normal exercise of power on the international stage. What we are witnessing at present is a new type of normality. This does not amount to just a terminological question but to the intimate connection between war and politics (and the economy) in the globalized world.

Alain Joxe defines the current state of the world as 'barbarianism' and, hence, as a process of 'barbarization' of peace through the proliferation of civil wars and never-ending overseas operations. In the present global crisis, the barbarization of war passes through policing strategies that also contaminate the notion of peace. The current strategic mechanisms indicate a close connection between war and the macro-economic, political and social strategies inherent to globalization. Modern 'war' has not led to a state of total chaos in the world. Rather, it has given rise to a structured chaos that organizes a false portrayal of war by censoring or cleverly concealing the action of social and political strategies. Wars create insecurity for civilian populations because their political objective is no longer the plunder of territories by a conquering state nor the control (and, by implication, the 'protection') of their inhabitants by regular troops. According to the dominant Western ideology, only the political administration of the irresponsible classes of the 'new rich' (who are the cause of disasters across every continent) is able to impede the multiplication of environmental and financial crimes that are an upshot of contemporary wars.

Roberto Ciccarelli's chapter concentrates on the relations between war and the debate on sovereignty. Despite the difficulty of conceiving the existence of a sovereign (be it a state, a confederation or an alliance of states) in a position to dominate the world, the theoretical debate on exceptionalism has nonetheless been overshadowed by political theology. In fact, it is commonly assumed that the 'state of exception' is 'permanent'. Contrary to this assumption, the ambivalence between order and conflict, peace and war, norm and exception, between the will to create a 'democracy' and the need to guarantee a multinational company's interests has reached such a point as to make it difficult to distinguish between violence and authority, well-being and sacrifice, domination and freedom. Most significantly, the distinction between peace and war has become increasingly hard to maintain. Today, 'security' is no longer an internal question of public order that is exclusively managed by states, but rather requires a series of military, humanitarian and policing policies to simultaneously neutralize global threats and safeguard the living conditions of Western populations.

Massimiliano Guareschi's chapter examines how the relationship between politics and war was theorized by Michel Foucault, Giles Deleuze and Felix Guattari, and Raymond Aron at a time when much of French philosophy was committed to a critique of Western political categories. 
One of the most interesting aspects of their reflections regards the reversal of Clausewitz's famous formula about war representing the continuation of politics by other means. Foucault's approach to the question is marked by the need to elaborate an analysis of power that moves beyond economistic and substantialist perspectives. War, as an analytical operator, thus plays a similar role to that of the contract in political philosophy. On their part, Deleuze and Guattari refer directly to Clausewitz when they describe the dynamics of the 'nomadism' of war and the 'capturing' functions of states. Despite the refusal by some theoreticians and scholars of Clausewitz to invert the classic formula (and here the focus falls on Aron), the work of both Foucault and Deleuze and Guattari provides us with fundamental insights for understanding the role of wars in the globalized world.

In his contribution, Luca Guzzetti examines the relations between techno-scientific research and the military from the end of the Second World War to the present. Guzzetti focuses primarily on the United States. First, this is because the US, one of the two military superpowers during the post-war period, is now the only superpower left. Second, the US has always led the technological race (apart from a few years following the Soviet Union's launch of Sputnik), both in the civil and military sector. Today, the United States alone invests more than half of what is spent by all countries worldwide on military research. In his chapter, Guzzetti analyses new changes in the technology of war and its dependence on recent strategic thought, in particular the so-called Revolution in Military Affairs.

Didier Bigo examines how public opinion has tended to accept in an uncritical way the series of narratives that followed 11 September. Even when we try to adopt a critical stance, our main arguments are borrowed from the narratives of global insecurity and a necessary state of emergency. In his chapter, Bigo discusses these narratives by adopting Pierre Bourdieu's concept of 'habitus' - in other words, the set of perceptive and cognitive frameworks embedded in the different fields of social actors. The term 'regression' is used to explain public opinion's acceptance of control and surveillance as solutions able to halt transnational political violence in the so-called age of hyper-terrorism. The question of regression is much broader than the argument about the state of exception, especially now that, after the end of the Bush era, Obama's policy of limiting the exception has seen the continuation of war (in Afghanistan) and surveillance against terrorism.

In his chapter, Salvatore Palidda argues that social research lacks an indepth, coherent analysis of changes in police practices at the same level as the Revolution in Military Affairs (RMA). He therefore proposes to examine the 'Revolution in Police Affairs' (RPA) by first discussing the main theoretical and methodological aspects that are indispensable for an analysis of the management of the neo-liberal/neo-conservative disorder of the current era. This can be understood, in Foucauldian terms, as the shift from pastoralist governmentality to a form of occasional management that 
is interested only in the bic et nunc (the here and now) and has no concern for the future of society. It is in this general context that we can consider the rise of the violent management of disorder and the concomitant weakening of a peaceful social order. Despite the spread of the military discourse in the West, the police are unable to abandon their informal and sometimes unlawful rapports with different members of local society because they cannot declare permanent war with any one particular group. As Palidda demonstrates, the apparent victory of the neo-conservative revolution in police affairs appears entirely ephemeral precisely because unlike military forces - it is an institution that is embedded in society and cannot survive according to a logic of permanent war.

Eric Heilmann analyses the development of the new technologies of surveillance and demonstrates how this phenomenon has removed the barrier that once separated private from public life. Anyone today can have a webcam or mobile phone with which they can produce their own images, from the most banal to the most intimate, which can then be placed on a personal or community website. For the police, these technologies, which were of only limited use a few years ago, have produced a significant breakthrough in identifying individuals. More importantly, argues Heilmann, the use of these new systems should encourage people to consider how surveillance is affecting them. The success of CCTV was based on creating a dichotomy between the respectable majority (who have nothing to fear) and a deviant minority (who should feel threatened). If the argument put forward here turns out to be correct, then it is possible that with this distortion, we are beginning to see the first signs of the emergence of a genuine, identity-based resistance to images produced by CCTV.

Gabriella Petti discusses the results of an empirical study of trials of 'terrorists' in Italy. In her analysis, courtrooms are not just a place where definitions of criminals (or terrorists) are assigned and tested, but are also the arenas in which the rights to punish and the powers to divide the guilty from the innocent are ritually celebrated. Thus Petti finds the courtroom interesting primarily as the setting where discourses, forms of knowledge and practices that reproduce social images of terrorism are developed and redefined. Trials tell us something about terrorism that is difficult to discern from official discourse. They demonstrate how the practices and activities of courts produce effects and influence legal definitions of terrorism. According to Petti, the court, by following the ceremonial procedures laid down by law, represents the possible point from which terrorists, migrants and an entire body of abnormal humanity set out on an invisible journey towards their own 'disappearance', to the general indifference of the public.

According to Marcello Maneri, the global success of the war discourse during peacetime cannot be understood without taking into account the role of the media. This role, however, has been increasingly conditioned 
by the consequences of the neo-liberal globalized order. A first key consequence has been a veritable war against migration, while a second major repercussion has been the series of military interventions that are defined by oxymorons such as 'peace keeping', 'international policing', 'pre-emptive war' and 'humanitarian war'. At a communicative level, these two effects underline a sort of global 'regime of discourse'. Wars around crime, drugs, terrorism and security have released military personnel and police forces from the binds of red tape and exempted them from any accountability. The peacetime war discourse is thus discussed by Marcello Maneri as a disciplinary regime founded upon the use of force that is useful to govern our societies.

In their chapter, Laurence McFalls and Mariella Pandolfi examine the case of Kosovo as paradigmatic of the new global 'therapeutic' order. At a discursive level, Kosovo has illustrated the rhetorical efficacy of a global appeal to the ultimate value of human life. Accordingly, we face what seems to be a democratically constructed information mechanism: a space that appeals to the need for interventions or the prevention of catastrophes and appears democratically irreprehensible. The authors thus confront the paradox of the coexistence of the noblest will to share information and the most opaque procedures implemented in zones of intervention. The combination of the mobility of the 'cosmopolis', the urgent need for action in the face of real (or feared) emergencies, and the undeniable social utility of many interventions makes it nearly impossible to establish any global democratic mechanism for controlling interventions, despite their appeal to a certain democratic legitimacy. Be it in Kosovo, Afghanistan or anywhere else, the notion of a humanitarian management of crises in the grey zone pathologizes any peace accord, development and democratization process (staged with endless rhetoric but with little promise), just as it has pathologized the proclamation of Kosovo's independence in February 2008. The urgency/emergency is permanent: a paradigmatic oxymoron of our contemporaneousness.

In the final chapter, Federico Rahola examines the realm of 'detention camps' and suggests a different approach to interpreting their political and social 'status', which questions the borders in which camps are supposed to have been instituted and where exclusion is included. Detention camps are not areas of 'waste' or a suspension of the law, but excessive places, in the sense that they are spaces that exceed the reach of the 'national' legal system but nonetheless are invested with a proliferation of administrative decrees and security policies. According to Rahola, to write a 'genealogy of camps' means to relocate camps in a territory that exceeds every representation of modern national borders and indicates, at the same time, this territory's spectral artificiality and intrinsic weakness. From this perspective, camps are the symptom of a space that has always transcended the specific space of nations, within which it has been historically colonized, plundered and racialized, but never totally absorbed. 


\section{Notes}

1 The observation is interesting and revealing because the author, as well as being an eminent historian of war in ancient Greece, is also an ultra-conservative commentator. In any case, the fact that the winners of the Nobel Peace Prize are not always pacifists is not a novelty. Henry Kissinger, who had actively collaborated with the dictatorial regimes of South America, was awarded the Nobel Peace Prize for his negotiations with North Vietnam.

2 As the chapters of Dal Lago, Bigo and Ciccarelli here demonstrate, the coexistence of war and peace appears today more than in the past as something normal, indeed 'banal' in the sense provided by Arendt (2006).

3 On this aspect, see the chapters by Guareschi, Dal Lago, Bigo and Joxe in this volume.

4 There exists an abundant bibliography on this matter. See, in particular, Kaldor (2000) and Zolo (2000). For a definition of neo-liberalism, see Harvey (2005) and Foucault (2008).

5 Among the first strategic declarations regarding terrorism in the US context, see Weinberger (1984).

6 On the purely conventional and artificial character of the definition of 'civilization' in Huntington, see Dal Lago (2006a).

7 The Iraqi army that was defeated in 2003 was also 'regular'. But, as Ricks (2006) has shown, the true war began in Iraq after George W. Bush officially announced its end. From this moment, the war in Iraq has become the ideal model of every asymmetric conflict fought between a hypermodern army, on the one side, and insurgents or guerrillas, on the other. For the concept of asymmetric war, see Hammes (2006).

8 By 'constructed' we mean 'objectified', 'unified' and so on. This does not mean, also in reaction to the rising hostilities towards Islam in the west, that Islamic radicalism is not capable of global influence. On the cultural significance, and in particular the great capacity for propaganda, of contemporary radical Islam, see Kepel (2004). This theme is examined in depth in the chapters by Maneri and Petti.

9 For a description of the principal categories of the conflict between the developed world and these new enemies, see Barber (2001).

10 For an analysis of this strategic turn, see Joxe $(1990,1991)$.

11 Traditionally, first generation warfare is defined as a conflict where troops confront each other face to face with firearms; second generation when indirect artillery fire is used; third generation when the aim is to penetrate the enemy lines to defeat it without necessarily destroying its forces (as in the so-called Blitzkrieg). For the respective definitions, see Lind et al. (1989) and Hammes (2006). Others speak of contemporary warfare in terms of a 'fifth' dimension that is composed of the infosphere (Lonsdale, 2004). The concept of asymmetric warfare refers to armed conflict between conventional armies and insurgents who use the methods of guerrilla warfare and terrorism.

12 For a critique of RMA and its real impact on contemporary war, see Gray (2005). On US strategy in Iraq, see Record (2003a, 2003b).

13 See the chapters of Dal Lago, Ciccarelli and Bigo in this volume.

14 For a terminological analysis, see Benveniste (1971).

15 See, for example, Fukuyama (2006).

16 See Kagan (2003). The reference to The Godfather II is suggestive. It is worth recalling that, in the film, Hyman Roth is a gangster financier closely associated to the godfather Vito Corleone.

17 See T.C. Miller, 'Contractors outnumber troops in Iraq. The figure, higher than reported earlier, doesn't include security firms. Critics say the issue is 
accountability', Los Angeles Times, 4 July 2007 (available at http://articles. latimes.com/2007/jul/04/nation/na-private4):

The number of US-paid private contractors in Iraq now exceeds that of American combat troops, newly released figures show, raising fresh questions about the privatization of the war effort and the government's capacity to carry out military and rebuilding campaigns. More than 180,000 civilians - including Americans, foreigners and Iraqis - are working in Iraq under US contracts, according to State and Defense department figures obtained by the Los Angeles Times.

According to the report of Moshe Schwartz, Department of Defense Contractors in Iraq and Afghanistan: Background and Analysis, 14 December 2009 (assets.opencrs.com/rpts/R40764_20091214.pdf): 'These analysts point to recent contingency operations in Iraq, Afghanistan, and the Balkans-the three largest operations of the past 15 years-where contractors have comprised approximately $50 \%$ of DOD's combined contractor and uniformed personnel workforce.'

18 On the logic of humanitarian interventions, see Fassin and Pandolfi (2009).

19 See 'FP7 in Brief. How to get involved in the EU 7th Framework Programme for Research' (http://ec.europa.eu/research/fp7/understanding/fp7inbrief/home_ en.html). The quotations are taken from this document.

20 According to official documents of the Commission, the European Commission has made 1.4 billion euros specifically available for Security Research (see http://ec.europa.eu/research/fp7/understanding/fp7inbrief/home_en.html).

21 See 'Towards a more secure society and increased industrial competitiveness', Security Research Projects under the 7th Framework Programme for Research, May 2009 (ftp://ftp.cordis.europa.eu/pub/fp7/security/docs/towards-a-moresecure_en.pdf).

22 Funded research includes the AMASS (Autonomous Maritime Surveillance System) project, which is concerned with providing the Blue Border Surveillance the technological capacity to better contend with 'continuous 24/7 surveillance as a counter measure to illegal immigration'. The BeSeCu project (Human behaviour in crisis situations: A cross cultural investigation in order to tailor security-related communication) claims 'to investigate cross-cultural and ethnic differences of human behaviour in crisis situations in order to better tailor security related communication, instructions and procedures with a view to improving evacuation and protection'. It consists of a study of natural or criminal catastrophes that claims to improve the reaction time in such events. In short, it is one of those sorts of research projects that often contributes to cultivating fears. The same can be said for the CAST project (Comparative assessment of security-centred training curricula for first responders on disaster management in the EU), which explicitly refers to the risk of terrorism. COCAE (Cooperation Across Europe For $\mathrm{Cd}(\mathrm{Zn}) \mathrm{Te}$ Based Security) is instead a project about security in relation to nuclear risks. COPE (Common Operational Picture Exploitation) concerns crisis management (although after Hurricane Katrina we know that such management can turn into opportunities for business and social Darwinism). CPSI (Changing Perceptions of Security and Interventions), in its own way, enters into the core of the mechanisms that produce alarm about fears and insecurity:

CPSI aims to create a methodology to collect, quantify, organize, query, analyse, interpret and monitor data on actual and perceived security, determinants and mediators. The four main objectives of the project are to: develop a conceptual model of actual and perceived security and their 


\section{A. Dal Lago and S. Palidda}

determinants; design a methodology to register and process security-related data; develop a data warehouse to store amassed data and; carry out an empirical proof-of-principle study to test the model, methodology and data warehouse. In CPSI we focus on security related to 'everyday' crime, such as theft, assault and vandalism. The CPSI methodology, however, can be applied to other areas of security as well, such as terrorism or financial security.

DETECTER (Detection Technologies, Terrorism, Ethics and Human Rights) is a project that is clearly inscribed in the activities of the security agencies. The same is the case for EFFISEC (Efficient Integrated Security Checkpoints). It is not a coincidence that in these kinds of projects there are also Israeli partners. ODYSSEY (Strategic Pan-European Ballistics Intelligence Platform for Combating Organised Crime and Terrorism) is clearly useful for the police forces and secret services. The same can be said for SAFE-COMMS (Counter-Terrorism Crisis Communications Strategies for Recovery and Continuity) and for STRAW (Security Technology Active Watch).

23 See http://en.wikipedia.org/wiki/Mass_surveillance; many critical articles on these questions can be found in the journals Surveillance \& Society, Cultures \& Conflits and Conflitti globali.

24 According to Eurostat (2009), approximately eighty million EU citizens (equal to 16 per cent of the population) are directly affected by the phenomenon of poverty.

25 In 2008, the head of the European Agency for Security and Health at Work (EU-OSHA) declared:

Every three-and-a-half minutes, somebody in the European Union dies from work-related causes, and every four-and-a-half seconds, a worker in the EU is the victim of an accident that forces them to stay at home for at least three working days.

(http://ec.europa.eu/health-eu/newsletter/14/newsletter_it.htm) 
Part I

The constituent role of armed conflicts 



\title{
1 Fields without honour \\ Contemporary war as global enforcement
}

\author{
Alessandro Dal Lago
}

I'm a war president. I make decisions here in the Oval Office on foreign policy matters with war on my mind, and the American people need to know they got a president who sees the world the way it is.

$(\text { George Bush })^{1}$

At the end of the 1980s, with the dissolution of the Soviet empire, some believed that capitalism would rule supreme as the only form of economy and society on Earth and, as a consequence, would give rise to a lasting phase of prosperity and peace. ${ }^{2}$ Today, we know that this was an illusion, also in the case of Europe, which had actually been at peace for almost fifty years since the end of the Second World War. ${ }^{3}$ At first, the progressive disintegration of the Yugoslav federation led to a series of armed conflicts that engulfed the Balkans. From here on, various US-led coalitions intervened in different parts of the world in the name of 'international legality' (Kuwait in 1991), 'humanity' or 'human rights' (Somalia in 1993 and Kosovo in 1999), 'enduring' freedom (Afghanistan in 2001), the war against terrorism or simply in order to exert hegemony (Iraq in 2003). A state of war has now existed for almost twenty years and, more importantly, seems destined to continue indefinitely. But it was only with the attacks of 11 September 2001 that vast layers of Western public opinion realized that war, even if it now assumed a new form, had reappeared in everyday life (Munkler, 2004; Kaldor, 2007a, 2007b).

It is therefore necessary to establish if and how the permanent war that we have effectively become accustomed to is changing our society. In order to be approached correctly, this problem requires an understanding of the nature of contemporary war. This is a source of great difficulty in social analysis. The majority of current conflicts elude the typical notion of warfare that had held for most of the twentieth century. In contrast to the world wars that characterized European life for thirty years, ${ }^{4}$ during the conflicts that occurred after 1989, Western everyday life would continue more or less unaltered. In a certain sense, for most of European public opinion, 'permanent war' remained a distant rumble, just like the colonial wars of the nineteenth century. ${ }^{5}$ 


\section{A. Dal Lago}

After the attacks of 11 September 2001 in New York, 11 March 2004 in Madrid and 7 July 2005 in London (not to mention those in Bali, Morocco, Pakistan and elsewhere), this was clearly revealed to be a fragile façade. But the presence of war in our lives is not limited to the spectre of terrorism. Rather, it has led to a mobilization that, far from constituting an exceptional situation, has steadily redirected our habits - in other words, the forms that social life normally assumes. Some of these changes are clear to everybody and can be summarized by the primacy of security formula: harsher controls at borders, airports and transit places in general, the strengthening and pervasiveness of intelligence services, a generalized suspicion towards foreigners, especially if they have North African, Middle Eastern, Arabic or 'Islamic' origins, and the setting up of camps for prisoners who lack a precise status and hence any sort of guarantee (such as Guantanamo and the camps in Iraq and Afghanistan). ${ }^{6}$

The primacy of security ultimately means the militarization of social control, namely, the militarized management of threats faced by Western societies, not only from the outside (terrorist infiltration), but also from within (terrorist sleeper cells, as well as various types of dangerous subjects). ${ }^{7}$ The militarization of control entails two main consequences: the first is that certain categories of human beings who are suspected of connivance with the enemy are withdrawn from the normal judicial guarantees upon which the West has constructed its self-portrayal as the cradle of the law. The Patriot Act signed by Bush in October 2001, the setting up of detention camps like Guantanamo, the evident normality of torture in Abu Ghraib prison all represent the establishment of a special military regime reserved for 'terrorists'. ${ }^{8}$ The second consequence is the virtual and actual indictment of those human types, in particular migrants, who are considered susceptible, as a result of their irregular social 'nature', to the propaganda of the enemies of the West. In this sense, detention centres for unlawful or 'clandestine' migrants (which today are spread across the world) are not formally different from special military prisons, insofar as they are reserved for subjects who lack any sort of social legitimacy. It may also be noted that the principle of enmity (on which the militarization of control is based) tends now to encompass any threat to the established order (and, under specific circumstances, can also include internal opposition in the West, as well as different types of social outcasts). ${ }^{9}$

The most decisive change that is probably able to produce unpredictable effects can be summarized in the formula of the primacy of armed decision. As of 1999, with the NATO war against Serbia undertaken without the UN's consent, the principle of the West's military interference throughout the world has prevailed. The justification or legitimation of this global enforcement activity rests on the threat of terrorism and of those who supposedly support it (first and foremost, the so-called rogue states), but it is at the same time essentially self-referential and tautological. Assuming that only the West enacts the law in internal and international relations (finding 
itself in an ideal judicial situation) and that it has the means to enforce compliance, the premises are effectively established for constituting a global military power legitimated by circumstances. Moreover, these circumstances are long-lasting, for it is deemed that any foreseeable armed opposition to the exercise of a global military power falls within the category of terrorism. This is the underlying meaning of the enduring freedom slogan and Bush's declarations that the struggle against terrorism may last for 'entire generations'. Hence, the war against terrorism rests on a de facto power or the capability of military intervention that can be explicitly justified by appealing to the cultural (economic, social and also military) superiority of 'western civilization', or to 'human rights' and even a liberal ideology. ${ }^{10}$ In this sense, the power of intervention - that is, war - takes on a constituent function that is thus capable of reconfiguring global power relations. ${ }^{11}$

To claim that war presently assumes a constituent power or role is therefore to imply that it is the source of new social and political relations. First of all, alongside national and international political authorities, on the one side, new powers develop and, on the other, those that have been established for some time are able to change their functions and areas of intervention. Examples of the former are the ad hoc alliances that have fought the wars in Afghanistan and Iraq and present themselves as the de facto armed wing of 'international legality', with or without a UN mandate, as well as the European rapid intervention military force, whose range of action is certainly not limited to Europe. The latter includes NATO, which intervened in Kosovo in 1999 and presently operates in Afghanistan. In both cases, these military structures, regardless of whether they are occasional or permanent, tend to promote or impose new forms of political and economic organization for the countries in which they intervene: a military and civilian presence in Afghanistan, a NATO military protectorate in the southern Balkans (Bosnia, Kosovo and, broadly speaking, Macedonia and Albania) or the coalition that has managed the occupation of Iraq. This last case was formed by the armed forces of the two states that overwhelmed the Iraqi army in 2003 and by the military forces deployed by various European, Asian and South American countries undertaking military policing tasks. In reality, these forces are merely the armed vanguard of an occupation structure that includes substantial private security forces, ${ }^{12}$ businesses assigned the task of rebuilding the infrastructure and economic system (a majority of which are American) and public or part-public Western agencies (such as secret services, NGOs and UN personnel) that manage civilian structures, from education systems to cultural heritage. It hence amounts to a political, economic and administrative occupation, whose only source of legitimation is the military victory of 2003.

War is therefore a dimension that is capable of transforming society in largely innovative directions. The same concept could be expressed by 


\section{A. Dal Lago}

defining contemporary war as a 'social system of thought'. The expression is inspired by the work of Michel Foucault and identifies a cultural complex that, without necessarily being organic, explicit or represented by official or canonical traditions, is nonetheless capable of guiding the theoretical and practical way of thinking of a certain epoch. It could be considered a type of ideology. Foucault analysed systems of thought as the minor scientific representations spanning the Enlightenment, the image of madness in the classical age, modern prisons and discipline, and the 'will to know' in the contemporary culture of sexuality. But he also identified the essence of modern wartime thought in 'state racism' (Foucault, 2003) and started to study the relationship between war and 'governmentality' namely, the complex of political and non-political powers that govern a society. While these provide extremely fertile insights, Foucault's perspective was still limited to national states and single societies and did not extend to the trans-state and transnational dimensions which are now understood under the label of globalization.

Foucault insisted on the need to overturn Clausewitz's longstanding maxim whereby 'war is nothing but a continuation of politics by other means'. For Foucault, on the contrary, politics is the continuation of war by other means (as, in a certain sense, it was for Thomas Hobbes and Carl Schmitt). For Foucault, what is 'political' is the manifestation of a fundamental and largely latent civil war between social groups, essentially between the dominant class and a riotous social body. In my opinion, this position aptly innovates the Clausewitzian theory, according to which the continuity between war and politics was exclusively limited to relations between states and, hence, to foreign policy. ${ }^{13}$ But today it is impossible to assume a clear separation between internal and foreign policy. And this is not because of the decline of national states, which have supposedly given away parcels of sovereignty to global authorities, but precisely for the opposite reason - namely, the reorganization of national states into constellations or coalitions that vary to a greater or lesser degree and that act on a global stage for hegemonic reasons. In other terms, one could retranslate Foucault's version of Clausewitz's maxim into the following proposition: global politics is the continuation of global war by other means. With this, the existence of a continuous dimension of global war and politics, even if this can obviously be divided and differentiated, is essentially established. ${ }^{14}$

Overall, Foucault's intuition allows us to free ourselves from the common-sense opinion whereby war is supposed to be an anomaly, the deviation from the right path of humanity, the emergence of an antiprogressive irrationality, the unleashing of archaic impulses, and so on. ${ }^{15}$ Of course, there is something true in these judgments, at least if one places oneself at the level of the individual combatant and the horrors that he or she takes part in. But matters appear to be entirely different when the analysis concentrates on military mechanisms and systems in their organic 
connections with global politics and the global economy. Here, instead, war appears as the other side of global politics, a system of choices that is not alternative, but rather entirely complementary to peaceful systems of government.

Since the end of the Cold War, military violence - that is, the imposition of political choices through the use of weapons - has appeared to be a continuous, normal, daily resource within an evolving political framework. Wars have been political to varying degrees and aimed at diverse targets that have not always been evident or entirely comprehensible according to the rational framework that was supposed to motivate or justify them. They have consisted in wars for the control of resources, for the elimination or containment of local resistance (as in the case of the permanent state of war in Palestine), for the redefinition of areas of influence or for all of these reasons placed together. The fact that some of these wars have not only never been declared but, in some instances, have not even been considered as such simply shows that today the state of war is ubiquitous. ${ }^{16}$

This is certainly not a novelty. Rather, the fact that the scale of conflicts today is global in every corner of the world (which means that, in principle, any local conflict has effects on the entire world) has torn through the veil of Western ideology that had marginalized the role of war in the ascendency of Euro-American culture: a liberal, economistic, democratic ideology, according to which the success of Western 'values' - economic well-being, political freedom, representative government, scientific and technological development - is supposedly the result of a superior intrinsic ability and not, instead, the outcome of a state of war that, over a couple of centuries, has left in its trail hundreds of millions of corpses. It is an explicit, but more often implicit, ideology that is based upon the characteristic removal of an extreme division of intellectual work. The erasure of war and its normality in social sciences and political and economic theory, philosophical aphasia, the reduction of war in historical discourse to a variation in the political-diplomatic game: these deletions reach their climax in the bizarre idea of the pathology, as if war were a disease suffered by the West rather than its physiological condition.

Following Foucault, one could proceed to draw up an archaeology or a genealogy of the removal of war in the self-construction of Western thought. This task is not impossible if only one were to rely on the counterpoint in philosophical discourse of the lack of interest and the occasional belligerent drive - something which, between instances of reticence and homicidal rage, would take us back to the source of the Western narrative. ${ }^{17}$ The occasional intuitions of a Machiavelli or a Schmitt, Kant's convoluted pacifist projects, the lightning bolts of Nietzsche - and even Foucault's or Deleuze's brilliant historical-philosophical plots ${ }^{18}$ - are not enough to absolve the philosophical tradition from the suspicion of a general connivance and silent approval on the matter of war. 


\section{A. Dal Lago}

To claim that war presently assumes a constituent function more than in the past, even if this is implicit or removed, means recognizing not only that political-social and military planning are in perfect agreement, but also that it is the latter that largely determines the rhythm of the former. Here, the discussion is not restricted to the technologies that have become perfectly normal in everyday life (and, rather, are assumed as a symbol of peaceful development and even the freedom to communicate) and that, in some cases, like the Internet, have military origins. It is enough to limit oneself to the fact that in the currently triumphant market societies, where the role of public intervention is considered scandalous, the most extraordinary apparatus of military welfare that the world has ever seen is thriving. If Rome, which had around thirty active legions at the time of its maximum development, was considered the most militarized empire of ancient times, and Frederick II's Prussia, with an army of men totalling a few tens of thousands, represented a veritable barracks state, what then are we supposed to say about the contemporary United States, whose Department of Defense has over two million men on its payroll, without taking into account its reservists, the National Guard and millions of other people working in the civilian sector of its military-industrial complex ${ }^{19}$ And what should be said about the millions of other armed people (and discounting mercenaries) with civilian tasks, such as various types of police officers recruited in the endless war against terrorism?

The military system, apparently silent or frozen in peacetime, and more or less triumphantly deployed in wartime, has seemed to be a sort of implicit necessary evil until, after 1989, the intellectual, political and judicial conventions began to crumble, revealing the world as a single great battlefield. Naturally, it was a profoundly new martial landscape, but perfectly in line with the directions that the economy and technology have been taking over the last decades. To begin with, the early 1990s witnessed the prevailing of a new technocratic utopia in war strategy, known as RMA or Revolution in Military Affairs. To understand the significance of this transformation, it is necessary to recall that European military history had been conventionally marked by shifts that were termed 'revolutions' ${ }^{20}$ Examples in the modern epoch include the large-scale diffusion of firearms (between the sixteenth and seventeenth centuries), the introduction of conscripted armies (between the eighteenth and nineteenth centuries) and the aforementioned adoption of armoured forces and strategic aviation (in the first half of the twentieth century). RMA marks a further shift, and the most radical of all, insofar as it is not just capable of assuming the whole world as the arena for its implementation, but also, and most importantly, it can in principle achieve the progressive reduction of the human element in combat, if not its total disappearance (O'Hanlon, 2000). The strategic core of RMA is basically constituted by the use of new computer, communication and robotic technologies in the military sectors where the human element has always prevailed: information gathering on the ground and 
combat. Here, flesh-and-bone soldiers would be progressively, if not entirely, replaced by the automation of information systems (infowar) and a predominant use of aerial and missile warfare to neutralize enemy armed forces (De Landa, 1991).

In a certain sense, the second Gulf conflict of 1991 represents the transition from the twentieth-century type of warfare to RMA. ${ }^{21}$ Although the communication and air defence systems (as well as the Iraqis' land defences) were entirely neutralized by the allies, the land forces (armoured and infantry) were assigned the task of 'completing the job' and of 'cleaning' Saddam Hussein's troops out of Kuwait. In any case, the extraordinary disparity in the calculated losses (little more than 300 among the allies; several tens of thousands among the Iraqis) gave rise to the illusion that the incomparable Western dominance in terms of computer, aerial and missile technologies had now rendered land warfare marginal. Even land warfare, based as it now was on the integration of armoured forces and tactical aviation (flying gunships and combat helicopters), would also become more or less a formality.

Immediately after the 1991 Gulf War, the ideology of 'zero losses' (among Westerners) was hatched, together with propaganda about the capabilities of missiles and 'intelligent' bombs to cause a minimal number of victims ('collateral damage') among the civilian population (warfare with 'zero human cost'). The height of the combination of utopia and propaganda that comprised RMA came with the 1999 war in Kosovo where, for the first time in the history of NATO alliance attacks, there was not even one death among the attackers and a 'few hundred' (but, in reality, a few thousand) victims, who were primarily Serbian-Yugoslav civilians.

Moreover, the theory of 'asymmetrical' warfare prevailed during this period. Among the more visionary theorists, the idea began to circulate that the enemy's response to Western invincibility would be to abandon conventional warfare as well as traditional guerrilla warfare (epitomized by the people's war theorized and practised between the 1950s and 1970s by the Vietnamese general Giap) because these were too costly in human terms. The asymmetrical response would consist primarily in forms of 'netwar' where small, autonomist terrorist cells lacking any centralized structure would seek to strike at the nerve centres of the West and the USA, following the well-known strategic precept of 'swarming', in which all move separately so as to strike together. ${ }^{22}$ There is no doubt that, from the very start, American strategists had the Al Qaida model in mind, which they knew perfectly because the US had participated, directly or otherwise, in financing Osama bin Laden at the time of the guerrilla warfare against the Soviets in Afghanistan (Burke, 2004). The underlying principle is that terrorist guerrilla warfare must be opposed with a counter-guerrilla effort that is based on the same strategic principles. ${ }^{23}$ The first response to 11 September (which US analysts had widely predicted, even if they had 
obviously been unable to pinpoint the attack) was the war in Afghanistan, where RMA appeared to find its fullest implementation: strategic bombing of Taliban and Al Qaida sanctuaries, with the Northern Alliance acting as proxy for the dirty work (eliminating Talibans on the open battlefield) and the use of small counter-guerrilla units (including CIA and British officers, Rangers, Delta Force and British Special Forces) to swarm against the Al Qaida network in the mountains between Afghanistan and Pakistan.

The American and British decision to invade Iraq in March 2003 with a relatively 'light' force was not just the result of errors in strategic assessments (nobody had foreseen the Iraqis' choice not to sacrifice their troops in land clashes where the outcome was a foregone conclusion and to instead save themselves for the fighting after the 'victory'), but was also the upshot of their excessive confidence in the new way of conducting war. Convinced that the victory in 1991 and subsequent embargo, coupled with the usual and devastating aerial attacks, would have annihilated any possible resistance, the American and British forces entered into an undertaking that immediately revealed itself to be infinitely more difficult. At this point, it is essential for us to ascertain the distance between theoretical strategies and practical applications. This distance also depends on conflicts between civilian advisors (fundamental to the American decisionmaking system) and military hierarchies, and, in the case of the latter, conflicts between different strategic schools. By and large, military hierarchies are cautious when it comes to espousing the more futuristic strategic concepts and are bound to a traditional military culture. Here, at least two relevant conflicts can be noted: the first was the removal of General Wesley Clark during the aerial war in Kosovo, who had argued that a land intervention in Kosovo was indispensable, while the second was between the US army's chiefs of staff and the defence minister, Rumsfeld. The military officials felt that the invasion of Iraq had been prepared too hastily and that the 300,000 or so individuals who had initially taken part (of whom only a third were combatants) were not sufficient to maintain order after the possible capture of Baghdad. ${ }^{24}$ All this demonstrates that RMA is merely a theoretical vision, and one that is also controversial, and thus we must not draw any long-term conclusions regarding the evolution of contemporary war. ${ }^{25}$

The current method of waging wars appears to be faced with an array of options that are largely political, often in contradiction with each other and broadly coincidental. But this means admitting that there is no solution of a fundamental continuity in the choices between peace and war in the Western hegemonic system. ${ }^{26}$ The strategic failure in Iraq widely conditioned the US presidential election in November 2008 (which was not at all a referendum on peace, but rather on the optimal way of conducting war). Although the adventurist strategy of the American neo-conservatives was defeated with the election of Barack Obama, the military options did not fade away but were inserted, exactly as had happened in the past, into 
a scenario in which the military apparatus is ready, at any time, to act as the armed wing of the 'security' policy, that is, of American hegemony.

War also exercises a constituent function in a wider sense, insofar as it influences the global structures of culture. Let us consider the sphere of information. Although apparently pluralistic at a planetary scale, due to its articulation into countless local and national spheres, in reality global information is influenced by a small number of news sources and media organizations that fall within the orbit of the West and, above all, the United States. Even television channels praised for their impartiality ultimately depend, during international crises, on networks that are close to the American political-military establishment, such as Fox TV. Moreover, the events of 11 September 2001 ensured that almost the entire Western media aligned itself with the positions of the American government, in the name of patriotism or in the defence of civilization. At the same time, since information came to be openly considered essential to military strategy, the media has effectively been recruited into Western armies, rendering independent coverage of conflicts impossible. ${ }^{27}$ In 1991, the chiefs of staff of the coalition prohibited freedom of movement for reporters in the theatre of operations. In 2003, journalists were embedded - in other words, dressed in uniform and attached to second-line units. Alternative or independent information was discouraged by swift and, in any case, military means. In 1999 during the war in Kosovo, Serb television was destroyed by a missile attack, while in Iraq several film crews of Arab broadcasters like Al Jazeera were repeatedly targeted by the Americans during the capture of Baghdad.

The militarization of information is not in contradiction with the apparent communicative pluralism that befits a global market society. Rather, it acts intermittently during the phases of mobilization and at the height of conflicts. Furthermore, it extends to the ordinary processes that filter news, providing them global prominence or demoting them to the background or causing them to disappear altogether off the media map. Even without any diktats from the military or politicians, news items that contradict the official political truths vanish, simply because there is no media organization interested in reporting them. ${ }^{28}$ Given the mass of information theoretically available, something becomes news only when it is politically supported in other words, when it is produced, filmed or validated by the institutions that are equipped with authority on a global level. The American government was capable of convincing the world that the Iraqis were in a position to strike the West with weapons of mass destruction only because, after 11 September, it was endowed with a sort of claim or right to truth. ${ }^{29}$

The influence of war on culture is also exercised at a far wider level than the mere imposition of a political-media agenda. While Western leaders (apart from the more amateurish ones like Berlusconi) are capable of showing cautiousness in making correlations between terrorism and the Arab world or between global subversion and Islam, this is not the case 
with their advisors, the most influential intellectuals or simply those commentators whose purpose is to stir up the waters in order to sell articles or books. Huntington's essay on the 'clash of civilizations', which was aimed at an educated public, or Oriana Fallaci's obscurantist pamphlets, which were aimed at the general public, confirm the opinion that there is an ongoing war between cultures and religions, or a general terrorist attack against the West. ${ }^{30}$ This does not need to be a widely held opinion (in fact it is not, if one is to believe the surveys by international research institutes). It is sufficient for it to be legitimated and diffused by the popular media and for it to therefore build the foundation for Western governments to justify their strategies, explicitly or implicitly.

The militarization of culture translates, above all, into widespread modes of thought (or non-thought) that do not always need to be explicitly expressed. In any kind of war, the enemy loses every specific connotation to become the exclusive target to strike. ${ }^{31}$ Nowadays, the generalization of the hostility implicit in contemporary wars - 'terrorists' thus refer to Arabs or Muslims and 'rogue states' to the whole of a population - ensures that a considerable part of humankind becomes a potential target and is hence dehumanized. This gives rise to the notable indifference towards the fate of populations involved in contemporary conflicts. Very few voices were raised to denounce the effects of the UN embargo against Iraq after 1991, which caused, directly or indirectly, the death by starvation or lack of medical treatment of one and a half million people. Likewise, few people were concerned about the civilian victims of Western military actions and bombings in Somalia, Kosovo, Serbia, Afghanistan and Iraq. Massacres, torture, extermination camps and the suffering of civilians are only brought to light when the West is not involved. ${ }^{32}$ As Derrida observed, the current political-military terminology reduces enemies or targets either to enemies of humanity (terrorists, scoundrels, bandits and criminals, when they exercise an active role) or to animals or inert material (when 'other' populations are involved in the West's wars) (Derrida, 2005).

The debasing of the enemy has varying nuances. It ranges from the creation of ad hoc categories, like the one of 'enemy combatant', used to define the 'terrorists' captured in Afghanistan and elsewhere and imprisoned in the American base in Guantanamo, to the straightforward cancellation of the registering of victims. From 1991 to date, there has not been a single war in which the victors have bothered to calculate civilian casualties. The use of the expression 'collateral damage' to indicate the civilian victims of bombings perfectly expresses the way in which 'other' human beings are equated to mere things fatally affected by war. Moreover, this style is entirely coherent with the military practice of 'indiscriminate response', which establishes a pure and simple linguistic extension. When a Western combat unit is attacked on the ground, it reacts by creating a void around itself. As the enemy is, and always will be, a terrorist, the aim is to destroy their civilian habitat, and hence not just to strike 'anything that moves' but 
also the population amongst which they might be hiding. The dynamics of urban fighting in Mogadishu (1993), Palestine, Chechnya, Iraq (particularly in 2004) and today in Afghanistan are basically the same. ${ }^{33}$ The regular armed forces strike civilians in a generalized manner, bombing the sanctuaries of terrorists or guerrillas that are found in urban areas, and hence essentially seek to 'obliterate' any support, actual or otherwise, for the enemy. In this way, Western tactics are substantially a mirror image of those of the terrorists, whose aim is to mobilize civilians against the West.

As we have already pointed out, we are dealing here with a clear case of asymmetrical warfare, which can be defined as a conflict where one side equipped with overwhelming force seeks to destroy an infinitely weaker enemy that fights in an unconventional and 'improper' way (Metz, 1997; Pape, 2005). However, the asymmetry has a far broader significance beyond its military dimension. In general, when the West fights it could be considered an anthropological type of asymmetry. The military definition of the enemy as barbarian or criminal excludes any recognition of their status as combatants. Accordingly, they are treated as a mere technical problem, at the same level as a disaster or natural calamity. Unlike in the past (particularly during the 1930s and 1940s), today there is no need for an explicit theory about the inferiority of races to justify the use of asymmetrical warfare. As long as it is assumed that ours is the only (legitimate) culture, the others will always be considered to lack culture or to be bearers of abnormal or monstrous cultures (as in the case of fundamentalism). Therefore, asymmetrical war is not fought against different individuals, but against non-persons. As such, the treatment of the enemy is racist to a new extreme because it does not assume its inferiority, but rather its a priori exclusion from humankind. ${ }^{34}$

It is not necessary to read between the lines of their texts to see that the advisors of Western leaders are entirely aware of the racist character of contemporary conflicts. ${ }^{35}$ The 'right to wage war' is proclaimed at present on the basis of the claim to an absolute cultural superiority (Kagan and Kristol, 2005). The 'barbarization' of the enemy enables both the production of consent across most of the West for permanent war and the management of conflicts without any reference to the judicial 'forms', conventions or constraints imposed by international law. ${ }^{36}$ In this field, the only formality is ideological and has the purpose of conditioning Western public opinion by justifying, in the name of higher goals (the defence of our civilization, 'human rights' and so on), measures such as the internment of enemy prisoners in camps beyond any external form of control, the systematic use of torture and the use of weapons of mass destruction. ${ }^{37}$

If this is the reality of contemporary war, it is necessary to acknowledge that, for the time being, we do not possess adequate theoretical tools to imagine future developments and, even less so, to prefigure exit strategies. A political thought based around the centrality of warfare in the current world system has still not even begun to emerge. On the one hand, there is 
a lack of real awareness of the role that war has played and continues to play in the rise and advance of Western (first European and later American) hegemony around the globe. On the other hand, while it is not empirically difficult to trace the military expressions of Western supremacy as this has developed since 1989, obscurity and confusion reigns as to the nature of the opposition to this supremacy. I believe that it is not too far away from the truth to stress that this opposition is composite and heterogeneous, insofar as it is a reaction to the logic of what tends to be defined as empire. ${ }^{38}$ It has become common to define this logic as 'exceptionalism', drawing on the German debate of the 1930s about the 'state of exception' (Agamben, 2005). However, this definition conceals a number of misinterpretations. According to Carl Schmitt (who took to the extreme the Weberian definition of the state as the holder of the monopoly of legitimate violence), the state of exception is the measure that the beatus possidens of a formally legitimate power may structurally assume to eliminate a situation of internal civil war. ${ }^{39}$ Hence, it is difficult to understand how such a concept can be extended to a planetary level, since never, other than through the partial duplicity of world institutions like the UN, has it been governed by a legitimate monopoly of force. Violence and war are not the derivation of a legitimate order, but rather the conditions for the normal exercise of power on the international scene. ${ }^{40}$ What we are witnessing at present is a new type of normality. This does not amount to a mere terminological question but, more simply, to the intimate connection between war and politics (and economy) in the globalized world.

For as long as the world economy is based on what Weber called the 'economic struggle for existence, atrocious and without compassion, which the bourgeoisie defines as the "peaceful work of civilization"' (Weber, 1988: 41), war in any form - traditional or otherwise - will remain the interface of global social life. For those who live in the more or less safe confines of the empire, this consists, at most, of the spreading of paranoia in culture and the echoes of nearby or distant explosions. Everybody else, whether real or virtual enemies, is faced with the concrete possibility of destruction and death. A movement of global opposition to war, capable of neutralizing the militaristic nature of imperial powers, is little more than a utopia. It is up to us, inhabitants of the imperial constellation, to assume the theoretical and political duty to begin to deconstruct the global racism upon which the present state of war has constructed and which is characterizing its project in an increasingly explicit manner.

Translation by Yasha Maccanico and Nick Dines.

\section{Notes}

1 G.W. Bush, interview with NBC on 23 February 2004.

2 This is the position expressed by Fukuyama in a well-known essay from the early 1990s. See Fukuyama (1992). 
3 Sheehan examines the wars of the last twenty years, and especially during the period after 11 September 2001, against the backdrop of European postwar history (Sheehan, 2008).

4 For an analysis of the 'twentieth-century thirty years war', see Ferguson (2006).

5 I have discussed the analogies between colonial conflicts and contemporary wars in Dal Lago (2010).

6 The argument could be extended to global electronic surveillance networks, such as the notorious Echelon system, and to the various cooperation agreements in the field of intelligence, prevention and control that are stipulated at different levels by Western states (Campbell, 2000).

7 On the continuity of external and internal social controls, see Simon (2007).

8 The fact that these are considered 'enemies of civilization' means that they are not even protected by conventions on war, irrespective of the latters' often arbitrary nature. However, this does not mean, as is often argued, that the measures adopted by the US government (as well as others) are 'illegal' - as if a substantial legality existed in this field. Rather, they are formally legal procedures through which the 'war against terrorism' is withdrawn from the control of ordinary law. It is an apparent paradox that has some famous precedents, such as the special regime established by the German state for Jews (Fraenkel, 1941). For a discussion on the impact of exceptional measures in the USA after 11 September, see Leone and Anrig (2003).

9 For example, it has become normal to argue, often but by no means exclusively on the right, that violent behaviour, such as that during a street demonstration, is the first step towards terrorism. European news reports include numerous cases in which a connection has been drawn (not only by journalists but also at a judicial level) between 'social subversion' and 'Islamic terrorism'.

10 By way of example, see Berman (2003).

11 In recent years, numerous authors have reaffirmed the West's intrinsic superiority over any other kind of culture, past or present. In this sense, Hanson (2001), who attributes Western military supremacy to the rationalism from the time of Marathon through to the Gulf War, and Landes (1998), who claims 'our' economic superiority is a result of the freedom of enterprise, are both emblematic. For a critique of retrospective Eurocentrism, Said (2002) remains indispensable. In my opinion, the only approach that is scientifically sound remains the comparative one adopted by Louis Dumont (who owes much to Marcel Mauss). Cf. Dumont (1986).

12 The transfer not just of support structures (logistics, provisions, policing, security, etc.) but also of combat activities into the hands of private businesses is one of the most innovative features of contemporary war (Schwartz, 2003). According to Traynor (2003), the ratio of private soldiers to regular armed forces at the start of the Iraq war of 2003 was around one to ten, whereas at the time of the 1991 Gulf War, it was one to 100. Singer (2004) believes that the actual figure for private military personnel is far higher.

13 For a recent summary of the Foucauldian analysis of war, see Guareschi (2005).

14 For Foucault, war is essentially regulatory, which, strictly speaking, entails a passage from government to 'governmentality', in which war loses any element of exceptionality (Foucault, 2008, 2009). On the idea of regulatory violence in globalization, see among others Kurtenbach and Lock (2004). For a sociological discussion on the continuity between internal and external violence, see von Trotha (1997) and Dal Lago (2008).

15 This amounts to a mythology that has been widely advanced by human sciences, in particular psychoanalysis (Pick, 1996). 


\section{A. Dal Lago}

16 As such, it becomes the object of theories that can be applied without distinction to complex matters, from economics and history to natural catastrophes. For an illustration of this argument, see Buchanan (2001).

17 Ancient-war historians noted that in Greek philosophy the contemporary ubiquity of war did not merit any more than an occasional reflection (Garlan, 1975; Villatte, 1999).

18 Obviously, the reference here is to the chapter on nomadology and war machines in Deleuze and Guattari (1987).

19 At the height of the Roman Empire towards the end of the first century AD, the overall number of legionnaires defending the borders of a territory that ran from Scotland in the north to Persia in the south-east was no more than 180,000 men (Wells, 1984). As the historian Procopius has taught us, the armies of Justinian, one of the most aggressive Byzantine emperors, rarely surpassed 15,000 to 20,000 men each (Bréhier, 1949). Until the time of Napoleonic armies, and in spite of an incessant series of conflicts, European armies rarely surpassed the size considered optimal of 30,000 to 40,000 men (Keegan, 1994). It is true that the sizes of armies in different historical epochs are not commensurable. Nonetheless, even if we disregard the two world wars, the twentieth century witnessed an extraordinary expansion of military apparatuses. The anti-Iraqi coalition of 1991 comprised around 700,000 individuals, two thirds of whom were non-combatants.

20 The literature here is vast. For a synthesis of the question, see the classic work by Preston et al. (1956), and also Parker (1996) and Knox and Murray (2001).

21 The first Gulf conflict is conventionally considered to have been the war between Iraq and Iran (1979-1988).

22 See Arquilla and Ronfeldt (2000) and Edwards (2000). It is worth noting that, in these hyper-theoretical and utopian theories, the 'swarm' is considered, to a certain extent, a timeless tactic and, as a consequence, old (including ancient) classics of strategic thought are reread in a modern key. This is a further example of the rather self-referential character of strategic discourse. It is nonetheless true that, alongside the theories about 'grand strategies', there has also been a concern throughout history for 'minor wars', border wars, anti-insurrectional warfare and so on, at least since the time of Byzantine military thought, which found itself tackling irregular or non-conventional combatants, such as Turks, Pechenegs and Arabs. See, in particular, the Strategikon by Emperor Maurice and Taktika by Leo VI the Wise. Ample excerpts of these treatises, which have become fashionable again in American military thought, can be found in Chaliand (1990).

23 The literature on this matter is extensive. For a recent synthesis, see Berkowitz (2003). The idea that war necessarily evolves in this direction is very controversial. For a traditionalist view, see Gray (1999).

24 Shortly before the Iraq war, the magazine of the US Army War College, one of the most important academic institutions of the American army, published a scathing rebuttal of the Bush-Rumsfeld doctrine (Record, 2003a: 4-21). Later, the same author harshly criticized the conduct of the war in Iraq (Record, 2003b). These interventions published by military institutions had considerable resonance in the American press and contributed to break the 'mission accomplished' myth.

25 One is left with the impression that RMA is assessed on the basis of the 'visions' of its theorists, rather than by an analysis of its true impact. An interesting case is that of the appropriation by the Chinese of the 'secrets' of RMA. A few years ago, the press reported the concern among the American military fold following an essay by two Chinese air force officials (Liang and Xiangsui, 2002). In reality, almost all the material cited by the two authors is easily accessible on the Internet. 
26 After all, the concept of pre-emptive war (drawn up at the time of Clinton) indicates a permanent state of alert and war, which hence becomes an ordinary foreign policy option. See Carter and Perry (1999).

27 The manipulation of information as an instrument of global war is theorized in Arquilla and Ronfeldt (1997). The Gulf war was perhaps the most sensational example of military fabrication before Saddam's 'weapons of mass destruction' were used as a casus belli in 2003. From the invention of crimes committed by Iraqis in Kuwait to censorship on military operations, all the information about the war was manipulated by the allied chiefs of staff. See MacArthur (1992).

28 See Lydersen (2003). Consider, for example, the figures for civilian and military victims in the wars in Iraq and Afghanistan. These are figures that, if they became and remained news items, would draw the world's attention to the failure of the Western occupation of the two countries after the easy victories (or pseudo-wars) of autumn 2001 (in Afghanistan) and spring 2003 (in Iraq). For far less, namely the death of around twenty Rangers in Mogadishu during a clumsy attempt to capture two of Aidid's lieutenants, Bill Clinton withdrew US forces from Somalia (Halberstam, 2001). But the current figures are not news, for the simple reason that the global media does not turn them into news. It is difficult for these figures, easily obtainable on the websites of pacifist organizations or independent research institutes, to move beyond the web, where they are available for hundreds of thousands of Internet users. However, the Internet does not constitute a global informative stage, although on certain occasions (such as pacifist mobilizations or those against the G8) it promotes a global diffusion of information. While the web may shift important, albeit minority, sectors of world public opinion, it cannot impose specific news items in the political-media agenda, which remains dominated by major television networks and press organizations.

29 Even after the story about Saddam's weapons was revealed to have been unfounded, the media close to the US establishment have largely absolved Bush and the government, by assigning responsibility to people in subordinate positions or bad advisors. See Hosenball et al. (2003).

30 On this point, see Dal Lago (2006a).

31 It is nonetheless easy to demonstrate how this perspective based on fear makes the system (today, the USA) that supports it fragile, forcing it to perpetually keep its finger on the trigger (Barber, 2003).

32 This reflects the cross-eyedness, cultural before moral, that I feel is prevalent in the widespread literature about the different types of genocide, as if 'democracies' were by definition immune from such practices. Recently, while discussing Clausewitz's work, René Girard stressed the systemic character of contemporary global violence (Girard, 2007).

33 Desh (2001) discusses the insurmountable difficulties of urban combat for a conventional army, even when this is equipped with the most sophisticated weapons.

34 For a discussion on the evolution of conflicts in this direction during the twentieth century, see Sloterdijk (2004).

35 On the relations between racism and contemporary war, see Girard (2007).

36 I use the term 'barbarization' here to indicate the a priori debasing of the enemy. The idea of 'barbarianism' as the deviation of Western rationality often conceals the destructive forces that Western rationalism constitutively unleashes. For a discussion on this issue, see Miller and Soeffner (1996).

37 These higher goals can also be found occasionally in 'human rights'. For a wideranging rebuttal of the premises for 'humanitarian' interventions, see Zolo (2002). 


\section{A. Dal Lago}

38 Hardt and Negri (2004) appear to put forth the hypothesis that imperial war is opposed by a sort of global democratic movement that, after a patient gathering of forces, may be able to turn, sooner or later, into a sort of general insurrection. Obviously, a thesis of this kind cannot be refuted, as it is based on a petitio principii. Here, the constitutive weakness of the no-global movement becomes, through a theoretical contrivance, its strength. I limit myself to observing that the concept of 'multitude' disregards the extreme (political, economic, social and military) heterogeneity of those who oppose imperial policies.

39 See Schmitt (2007). Foucault (2009) has also shown how the concept of 'state of exception' may be traced back to the classical notion (for example, in G. Naudé) of the coup d'état as a measure for the monarch to re-establish order. It is rather peculiar that among Schmitt's work discussed today, his essay on the international order and war is far less cited, where he expresses a sort of nostalgia for a time when war supposedly 'complied with regulations'; in substance, a bloody game regulated by the conventions between its antagonists (Schmitt, 2003). The reading of this text (alongside others such as Land and Sea) indicates that Schmitt saw in the supremacy of resources the advent of a war of destruction in which the old categories of international law could no longer apply. Hence, it is not exceptionalism in this Schmitt, but the political normality of global war.

40 This is easily deduced from the fact that UN Secretary-General Kofi Annan's definition of the Anglo-American aggression against Iraq as 'illegal' (after an initially ambivalent response) did not have any practical consequences. In this sense, it is more realistic to define the contemporary global situation as a condition of anarchy, in which the strongest military power (the USA) no longer seeks to found or support a legitimate order, but rather to exploit the situation for its advantage through a continuous, military mobilization. For a definition of international anarchy, see Bull (1995). 


\title{
2 The barbarization of peace \\ The neo-conservative transformation of war and perspectives
}

\author{
Alain Joxe
}

For gold is not sufficient to find good soldiers, but good soldiers are quite sufficient to find gold.

(Machiavelli, Discourses on Livy)

\section{Introduction}

This contribution seeks to describe the current state of the world as barbarism and, hence, as a process of 'barbarization' of peace through the proliferation of civil wars and never-ending external operations (OPEX). In the present global crisis, the barbarization of war passes through strategies of international policing that also contaminate the notion of peace.

Barbarism is laden with details and any description is not wholly satisfactory unless it is accompanied by an analysis of such ladenness. To that end, we would need the breadth of a whole book and the attention to historical anecdote that, for instance, we find in Guicciardini's political suggestions. ${ }^{1}$

The new wars always have political and social goals, but these are neither national political objectives, nor traditional imperial objectives any more. This transformation can be explained by the change in the dominant classes, which manage the globalization of the market economy thanks to the digitalization of the financial system and to the technical change in the morphology of the use of violence, also made possible by the electronic revolution. Under this double relationship, the space-time of national objectives of the bourgeoisies of yore has disappeared. It is not a big loss, but it is a big change that, for the time being, destroys the consensual framework of democracy that has long been tied to the scale of the nation-state, which has become inadequate, not to say stupid, in the presence of global strategies. The destruction of 'national' or 'Westphalian' war objectives has, as its corollary, the proliferation of wars of policing and permanent repression that, without the control and adaptive answers coming from popular forces, could everywhere turn into a form of concentrated and globalized fascist strategy, which would drag the 
oikoumene ${ }^{2}$ towards a permanent, Schmittian state of exception. A sort of universal barbarism (the inverse of Kant's universal peace) would thus provide legitimacy to all kinds of pillaging and destruction of the environment, capable of increasing the wealth of the rich and the poverty of the poor to a boiling point.

\section{The barbarization of aims: deconstruction of a process of strategic globalization}

In Europe, since the sixteenth century, the predatory logic of conquest by the prince or monarch and eventually the Republic (or Commonwealth), which was formalized by Machiavelli and Hobbes, had as its objective the pacification and the economic and military exploitation of conquered and protected peoples. This objective has disappeared with anti-statist neoliberal deregulation. This disappearance is so recent that it has engendered a major strategic confusion. Moreover, all the 'laws of war' - jus ad bellum and jus in bello - are constantly violated, as are human rights and UN resolutions. These four types of regulation, archaic or modern alike, had been conceived for an inter-national system, which has now been dismantled by trans-state market forces.

\section{The end of the imperial strategies of conquest/protection}

The principle of sovereignty, which we may refer to as 'Roman' in the West, is based on the logic of the protection of conquered peoples, a protection that is necessary to exploit them. This principle, pulverized under the barbarian kingdoms and feudal anarchy of the early Middle Ages, was subsequently re-federated by monarchs who fantasized about the revival of the Roman Empire, with the geopolitical projection of the Crusades and the conquest of the Americas. The principle of protection had been preserved, as they competed for world power, by the colonialist nation-states and by the industrial armies of the twentieth century (the First and Second World Wars). In spite of the massacres of conquest, the protective political objective of Pax Romana had not disappeared from the ideology that supported colonial empires (also to put a brake on decolonization). According to Lyautey or Galliéni, 'protected' societies were asked not to rebel and survive in conditions of 'acceptable poverty' on the path to progress, while their cultural identities were respected.

It is not a matter of paradise lost, but of rational strategic and political objectives to organize an economic dominion, which, at the time, necessarily passed through domination and political control of the entire local society. Exploitation of the colony, composed by tribes, and large traditional or colonial landowners, by indigenous farmers or small-scale colonization by settlers, commercial networks, water and mineral resources, called for complete geographical command to enable a selective and 
peaceful predation of natural stocks and heterogeneous flows of profits, some of which were already deriving from the globalization of certain markets. Hence the necessity of maintaining permanent order in a political space bounded and defended from appetites foreign to Empire.

The Second World War put everything back into flux, but the imperial principle of the 'protection of conquered peoples' and 'imperial peace' did not disappear amidst the bipolar and nuclear clash of the Cold War (1945-1990). Although the 'protection of peoples' through the 'threat of planetary destruction' led to an oxymoron, the global strategic outcome that was finally sought amounted to the peaceful coexistence between the two imperial blocs and peace within the two rival systems.

\section{The US imperial module: the Latin American paradigm}

Historically, in Latin America, the United States has given rise to a modernized definition of Empire. South of the Rio Grande, Washington organized a domination that was without conquest nor imperial annexation; just a few border corrections here and there, some operations by the Marines and, even better, indigenous military coups were sufficient to defend the economic dominance of the American empire, the first empire managed by a dominant class that was essentially industrial after the victory of the Union over the Confederacy in the Civil War. Thus, Americans have been more advanced than Europeans, including the Russians. By renouncing to annex all of Latin America beyond Texas and California, the US meant to unshoulder the burden of responsibility for and protection of the traditional feudal and slave-driven agrarian structures deriving from the conquista. This freed the American government from direct responsibility of the violent archaism of the states and classes of the Spanish- and Portuguese-speaking colonialists who stayed for a long time at the head of the post-colonial state and were responsible for the old-style management of social apartheid structures. The Latin American paradigm was later useful to the United States to make the liberation of European peoples from Nazism a sort of post-imperial balkanization of the fascist Third Reich (including Mussolini, Franco and Pétain) and to reduce them, without conquest, into a space integrated into the American empire through a community of interests of dominant classes facing the communist threat. Hence, since 1942, to the eyes of Roosevelt and then his successors, Gaullism has looked like an archaism, a phenomenon of autonomy first related to the protection of the French empire, and later to the likewise 'archaic' maintenance of the social autonomy of the Republican nation-state. Conversely, British strategic alignment to US leadership, with the progressive dilution of the empire into the Commonwealth of nations, enabled a peaceful co-optation of the elites of the British empire by dominant rich strata at the head of the American empire. 
The decline of states (metropoles of empires or not) was not yet visible at the stage of postwar planned reconstruction; the economic and social sovereignty of states and empires had survived; the UN remained a society of nation-states. But later, during les trente glorieuses, with the dissolution of colonial empires, the growth of a deregulated market economy continued unabated with the development of business 'transnationalization'. From then on, in the West, the neo-liberal dynamics have constantly pursued a single objective: the end of economic protectionism, and thus the end of political and social protection as a principle of state sovereignty. Hence, the United States has long prepared to create a world empire based on market domination rather than military conquest.

\section{The spread of a deregulated market economy to the whole world puts an end to the neo-colonial American empire}

The current demolition of the French model by neo-liberal modernism is an alignment that allows integration into the American empire. But this alignment arrives too late: France joins an empire that is actually weak, that is no longer purely American; with Obama's election, the American state itself reaches a critique of the perverse consequences of globalization.

The global neo-liberal shift launched by the Reagan-Thatcher duo in the 1980s set off from a strategic vision that was legitimized by the growing globalization of industrial and financial groups. A transnational class was formed that explicitly aimed at unifying the world market through the ending of national protections and which, in the space of a decade, managed to speed up globalization. However, the triumph of such process in the 1990s, with the alignment of the USSR and China to liberal capitalism, also put an end to the American phase of neo-liberal empire. With this historical re-alignment, almost all protections of socioeconomic sovereignty started to come under attack in the European Union and were forcibly dismantled in the former communist republics. The predatory process, based on the exploitation of non-renewable natural resources and the rise of new poverty and new wealth through financial speculation, then became truly global through profits certified by the delocalized accounting of transnational financial firms.

The Soviet Union's self-destruction and China's alignment to the market economy were the initial macro-strategic conditions for a veritable economic globalization. The balkanization of the Soviet empire is formally reminiscent of the collapse of Spanish and Ottoman empires. (It could have well ended up under Washington's control as final fulfilment of its triumph, with American empire collecting all its fallen pieces: popular democracies, Baltic republics, then the movement seemed to extend towards Ukraine, Georgia.... .) 


\section{America: a super-armed mercenary power in the global system}

It is increasingly evident that there is no longer a purely American empire, but rather a complex system, perhaps Euro-American or Sino-American. Only the military supremacy of US armed forces is not in doubt; but, already after the first Gulf War, one could wonder whether the Americans were about to become the 'mercenaries' of the global system. ${ }^{3}$ The cost of that war was shouldered by Europe, and it also turned out to be 'beneficial'. From that moment on, the US has become unable to finance its wars and weaponry, and to maintain internal consumption as driver for its growth without accumulating massive foreign debt. The Chinese and the Arab oilproducing kingdoms have accepted to accumulate US treasury bills to cover for US internal consumption and trade deficit. Without the economic alliance with China, without the financial support of oil-producing fiefdoms and without the political alliance with the EU, what looks like American world leadership could be put into question. The American global empire is no more, but there is not yet a Global Federal Republic. And in the absence of a sovereign body that politically manages the current system on a global scale, there is no civilization, but rather global barbarism.

\section{The barbarization of the means of global empire: hyper- modern imperial hubris and clandestinity of global policies}

Barbarism is a strategic quality of the system: it is what reigns beyond the limits of the coordinated civilization of the cities, kingdoms and empires. Not having any limits or government any more, the universal empire of the market, a reflection of global speculative private interests, turns into barbarism due to its not being a republic. This barbarism manifests itself not only through the nullification of political aims, but also in the barbarization of military means and of the strategic definition of war. This strategic change has been a function of the Revolution in Military Affairs (RMA) triggered by the application of electronics to military surveillance and precision targeting, as the communist empire met its demise. This shift heralds the cancellation of political goals and tactical pertinence and, to maintaining order, the emergence of new types of weaponry suited for infantry combat and urban warfare. The seeming triumph of imperial America has led to the acephalous transnationalization of violent 'governance', whose promotion the US ensures through the continuous strategic modernization called RMA and, more recently, Military Transformation.

\section{The barbarization of means: from RMA to transformation}

Analysing the change in US arsenals from the 1990s to the 2000s, with the abandonment of unused arms systems inherited from the Cold War, it is possible to describe a barbarization of the representations of mortal combat 
and of the virtual enemy that goes under the rubric of terrorism, which constitutes a threat at a level that is far inferior to that of the Cold War. Antiterrorist measures are actions that are considered legitimate by political classes that are, at the same time, purchasers both of arms in a technoindustrial sense and of weapon systems in a military sense. The grand imperial strategy of the Republican right was best articulated through the electronic revolution, and this has led to two paradoxical results:

- The Right's political and strategic thought continues to hegemonize the modernization of means, even under Democratic presidencies, providing continuity to the strategic definition of American wars as wars without end, ruling out any form of negotiation with the enemy, aiming at the destruction of the opponent and, eventually, at the weakening of states through balkanization in the sense of 'intercommunitarian strife'.

- This implies costly expenses and military failures, and leads to the deAmericanization of war, as it can only continue thanks to the financial support coming from China, Arab oil-producing countries and the European Union.

At the outset, the evolution of means was launched by Democratic administrations, neo-liberal but not neo-con. These governments were the first that emphatically embarked upon a total reform of military means in the name of RMA and 'cyberwar'. They did seek to keep in check the technostrategic and policing drifts of the Republican right (the majority in Congress since the end of Clinton's first mandate). But they could not manage to do so entirely because, although they opposed the far right's political representations, they were still unable to modify the Military Transformation in its techno-industrial development, and were hence unable to control the American military-industrial lobbies and to thus hold back its futuristic tactical culture of high-precision targeting on a world scale and in real time. It is futuristic modernization that leads to asymmetrical and apolitical strategies and that produces wars that may be considered experimental, with theirs massacres of civilian populations and other war crimes. ${ }^{4}$ In fact, the doctrines for the use of force depend on arsenal availability, and the modernization of arsenals is not immediate; but in the United States this process is re-launched every four years (Quadriennial Defense Review) within programmes that range for between ten and twenty years. The Transformation that was orchestrated by Republicans with Rumsfeld since 2001 was conceived by neo-conservatives well before the attack against the Twin Towers, and it remains the hegemonic thought of the modernity we are living in. It has not brought the successes hoped for by its proponents, either in Afghanistan or in Iraq, but it has brought about the demise of the endless wars through which the Democrats had hoped to conquer supremacy, thanks to RMA seen as a tool for imposing peace. 
The peace processes initiated under Clinton in Somalia, Palestine and Colombia have all failed. The United States does not yet manage, not even under Obama, to put an end to the three ongoing experimental wars (Israel, Iraq and Afghanistan-Pakistan). Obama himself is tied to the string of military modernizations that go under the rubric of Transformation, and he announced as much in his speech on the AFPAK war held on 27 April 2009. He just hopes to be able to transform this war - which risks to set Asia ablaze - into a great global conference, which would help him to get out of it. This is the de-Americanization of leadership.

\section{De-Americanization of strategies}

Following step by step the principles and means employed by American neo-conservatives to rearrange the world, we have noted that it is precisely them who have engendered a de-Americanization of global leadership because they have lost the means for economic leadership and only retain absolute military supremacy. How does this process advance?

- First, the decline into which the neo-conservatives have dragged the United States is inherent in the central strategic contradiction of this school of thought and its fanciful representation of the Universe. On the one hand, it is a militarist, albeit anti-statist, form of strategic thinking; on the other hand, it is liberal, although violent. This ideological cocktail has led to three military consequences:

1 to the legitimization of the de-statization of violence and the subcontracting of the most questionable operations to private military companies or militias recruited among criminals, who effectively behave like out-of-control barbarian criminals;

2 to the destruction of the socioeconomic sovereignty of democracies and the promotion of neo-liberal democratization through violence in the areas of intervention. This is a far worse oxymoron than 'nuclear peace' because it brings about military defeat;

3 to the reappraisal - due to their effectiveness and tactical intelligence - of the successes obtained in the wars of decolonization by resorting to barbarian methods of territorial occupation in the context of urban warfare (like in the Battle of Algiers), omitting the fact that those wars were strategically lost as a result of such exactions (General Petraeus, 2008).

Hence, the extreme neo-con vision is responsible, after Reagan, for all the successes of infra-nuclear neo-militarism up until the victory for abandonment over the USSR in 1991, and then for all the system's failures in actual wars, down to the current financial crisis. This ideology inevitably built up an evolution of the world out of the coherent control of states and hence, finally, out of the control of the United States itself as a sovereign state. 
- Second, the Transformation has not simply been an application of neoliberal thought with its absurdities; there has been a reciprocal influence between the neo-cons' ideological representation and the tactical capacities for destruction of the new arsenals that have been conceivable, proposed and produced thanks to the information revolution. The Transformation has been the locus of interaction between military software and hardware, driving the modernization of air-land combat towards a strategic change of war. Heading towards asymmetry leads to predation and implies the inevitable recourse to abuses in 'communitarian' wars that are without political recognition and social mediation: we reach the point of disguised interventions by 'the rich against the poor' in the globe's urbanized zones.

This evolution had been envisaged since 1997 in neo-con military literature (for example, by Commander Peters in his 'Constant conflict' article of 1997), ${ }^{5}$ except for the fact that it did not foresee the decline of US preponderance, but rather its reinforcement in the barbarization of North-South global war, a priori described as inevitable and long-lasting.

\section{Hyper-modern conformity and political disproportion of the doctrines for the use of military forces and financial forces}

In this way, neo-conservative representations have lead to the quagmires in the Afghanistan and Iraq wars. Today, their results are considered disappointing, but President Obama believes that he must continue (in Afghanistan and in Pakistan, now bound together in the so-called AFPAK war) down the road of precision targeting and special operations. In other terms, he intends to continue with the electronic modernization programme (real-time reconnaissance, targeting and surprise firing) to beat the Taliban enemy. ${ }^{6}$

The qualities (tactical capabilities) of the weapons systems modernized by the electronic revolution continue to function as autonomous factors in the creation of new strategies, stronger than any kind of political and social reasoning, due to their unquestionable modernity. In this field, the logical contradictions stem from a logic of disproportion or hubris $(\gamma \beta \rho \imath \varsigma)$ which, since ancient times, in the vocabulary of ancient Greek political science, has constituted the place in which the empire's military logic (and the emperor himself) becomes disrupted by the escalation of violence, due to the lack of common measure (asymmetry $=\alpha-\sigma v v-\mu \varepsilon \tau \rho \imath \alpha) .^{7}$ The belief in one's absolute superiority leads to a loss of proportion in the forces deployed against the enemy and in the knowledge one has of the enemy. This military modernity, which is a form of (military) religion just like market deregulation has become an economic religion, sits next to three other types of 'disproportion' that mark a regression towards pre-industrial political ideas. 


\section{Disproportion of religiousness in global confrontation}

The neo-conservative quagmire seems the negation of nineteenth-century liberal ideology that believed in the effectiveness of free trade to civilize mores; it is now construed as a stabilized trait of strategic modernity: a unilateralist, asymmetrical military strategy that autistically regulates violence, associated to an economic strategy founded on a religious faith in the self-regulating effectiveness of the Global Market. This is market fundamentalism, according to the expression used by George Soros. ${ }^{8}$

For neo-liberal extremists, the market, freed from any constriction, is like an end in itself, a global good, the universality of the Holy Ghost, the realization of the Umma. It has turned into an extremist vision, the equivalent of a Sharia that supposedly justifies the barbarian treatment of opponents when, under the framework of globalization, the articulation of political measuredness appears to have been cancelled. There is in fact a coherence, a conformity, a homomorphism, between the holistic treatment of asymmetrical wars for force projection and the economic deregulation of the global market as a religious end.

\section{Disproportion of the crematistic economy}

In the configuring of the Transformation left behind by Rumsfeld, the disproportion of the relationship of dominance is not only military; it is associated (evidently, with the current world financial crisis) to the certain support of global neo-liberalism for a disproportion in the economy. It is by noting the development of detailed and solid control of space-time through electronic targeting that one could already take stock, in 2004, of the extraordinary growth of everything that could be referred to, as Aristotle did, as crematistics, the art of speculating on species and beliefs that now prevails over the economy of stocks and flows of real goods. Econo-

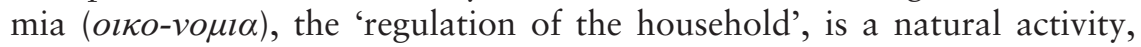
whereas Crematistics ( $\chi \rho \eta \mu \alpha \tau \imath \sigma \tau \imath \kappa \eta)$ is deemed by Aristotle to be the source of 'artificial' profit, against nature - that is, without measure; deprived even of the moderation of the raider, whose preoccupation is 'not to kill the goose that lays the golden eggs'. ${ }^{9}$ As I wrote six years ago:

Crematistics may constitute the means of temporary growth through the extreme acceleration of economic decisions and financial derivatives; this prevents the globalized economy from tackling national and even regional problems, and has become globalized not only in space but also in terms of time, whose span is now too brief to correspond globally to an associated economic time-frame.

(Joxe, 2004)

Through the electronic time-frame that dominates its decisions, crematistics, once ancillary to the economy, has become a factor of economic 
destruction, and hence a cause of unpredictable and unmanageable disorders and wars. Let us not forget that the speed in targeting and firing is a military quality that improves the capability for destruction. The electronic financial globalization is a sort of militarism that takes root on the timeframe of economists, not on the long production times, but on the short, impatient, time of destruction. 'Why do you want to destroy my city if it will be yours tomorrow?', said Croesus, King of Sardes, made prisoner by Alexander who was furious about the resistance of its inhabitants. ${ }^{10}$ But today who worries about taking over a city or a country and ensuring its prosperity? On the contrary, it is quick profits that are sought, without the concomitant costs deriving from taking charge of the conquered society.

\section{The combined disproportion of technological modernity and the power of lobbies}

The double, techno-military and techno-financial, disproportion that underlies the grand strategy, left as a legacy to the West and the world by President Bush, makes it difficult to return to a common measure of war and peace, which would enable the regulation of the end of wars.

However, with Obama's victory, something has changed. He has restored the right to pose all these questions, although he has not yet reached the point of answering them with concrete decisions. It can be shown that, in spite of the decline of states pursued by market forces, it is impossible to eliminate politics from the list of concepts required to conceive the start and the end of wars - that is, to think up peace. Nonetheless, in the United States, the Right's ideological software (the need for repressive violence) and the Left's (the need for liberal good governance) alternate to ensure the resilience (or adaptability) of a strategy of means, which drives a strategy of action that continues to pursue the total destruction of the enemy.

The two American political parties are both vectors of the 'continuity of modernity' that leads to the barbarization of war/peace. It may be granted, in order to simplify matters, that this resilience is explained by 'the power of the military-industrial lobbies', so that one must look for its causes at the technomilitary or techno-economic level. But it is more interesting to say that it is a global strategy, which, like in any war, must be linked to a kind of politics.

\section{Maintenance of the Clausewitzian template in global policy- making, which is clandestine since it lacks institutions}

At the point that we have reached, one wonders if the evanescence of what is the political is the state of today's world and, hence, if wars will cease to be Clausewitzian. In effect, we also witness a temptation to turn Clausewitz's formula upside down (politics as continuation of war by other means) through formal sophistry that refers to British humour more than to Socratic irony and that, hence, is more an expression of perplexity 
than an expression of an issue. Rather, I would say that we have simply reached a moment in globalization in which the political institutions of the global world have yet to emerge: there are global diplomatic institutions but there is no Global Political Constitution and thus political power remains informal, not to say imperceptible. It may also be the case that, in a crisis, world elites prefer to remain 'clandestine', concealed behind technical organizations that have remained 'inter-national', or behind the media commotions that national governments have become, whereas Grand Policies, when they exist, are clearly transnational.

On the one hand, it has been clearly shown that with the Transformation the Clausewitzian articulation of war and politics transforms the latter through the intermediation of tactics channelled through arsenals and their capabilities. But in strategic terms, politics cannot disappear. On a theoretical plane, the strategic approach mobilizes two disciplines. An anthropology of combat and of combatants' morale to lend value to the political aim of war (Zweck), based on representations of the long term and on the logic of quick (and informed) decision-making in the sphere of danger, in order to manage deadly threats and the military objectives of war (Ziele) in the urgency of combat. The second discipline, strategy, can and must stay Clausewitzian, in the sense that the relationship between these two disciplinary components bounding two distinct kinds of temporality is well included in his maxim. Clausewitz does not deny, but rather stresses, the importance of politics in the military definition of missions and notes its influence, also at the troops' combat level, in defining the relationship between morale and the balance of moral forces, even when the state disappears and the fighting goes on nevertheless, with the resistance of guerrillas acting for its rebirth. In this, Clausewitz remains valid, in spite of the transformation in strategic identities and arsenals over the last 175 years. The 'anthropology of combat' forced Clausewitz to understand combatants; the 'logic of decision' in war induced him to explain the policies that structure war objectives and correct tactical and strategic mistakes.

The failures and barbarism of behaviours must be attributed to mistaken strategies and to criminal policies. Without states that can be designated as the central authorities in war policy, it is not enough to say that the European Union and China and the corrupt presidencies of Africa are accomplices of the American empire. The debate on the Clausewitzian rationality of current military and financial strategies can remove from the debate any 'indictment of the United States', or 'of the United States and the European Union', or of 'globalization' in general, as politically responsible for all evils. If there is not any political responsibility of states any longer, the critique of global deregulation policies is a critique directed at whom? Such criticism must deal not only with the technical characteristics of military and financial modernization, but also with the interests of the new dominant classes on a world scale. In other terms, the irresponsibility of states and interstate alliances, and the absence of a sovereign global 
political institution does not rule out designating a new structure of the dominant classes as responsible for the forms taken by war. Simply said, war remains the continuation of politics by other means on the part of the ruling classes that have hegemonized globalization.

\section{Barbarization of the dominant classes: a global 'nobility' without peoples or kings}

The importance of Schmittian ideology and the 'religion of the market', faith in its self-regulating capabilities, this is what motivates the most influential experts of neo-liberalism, ${ }^{11}$ promoted by the rather limited but influential group of American neo-conservatives, the sarcastic remarks of many qualified economists notwithstanding. This is added to by the importance of the digital revolution as driver of the two space-time metamorphoses in military action and economic action. These concomitant metamorphoses tend to reduce military action to targeted police repression, and economic action to 'spasmodic' financial speculation.

In effect, neither the sectarian action of a fundamentalist group, nor the dazzling progress of information technology alone can explain a phenomenon that is as global and destructive as present-day globalization. It may be supposed that misfortune has seen to it that the different politicalreligious, techno-scientific and economic-financial developments have combined in generating the complex randomness of such a revolution. However, for more than a decade, an array of critical diagnoses have more or less described the social, economic, political and military consequences of such configuration. The unease does not derive from the fact that 'we cannot understand anything about it', but from the fact that there is no democratic politics, neither on the global scale, nor at the level of the phenomenon at hand. Dealing as we are with human phenomena, and not with the chaotic randomness of the physical world seen in the vortex of a typhoon or the fall of a comet, it makes sense to look for social causes having social consequences. These have been visible for years: everywhere, global deregulation has accompanied a drastic increase in social inequality. The job losses attributed to industrial automation have led to job creation in poorer countries; but the objective of corporations is not the creation of workplaces, it is the maintenance - thanks to productions swiftly offshored across the globalized market - of profit rates that, if possible, exceed 15 per cent on the capital invested; it is akin to the usurious interest rate applied by loan sharks, the return derived from speculative financial products in the good years. A kind of luxurious rent.

\section{A new nobility of income without peoples or kings?}

It is well known that accumulated social injustice can lead to major outbursts. In fact, part of the new reflection on strategy concerns the alarm 
resulting from the generalization of internal/external armed conflicts. It is a field of studies that is not about research for peace, but rather focuses on local conflicts and fixates on forms of attack. Today, war research does not just crowd out peace research, but it seems to take its place, with its overarching preoccupation of physically eliminating the enemies of the ruling order. Such enemies are supposedly identifiable through their activism in the midst of a supposedly passive population that merits no further socioeconomic or political definition than being the object of conquest or liberation. It is a global population that after the $9 / 11$ attack suffers from two terrorisms at war on its territory: Al Qaida and the US military rule of the world. This simplistic and reductive approach has not yet been fundamentally challenged by the Obama policy team.

In fact, we observe how representations of war tend to become fixed in military training manuals as charitable ideologies worthy of science fiction. If an Afghan farmer states that he was happier during the times of the Taliban, in spite of their frenzied Islamism, because there was peace and at least foreigners did not bomb villages, killing people randomly, the immediate reaction is that he does not understand the situation at all. The underlying hypothesis of this benevolent representation of the 'other' society is that, as a result of brutishness, the populace is not competent to understand the difference between submission and freedom, malaise and well-being, good deeds and misdeeds. This idea is not something new; on the contrary, it is quite archaic: its origin is aristocratic. Assumptions about the lack of humanity of those being excluded (slaves, servants, workers, colonized peoples, women, people who live in urban ghettos or are marginalized) seep out of an elitist managerial culture. At present, this culture does not seem to be tempered by any identifiable ethical source, apart from faith in market self-regulation and the logic of profit. It is a faith that is quite literally religious. There is also an additional belief in the attractiveness of policing, in the pacifying virtues of mass repression understood as maintenance of law and order, an act of blind faith that refuses to draw lessons from the experience of colonial wars.

By now, such beliefs and 'new' interests belong to a sort of transnational delocalized caste which, therefore, has no historical memory: an aristocracy that is not 'purely American' - this goes without saying - and aims for an unlimited level of consumption, for a 'princely' standard of living. The trend is a convergence of the incomes of the rich towards the levels existing in dominant countries and the levelling down of the livelihood of the poor towards a lower level. In concrete terms, what follows is the explosion of a series of small, cruel wars of force projection almost everywhere, which meld into the local unrest resulting from the economic anarchy of corruption, and the various forms of depredation populations in 'developing' countries suffer from.

But the web of the causes that lead to such wars is not taken into consideration, neither by the states nor by empires, nor by social classes; 
nobody takes responsibility. Disorder and violence, sometimes privatized, spread like a dominant trait of global imperial culture beyond its protected or even fortified perimeters, where state walls are no longer necessarily coterminous with state borders. How can this apparently medieval regression be explained?

\section{The crisis as revealer of actual powers}

In the light of the comical revelations resulting from the crisis, we can observe the behaviours of this new Grand Nobility that threatens to take power on a world scale by claiming princely income. This class believes in the total deregulation of markets because this practice enables the unrestrained globalization of the stocks of intensive profits by speculating on addictions - that is, on markets that are captive, not because of government regulation, but because they are based on global, pent-up crossborder demand. Demand that has become compulsive makes it possible to set prices without any relation to production costs, and this generates 'excess' profits. On the global scale, it may result from physiological addiction as in the case of the markets for drugs and prostitution, but it can also be induced by advertising and maintained by the effects of fashion. Finally, markets may reach the point of abetting deadly speculations on vital needs such as water (milk), seeds, health or housing. Due to natural or induced scarcity, means of subsistence have become a source of intense profits, but also of violent conflicts and wars, as if eating or drinking had become, in times of speculative bubbles, mass addictions, thus determining prices that have no relation to the cost of production.

In the context of states, hoarders who turned shortages into starvation were deemed criminals and convicted as factors of disorder. In globalization, this simple definition of criminal economic behaviour disappears, as markets go ballistic with speculation, i.e. the temporary source of high returns.

The so-called subprime crisis was preceded by a ballooning in real estate prices, as well as in lending offered to poor and insolvent citizens. It was the process of selling long usurious loans to poor citizens, driven by complex financial products, which were well graded by ratings agencies because they gave outrageous returns, that caused the financial crisis in the United States and the world. This particularly perverse bubble should have, or could have, called for an urgent control of the visible factors of imbalance engendered by what we may call crematistic criminal activity. The ostensible aim on the part of economic elites to 'make a fortune' through the predation of the reserves of profits accumulating out of speculation on a global deregulated plane, watched over by ingenious and lusciously paid traders, who match the compensation of top athletes enjoying international recognition.

In order to move the bar in the direction of human progress, it is no longer needed to focus on the 'national bourgeoisies' of the recent past, 
since nowadays they only comprise small entrepreneurs. This is why the concept of a global hegemonic social class dominating politics, and hence war, becomes relevant again.

\section{Crimes of crisis and crimes of war}

These institution-less classes subscribe to a generalization of the prosecution of war crimes and crimes against humanity. It is unclear how such a case and the criminal indictment can be made, as this statement has no judicial value, but rather an anthropological and ethical meaning. The perpetrators of such crimes are necessarily human beings. But the political anthropology of the new elites is yet to be established. There is only the admission that this is now more urgent and critical than refining the normative discourse about the ideal of good governance, recommended by philosophers who still harbour a naive hope about an impending extension of the virtuous democratic institutions, when the exact opposite is prevailing: a corrupt delocalized authoritarianism, managing the rise of fascist violence and hijacking huge capital flows towards sumptuous spending and the destruction of non-renewable resources, relentlessly causing environmental catastrophes, poverty and wars. If there were an emperor, he would have no clothes. But there are neither kings nor emperors of the world. An imperial senate appears to be taking shape in the form of the G20: when the agenda concerns global regulation, the representatives of banks and corporations are invited by governments as experts. G20 meetings are not an imperium; governments appear as the deputies or tribunes of the people, untouchable and ready to legislate, but without any longer enjoying autonomy other than in repressive matters (lictores). Everything depends on the will of the Senate, which comprises the representatives of the truly global crematistic powers, which are the guarantors of growth (auctoritas) and priests of the free movement of the Spirit of the Global Market (Pontifex Maximus), and are present in the corridors.

'Politicians' in every country are now back in business, after the uproar caused by the behaviour of banks that were bailed out with government guarantees accorded in 2008 and reiterated in 2009. Once the banking crisis was avoided, in America and Europe alike, banks immediately returned to their speculative activities and the overcompensation of traders, those proletarians of intensive profit. The visibility of the 'scandal' is cause for concern: public opinion may end up questioning the totality of the globalized system. To allay such fear, the hunt has been launched to catch tax evaders, whose delinquency, tolerated through the impunity accorded to 'tax havens', has been a part of the system for thirty years. Swiss banking has been sacrificed in the media on the altar of fiscal virtue. However, the real winners in the globalized economy do not need to contravene laws. They can profit from favourable legislation. Small evaders are necessarily national entrepreneurs, petty industrialists who survive only through tax 
fraud and/or by violating labour laws, i.e. through black or grey economies. The great speculators continue to skate on global financial markets, freed from any duty to protect the wage-earners of the real economy.

\section{Some other considerations}

Everything will depend on the evolution of Europe, United States and China as powers that have a major stake in stability, and as conglomerates liable to propose regulations carrying sufficient weight to enable the reform of the system without causing further panic.

\section{Two non-democratic barbarisms: the European Union, the United States}

Contrary to what we would like to believe here in the Old Continent, this shift towards 'barbarism', with the Res privata replacing the Res publica, is more advanced in Europe than in the United States. This can be argued on the basis of an analysis of the differences between the roles played by lobbies in Brussels and lobbies in Washington, in order to assess how the political sovereignty of states has been diminished. In Brussels, lobbies penetrate into the executive bodies of the EU, which are in effect legislative bodies as well, when it comes to drafting new legislation. Lobbies influence and even organize the details of the Commission's agenda, without having any legal status other than being 'experts'. In the United States, lobbies are integrated into and monitored by the law and in the regulations of parliamentary institutions, particularly insofar as the separation of powers executive, legislative and judiciary - is concerned. It is well known that the states that make up the US have not been sovereign political entities since the Civil War, and they do not pretend to be. The US is a federal state; it is an imperial conglomeration on a world scale. In Europe, the states making up the Union continue in their mimicry of national sovereignty; a European federal state does not exist and the fledgling confederal state, in any case, is not a democracy yet. Hence, paradoxically, democracy is more at risk in the European Union, where all the real power is managed in the ambiguous shade of a sovereignty that has been spirited away towards bureaucracies and lobbies, rather than in the United States, where presidential elections have the merit of shedding light on the great strategic debates. Although it is a mere rhetorical or moral jolt, in America the discourse of the refusal of the excesses of globalization has become legitimate once again.

What still clouds prospects is the fact that the disappearance of state apparatuses is not on the agenda; they still have two irreplaceable technical capabilities: taxation and the repression of disorder - that is, the organization of the maintenance of order amidst the growing social disorder generated by global deregulation. The political power of states disappears but 
their policing powers have been strengthened. As for military power, once tied to the political definition of national interest, it is now invited to join policing operations in potentially escalating trend in the repression of disorders titled 'European security' or, outside of Europe and under US command, in 'external NATO operations'.

But there is nothing left of what, in the national interest, called for popular unity and the equality of citizens as bastions of the defence function. The transnational interests of global elites cannot take them into account.

\section{The United States, at a turning point before Obama?}

In one of her articles, Mary Kaldor ${ }^{12}$ outlines two possible approaches for the definition of European security policy. As her prime concern is the protection of civilian populations from genocide, slavery and human rights violations, the author is certainly not complacent with a continuation of Bush's imperial policy. Rightly, and with realism, she does not foresee that Obama's election will, as such, lead to an abrupt change. Somewhat vaguely, Kaldor draws two branches of what is a trivium: the right branch is the - now failing - option of the American right. However, at the same time, what she defines as the 'alternative' (she calls it even 'perestroika') is based on the idea that the essential turn had already been taken at the military level in 2006, before the outbreak of the financial crisis. These are the options that Kaldor describes:

Option 1 (exit to the right). Continuing with Rumsfeld's program of world domination through unilateral destructive action; thus continuing to autistically dominate the world via external operations that are destined to force states to abandon any claim of regulating the economy.

Option 2 (exit to the left). Maintaining and perfecting the elements of the military dispositif; this way, the sophisticated know-how of pre-emptive control would advance further, and efforts would be made to create social and political consensus in the societies targeted by military expeditions; hence, the idea of a global configuration that seeks the securitarian pacification of deregulated societies.

This school of thought corresponds to a resurgence of critical thinking in the Army and the Marines and which is expressed rather clearly in military periodicals such as Small Wars Journal. ${ }^{13}$ These authors are entirely critical of Bush's policy during the outbreak of the war, but they deem there is no alternative to moving forward, because there is no longer a strategic turn to take: it was taken after the surprising combination of the HamiltonBaker Report of December 2006 and the decision taken by Bush to proceed with the surge, announced on 10 January 2007. 
According to this reading of the sequence of events, the surge is not just a 20,000-strong military escalation, but a radical change of strategy, confirmed and formalized by the publication on the 8 July 2008 of the new 'Counterinsurgency Guidance' by General Petraeus. Appointed as the head of CENTCOM - that is, in charge of the two wars, Iraq and AFPAK - the author orders American troops to put themselves at the service of the population and ensure its security, but also to use money as a weapon, in other terms, to ensure allegiance and consent through corruption. This is what has been practised in Iraq. Rather than a strategic shift, this is a search for bearable barbarization. The Petraeus option is the choice of an intermediate military path, and those who believe it will suffice to put an end to the Iraq war and downscale the AFPAK war to a grand bargain run the risk of being disappointed.

\section{Towards a political recomposition via regional subglobalizations?}

The civilization of war or the barbarization of peace hang over our heads, signalling the deplorable state of world civilization. But it is a byproduct of the power seized by the new financial aristocracies. By now, anxiety rules over the system itself and major actors through their strategies seek to protect themselves by rearranging space on a sub-global scale: the European Union plus Russia; the United States of America and the oil-producing Middle East; China-Japan-Korea. Latin America and India are the weaker ones. They all propose the consolidation of their respective blocks, perhaps the sub-division of the global nobility into three neo-Westphalian confederations under three different monetary regimes, avoiding the constitution of a global confederated state that would force the 'global nobles' to expose themselves publicly and thus become subject to the political and judicial sanctions they currently escape.

Eluding politics, to allow the maintenance of a global repressive strategy without an identifiable organizer, and without democratic accountability: this is what can be called the 'civilization of war', similar to sinister expressions like 'Nazi culture' or the 'peace of cemeteries'.

I prefer to call it the barbarization of peace from the prospect of a radical overhaul of global politics that is still possible and necessary, at every level of democratic action. There is the need to put an end to the antisocial violence of financial elitism and fundamentalist religion. Only by placing under political tutelage the irresponsible classes of the 'new rich' (who are causes of disaster in all continents) will we be capable of preventing the multiplication of environmental crimes and financial offences perpetrated by these 'no land's men' ruling over no man's land, and of triggering the process of reconstruction of a civilization of peace.

Translation by Yasha Maccanico and Alex Foti. 


\section{Notes}

1 His method is based on the epistemological principle of

detail due to the heuristic importance that the study of detail takes on in a situation in which we are as a result of a general political crisis, in the midst of the wholesale breakdown in the systems of strategic, ethical, social and military representation. Hence, what is required is a selection of detailed facts that may offer, provided that they are well chosen, the keys to the century that begins.

See the introduction by J.L. Fournel (1988: 18).

2 Oikoumene is a term originally used in the Greek-Roman world to refer to the inhabited earth (or at least the known part of it). In more modern versions, it refers either to the projection of a unified Christian Church or to world civilizations (cf. infra) [editors' note].

3 See Alain Joxe (1992). Among the recent works of this leading author, see Joxe (2002), also published in French, Spanish and Italian [editors' note].

4 See some of the author's articles, particularly those about the war in Gaza in 'Le débat stratégique' (www.cirpes.net/) [editors' note].

5 Commander Ralph Peters (1997: 4-14):

Those humans, in every country and region, who cannot understand the new world, or who cannot profit from its uncertainties, or who cannot reconcile themselves to its dynamics, will become the violent enemies of their inadequate governments, of their more fortunate neighbors, and ultimately of the United States. We are entering a new American century, in which we will become still wealthier, culturally more lethal, and increasingly powerful [emphasis added]. We will excite hatreds without precedent.... There will be no peace.... The de facto role of the US armed forces will be to keep the world safe for our economy and open to our cultural assault. To those ends, we will do a fair amount of killing. We are building an information-based military to do that killing ... but the relevant systems will not be the budget vampires, such as manned bombers and attack submarines.... [Our] technologies will be those that support soldiers and Marines on the ground.

6 See President Obama's declaration about the Afghanistan war, 27 April 2009.

7 Hýbris is a technical term drawn from Greek tragedy and literature; it literally means 'arrogance', 'excess', 'haughtiness', 'pride' or 'abuse of position' [editors' note].

8 There is a widespread assumption that democracy and capitalism go hand in hand. In fact the relationship is much more complicated. Capitalism needs democracy as a counterweight because the capitalist system by itself shows no tendency toward equilibrium. The owners of capital seek to maximize their profits. Left to their own devices, they would continue to accumulate capital until the situation becomes out of balance. Marx and Engels gave a very good analysis of the capitalist system 150 years ago, better in some ways, I must say, than the equilibrium theory of neoclassical economics. The remedy they prescribed - communism - was worse than the disease. Unfortunately we are once again in danger of drawing the wrong conclusions from the lessons of history. This time the danger comes not from communism but from market fundamentalism.

(Soros, 1998: 19)

9 For Aristotle, 'crematistics' is the art of accumulating wealth, but the latter is not limited to the former, as it happens in the modern context [editors' note]. 
10 Financial profit is disconnected from the way the economy is traditionally defined and measured (the production and logistics of the flows and stocks of consumer goods). The economy, as its name implies, is regulated by a concern for the good management of the needs of human inhabitants - oiko-nomia

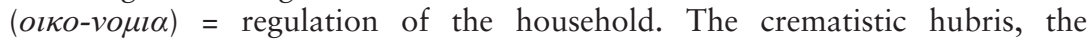
unbounded accumulation of profits without relation to production, resonates with the militaristic hubris of weaponry that is dominant at all levels and for all types of risk, to legitimize the defence of the common good (the global market).

11 For example, Alain Minc (1997).

12 See Mary Kaldor (2008). Kaldor directs the 'Centre for the Study of Global Governance' based in the London School of Economics and advocates the concept of 'human security'.

13 The question of whether we were right to invade Iraq is a fascinating debate for historians and politicians, and a valid issue for the American people to consider in an election year. As it happens, I think it was a mistake. But that is not my key concern. The issue for practitioners in the field is not to second-guess a decision from six years ago, but to get on with the job at hand which, I believe, is what both Americans and Iraqis expect of us. In that respect, the new strategy and tactics implemented in 2007, and which relied for their effectiveness on the extra troop numbers of the Surge, ARE succeeding and need to be supported. In 2006, a normal night in Baghdad involved 120 to 150 dead Iraqi civilians, and each month we lost dozens of Americans killed or maimed. This year, a bad night involves one or two dead civilians, U.S. losses are dramatically down, and security is restored.... We are now in a position to pursue a political strategy that will ultimately see Iraq stable, our forces withdrawn, and this whole sorry adventure tidied up to the maximum extent possible so that we can get on with the fight in other theatres - most pressingly, Afghanistan.

(Kilcullen, 2008) 


\section{Norm/exception}

\section{Exceptionalism and governmental prospects in the shadow of political theology}

\section{Roberto Ciccarelli}

Two events have revived the philosophy of exceptionalism: the terrorist attacks on the Twin Towers in September 2001 planned by Al Qaida, a fundamentalist Islamic movement whose identity is not clear, and the subsequent response of the 'War on Terror' waged by the US administration of George W. Bush, which culminated in the military operations in Iraq and Afghanistan. Within a short period of time, from 2001 to 2008, a philosophical common sense has become established according to which the war against global terrorism represents the most advanced point in the creation of a 'permanent state of exception'. This state of exception, limited in time and delegated to specific subjects by its legal nature, has thus supposedly been extended indefinitely onto a global scale during the War on Terror and has assumed the form of a sovereign dictatorship.

Exceptionalism is the political and theoretical narrative that has drawn attention to the crisis of US global hegemony that arose after the Second World War but which has lost coherence and legitimacy. The failure of 'exporting democracy' to the 'Great Middle East' envisaged by a few American ideologues - the so-called neo-conservatives - demonstrates how this narrative has been more of an instrument in the ideological struggle than a useful theoretical framework for explaining the deep reasons for the current crisis. In the short term, the war against terrorism made it possible to believe that there was still space for the unilateral exercise of an unconditional sovereignty in the world, only to later discover that the political pretence in the narrative generates a real and very determined opposition. The idea that the theory of 'pre-emptive war' and the war against terrorism could neutralize the 'enemy' has proved to be an illusion. The enemies have multiplied, while the 'world order', if ever there was one, has dissolved. The 'state of exception', if this ever existed, is the result of legislation desired by a particular party (the US Republicans) and ideology (neo-conservativism), which unscrupulously used political and legal instruments in relation to the constitutional prerogatives that regulate emergency situations. ${ }^{1}$

In this chapter, I will not discuss the philosophical debates on exceptionalism (from Carl Schmitt to Walter Benjamin), its contemporary uses 
(from Jacques Derrida to Antonio Negri and Giorgio Agamben) or the wide-ranging criticisms that these have received. ${ }^{2}$ I believe it is more interesting to interpret the latter as the reflection of an underlying character of contemporary political culture: the crisis of sovereignty. ${ }^{3}$ Despite the denial of the existence of a sole sovereign who dominates the world and decides its order, and the rejection of the absolutist and theological collective imagination that has nourished the project of pre-emptive war (to annihilate potential and individual and not just legal and state enemies), the theoretical debate on exceptionalism has nonetheless been characterized by these theses, or by the shadow of political theology. In fact, once the hypothesis of the existence of an absolute sovereign was excluded, and hence with it the image of divine omnipotence that feeds the original theory of sovereignty as the 'decision about the state of exception' put forward by Carl Schmitt, the idea emerged that the state of exception was permanent. This permanence is supposedly due to an ontological mechanism, no longer political, according to which, at present, all political decisions are supposedly not dictated by personality, but rather by the function of the person holding an absolute power.

Thus, a paradox emerged. At the moment that the sovereign's main function is exercised in an explicit and unilateral way - in other words, their decision on the state of emergency - it reveals a failure. Every decision on the state of exception has been shown to lack political effectiveness and to have produced opposite outcomes to those planned. The re-affirming of the prerogatives of an absolute power has demonstrated the impossibility of its presence in the world. The order produced in the world has merely threatened the sovereign that was supposed to enjoy its privilege. The sovereign is dead, yet has never been so alive; and the part of it that lives on continues to re-produce its own death. Paradox is the style of the philosophy of exceptionalism, but it also shows the disastrous outcome of its action in the world.

Hence, while this represents the philosophical problem of exceptionalism, it cannot be denied that it has contributed to the denunciation of the transformation of the state governed by the rule of law (Rechtstaat) into a Power-State (Machtstaat $)^{4}$ in which law, far from limiting power as a guarantor of rights, becomes its armed wing and the logic of political crime assumed by emergency legislation (the 2001 and 2002 Patriot Acts in the United States and analogous legislation adopted in Europe) to fight international terrorism and to justify armed interventions without the authorization of international law (Ferrajoli, 1984).

At the end of this political cycle, it is nonetheless clear that, having cancelled the classical distinctions between military and civil war and between just and ideological war, it has not lent value to the permanent state of exception, but has been further proof of the definitive neutralization of sovereignty. This operation has not led to the exercise of an impersonal and unfounded absolute power, but rather to a regime of government 
erected upon the state of emergency; that is, on the extra-legal status that governs the daily exercise of the production of political, administrative, productive and economic norms and practices - in other terms, of life in the time of global governance.

\section{What exception does not say about the norm}

The norm is what is removed by the philosophies of exception. The crisis of sovereignty is not so much due to the extreme difficulty of determining an essence of exception through decision as it is to the amphiboly that exists in the definition of the 'norm'. The emphasis placed on the concept of exception infers that the norm is always understood in a legal and political sense; that is, as a consolidated legal fact, a state of being that is defined forever - in other terms, a legal regularity that is the starting point from which the exceptional and unpredictable functions of power are exercised. Only in this way can exception be understood, on the one hand, as what constitutes the norm and, on the other, as its continuous variation.

The thesis of exceptionalism holds that there is a constitutive void at the centre of the law, and that the state of exception corresponds with this void. 'Also the legal order, like any other order, rests on a decision and not on a norm' (Schmitt, 2006). The decision is a repetition of the same act that does not have any foundation or justification. No decision can be regulated by a norm. Only the decision can lend normative substance to this 'void', and it can do so by deciding about the state of exception. For Schmitt, it is possible to lead the void that is expressed as the state of exception's pure and anomic violence back to the level of law. Sovereignty would thus be the place in which a decision turns violence into law, anomie into norm, chaos into order. Violence is the minimal condition of law.

In contrast, Walter Benjamin argues that violence is an external power that transforms the law and has the strength to usher in a new world, and hence a new (form of) law. The state of exception is initiated by a decision that does not have the goal of preserving the existing legal order, but rather to transform it radically. In Benjamin's view, it is not possible to conceive the coexistence of exception and norm. The state of exception never keeps within the rule that one would seek to limit it. It remains outside of the order and strikes this order with a violence - such as a war or a revolutionary general strike - capable of bringing about its destruction. Linking violence and law, as Schmitt does, is hence a fictitious representation that seeks to maintain the law in an infinite suspension. But thinking along the lines of Benjamin that an anomic condition exists beyond the law means to claim that the law is a monad, suspended in a void in which there are no norms (Benjamin, 1962: 10).

What is removed in this debate (the inspiration for the philosophy of exceptionalism) is the area of indistinctness between norm and exception, 
the void in which the law is supposedly suspended, and between the immanence of life and norm. Thinking that life is a normative void that must be alternately filled by a decision or by the invocation of pure or 'divine' violence means reducing it to the consistency of a spectre, that of the sovereign, which is more real than the void that the decision seeks to 'suspend' in the state of exception. We thus witness the creation of a spectral world in which the sovereign's life is suspended in an indecipherable zone that is not subject to politics or to law.

\section{Internal enemy $\neq$ unlawful enemy combatant}

An example may be useful to illustrate this argument: that of the 'special laws' adopted by European states during the twentieth century, particularly in the 1970s, to counter internal left-wing terrorism. If these laws are compared with the norms established by the Patriot Act and the Military Order of 13 November 2001 and the practice of 'forcible abduction', originally authorized by Bill Clinton to counter the growth of the Al Qaida network and later formalized by George W. Bush, we can see that, in both cases, the legislation grants governments powers to act above legality. In doing so, they deny recognition of the 'political nature' of their opponents, denying them the possibility of becoming 'future governors' and attributing them the identity of 'perpetual dissidents' - that is, of people in total disagreement with the system that they live in.

However, while the first legislation punishes the right to dissent by organized groups at a national level in relation to the decisions taken by a government, the second legislation punishes membership of a non-state and global organization that counters a country's sovereignty. The 'internal enemy' - the object of European special laws in the 1970s - is not the same political and legal figure as the 'unlawful enemy combatant' which is the object of the Patriot Act and attributed to the militant of a fundamentalist Islamic group but which is not recognized by the additional protocol to the 1977 Geneva Conventions (article 37, point 1). This definition of an unlawful enemy combatant expresses two features that are absent in that of an internal enemy: extraterritoriality and acting contrary to the laws of war. Unlawful enemy combatants have never been arrested for political crimes, as did happen in the case of internal enemies, but for war crimes. The former have always been denied the possibility of declaring themselves 'at war' against the state. Instead, the will to wage war against the state has been attributed to the latter.

The nature of exception regarding the legal status of the internal enemy differs from that of the unlawful enemy combatant. The internal enemy was the result of a global process during the postwar period that widened the definition of 'political crime' to forms of conduct involving general disagreement, generalized the pre-emptive repression of political dissent, translated political crime from one language to another, and reversed the burden 
of proof by compelling incriminated subjects to show that they were not involved in 'terrorist' organizations. ${ }^{5}$ The unlawful enemy combatant was defined as a result of a process that was contiguous to the one described above, but was different in one essential way. The American Patriot Act represents the first legal definition of an enemy in the absence of a hostile state, which had been the case from the seventeenth century until the Cold War, in the absence of hostile political groups that can be identified on a territorial basis, and without a war undertaken by terrorists against a sovereign state being definable in legal terms. Not possessing the citizenship of the country whose sovereignty is under attack, and sometimes not even with the citizenship of an 'enemy' state, unlawful enemy combatants have been denied the status of internal enemies because they are 'absolute enemies'. This means that they may be annihilated, without anyone being able to appeal to constitutional guarantees at a national and international level, in contrast to what was possible in the case of internal enemies.

The scope for the implementation of norms and the nature of exception has changed. Exception is the point of arrival of a process caused by a series of behaviours, whose purpose imposes the adoption of measures that derogate from the codes. In the case of the fight against terrorism, the exceptionality of these norms also represents the political decision's point of arrival, and not its starting point: that is, its adjustment to the conduct and, especially, to the presumed intentions expressed by such conduct in relation to the imperative of defending security. The brief and hapless period of the war against terrorism was, in other words, not characterized by a state of permanent exception, but rather by a permanent state of emergency. The state of emergency is the object of a political mechanism that governs the distinction between war and peace, between hostility and its legitimation, and sets a new primacy, that of security. The state of emergency is an infinitely flexible and modifiable legal condition that enables the exercise of wartime law, like political hostility itself, in internal and international relations.

\section{Politics of war}

The centrality of the analysis of war is a crucial aspect of philosophies of exceptionalism. As an act of absolute hostility, war is the annihilation of any other being. Thus, it does not fall under a norm. It is the exception that allows the existence of a norm. The absolute hostility of war is a real possibility in any form of human coexistence and the precondition for the state's political unity. As a possibility, or precondition, war does not translate the essence of the state. Despite internally possessing a constant state of conflict, the state is the outcome of a regulation of war - in other words, of a hostility with another state. This regulation implies a decision on the norm in the name of exception. According to Schmitt, only the state can draw this distinction. 
The distinction between friend and enemy shows that the political unity of a state is constructed upon enmity towards the exterior (Foucault, 2001), namely, on opposition against an enemy that has no characterization other than that of being 'foreign'. Any conflict within the state - for instance, against migrants who are foreign individuals and do not represent any state bodies - thus loses any political meaning. An act is political when it is directed against another state and disposes of the life of its own and the other's population. The daily governing of the population is an administrative act, not a political one, which involves policing and not warfare, and whose goal is to pacify the internal order. Administrative life is a 'normal' act, whereas war is an 'exceptional' act. War is a transcendental condition of the legal order but does not concern the political and social conflict that takes place within this order. A political unit rests solely on external war, but there is no conflict inside this unit. Violence is at work beyond the state's borders, but is silent within them.

It is evident that this represents an imperfect transcendentality, whose functioning is not understood by Schmitt in the universal sense of the term. This portrayal is drawn from the notion that social life is intrinsically pacified. The violence that the state normally exercises to attain such a 'pacification' is not acknowledged. This removal alludes to a policing policy that uses instruments of war inappropriately. The political opponent is understood as an internal enemy, assigned the identity of an enemy but without the recognition of equal dignity attributed to an enemy state. The pacification of social life occurs at the price of an exceptional use of force by the state. Denying what is transcendental about war at an internal level, however, does not mean eliminating its effects. Victory in war against a state and the internal pacification of social and political conflicts exist on incommensurable scales. In other words, war is managed as an internal political problem, while internal political problems are managed like war, without a war actually ever being declared.

However, it would be reductive to merely consider Schmitt's exceptionalism the philosophy of a police state. When he wrote The Nomos of the Earth in 1950, the German jurist showed his understanding of the contradiction of what is transcendental about war. In this significant volume, he announced the end of jus publicum europaeum - that is, the Eurocentric distinction between internal and external, between national order and international order (Schmitt, 2006). This representation of the world ended with the First World War and was abandoned definitely after the Second World War, when war became 'total' and state war turned into a global civil war. Under these new conditions, it became very difficult to distinguish between friend and enemy. The transcendental condition of what is 'political' comes into contradiction with the reality that it seeks to regulate. War remains a precondition of the order, but this does not mean that it manages to find a subject capable of leading it back to its previous state form. The prerogative of sovereignty to decide about the state of exception is seriously challenged. 
In the mid-twentieth century, it was impossible to restore the sovereignty that Schmitt himself - through his theory of the state of exception claimed had been lost forever. He acknowledged that this view is difficult to apply to a global scale where space is not placed in relation to the national or interstate level, but can be applied to a network of state and non-state subjects that interact in a continuous state of conflict. In the global space, it is impossible to imagine the existence of a sovereign possessing the necessary force to decide the fate of the entire system, or a possible technical mediation capable of resolving conflicts, even by resorting to the extreme resource of war. In this space, a clear division between the internal and foreign affairs of states can no longer be appreciated. Moreover, a stable hierarchical order between different levels of sovereignty and a clear definition of the enemy that is neither public nor political are both absent.

This awareness led Schmitt to exclude the idea that the origin of the legal order is the normative void, as he had asserted in the 1920s. Unlike the present-day philosophies of exceptionalism that are inspired by his oeuvre, Schmitt discovered 'concreteness', namely, the normativity of concrete orders, which does not descend from other norms, but produces such norms. This concreteness lies in the 'space' that is not understood as a natural fact, but as nomos - that is, the determination of what is political. Hence, nomos is the new transcendental condition that, alongside exception and war, allows what is political to govern the world, to divide and take possession of the earth, to revolutionize the old geometry of state borders, producing new supranational political entities. However, Schmittian exceptionalism recognizes the dialectics of the nomos that characterize the concreteness of any order. It is a new attempt to reconstruct the impossible order between norm and exception by following the same scheme: Schmitt moves away from the materiality of events and, by following a transcendental dimension, identifies the pure and unconditioned origin of the decision to which he finally attributes the role of mediation between irreconcilable demands.

The nomos is the new 'foundation' of the 'Political'. Unlike the theological nexus between decision and law, this foundation expresses the transcendental nexus between space and law. The search for the origin thus reaches an essence that is even more uncontaminated than those of the state and that which is political. The goal is to identify, once and for all, the order that constitutes the world, the primary direction that creates laws, and the decision that does not obey a norm but creates the norm. In the global space in which everything is deterritorialized, where there is no single measure for events and the concreteness of orders is provided by the processes that constitute them, Schmitt re-proposes a foundation without principle, a measure without form, and transcendentality without universality. In reality, the nomos is a platonic idea: an uncontaminated 'outside' that is expressed in the world through the primary violence of 
the decision and the war that restructures the earth on the basis of a project that has always been given. The aporia is always the same: there is no absolute sovereign in the world, but this does not mean that one must do without a single foundation of things. The effect, as is well known, is neutralizing. The idea of nomos expresses the condition in which the world remains what it is: a passivity awaiting a decision, a sin awaiting redemption, a mistake awaiting the reason that will correct it. The world is indecipherable, motionless even when it moves quickly, a totality without totalization, a story that has never started. The final outcome of Schmittian exceptionalism is the product of the Kulturpessimismus of twentieth-century European philosophy. Its paralyzing effects descend from an ahistorical reading of a widespread narrative genre in human sciences: that of 'modernity'.

The narrative solidity of the philosophical genre drawn up by Schmitt is in fact based on an option that is as convincing as it is illusory. When a system is in crisis, disorder appears to be permanent and any mediation useless; the only remaining option is technique. A neutrality is attributed to technique that is capable of resolving the problems of governing an epochal crisis. Politics thus re-conquers a prominent place in the narration of the contemporary world. No longer restricted to the loss of representativeness and legality, as the 'modern' tale would have it, politics resurfaces as the government of technique, and technique is the final foundation of politics that does not have any foundation. The optical illusion is evident. A crisis is 'epochal' because it excludes the possibility of a solution. Locating it in the neutrality of technique means indicating a solution that is part of the crisis. It is not possible to claim the end of sovereignty and recognize the ability to solve conflicts in technique. If the sovereign - who, by definition, occupies the place of neutrality - is dead, to what neutrality will technique have to resort to enact its politics?

\section{Phenomenology of the kamikaze}

'Before having to defend ourselves, we must be certain of the need to defend ourselves.' This is one of the comments heard shortly after an attack against Italian soldiers in Kabul in September 2009. This is how a general of the defence chief of staff summarized the extreme difficulty for a professional army to distinguish civilians from terrorists in contemporary wars. The time that normally passes between the idea of defence and the need for defence gives kamikaze warfare a strategic advantage. But this is not the only element that makes it devastating. Compared with the citizensoldier, whose mission it is to safeguard theirs and other people's lives, the kamikaze finds his/her purpose in the annihilation of the enemy and civilians. Through suicide and the destruction of the other, including women and children, they sanctify their own bodies and the need to kill and be killed (Ciccarelli, 2009). 
What is disturbing about kamikaze warfare for Western liberal democracy and for its military culture is the reversal of the value of life and death. The latter considers the possible death of an enemy a means to defend the sacredness of life in general. Conversely, suicide terrorists believe that life, their own and that of other people, may be sacrificed, but they cannot be killed because as 'living martyrs' they survive for eternity, while their victims are sentenced to death. Even in this situation, the consolidated relationship between the 'normality' of the protection of life and the 'exception' of killing in war is transformed. It is not a mere reversal of the biopolitical rule decreed by Michel Foucault at the start of the modern 'biopolitical' era. Western liberal democracy has already been experiencing the overcoming of this rule for some time. There are many areas where it continues to be present, but it is precisely in the war against terrorism that its eclipse is by now evident.

The reversal of the relationship between norm and exception has led to the cancellation, or at least the removal, of the tragic element of the socalled war against terrorism. Personal motivations should not be sought to explain what leads a man or a woman to die with the enemy. Psychoanalytical arguments, for instance the assertion that there exists 'a culture of death' in Islam in opposition to 'liberal culture', do not explain this phenomenon either. The uniqueness of the suicide attack lies in the circumstances in which it takes place. When claiming that the kamikaze enjoys the social status of martyr and draws the symbolic gain of immortality from sacrificial self-destruction, one ignores the real interest in the use of this tragic resolution. The suicide attack is an instrument of war that has been adapted to the execution of a rational project of annihilation. Its motivations are military, not theological (Asad, 2007).

The impossibility to distinguish the value of life from that of death during war is not a prerogative of kamikaze war. It also applies to war as practised by professional armies. Humanitarian law on conduct during war forces a democratic state to kill proportionately to the offence encountered. However, when it is no longer possible to distinguish 'civilians' from 'terrorists', it is obvious that this proportion loses meaning and fuels the difficulties that armies face in Afghanistan and Iraq. Terrorism and the war on terrorism are expressions of an antagonistic military logic that shares the same culture of war. It is not a matter of establishing a naive and moralistic equality between 'democratic' and terrorist violence. In spite of the contingent strategic advantage, the readiness to die by the kamikaze cannot in any case be compared to the firepower of a professional army. Another thesis emerges: democracy and terrorism defend the value of life of their respective communities. The first guarantees everyone's freedom by trying to lawfully kill a terrorist enemy who cannot be further defined. The second sacrifices an individual to guarantee the lives of those similar to them.

The definition of the value of life or death takes place on a shifting threshold. On this threshold, the struggling forces continue to negotiate the 
criteria that make a behaviour normal or exceptional and the value that must be assigned to it. This is the biopolitical conflict that currently sets the two political rationales for war against each other. Hence, war is not a 'clash of civilizations' between Islam and the West, but is rather the permanent exercise of the distinction between the life of the 'civilized' and the 'uncivilized'. Each of the parties in the struggle enacts this distinction against the other. Nonetheless, they share a common goal: to establish the value of one's own life and to set it against the death practised by the 'other', the 'uncivilized'. It is a game of mirrors: Islamic fundamentalists cultivate a view of the West as a mechanized society lacking spiritual authenticity. The liberal-democratic West cultivates an opposite view inspired by Orientalism, according to which non-Western peoples are targets lacking humanity. Just as the former portrays the West as a corrupt zone of the planet, the latter portrays non-Westerners as an inferior species. These two political rationales share the same prejudice: the idea of the other as an inferior being that translates into the destruction of human beings.

Islamic fundamentalists believe an essentialist portrayal of the West that can be very harmful and stereotyped. Thinking that the West is corrupted by a soulless materialism is a classical representation that Westerners have offered of themselves during the course of history. Thinking that 'Muslims', as a large part of 'non-Western' peoples, are incapable of building a 'decent state' and hence a democracy that is worthy of liberaldemocratic standards is a representation that is equally essentialist and harmful because it justifies armed interventions in the name of democracy. When the politicians of Islamic fundamentalism voice these discourses, they reproduce a mentality created by the Westerners who they believe they are fighting. When the politicians of liberal democracies dust off their Orientalist paraphernalia, they simply reproduce the conflict from which they should keep a distance.

My thesis is that this 'cultural' conflict consists in the defence of life and its 'civil' value. Over the last ten years, this defence has imposed a new way of experiencing death. What liberal-democratic eyes find worrying about suicide bombers is the individuality of their death. Their access to a limited freedom draws no distinction between civilized and uncivilized life, or between crime and punishment as affirmed by modern law. It would nonetheless be a mistake to imagine that this worrying freedom is 'natural' for those practising kamikaze warfare. In certain circumstances, any culture could produce suicide terrorism. Over the last few years, we have understood that kamikaze warfare is a phenomenon that proceeds in waves and is reproduced in different societies for reasons that are also very different, from anger against oppressors to personal disappointment. On this matter, one may recall the case of a member of the Japanese Red Army, Kōzō Okamoto, who participated in the attack on Tel Aviv's Loid airport in 1972 with George Habbash's Popular Front for the Liberation 
of Palestine. Okamoto was arrested, while his comrades blew themselves up. At the time, it was claimed that only the Japanese could have accepted to commit suicide, whereas Palestinians would have never done it because they were not courageous enough. As we know well, this is no longer true today. Suicide terrorism is hence not just a matter of courage, it is a cultural practice that has changed over time and has been adopted through a long and dramatic cultural process by Jihadists in Palestine, Iraq or Afghanistan (Margalit, 2009).

In the same way, one has to exclude any 'naturalness' in the relationship that liberal democracies entertain with the law. With the 'exceptional' legislation against terrorism and, previously, through the so-called 'humanitarian wars', we have understood that a sovereign democratic state is ambiguously linked to humanitarian law. Namely, it must respect the criteria of the legal order, but it must neutralize the scant, but terrifying, military potential of the suicide terrorist through any available pre-emptive means. This is necessary to defend the 'value' of the lives of its own population and its soldiers. The kamikaze's willingness to die cannot be compared with a professional army's firepower, despite the contingent strategic advantage. The difference between a civilized and an uncivilized life is an effect of the destructive capacity of military technology and its economy. It is on this basis that the value of one life in relation to another is decided, over and above the strategic importance of a death in relation to gratuitous cruelty.

\section{Norm/exception in current governmentality}

It is interesting to note how the philosophical foundations of contemporary exceptionalism have been relativized in the work of the latest generation of academics through a rethinking of the Foucauldian analysis of governmentality. The problem of norm and exception in global governmentality no longer exclusively concerns political-legal sovereignty at the nation-state level, but has crossed over into the analysis of power, with ethnographies of the conduct of those subjected to power, anthropological studies on the organization and operative systems of power, and a concern on the part of political science, economics, management and accounting, bio-medical and bio-economic research to concentrate on the autopoietic logic of governance (Ong and Collier, 2005; Ong, 2006; Murray Li, 2007).

This is also proof that critical thought, which has underpinned the current philosophies of exceptionalism, from Derrida to Agamben, has been historicized in relation to its own constitutive limits: by keeping within sovereignty and the aporiae of governmental rationality. This reproblematization of the discursive field starts by questioning a key assumption in the sociology of globalization: that the remainder of sovereignty in the global space must be considered one of the possible forms of governmentality. This has led to the definition of the global space as the 
governing of different temporalities in which populations live, and not just in terms of the management of human, financial and administrative flows that territorialize and deterritorialize the state-controlled nomos.

The global space overturns the traditional relationship between space and time. Governmentality is the mechanism that enacts this reversal, as it intervenes upon both forms of life and the division of territories. The creation of a mentality about the government of oneself and of others first modifies the way of living one's temporality and hence of perceiving a space. This affects the shifting topography of territories and the construction of political identities, as well as the devices required to control global assemblages (Sassen, 2008).

The testing of norms and institutions useful for the replanning of times and spaces, of the norm and exception, is the object of political experience in global governmentality. Starting from the idea that a life is the expression of the immanence of knowledge and power, of the norm and exception, the inevitable conclusion is that this process also runs through analyses that deal with this life. To be understood, governmentality requires a pragmatics of the present that is capable of questioning its own premises alongside its related conclusions. Hence, it must conceive the present both as history and as the updating of an infinite virtuality. This is how what is transcendental the state of exception - can be radically historicized and its historical transformation - the normative project - can be envisaged. Immanence translates this materialistic methodology and the analytics of power into a pragmatics of the present that marks the difference from modernity and from the philosophical genre of sovereignty (Ciccarelli, 2008).

The epistemological reversal that was already widely envisaged by Foucault in the late 1970s has now happened. The emergence of the global space has coincided with the spread of this model of government worldwide. During the last thirty years of the twentieth century a monolithic power was not imposed, but a modality of government was spread in democracies and totalitarian regimes alike. The neo-liberal season of global governmentality has certainly been characterized by the attempt to impose the same political rationality, even if its implementation has depended on local cultures, political and religious traditions and individual histories.

Governmentality does not just pass through armies that pursue strategic goals or NGOs that practise humanitarian ideals. It is promoted by local institutions, by the administrative know-how adopted to resolve daily problems, by the criteria adopted to promote an economic and social progress that is compatible with environmental, cultural or individual security. Obviously, it is not a peaceful process. Global governmentality does not cancel the difference between the norms of one's own political rationality and individual forms of conduct, the stories and values of individuals and their communities. Rather, it may be said that this remains its problem that is impossible to overcome. Reducing multitudes of people to statelessness does not guarantee their consent. 
In this situation, the ambivalence between order and conflict, peace and war, norm and exception, between the will to create a 'democracy' and the need to guarantee a multinational company's interests has reached a point in which it is difficult to distinguish violence from authority, well-being from sacrifice, domination from freedom. This is the dilemma that governmentality always leads to. 'Peace' and 'war' are not different moments of the same military conflict. Today, such a distinction should be conceived as an expression of the same policing policy. In the global space, security is no longer a task that states manage in an exclusive manner as an internal public order issue, but rather requires a series of military, humanitarian and policing policies to neutralize threats at a global level and, at the same time, to safeguard the living conditions of their own populations. These are the reasons why governmentality is an expression of a global policing policy (Dal Lago, 2003).

Translation by Yasha Maccanico and Nick Dines.

\section{Notes}

1 Among the first to criticize the president's powers to manage a 'state of emergency' in the United States' constitution was Rossiter (1948). For an analysis of this problem, in the light of the theory of 'war for democracy, see Ackerman (2006).

2 There exists an already extensive critical literature. See Butler (2004a); Dal Lago (2005); Reid (2006); Butler and Spivak (2007); Neal (2008); Bigo and Tsoukala (eds) (2008); Neal (2009); Dillon and Neal (2009).

3 Derrida (1994a; 1994b; 2003; 2008); Agamben, (2005); Saint-Bonnet (2001); Hardt and Negri (2004); Paye (2007s).

4 Mir Puig and Corcoy Bidasolo (eds) (2004); Dal Lago (2006b); Ferrajoli (2006); Papa and Donini (eds) (2007).

5 Military Order (2001); Ciccarelli (2006). 


\title{
4 Reversing Clausewitz? \\ War and politics in Foucault, \\ Deleuze-Guattari and Aron
}

\author{
Massimiliano Guareschi
}

When discussing war, it is almost compulsory to quote Clausewitz, or at least the maxim that 'war is merely the continuation of politics by other means'. At the same time, the formulaic symmetry of this well-known adage exposes us to the temptation of reversing its meaning; in other words, it raises the question whether it is perhaps not politics that is the continuation of war with other means. This question has been directly confronted by a range of authors, from Johan Huizinga to Ernst Jünger (Huizinga, 2004: 84-85; Gnoli and Volpi, 1997: 83). One of the earliest proponents of the need to reverse the formula was Erich Ludendorff who reflected upon the matter in the transformed conditions of Der Totale Krieg (Ludendorff, 1922: 23). One could mention countless other examples. This chapter, however, does not intend to systematically deal with how Clausewitz's formula has been challenged or how, through the course of the twentieth century, its has occupied a special place in debates about the interconnections between war and politics, the military and the civilian population, national-international space and the global dimension. Rather, it limits itself to a particular geographical and historical context - France between the 1970s and 1980s - in order to examine the very different theoretical approaches of Foucault, Deleuze and Guattari, and Aron.

\section{Michel Foucault}

In 1976, Foucault gave a course at the Collège de France entitled Society Must Be Defended in which a central aim was to reverse Clausewitz's wellknown assumption (Foucault, 2003). The point of departure for the Foucaultian discourse is the need to re-problematize the concept of 'power' by inverting both its sense and scale and, in doing so, break with the models that had been layered up over centuries of philosophical and legal thought (Foucault, 1995, 2000). In such a vision, the key to understanding power needs to be sought not at the level of sovereignty and law but at the molecular level of a 'microphysics', which is focused upon exploring the dynamics of power relations that underpin a relationship characterized by some form of asymmetry (Guareschi, 1999). 
In his research, Foucault seeks to free himself from an economistic conception of power relations, which, in varying ways, characterizes both liberal and Marxist perspectives. In the sphere of liberal thought, the dynamics of power are equated with the circulation of goods, as demonstrated by the frequent articulation of private-law categories (such as the contract, the power of attorney or the mandate) within a public-law domain. In contrast, with Marxism, the syntax of power tends to trace itself in the structure of relations of production, which it serves to legitimate and stabilize (Foucault, 1995: 13). In order to design an alternative to these 'economistic' paradigms, which instead posits power as an autonomous element of investigation, Foucault therefore identifies two viable analytical operators: repression and war (ibid.: 16).

The use of war as an operator to analyse social peace immediately brings to mind the name of Thomas Hobbes, who commenced from the concept of war in order to work out how to construct an artificial order guaranteed by the Leviathan. ${ }^{1}$ Foucault rejects such an association because, in his opinion, war itself does not play any role in Hobbes's theoretical proposition. This observation is based less on the hypothetical character of bellum omnium contra omnes than on the fact that, in the state of nature contemplated in The Leviathan, violence and the actual enactment of war would never take place. In effect, Hobbes does not discuss war but rather a 'state of war' to indicate the play of mimetic representations and 'infinite diplomacy' on the basis of which each individual, even the strongest, comes to the conclusion that they are unable to guarantee their security from the attacks of others (Foucault, 1995: 92). For Foucault, therefore, Hobbes is far from being the theoretician of the relationship between war and constitution of the political order, but instead assumes the guise of an author determined to eliminate war as the historical reality of the genesis of sovereignty. In this sense, his theoretical construction is understood by Foucault to be contrary to a historical discourse centred on war and invasion, which was used and appropriated in multifarious ways and had notable currency in revolutionary England. Such a discourse refers to Angles, Saxons and the Norman invasion, which established a new sovereign in England, William the Conqueror, and a new aristocracy originating from across the Channel. Stressed in different terms, this account could also function as a discourse that both legitimises royal absolutism on the basis of the right to conquest, but also discloses the usurpatory origins of the royal and aristocratic order, thus evoking the right of resistance that would appertain to the descendants of the oppressed Angles and Saxons. It is against such a 'political use' of history that, according to Foucault, the Hobbesian attempt to neutralize real wars operates, and hence leads to the conceptual antidote of the 'state of war' in order to delineate a condition characterized by the absence of winners and losers, and dominators and dominated. 
For Foucault, identifying the polemical target of Hobbes coincides with underlining a typology of discourse, defined historical-political, which begins to assert itself from the seventeenth century onwards and in which he identifies an alternative to legal and philosophical models centred on sovereignty, representation and the contract. The theme of conflict between races plays a central role in this discourse and serves to stabilize a dichotomous and discordant vision of society, permanently traversed by an irreducible conflict induced by conquest and the asymmetry ushered in by the outcome of a historically situated battle. In such a perspective, therefore, war is neverending but continues as a permanent social condition under the semblance of peace. Or, put another way: peace as the continuation of war with other means.

In short, the theoretical scenario in which Foucault sets the inversion of Clausewitz's formula is marked by the need to elaborate a general frame in which to ensure coherency to an analysis of power removed from the burden of economistic and substantialist perspectives. War, as an analytical operator, is thus called upon to play an analogous role to that reserved to the contract in political philosophy (Duso, 1993). Reversing the formula, for Foucault, therefore means, first and foremost, asserting the fact that power relations are based on a relationship of force crystallized at a specific moment in time and from the outcome of a war. Therefore, the peace that follows is a condition that revolves not around overcoming but rather the institutionalization of the determining effects of the 'last battle'. On the basis of this hypothesis, 'the role of political power is perpetually to use a sort of silent war to reinscribe that relationship of force, and to reinscribe it in institutions, economic inequalities, languages, and even the bodies of the individuals' (Foucault, 1995: 15-16). The second significance of the reversal consists in the hermeneutic assumption according to which the conflict that permeates a political system, 'these political struggles, these clashes over or with power', should be interpreted as the continuation of war during peace (ibid.: 16). The third implication, which in some ways closes the circle, underlines how, once such a logic is assumed, only the resumption of war can bring about a resolution to the conflictual tension that accompanies peace.

Hereupon, Foucault invites a shift in perspective, proposing to read the famous maxim as itself the result of the reversal of a pre-existing formula. According to Foucault, Clausewitz had in fact simply inverted a preexisting formula, according to which politics was none other than the continuation of war (ibid.: 48). The reference, obviously, is to the historical-political discourse that is developed in the 1975-1976 course. Special attention is paid to the constitutional context, and particularly to the military dimension, in which its genesis is located. Foucault concisely traces the changes during the medieval and early modern eras that gave rise to the monopolization of war by the monarchy. From an oligopolistic instrument wielded by a military aristocracy, and prone to be transversally 
used by different ranks of power within the realm or empire (Brunner, 1939), war would later transform into a function reserved to the sovereign. It is the sovereign who guarantees internal peace within the realm. At the same time, the violation of law becomes a criminal deed and consigned to the courts, while war finds itself projected outwards onto disputes between states, which in doing so establishes the jus ad bellum of international European society (Schmitt, 2003; Bull, 1977). Foucault stresses how the 'statalization' of an act of war implies that 'the immediate effect of this state monopoly was that what might be called day-to-day warfare, and what was actually called "private warfare", was eradicated from the social body and from relations among men and relations among groups' (Foucault, 1995: 48). It is in the context of the statalization of war and its exclusive projection over interstate competition that, according to Foucault, a contrary historical-political discourse arises, centred around the permanence of war and the establishment of peace within the borders of the royal state, which acts as the 'ineradicable basis of all relations and institutions of power' (ibid.: 49). Hence, in contrast to the monism of the theory of sovereignty, in which the dimension of war is displaced from the infrastate space only to re-emerge in the 'state of nature' of international anarchy, there instead exists a binary vision of social reality, marked by the incessant struggle, manifested in different forms, between two fronts for which war has never ended.

Significantly, the Foucaultian genealogical inquiry interprets various nineteenth- and twentieth-century perspectives, especially Marxism and racism, as derivations of the historical-political discourse, which, in opposition to the liberal vision of the contract and the composition of individual and collective interests, propose a representation of social reality in terms of latent war, zero sum games, or, to use a concept of Clausewitz, 'polarity' between classes and races. As such, it is no coincidence that the temptation arises, explicitly or implicitly, to invert the formula. Take, for example, the rival positions of Ludendorff and Lenin. For the former, the dimension of total war ousts the primacy of politics and puts it at the service of war. For the latter, on the other hand, it is the exclusive positioning of war in the space of interstate relations that enters into crisis. Indeed, a far more radical fault line intersects the various fronts of the inter-imperialist war and cuts across the geography of state borders: that of class conflict.

The reference to Marxism brings us back to one of the principal subtexts of the archaeological digressions in Society Must Be Defended. As confirmation of this reading, one could cite the various declarations contained in 'minor' texts written around the year 1976, in which Foucault criticizes the traditional Marxist approach to the concept of 'class struggle' for privileging 'class' and overlooking questions connected with struggle. This, he argued, had led Marxism to seek solutions in the sociology of social class or to rely on the optimism of the philosophy of history and dialectics (Foucault, 1994: 268, 310-311). In this context, reversing 
Clausewitz means, first of all, reacting to the neutralization of 'internal' conflict implicit in the projection of war over international space. Politics, over and above the adjectives that might be used to describe it, is the continuation of war with other means, to the extent that every relation of power rests on an agonal basis and on the exertion of a local power relationship. A study that might appear little more than an erudite exercise ultimately reveals a political intentio directly linked to the contemporary situation. This same dispute - more with Marxism than with Marx himself - resonates with the political and ideological climate of the 1970s, and the events and debates that directly involved Foucault as a militant, from the foundation of the university at Vincennes to the Prison Information Group (GIP) (Eribon, 1991: 214-313). Set against such a backdrop, the re-problematization of the concept of power, then at the centre of Foucault's theoretical engagement, acquires not only an intellectual but also a practical value, in the prospect of a renewal of the scenarios of political action. As a result, one returns to the question of the analysis of power. It is from here that Foucault had embarked to arrive at the theme of war, and the study of an 'antecedent' alternative to the contract as the cipher to an approach to power that is irreducible to models of sovereignty. Such a perspective was then abandoned. Over the following years, other questions, in particular the government of others and of the self, would become the privileged objects of research. A determining role in this shift was, without doubt, the new direction in Foucault's militant politics. Remaining at a theoretical level, however, Vincenzo Sorrentino is right to point out how the assumption of the paradigm of war in the analysis of power relations actually leads to an impasse, about which Foucault appears to be clearly mindful (Sorrentino, 2008: 76-86). While connecting every kind of power relationship with war was surely suggestive as a theoretical gesture, this was evidently exposed to the risk of simplification, which was unable to fully comprehend the multiple ways in which power relations are manifested; subsequently compressing violent coercion and government, intersubjectivity and institutional relations, politics and war onto a single register.

\section{Deleuze and Guattari}

The underlying project that runs through Anti-Oedipus and A Thousand Plateaus is to make world history delirious (Deleuze and Guattari, 1977, 1987). Deleuze and Guattari's discourse develops along a wide set of time scales, where the national-international order, the sole focus of the Foucaultian analysis, constitutes just one element among others. The places and times in which the reversal of Clausewitz's formula is 'set' are consequently very different. The 'plot' has two principal protagonists: the apparatus of capture (or state) and the nomadic war machine, two different concatenations caught in the intrinsic instability of their relations. 
For Deleuze and Guattari, the war machine - a composition of men, arms and animals - is an invention of nomads. The state, as such, does not possess war among its functions. This it must subtract from the nomads; capturing their machines and transforming them into something quite different: an army and a military function. The great kingdoms that had appeared to emerge from almost nowhere at the dawn of history in Egypt, Mesopotamia, Crete and India were overwhelmed by the sudden invasion of hordes armed with longbows and chariots - the Hyksos, Hurrians, Kassites, Hittites, Aryans, Mycenaeans and Scythians - against whom the kingdoms and empires proved powerless. Learning the lesson, they assimilated the nomads' innovations so as to in turn equip themselves with a military potential.

In Deleuze and Guattari, the capture of the war machine and its military institutionalization, however, did not proceed in a linear way or acquire a complete and definite form, but turned out to be an open and reversible process that was continually traversed by tensions. This was because the war machine and the apparatus of capture depended upon different sets of logic. The war machine was an invention of nomads: it was their way of occupying the space of the desert and did not necessarily have anything to do with war. Or better, it was correlated in exclusive terms to war only when it was appropriated by a state apparatus. The war machine is therefore not defined by war (which it instead encounters the moment its movement clashes with the striations that sedentary peoples have placed in its path), but by the means in which the nomads are distributed and structured in the smooth space of the desert (Deleuze and Guattari, 1987: 417). To understand the sense of the discourse developed by Deleuze and Guattari around this matter, it is perhaps useful to recall a well-known passage of Vom Kriege in which Clausewitz underlines, in rigid sequential order, how the decision of war rests with the defender and not the attacker because the latter would be more than glad not to meet with any resistance and sweep straight towards the realization of its goals (Clausewitz, 1976: 377).

The incorporation of the war function by the state, which can take on different forms (the recourse to mercenaries or a territorial militia, conscription or a professional army), proceeds from a specific operation that denaturalizes the war machine - originally aimed at occupying the space of the desert and encountering combat only through chance contact with the striations that block its path - by making war its exclusive objective. In the words of Deleuze and Guattari:

It is precisely after the war machine has been appropriated by the state [...] that it tends to take war for its direct and primary objective, for its 'analytic' object (and that war tends to take battle for its objective). In short, it is at one and the same time that the state apparatus appropriates a war machine, that the war machine takes war as its objective, and war becomes subjugated to the purposes of the state.

(Deleuze and Guattari, 1987: 418) 
According to Clausewitz's choice of language, this would be seen to be the subjugation of war to politics, which establishes the objectives and confides their accomplishment to military action. This introduces one of the most controversial themes of the Prussian general's thought: namely the concept of absolute war, an act of force performed without a solution of continuity until the accomplishment of the objective that, according to the 'logic of the concept', should characterize the activity of war (Clausewitz, 1976: 579-581). The critical literature has dwelt widely on this question, starting with the often inconsistent observations made by Clausewitz himself, which oscillate between depicting absolute war as a logical-theoretical hypothesis, whose practical realization is impeded by the pressure of material and political circumstances and seeing it as an extreme case that can nevertheless materialize, as his references to the Napoleonic campaign demonstrate. Deleuze and Guattari, for their part, consider this problem in light of the structural differences between the war machine and the regulation of war according to the political objectives of the state:

The distinction between absolute war as idea and real war seems to us to be of great importance, but only if a different criterion than that of Clausewitz is applied. The pure idea is not that of the abstract elimination of the adversary but that of a war machine that does not have war as its objective and that only entertains a potential or supplementary synthetic relation with war. Thus the nomad war machine does not appear to us to be one case of real war among others, as in Clausewitz, but on the contrary the content adequate to the idea.

(Deleuze and Guattari, 1987: 420)

Thus, the Clausewitzian maxim according to which 'war is merely the continuation of politics by other means' should be read less as a statement than as a normative assumption about the means by which the war machine is incorporated into the state apparatus, with politics forming the frame in which military action takes place. From a similar point of view, it is significant that Clausewitz should identify in the people's war of Napoleon, and in an army that assumed the features of a machine able to sustain itself on the 'fuel of nationalism', the element of rupture that seemed to lead the logical-deductive scheme of 'absolute war' (Clausewitz, 1976: 579-581) to its concrete realization (De Landa, 1991). War would, therefore, appear to represent a flow that states are only partially able to appropriate; subjugating its objectives and the destruction of the adversary to the aims of their political project.

According to Deleuze and Guattari, however, 'when total war becomes the objective of the appropriated war machine [...] the objective and the aim enter in new relations that can reach the point of contradiction' (Deleuze and Guattari, 1987: 421). From here derives the ambivalent 
attitude of the author of Vom Krieg towards absolute war and its possible realization during the Napoleonic wars:

This explains Clausewitz's vacillations when he asserts at one point that total war remains a war conditioned by the political aim of state, and at another that it tends to effectuate the idea of unconditioned war. In effect, the aims remain essentially political and determined as such by the state, but the objective itself has become unlimited. We could say that the appropriation had changed direction, or rather that states tend to unleash, reconstitute, an immense war machine of which they are no longer anything more than the opposable or apposed parts.

(Ibid.)

And so the state, after having seized control of the war machine, finds itself facing a sort of return effect that sees it submit to the object which it had appropriated and which, exceeding the function assigned to it, takes on the form of total war, considered not simply as a war of annihilation but as a conflict that transcends military decisions and the rules of the game to involve the whole of society. In order to identify the decisive shifts that mark the appropriation of the state by the war machine, Deleuze and Guattari focus their attention on historic forms of fascism and the Cold War. In the case of fascism, they underline how war, even when nominally subjugated to political purposes of an imperial nature, assumes 'an unlimited movement with no other aim than itself' (ibid.). Another key moment is represented by the bipolar order of the Cold War, in which a planetary war machine pursues the peace of 'survival' and 'terror' as its objective. In considering the balance of mutual destruction, Deleuze and Guattari tend not to dramatize the contending elements between the two blocks so as to underline the functional convergence which leads to the seizure of a single war machine over the entire globe.

To summarize, the state appropriates the war machine, to which it attributes the exclusive ends of war, subjugating this to its own political purposes. And so here we encounter Clausewitz's formula: 'War is merely the continuation of politics by other means.' Napoleon and the people's war through patriotic and nationalist mobilization remains within such a paradigm, even if the consistency with which the objective (Ziel) is pursued short-circuits the prescriptive and command function of the political aim (Zweck). Albeit with some hesitations, Clausewitz hence speaks of absolute war. The increasing integration between war and economy, which in the following century leads to 'materialized war', marks a deep shift in the dimension of war. We are in the arena of total war and mobilization, which instigate an overall reorganization, starting from military needs, of social, political and economic relations: 
The various factors that tended to make a 'total war', most notably the fascist factor, marked the beginning of an inversion of the movement: as though the states, through the war they waged against one another, had after a long period of appropriation reconstituted an autonomous war machine.

(Ibid.: 466-467)

Up to this point, however, the Clausewitzian maxim seems to conserve a minimum of descriptive capacity, because 'fascist war still fell under Clausewitz's formula "the continuation of politics by other means" even though those other means had become exclusive, in other words, the political purpose had entered into contradiction with the ends' (ibid.: 467). Out of this arises the concept of 'suicide state', coined by Paul Virilio in reference to the Nazi experience (Virilio, 2006). In contrast, it is possible to speak of a true inversion of the formula in the situation that arises following the end of the Second World War, with the balance between terror and deterrence. The objective of the war machine at this point is no longer war but peace, whereby it absorbs, in keeping with the terminology of the Prussian general, the aim (Zweck), or rather, the component of political command:

This is where the inversion of Clauewitz's formula comes in: it is politics that becomes the continuation of war; it is peace that technologically frees the unlimited material process of total war. War ceases to be the materialization of the war machine; the war machine itself becomes materialized war.

(Deleuze and Guattari, 1987: 645)

According to Deleuze and Guattari, in the bipolar world order the war machine is reorganized so as to assume, over and above the oppositions between the two sides, the entire globe as a smooth space. The flow of absolute war which had been appropriated by states and subjugated to political aims seeps out from the limits assigned to it as a military function - the subjugation of the objectives to the aims - and is reconstructed as a war machine:

The war machine reforms a smooth space that now claims to control, to surround the entire earth. Total war itself is surpassed, toward a form of peace more terrifying still. The war machine has taken charge of the aim, worldwide order, and the states are now no more than objects or means adapted to that machine. This is the point at which Clausewitz's formula is effectively reversed; to be entitled to say that politics is the continuation of war by other means, it is not enough to invert the order of the words as if they could be spoken in either direction; it is necessary to follow the real movement at the conclusion of 
which the states, having appropriated a war machine, and having adapted it to their aims, reimpart a war machine that takes charge of the aim, appropriated the states, and assumes increasingly wider political functions.

(Ibid.: 421)

Evidently, many of these reflections not only appear to refer to the recent past but can in many ways also be extended to the unipolar context, in both its soft and hard phases, which characterizes the change in scenario that occurred following the end of the Cold War. What appears even more topical are the observations about the materialization of a system of organized insecurity and the figure of 'the common enemy' who, having emerged during the previous geopolitical configuration, seems today to establish its functionality with ever greater clarity (ibid.: 422).

\section{Raymond Aron}

In 1976, the same year in which Foucault gave his course Society Must Be Defended, Aron's two volumes of Penser la guerre: Clausewitz (in English, Clausewitz: Philosopher of War) were published with the respective titles L'Âge éuropéenne and l'Âge planétaire. In them, Aron engages in a hermeneutic bout with Clausewitz's text and, in particular, with the interpretations of the Prussian general's work over the subsequent course of history. This inevitably leads him to question the meaning of the 'formula' and, obviously, the possibility and/or necessity of reversing it. For his part, Aron is absolutely categorical in opposing any reversal. There are two reasons for this. To start with, if the Clausewitzian conceptual framework is faithfully followed and correctly understood, then there can be no room to attest the reversibility of the two terms of the formula. War is an instrument of politics, which it uses to achieve its own aims. In contrast, politics can never be at the service of war in so much as the objective cannot in any way be subordinate to the means. The other reason why Aron is particularly critical about the periodic practice of inverting the formula goes far beyond the realm of philology and links with the desire of arriving at an adequate understanding of current political events and the relations between states.

Aron reiterates the need to clearly discriminate between war and peace, and particularly disputes those positions that would see the Cold War as representing a sort of intermediate situation between the two terms. However, despite his efforts, the formulation of clear and unequivocal criteria to distinguish war from peace proves to be very problematic. The resort to violence organized through the armed forces against another state is identified as the distinction that, once crossed, makes it legitimate to talk about war. For such a principle to be confirmed, it is necessary first of all to take a position regarding the claim that violence cannot be limited to 
the sphere of physical coercion. On this regard, Aron critically considers the concept of 'symbolic violence' proposed by Pierre Bourdieu, which he sums up as follows:

It consists of imposing conceptual frameworks and moral norms, arbitrary because they vary from society to society, on members of society and particularly on the very young. To impose ideas, beliefs, and ways of living and acting that are called habitus ('ethos' in Weber's terminology) is said to be violence.

(Aron, 1983: 393; Bourdieu and Passeron, 1970)

Such a perspective is judged by Aron to be unacceptable in that it compromises the possibility of distinguishing between socialization, which inevitably refers to the influence of the group upon the individual, 'and the constraint, which presupposes conscious or other kinds of resistance by those in power' (Aron, 1983: 393). In the same way, theories invariably defined as sociological are criticized for their tendency to read all asymmetric relations, at both an infrastate and an international level and including those of an economic or cultural character, in terms of violence, so as to allow for a distinction between the dominated and the dominant. For Aron, such broad interpretations empty the concept of violence of any specificity, rendering it de facto applicable to any type of reality: "If we regard as "violent" any social order which we call inequitable or against which part of the dominated element revolts, violence cannot then be conceptually grasped by virtue of its ubiquity' (ibid.: 395). At this point, the 'inversion of the Formula is thus made out to be self-evident' (ibid.). Against this position, Aron leans decisively towards a definition of violence that refers solely to the dimension of physical coercion and, it could be added, to the organized form of its military projection in an international dimension. As such, he emphasizes the need not to equate conflict with war, as tends to happen in the strategic thinking of the United States. Various dynamics of conflict can exist between states without this signifying the move to a situation of war. However, Aron does not say anything precise about the distinction that allows one to talk about war, besides recourse to stock phrases such as the 'military use of force' or the implicit reference to conventions that authorize the beginning and the end of hostilities. Rather, he limits himself to underlining how the boundary that distinguishes war and peace has demonstrated a degree of mobility over the course of time, as have the means through which states seek to exert pressure on one another also during times of peace (ibid.: 389). On the basis of such an approach, Aron cannot but assert that there is no war in progress between the United States and the Soviet Union. Certainly, conflict exists between the superpowers in a number of areas, although these are accompanied by convergences in other spheres - for example, the prevention of nuclear conflict. Therefore, the resort to propaganda and covert actions as well as proxy wars fought in peripheral zones, besides represent- 
ing nothing new with respect, for example, to the forms of military command that have historically underpinned the European balance of power, also denies the very idea that the United States and the Soviet Union are at war or engaged in a condition that is 'different from peace'.

Aron contemplates the prospect of a possible restoration of international society and a system characterized by a threshold of homogeneity that, following the turmoil of the twentieth century, is able to guarantee the mutual recognition of the unanimity and effectiveness of distinctions between, for instance, inside and outside, war and peace, military and civilian. Over and above the philological approach to Clausewitz's work or the critical observations regarding the broad use of the concept of violence and the equation between war and conflict, we need to understand Aron's steadfast opposition to 'reversing the formula' as reflecting his insistence to safeguard a formal setting that establishes the possible conditions of differentiating between war and peace and between internal politics and foreign policy. The aim is certainly not to remove war from the relations between states but rather, at least at an implicit level, to suggest a possible restoration, under new conditions, of a jus ad bellum and jus in bello. The fact that war is monopolized by units (i.e. states) that mutually recognize each other and do not manifest any designs to annihilate one other, and which enter into conflict for limited political stakes against a background of a common interest of maintaining an international system of shared rules, is considered an element of order that not only provides the basis for clear and evident distinctions but also limits the ubiquitous distribution of violence through it being 'turned into form'.

Within the context of the Cold War, Aron strives, as we have seen, to reaffirm the irreversibility of the relationship between politics and war. This presupposes a clear distinction between internal and external dimensions, the delimitation of subjects entitled to jus ad bellum, and the possibility of establishing a parallel between 'war as action' and 'war as state' (to draw on the concepts of Carl Schmitt); that is, on the one hand, between the materiality of the forms of combat and the distribution of violence and, on the other, the normative framework that fixes war spatially and temporally and defines the means of establishing peace (Schmitt, 2007: 195-203). This is what is at stake when we reverse the formula. Do new weapons (in particular nuclear arsenal), the spread of irregular forms of combat, the dissemination of ideological fault lines beyond the borders of the nation-state and the development of supranational organizations generate a 'war as action' that can be brought within the parameters of a 'war as state'? Aron is convinced that this is the case, demonstrated by the resoluteness with which he opposes all attempts to reverse the 'formula'. However, when it comes to delineating the features that distinguish war from other forms of violence, Aron's discourse becomes uncertain, and his reference to the evident state of things, far from fulfilling this objective, indicates the inevitable problems of projecting pre-twentieth-century models of international society onto a changed historical context. 


\section{Reversing Clausewitz?}

In answer to the question whether it is legitimate, or opportune, to reverse the formula of Clausewitz, which sees war to be the continuation of politics by other means, the positions of the thinkers examined here can be swiftly summarized as follows: Foucault, and Deleuze and Guattari both respond affirmatively, while Aron is adamantly opposed.

Foucault confronts the formula in a research project that aims to identify, within the tradition of modernity, a means of thinking about political order that provides an alternative to the one centred on the neutralization of conflict, which Foucault considers typical of traditional 'legal-philosophical' solutions. Reversing Clausewitz, in this context, implies insisting on the warlike character of power relations, seeing in the watermark of peace the signs of a war that has never ended, and recognizing that politics operates according to other means by affixing the real dynamics of submission and subjugation in the apparent neutrality of institutions and procedures. In such a perspective, inverting Clausewitz means first and foremost shifting the Prussian general's maxim from the interstate context in which it was originally situated to an internal dimension, and to locate the basis of power relations and the centre of gravity of political action in conflict and not in its neutralization.

In contrast, for Deleuze and Guattari, Clausewitz is not a pretext but a privileged interlocutor. The explicit and implicit references to Vom Kriege signal counterpoints to the parts of Thousand Plateaus dedicated to the war machine and the apparatus of capture. Inverting Clausewitz means projecting the models of the Prussian general, obviously reinterpreted in the light of their 'radical' theoretical hypotheses, onto world history up until the political, social and technological developments of the twentieth century. In this perspective, the war machine appears to take on the form of a concatenation which passes through centuries and millennia, becoming interconnected in different and instable forms with the state apparatuses. Such a formulation proves to be decidedly less conditioned by references to the forms, spatiality and oppositions (internal-external, military-civil, etc.) of political modernity than the one adopted by Foucault. This is the 'prophetic' character of Deleuze and Guattari's analysis with respect to the contemporary era: for while it is calibrated to the preceding context of the Cold War, it is nevertheless able to capture, beneath the continuity of old forms, the effectiveness of powerful processes of integration, the redesign of planetary orders and new combinations of smooth and striated spaces.

Aron, for his part, tackles the formula in an extensive study that is specifically dedicated to Clausewitz. The assertion that politics is the continuation of war with other means is a theoretical move that is deemed by Aron to be both philologically incorrect and politically dangerous. In his opinion, entertaining such a proposition means jeopardizing a whole regulatory spatiality that of an international society centred on states - to which he sees no possible alternative or, at least, one that is desirable. If the formula is reversed 
according to the position of Lenin, thus following a path in many ways analogous to the one sketched out by Foucault, and the root of infrastate politics is to be found in war itself and not in the overcoming of war, then it is 'the national unity' that disappears (Aron, 1983: 270), or better, the idea of a pacified space within specific borders characterized by the sovereign authority's monopoly over the exercise of legitimate violence. The relations between different states, in contrast, are specifically characterized by the fact that - to adopt a formula from Peace and War. A Theory of International Relations 'they take place within the shadow of war' (Aron, 1966: 6). However, Aron adds immediately afterwards that 'to use a most rigorous expression, relations among states involve, in essence, the alternative of war and peace' (ibid.), as demonstrated by the fact that at international level the figure of the soldier is flanked by that of the diplomat. It is here that Aron guards us against a second approach to reversing the formula; namely, the elimination of every distinction between war and peace whereby the latter is merely seen to be 'war conducted by other means' and interstate relations are represented exclusively in agonistic terms. This method of 'reversal' possesses various inflections. For example, in the position that leads from Ludendorff to Hitler, 'the relationship between states is defined by hostility even when it is not expressed through the taking up of arms' (Aron, 1983: 278). In a different register, the theoreticians of the United States' policy of deterrence are also accused of dissolving the distinction between war and peace by the way in which their complex theoretical dispositives lead to a proliferation of intermediate grades between the two terms.

Aron's categorical opposition to any reversal of the formula therefore brings the discussion back to the need to preserve some key distinctions internal-external, peace-war, political-military - considered fundamental to contain and rationalize the distribution of violence, through the restoration of an international society. Such an endeavour could be accused of indulging in nostalgia. It is easy to recognize the theoretical difficulties that it comes up against, the moment that it has to pass from criticism to positively setting forth the parameters in which to establish, for example, the distinction between war and peace. The developments that have occurred in the decades following Aron's work only seem to further accentuate the anachronistic nature of his formulations. This said, it is striking how many attempts are still made to rekindle categories and distinctions that have long been considered unable to account for the dynamics of the present; as if it were impossible to do away with them, even if this perhaps means reframing them in negative terms.

Translation by Nick Dines.

\section{Note}

1 For a discussion of war in Hobbes, see Y.C. Zarka (2001: 127-145). 


\title{
5 Global war and technoscience
}

\author{
Luca Guzzetti
}

In this chapter that reviews the relations between technoscientific research and the military after the Second World War, I will mainly focus on the United States. There are two reasons for this. The first is that the US has been one of the two military superpowers in the postwar period and is now the only superpower left. According to Defense News (9 February 2009), the overall Department of Defense budget for 2008 was equal to US\$676 billion, while China, the second highest spender in defence, spent US\$85 billion a year. The current US Department of Defense budget is 20 per cent higher in constant dollars than its top budget during the Cold War, for an army with a third fewer soldiers. That larger budget with fewer soldiers is mostly justified by the costs of research, development and procurement of new high-technology armaments. The second reason for focusing on the US is that, with the possible exception of the years just after the launch of Sputnik by the Soviet Union, it has always led the technological race, both in the civil and in the military sector. Today, the United States alone invests more than half of what is spent by all countries worldwide on military research (James, 2009).

\section{The military-industrial-academic complex}

The Second World War radically transformed the research system by fostering 'big science', especially in physics, with its large machines and huge economic investments, and marrying science and technology, creating what is now known as technoscience. The Manhattan project was the best example of what the military wanted: mission-directed research, where the disciplinary boundaries are of no interest at all. A series of very abstract physical ideas were very quickly transformed - by an 'army' of mathematicians, physicists, chemists, material scientists, engineers, technicians and whoever else could be needed - into the atomic bomb, a very innovative military device and the most powerful and destructive instrument of war of all times. The new great prestige assumed by science in the second half of the twentieth century clearly depended on the development of the atomic bomb. Politicians, military men and common people alike had to 
admit that scientists were really able to control and transform the world making the dream of the natural philosophers come true - since they had invented an instrument capable of blowing it up. Granted that wars have always accelerated the development of new technologies, this was especially the case during the Second World War, which gave a major impulse to the development of three 'families' of technologies: destructive devices, such as the atomic bomb; means of transporting such devices, such as missiles (V2s), bombers and navigational devices; and information technologies - first and foremost, the radar. Although the radical destructivity of the bomb prevented its use in a direct, 'hot' war between the two superpowers, both nuclear technologies and missile technologies continued to develop, orienting themselves towards mostly civil uses: nuclear energy and space technologies. Of course, satellites have later been used for military surveillance as well and the superpowers have tried to use space for further military applications (Sebesta and Pigliacelli, 2008).

In his often quoted 17 January 1961 'Farewell Address', American President Dwight D. Eisenhower warned his countrymen of the risks arising from what he called the military-industrial complex:

This conjunction of an immense military establishment and a large arms industry is new in the American experience. The total influence economic, political, even spiritual - is felt in every city, every State house, every office of the Federal government. [...] In the councils of government, we must guard against the acquisition of unwarranted influence, whether sought or unsought, by the military-industrial complex. The potential for the disastrous rise of misplaced power exists and will persist. We must never let the weight of this combination endanger our liberties or democratic processes.

(Quoted in Lens, 1970)

This part of the discourse is very well known but, immediately afterwards, Eisenhower continued, citing a third component of the 'complex', what we now call technoscience:

Akin to, and largely responsible for the sweeping changes in our industrial-military posture, has been the technological revolution during recent decades. In this revolution, research has become central; it also becomes more formalized, complex, and costly. A steadily increasing share is conducted for, by, or at the direction of, the Federal government. [...] Partly because of the huge costs involved, a government contract becomes virtually a substitute for intellectual curiosity. [...] The prospect of domination of the nation's scholars by Federal employment, project allocations, and the power of money is ever present and is gravely to be regarded. Yet, in holding scientific research and discovery in respect, as we should, we must also be alert to the 
equal and opposite danger that public policy could itself become the captive of a scientific-technological elite.

(Quoted in Greenberg, 1967)

Responding to the shocked reactions of scientists who were not expecting such accusations from a pro-business Republican president and five-star general, Eisenhower explained - through his Special Assistant for Science and Technology, George B. Kistiakowsky, who had worked on the Manhattan project - that he was not talking about science in general, but only about scientists who took part in military projects (Price, 1965). But already in 1961 it was not easy to distinguish between scientists working for military purposes, from scientists who thought they weren't contributing to war technologies. Such a melange between science and the military had been joyfully recognized and favoured by many in the United States at the end of the Second World War. For instance, the secretary of war in October 1945 had said: 'Since the laboratories of America have now become our first line of defence, I cannot make too strong or too emphatic, the interest of the War Department in the promotion of scientific research and development for new weapons' (quoted in Forman, 1987: 156). And Eisenhower himself as the army's chief of staff had written in 1946:

Scientists and businessmen contributed techniques and weapons which enabled us to outwit and overwhelm the enemy. [...] Scientists and industrialists must be given the greatest possible freedom to carry out their research. [...] Scientists and industrialists are more likely to make new and unsuspected contributions to the development of the Army if detailed instructions are held to a minimum.

(Quoted in Greenberg, 1967)

The Office of Scientific Research and Development (OSRD) was closed up right after the war by its director, Vannevar Bush, who considered it an emergency instrument, but major Federal research centres were created that were mostly run by academic institutions. This is the case of the MIT's Lincoln Laboratory for the development of aircrafts, founded in 1951, of the Stanford Research Institute for research on electronic communication, founded in 1946, and of Berkeley's Lawrence Livermore Laboratory for $\mathrm{R} \& \mathrm{D}$ on nuclear weapons, founded in $1952 .{ }^{1}$ In general, the Federal government decided to 'outsource' military research to universities and business firms under contractual arrangements. Academic institutions seemed quite ready to continue to participate in the war effort, although the war had become of a different genre, the Cold War having started. Besides the patriotic declarations about the need for academic institutions to contribute to the new war effort, what must be considered is that the most reliable supporter of science and technology was the defence establishment. While 
the appropriations for civil R\&D in Congress found a lot of obstacles and the allocation of a few thousand dollars needed long debates, the military would not hesitate to divert substantial sums to help research in universities. In fact, through the 1950s, for instance, the only significant sources of funds for academic physical research in the US were the Department of Defense and the Atomic Energy Commission, whose mission was mostly military.

At the beginning of his presidency, Eisenhower tried to reduce defence spending, but the launch by the Soviet Union of the Sputnik in 1957 made the demand curve go upward again and, when his second mandate ended, the expenditure for research and development had become four times higher (Price, 1965). Big investments by the Federal governments were made through a new agency called ARPA (Advanced Research Project Agency), which would later be more precisely renamed DARPA, with 'Defense' at the beginning of the name:

The agency was started in 1957 after the Soviets stunned and embarrassed the United States by launching the Sputnik satellite. President Eisenhower worried that America was loosing the science arms race and set up an agency so that the United States would never again be surprised by the technology of foreign powers.

(Singer, 2009: 140)

The point was that the launch of the satellite demonstrated that the Soviets possessed the rockets and the guidance devices for intercontinental ballistic missiles, capable of delivering atomic bombs over the US territory - while America continued to rely on bombers.

The chief military advantage of the ballistic missile is its speed and the consequent extreme difficulty of defending against it. From launch point in the United States to target in the Soviet Union, or vice versa, takes thirty minutes or less, as distinct from several hours for even the fastest bomber or cruise missile. The final plunge of a ballistic missile warhead back from space through the atmosphere to its target - the period when defence of the target might seem most plausible - takes on the order of a couple of minutes.

(Mackenzie, 1990: 15) Also as a result of the Cold War and the launch of Sputnik, Congress passed the National Defence Education Act, to support the graduate education of increasingly larger numbers of scientists and engineers, particularly in the physical sciences. The effects of that legislation were unmistakable; in the seven years between 1960 and 1967, the number of doctorates granted by American universities in science and engineering more than doubled, from 6,000 to 13,000. The historian Daniel J. Kevles has estimated that, in 1969, one third of the 132,000 science and engineering 
graduate students in the United States were being funded by the federal government. Fostering competition in certain scientific and technical domains - particle physics, aeronautical engineering, rocketry, microelectronics - became part of the nation's international and defence strategy (Kevles, 1978). And preservation of tacit knowledge, of scientific and technological know-how for future military uses, was one of the objectives of the huge public investment in education in the United States: 'Their interest in "basic" research was primarily as a means for creating new techniques, and secondarily as a means for maintaining contact with persons possessing intellectual abilities that could be turned to the advantage of the military services' (Forman, 1987: 220).

Furthermore, it is important to remember that military research and development were not carried out only in universities and public research centres, but in corporate enterprises as well. The state 'conscripted' both industry and the universities:

Overall, DOD accounted for about a third of all industrial R\&D spending in those years, but in defence-dependent sectors such as electronics and aerospace it was closer to three-quarters. Similarly, defence contractors employed (and continue to employ) something like a quarter of the nation's electrical engineers and a third of the physicists and mathematicians.

(Leslie, 1993: 2)

Many companies, seeing the money flooding into some sectors of R\&D, began opening research facilities, precisely to attract government funds. And people who had been consultants to the Pentagon formed their own companies for the purpose of conducting federally public-funded research. This is the case, for instance, of the RAND Corporation, originally established under the auspices of the Federal government to provide new systems of arms and strategic studies to the Air Force.

During the Cold War, secret military weapons development and wellpublicized engineering feats that enhanced national prestige were strictly intermingled; and if the ballistic missiles, for instance, had been created to deliver nuclear weapons, they were later transformed into space rockets in the 'pacific' technological race with the USSR, and then the satellites put in orbit by the rockets were used for military ends. 'Military satellites have come to perform functions as varied as early warning against missile attack, surveillance, reconnaissance, navigation, meteorology, and geodesy. They proved to be major factors in maintaining nuclear stability during the Cold War' (Hacker, 2006: 156-157). This mix of military and civil purposes, the dual uses of most new technologies, was recognized when the first statistics regarding research and development were devised in the 1960s: 
The OECD statistics group together military, space and nuclear expenditures under the heading 'national security and prestige'. These categories are also often referred to as 'big science' and 'big technology'. [...] There is an important sense in which the grouping together of military, nuclear and space programmes, at any rate in the 1950s and 1960s, may be justified. All of them depended almost exclusively on public funds during this period; all of them were heavily if not exclusively influenced by considerations of national security and prestige; and all of them involved special institutions to control and operate the programmes, usually of the 'big' variety.

(Freeman, 1974: 289, 291)

The military-industrial-academic complex, both in the US and in the USSR, worked on the development of new military technologies, but the incapacity by the USSR to have dual uses of such technologies has probably been an important factor in its collapse.

Senator J. William Fulbright - who added the term 'academic' to the 'military-industrial complex' expression - once said:

When the university turns away from its central purpose and makes itself an appendage to the Government, concerning itself with techniques rather than purposes, with expedients rather than ideas, dispensing conventional orthodoxy rather than new ideas, it is not only failing to meet its responsibilities to its students; it is betraying a public trust.

(Quoted in Leslie, 1993: 13)

Nonetheless, after the public discussions among the physicists, especially in the 1950s and 1960s, on the opportunity of participating in military research, further developing the nuclear weapons (Steinberger, 2005), and after the contrasts in the 1980 s on the space defence initiative, better known as Star Wars, and on the necessity of continuing the nuclear weapons tests (Hill, 1995; Gusterson, 1996), in more recent years only few individual researchers in the United States seem to have decided not to participate in military-funded research. Opposition to military funding has not even emerged in the community of computer programmers and hackers, who espouse a new-age philosophy based on free flow of information, decentralization and computer democracy:

Almost everyone else, even people who opposed the war, recognized that ARPA money was the lifeblood of the hacking way of life. When someone pointed out the obvious - that the Defense Department might not have asked for specific military applications for the Artificial Intelligence and systems work being done, but still expected a bonanza of military applications to come from the work (who was to 
say that all that 'interesting' work in vision and robotics would not result in more efficient bombing raids?) - [the hackers would deny the 'obvious'].

(Levy, 1984: 131)

Benjamin Kuipers, a computer scientist, explained how the involvement with the military may evolve among researchers who may have never thought to collaborate in military projects:

However there is a slippery slope that I have seen in the careers of a number of colleagues. You start work on a project that is completely fine. Then, when renewal time comes, and you have students depending on you for support, your program officer says that they can continue to fund the same work, but now you need to phrase the proposal using an example in a military setting. Same research, but just use different language to talk about it. OK. Then, when the time comes for the next renewal, the pure research money is running a bit low, but they can still support your lab, if you can work on some applications that are really needed by the military application. OK. Then, for the next round, you need to make regular visits to the military commanders, convincing them that your innovation will really help them in the field. And so on. By the end of a decade or two, you have become a different person from the one you were previously. You look back at your younger self, shake your head, and think, 'How naive'.

(Quoted in Singer, 2009: 172)

Summing up, we may say that, in the US since the Second World War, civil and military research has come to be part of a unified system, largely directed and financed by the Federal government: in other words, the research system has been fundamentally militarized.

Indeed, any reasonable foreign observer would be obliged to conclude that we have socialized our science, at best in a fit of absence of mind, and at worst with the purpose of subordinating it to the purposes of military power.

(Price, 1965: 5)

And the needs of the military, financing research in the first place, have inevitably influenced the whole technoscientific research system, orienting it towards some objectives rather than others: nuclear energy is probably the best example at hand of an economically and environmentally unsustainable technological system that was developed as a military spin-off, simply because the technology was available. 


\section{Information and communication technologies for war}

Between 1943 and 1945, one of the very first computers - another had been built in Germany in 1940 by Konrad Zuse and a third was being developed by Alan Turing in Great Britain - was built at the University of Pennsylvania, thanks to a military contract: it was called ENIAC (Electronic Numerical Integrator and Computer) and it was used by the physicists at Los Alamos for the last calculations on the atomic bomb (but most of the work had already been done by pen). After the war, the army made the major contribution to the development of electronics in the US: 'Between 1950 and 1960 annual factory sales of consumer electronics products showed no growth at all, while sales of electronic products to the military services increased $650 \%$ - in constant, uninflated dollars' (Forman, 1987: 160). The military bought all the integrated circuits produced in the United States in 1962, and by 1965 were still buying over 70 per cent of them (Mackenzie, 1990). As we have seen, as a reaction to the Soviet Sputnik, the Pentagon created its own high-technology office, at first called ARPA, then DARPA, which has become probably the most active funding institution of new research in electronics - the most important generic technology in the contemporary economy, finding applications in all sectors of industry and of the military apparatus - information technologies, computers, artificial intelligence and robotics. DARPA was the first to finance innovations like the Saturn V rockets that took man to the Moon, weather satellites, lasers, the Internet, cellular phones, military robots and drones.

[DARPA] works by investing money in research ideas years before any other agency, university, or venture capitalist on Wall Street think they are fruitful enough to fund. DARPA doesn't focus on running its own secret labs, but instead spends 90 percent of its (official) budget of USD 3.1 billion on university and industry researchers

(Singer, 2009: 140)

With the collapse of the Soviet Union and the end of the Cold War, history has not ended but we have definitively entered a new phase in world history. Globalization has become the keyword to address the major changes that have occurred in the last two decades, where information technologies have played a major role. Most likely, the technological revolution, the information-driven transformation of industrialized societies, the fact that we now live in a networked, information-based society, a society where the greatest wealth is knowledge; all this implies that contemporary wars as well are going to be based on information technologies:

The way any society engages in conflict reflects the way it does a lot of other things - especially the way its economy is organized. And just as 
the industrial revolution industrialized warfare, and mass production led to mass destruction, with Clausewitz as the theoretical genius of the era, so today the entire society is going beyond the industrial age and taking the military with it.

(Toffler, 1997)

The economic and technological transformation of contemporary societies would therefore lead to a Revolution in Military Affairs (RMA), with information and communication technologies at its centre.

With what has become known as 'netwar' or 'network-centric warfare' (NCW), there is a shift to the new information technologies of computers, the web, fibre optics, allowing higher levels of communication and information sharing. Network-centric warfare is:

an information superiority-enabled concept of operations that generates increased combat power by networking sensors, decision makers, and shooters to achieve shared awareness, increased speed of command, higher tempo of operations, greater lethality, increased survivability, and a degree of self-synchronization. In essence, NCW translate information superiority into combat power by effectively linking knowledgeable entities in the battle space.

(Cebrowski and Garstka, 1998)

Wal-Mart was the model that Cebrowski and Garstka, two of the most important theorists of the NCW, had in mind when they applied the new technological means of information and communication to the battlefield, or battlespace as they preferred to call it, since 'nations make war the same way they make wealth'. Wal-Mart was one of the first large companies to network every aspect of its business: every time a product was sold, automatically a new one was ordered from the warehouse, with each single cash register connected to the internal network. The supporters of the informational revolution in military affairs thought that the same should happen in the army, thanks to a real-time communications network connecting all the operators in the battlespace.

According to theorists of this revolution in military affairs, it is only the software and not the hardware of war that really matters, and information is going to take the place of weapons as the central feature of any future war. The near perfect clarity assured by the perfect and complete information about the situation on the battlefield (something reminding one of the illusory premises of contemporary economic theory) would lift what Clausewitz had called the 'fog of war' and would remove all the uncertainties of the battlefield, or 'friction', that is, the reality that military actions are planned but their execution on the battlefield takes inevitably a different course (Helmuth von Moltke used to say that 'no plan survives first contact with the enemy'): the information dominance would assure victory 
in any theatre of war. In the Network Centric Warfare, the United States should gain a total information superiority over its enemies:

we view Information Superiority in military operations as a state that is achieved when competitive advantage (e.g. full-spectrum dominance) is derived from the ability to exploit a superior information position. In military operations this superior information position is, in part, gained from information operations that protect our ability to collect, process, and disseminate an uninterrupted flow of information while exploiting and/or denying an adversary's ability to do the same.

(Alberts et al., 1999: 53)

For a good knowledge of the situation on the battlefield, the Pentagon already uses several types of unmanned aerial vehicles or drones and is developing micro-unmanned aerial vehicles - that is, insect-like drones, which should become the perfect instruments for spying activities - integrating thus the information gathered by satellites and higher-altitude spy planes. The objective of the armed forces on the battlespace of denying information to the enemy is obtained by the development of 'invisible' arms:

'stealth' has now become the shorthand term for a variety of techniques intended to render aircraft, missiles, and ships harder to detect by sight, sound, and heat as well as radar, the heart of the effort was defeating radar. [...] The first operational aircraft to include significant stealth features, the Lockheed SR-71 Blackbird, became operational in 1964.

(Hacker, 2006: 161)

In future netwars, the Internet is going to become the major medium for communicating in real time within the army, and the blinding of enemy's means of communication has become a clear objective of cyberwars. ${ }^{2}$ But the control of information is very important also outside the armed conflict, towards the general public:

a characteristic of the battlespace of the future is that it will no longer be private or remote. The Vietnam War was an early example of this. It was fought as much, if not more, in the living rooms of America as in the living jungles of Southeast Asia. More recently we experienced a similar visible 'defeat' in Somalia. The battlespace for these operations was no longer confined to the battlefield. The Information Age has changed the access that combatants and non-combatants alike have to information.

(Alberts et al., 1999: 63)

The solution chosen by the US Army during the Iraqi war in 2003 was that of embedding hundreds of reporters with coalition forces for providing 'a 
sympathetic view on the invasion' (Boot, 2006). 'Reliable and nearly instantaneous global telecommunications have transformed the military chain of command [...] Accuracy measured in millimetres allow commanders to see the exact location of their units at any moment, removing much of the fog of war' (Hacker, 2006: 156-157).

The big innovation in the first Gulf War was the so-called 'smart bombs' - laser-guided bombs and cruise missiles, whose higher precision was made possible by the massive use of improved, very powerful computers. But unfortunately 'only 7 percent of all the bombs dropped were guided, the rest were "dumb"' (Singer, 2009: 58). In the years immediately after the first Gulf War, the precision of bombs was further increased by the development of the military Global Positioning System (GPS), capable of giving the position of a receiver anywhere on the Earth. ${ }^{3}$ In 2003, during the second Gulf War, the amount of smart bombs rose to 70 per cent.

In the previous paragraphs, we have seen how the American defence and military research budgets have always being growing - and in some periods exponentially growing - since the end of the Second World War. After the sharp fall in the 1990s, at the end of the Cold War, the budgets for defence expenditures and military R\&D have both gone up again after 9/11; from 2003 to 2008, the annual national defence budget rose by 74 per cent. Research and development and new weapons procurement costs grew at least as much over the same period.

In addition, there is the 'black budget', the Pentagon's classified budget for buying and researching what it wants to keep secret. For obvious reasons, the black budget is not released to the public, but it is estimated by the Center for Strategic and Budgetary Assessments to be around USD 34 billion in 2009, up roughly 78 percent since 9/11. A core part of this massive post-9/11 research and buying spree has been new technologies, with a particular focus on anything unmanned.

(Singer, 2009: 61)

A list of expensive technological gadgets for future wars, at present under development by DARPA, NASA and other public and private high-tech organizations, may include: several types of different micromachines, primarily for spying and reconnaissance; battlefield robots; wetware devices for the mind to directly control machines; scramjets, hypersonic aircrafts exceeding Mach 6; helmet-mounted cameras; night-vision contact lenses; wearable computers to fit in combat suits; and exoskeletons, kind of hightechnology armours (White, 2005). Many of these arms have already been developed and produced, some are on the market, and some are presently being used by the United States in Iraq and Afghanistan.

In robotics for military uses, innovation comes from a classical 'triple helix' research system - based on the interplay of government, university, 
and industry - quite similar to the one we have seen at work during the Cold War, but possibly with a more independent role played by the private sector:

One estimate of applied research spending in the unmanned field was that 40 percent was flowing through private industry, 29 percent via military centers and labs, and 23 percent through university programs. At the center of it all is the National Center for Defense Robotics, a congressionally funded consortium of 160 companies, universities, and government labs. Work on military robotics isn't so much top-secret labs fuelled by UFO power sources as it is a simple synergy of military money, business organization, and academic researchers.

(Singer, 2009: 138)

One serious problem of these new unmanned arms and devices is their cost: for instance, the Global Hawk, which was originally conceived as the replacement for the U-2 spy plane, 'costs some US $\$ 35$ million, but the overall support system runs over US\$123 million each. Even so, the U.S. Air Force plans to spend another US\$6 billion to build up the fleet to fifty-one drones by 2012' (Singer, 2009: 36). It seems unlikely that a single country may, at the same time, invest such sums in high-tech devices, on the one hand, and maintain an efficient ground army, capable of intervening anywhere in the world and of military controlling large territories, on the other; the United States as well will have to make some choices and find an equilibrium between the two types of military investment (Desportes, 2009).

The development of drones and other unmanned war devices is connected to the perspective of arriving at a 'zero-casualties' conflict, where no American or Western soldier would be killed in action. Although not very realistic for the moment, ${ }^{4}$ such a perspective introduces further problems in warfare, virtualizing the conduct of war. Already now, the US drones flying over Afghanistan - responsible not only for intelligence, surveillance and reconnaissance duties but also for missile attacks - have their command centre in Nevada. A missile strike commanded from thousands of kilometres away by 'soldiers' who go home for dinner clearly introduces a 'video-game effect', where the responsibility for the war action and its casualties is further displaced by technology. In Afghanistan, lately the US has responded to asymmetric attacks by the Taliban with periodic spasms of 'shock and awe', executed mostly by unmanned drones, in which its devastating firepower engendered by its advanced technologies - is impressed upon the world by the instantaneous broadcasting through modern information networks. But such a display of force has often negative consequences on the ground, since it is not always easy to individuate the correct target from far away, and it has therefore alienated the consensus of the local civilian population - whose heart should be conquered to win the war - who is frequently victim of these air bombings, coming apparently from 'nowhere'. 


\section{The myth of Prometheus}

In Homer's Odyssey, a fortune teller announces to the giant Polyphemus the arrival of an enemy who will blind him. In his imagination, Polyphemus looks forward to the coming of another giant of invincible force. Instead, it is a small Greek who blinds him while he sleeps under the effects of the wine offered to him. Polyphemus has not lost his force, but such force has become almost useless (Galli, 2008). Mere force may be not usable, like in the case of the hydrogen bomb, or useless, as demonstrated by the defeat of the Americans in Vietnam. This is a lesson that Americans have probably learned, but their confidence in technology has, on the contrary, been growing. The myth of Prometheus has taken the place of the myth of Polyphemus: information and communication technologies are expected to restore Polyphemus' sight.

The constant military problem has always been how to prevail in the field against comparably equipped armies. During the modern period, perhaps especially in the United States, one way out of the impasse often seemed to be technological innovation - that is, striking 'comparably equipped' from the equation. This was the dream of decisive secret weapons that the Manhattan Project and development of the atomic bomb seemed to confirm. Directed research and development promised a constant edge to the nation able to sustain so costly an effort. The United States adopted what was, in effect, a policy of permanent technological revolution'

(Hacker, 2006: ix)

As far as the nuclear weapons were concerned, American technological edge did not last long, since in 1949 the Soviet Union tested its first A-Bomb. In the subsequent decades, the situation was of a virtual technological stalemate between the two superpowers, but the incredible destructiveness of the nuclear arsenals impeded the direct confrontation between the two 'comparably equipped armies'. As we have seen, in the course of the Cold War, innovative research progressively shifted from destructive arms (nuclear weapons) and launching instruments (missiles) towards information technologies, with the United States constantly trying to mantain a technological edge over the USSR. With the end of the Cold War and the dissolution of the Soviet empire, the United States became convinced that their technological superiority would go unchallenged for many decades ahead.

George W. Bush was a strong supporter of the network-centric warfare; as a presidential candidate, he said that the revolution in the information and communication technologies would have permitted the US to 'redefine war in our terms'. The question is: why should America's enemies accept such a redefinition? 
True believers in technology see warfare as being reduced to a onesided contest where the technologically superior side dictates all action. They never discuss what happens if the enemy selects a strategy where time is not essential. How can battle time be critical in a war that lasts decades? Or what do we do if the enemy works hard not to produce any collectible signals?

(Hammes, 2006: 191)

It is clear that the militarily and/or technologically weaker side will adopt all kinds of asymmetric tactics and strategies to fight its opponent.

And since popular resistance à la Vietnamese is very costly for lives (one million and a half dead Vietnamese people, against 58,000 dead Americans), it is sensible to imagine - independently from any moral consideration - that 'terrorism' has come to be a normalized form to be assumed by any resistance to hyper-technologically armed enemies. What we now call 'terrorism' has permitted the success of the clandestine Jewish groups against the British in Palestine, and the victory of the Algerian national liberation front against the French paratroopers.

(Dal Lago, 2006c: 5)

In October 1989, as the Soviet Union collapsed, a group of American military experts described the future form of war:

In broad terms, [...] warfare seems likely to be widely dispersed and largely undefined; the distinction between war and peace will be blurred to the vanishing point. It will be non-linear, possibly to the point of having no definable battlefields or fronts. The distinction between 'civilian' and 'military' may disappear. Actions will occur concurrently throughout all participants' depth, including their society as a cultural, not just a physical, entity.

(Lind et al., 1989: 23)

They named it Fourth Generation Warfare, and Colonel Thomas X. Hammes defined it:

Fourth-Generation Warfare (4GW) uses all available networks - political, economic, social, and military - to convince the enemy's political decision makers that their strategic goals are either unachievable or too costly for the perceived benefit. It is an evolved form of insurgency.

(Hammes, 2006: 2)

The theoretical antecedents may in effect be found in the works of Mao Tse-Tung, Ho Chi Minh and V.N. Giap, and in their guerrilla warfare strategies. 
This is also suggested in Unrestricted Warfare, a book first published in 1999 by two Chinese senior colonels of the People's Liberation Army, Qiao Liang and Wang Xiangsui. In their opinion, future wars are going to be a mix of different kinds of warfare, where the superiority of one side in a specific field - like American superiority in technology - will not be decisive for the final result of the conflict. They suggest that warfare is going to be characterized by military, trans-military and non-military activities. Military initiatives include the use of nuclear and conventional arms, but also guerrilla tactics and terrorism, as well as biological, environmental, space and electronic warfare. But in the future unrestricted battlefields, other old and new quasi-arms are going to be used too: diplomacy, intelligence, netwar, cyberwar, psychological and virtual warfare, drugs dealing, etc. All these different styles of warfare will be accompanied by nonmilitary instruments, like financial and commercial wars, ideological and normative competitions, the use of economic sanctions, media and information wars. For winning in such a complex environment, nations and groups will have to find the right combination of all these different approaches. Nobody - not even the American hyperpower - may assume that it possesses the win-all strategy, since its adversary may not gently accept the definition of warfare proposed (Henrotin, 2009).

If we may assume that the opinions expressed in Unrestricted Warfare have some official backing in Beijing, contrary to the Soviet Union, which had been confronting and finally chasing the United States in a symmetric competition, then the Chinese seem to prefer a complementary, asymmetric approach. They consider technology an important military instrument but definitively not the only one. From a strictly defensive point of view, they still possess a numerous ground army, capable of conducting a longduration war of resistance, and may employ the Mao Tse-Tung strategy of 'circling the cities by the countryside', if needed. In 1946, Mao TseTung said that the nuclear bomb was a 'paper tiger', created by the capitalists to scare the people, which looks terrible but is not. All the same, when they could, the Chinese constructed nuclear weapons and they still have a small but efficient nuclear arsenal. In the same spirit, if new technologies seem potentially useful, the Chinese try to develop them using the means at hand. When, in 2001, they captured an American EP-3E spy plane, they completely disassembled it, studying it through a technique of inverse engineering, and then they shipped it back to the United States. Drones appear an important instrument of contemporary warfare but they are extremely expensive to build; the Chinese army has thus transformed a great number of old planes into unmanned drones, spending very little in the operation. When the Bush administration developed a new space defence shield, militarizing the space, the Chinese responded by shooting down one of their own old satellites. The message was quite clear: if the United States thinks it is going to use the space for military purposes, it is not going to be alone. The Chinese are aware of their military weaknesses, 
compared with the United States, but they do not seem to suffer from any inferiority complex in front of the only superpower to survive the Cold War.

The United States runs the risk of thinking that their military and technological superiority is enough to confront any potential adversary. Information and communication technologies are important military tools - however, on the one hand, they cannot take the place of strategy and politics and, on the other, it is necessary to learn how best to use them.

Our advanced information systems are still tied to an outdated, hierarchical organization, that slows the dissemination of information. Although specific high-priority commands receive near real-time intelligence, most commanders must submit their intelligence requirements up the chain of command. Each level validates, consolidates, and prioritizes the requests, which are then fed through the centralized staff system to task the assets that will actually collect against the requests. [...] Thus, the premier benefit of the Information Age - immediate access to current intelligence - is nullified by the way we route it through our vertical bureaucracy.

(Hammes, 2006: 192-193)

In contrast, America's adversaries in Iraq, for instance, took advantage of the new information and communication technologies thanks to their network organizational model, where all components had a high level of autonomy and could act in real time. The US military as well may adopt a network organization if it wants to successfully face its enemies who have asymmetric warfare strategies. It may emphasize a system that increases flexibility rather than centralization; it may leave the decisions and initiative to the correct level: the lowest possible on the field. In other words, it may adapt the 'subsidiarity principle' to warfare decision-making and war action: the information disseminated horizontally should be used by all combatants in the battlespace to act on their own initiative, as insurgents learned to do long ago.

Lately it seems that the American military thinking has been strongly influenced by the availability of the new technical devices that the militaryindustrial-academic complex offers at an increasingly faster rate. It is this cornucopia of high-tech gadgets, promising ever new opportunities of victory over the adversaries thanks to a constant technological superiority, that seems to orient military strategies.

Unrestrained pursuit of technical perfection has produced a baroque arsenal, possessed of extraordinary capabilities at astronomical expense. [...] Although they could dominate the battlefield, they could not win the war. The widespread assumption that better technology 
meant victory had made military-technological innovation, to a significant degree, an end in itself.

There is a real fascination for technology in American culture, and this is true for American military culture as well. Such an idea that technology may resolve any problem has put technology in military affairs in a clearly predominant position, over strategy and politics. But American military problems in Iraq and in Afghanistan show that not only technology counts: in long-term operations, where it is necessary to counter an insurgent enemy using asymmetric forms of fighting, the cultural and political element becomes crucial. 'The technology emphasis must shift from speed of targeting to supplementing the human skills essential in understanding the fourth generation warfare enemy: language, area studies, social network analysis, history, and so on' (Hammes, 2006: 266). ${ }^{5}$ As it is now clear, the US armed forces in 2003 won only the battle of Baghdad, not the Iraqi war. Even the most sophisticated military technology alone may win some battles but it won't win wars.

\section{Notes}

1 Referring to the University of California at Berkeley, operating the Lawrence Radiation Laboratories and the Los Alamos Laboratory for the Atomic Energy Commission, Robert Oppenheimer said it was 'a great, liberal university that is the only place in the world [...] that manufactures, under contract with the United States government, atomic bombs' (quoted in Cowan, 1997: 261).

2 According to the New York Times (11 December 2009), in November 2009, there was in Washington the first high-level meeting between American and Russian military experts on the use of the Internet for military purposes.

3 The civil applications of GPS have now reached a larger public, but the ultimate control of GPS by the Pentagon has convinced other countries, NATO allies included, to develop their own independent system of satellites; the EU's positioning system is called Galileo.

4 Between 19 March 2003 and 16 December 2009, 4,371 American soldiers and 318 Allied soldiers were killed in Iraq - not to speak of the c.100,000 Iraqi citizens who were killed during the same period (source: www.iraqbodycount.net).

5 The lack of language skills on the part of analysts and military personnel, and the scarce number of intelligence agents on the ground abroad in 'enemy' countries, has been indicated as one of the major causes of the unpreparedness of the US to the attacks by terrorists on 9/11 (Clarke, 2004). 
Part II

Securization 



\title{
614 September 2001 \\ The regression to the habitus
}

\author{
Didier Bigo
}

No, you read it well. 14 September is maybe more important than 11 September 2001 because the world we live in is more affected by the counterterrorist policies of the US and their allies than by Al Qaida bombings. But we are now prisoners of so many encrusted narratives about 11 September that we tend not to rediscuss what happened. We believe the 'epitome', the short bible of what happened and what will happen; and even when we try to be critics we borrow the counter-arguments from this epitome of a global insecurity and a regime of exception. I want, in this short paper, to discuss these narratives and to explain differently what happened by insisting on the most banal and most important factor: the regression to the habitus in the face of unknown events on the part of the professionals of politics and the professionals of security of the Western world.

\section{September 2001: the epitome of the fall of the state system?}

11 September 2001 has been the epitome of the belief that the state was no longer in control of its territory. It has been the momentum of a condensed version of the long story of globalization of violence and insecurity, which began in the mid-1970s and took off after the end of the Cold War. The concise version has been encapsulated into an 'event'. The evocation of this event, reduced to a series of images of the Twin Towers falling, is then supposed to act as the full story. It is the image of a 'fall'.

This epitome is working well as it connects the personal memories of what each individual was doing that day - at what time he or she heard about or watched the images on the TV of the fall of the Twin Towers with the collective narrative of the end of a traditional understanding of what security means. By evoking it, it is not necessary to argue, to comment, but just to remember the feelings of that day. The images are fuelling the sense of disaster, of insecurity, and produce as such insecuritization, at least for a large part of the Western audience. ${ }^{1}$ 


\section{Brute facts, impressions and interpretations: 11 September 2001 as a global event of violence}

In the minutes following the fall of the second tower, the attackers were qualified as terrorists, even as hyperterrorists (Heisbourg, 2001). It was not an accident, but the will of someone to do evil, to destroy. The scale of the tragedy, of so many people dying 'during' a post-synchronized TV show, was a shock. Even worse, the sense of déjà vu was overwhelming and the realisation that it was an actual event and not a movie was horrifying (Virilio, 2002; Žižek, 2002a). It created what Yves Michaud has called 'pornography of violence', pornography which was so strong that even the most sensationalist media chose not to show the blood of people dying and instead concentrated on the fall of the buildings as 'symbols' (Michaud, 1978). Many observers have recollected how fascinated they were and the difficulty for them to admit it was real, that it was material, with real victims, and not a virtual effect in a catastrophe movie (Holland, 2009).

The overwhelming light on these events in New York partly overshadowed the other targeted attacks: on the Pentagon in Washington DC, and the failed attempt against the US presidential base in Pennsylvania where, in theory, the president flies in times of danger. ${ }^{2}$ The epitome concentrated the eyes of the public on the planes crashing into the Twin Towers of the World Trade Center, giving a sense that the 'consumer and developed world' and 'the cosmopolitan city of New York' were the central targets, not the military-industrial complex or the government. Jacques Derrida, in his discussion with Giovanna Borradori, immediately understood this difference of meaning in the public spheres and the differentiation of effects, as well as their diffraction when it will be a question rather than an answer. As he explained, the reduction of the event to the Twin Towers and the nomination of $9 / 11$ as a date in its specific US format are symbols of the incapacity to accept a concept of terrorism, and even to give a meaning to the violence, except by creating a date, the idea of an 'event', of an 'unprecedented thing which happened that day'. ${ }^{3}$ Only the conjuration by a date, and by a journalistic litany repeating the date again and again, can explain why the fear connected with Al Qaida's actions has been transformed into a more ontological fear, accusing the 'unknown', the 'unspeakable', of attacking the American way of life (Habermas et al., 2004).

To name it, it was nevertheless necessary to have a formula, in order to convert into words the images. This was done immediately by the qualification of these events as hyper, mega or giga terrorism, changing the patterns of what was terrorism, war and crime, and creating a radically new frame of the enemy, challenging the very foundation of the pact between the state and the citizen concerning their personal security, by calling for a global and world interpretation of any local form of violence. ${ }^{4}$ 'The traditional understanding of what it means to speak of war, of crime, of state 
security, of sovereignty has collapsed in the same second as the towers', said one of the senior intelligent analysts in charge in 2002. 'We have dust all around. Political science is at ground zero. Then we have to rebuild everything and to adapt to a new world, global and profoundly insecure'. This belief was also shared by major sociologists, such as Ulrich Beck, who wrote, 'The difference between war and peace, the military and police, war and crime, and national and international security are, from within and without, completely annulled' (Beck, 2003: 257).

\section{September 2001: a turning point for a radically new era?}

From the narrative of a very long list of experts emerges a new 'doxa', a new common sense, taking for granted the rise of a global insecurity at the world level, transforming the humanity of the planet into a single 'survivor', struggling in front of the imminence of Armageddon. As we will see later, the competition for a meaningful interpretation of 11 September 2001 and the Bali, Madrid and London bombings will be very tough, but the implicit understanding is that the attacks in New York and Washington were the certificates of birth and proof of the globalization of violence. A radically new era was born that day.

Hyperterrorism, terrorism from below, or asymmetric terrorist warfare, as analysts said, has the capacity and the will to destroy sovereign states, even the most powerful of them. The danger now comes from a handful of individuals, who may be religious fanatics and may have been provided with arms of mass destruction. This combination is fatal. Furthermore, this terrorism from below is now global and hidden. Networks have taken precedence over territorial borders. The threat no longer originates from a specific place and a specific enemy that can be watched.

The attacks and their framing as global terror have, therefore, activated a different form of fear, not directly linked to Al Qaida or other violent political clandestine organizations, but more to the ontological fear of a chaotic world where weapons of mass destruction are managed not only by rational state actors but also by a handful of fanatics, leading inevitably to the apocalypse. It looks like a revival of the fear of the first years after Hiroshima and the Cold War, despite the desegregation of the reassurance given by politicians and part of the academic community, such as Morgenthau, Aron, Gamson or Poirier, that the atomic bomb, once in the hands of irrational and ideological actors like the USSR or smaller actors, will nevertheless give them a sense of responsibility and that they will act rationally. ${ }^{6}$ It is a move from rationality to irrationality of agents' behaviours, claim the US leaders and some analysts. And it changes the structure of the international (dis)order. The meaning of anarchy is reframed as possible death any time, for no good reason, of any states, even the most powerful. It is not a form of survival in a time of neither war, nor peace. The suicide terrorists as fanatically religious have created a new 'paradigm' 
where the cost-benefit of the proposed action of destruction cannot be deterred by reciprocity of death, by retaliation, because de facto retaliation is too late. The conundrum of deterrence to play on the will of the enemy to prevent him launching a first attack is coming back. What if they don't listen? How do you calculate rationally an interaction with a supposedly irrational actor? Does it justify a first strike? How can you anticipate or predict an attack?

The number of people killed in the Twin Towers (more than 3,000, but estimated at 7,000 in the initial days after the attack), the reference to Pearl Harbor and the Second World War and the ashes and smoke coming from the burning towers all immediately created an emotional link between two different connotations of mass destruction and apocalypse: mass destruction by traditional means of killing, such as the use of civil aeroplanes as missiles against targets, causing many casualties; and mass destruction by the use of new technologies, such as nuclear, radiological, biological and chemical (NRBC) weapons. This played a crucial role in the belief that something radically new was at stake. It is also important to remember the role of the fear of anthrax letters in this association. ${ }^{7}$ Anthrax has been even more important than the Twin Towers in leading people to believe in the narrative that links NRBC weapons, indiscriminate targets and the actions of clandestine organizations. ${ }^{8}$ It gave grounds to the idea that violence was expressed through massive attacks that can seriously put the survival of the nation at stake. The anthrax letters created anxiety for weeks and complexified the situation by perpetuating fear of the unknown and a sense of a doomed future (seen so often in science fiction movies that deal with the extermination of humanity and with the lives of the survivors of biological warfare). ${ }^{9}$ Some members of the public adhere strongly to these feelings and they seem to continue to do so beyond terrorism. They are under the impression of a global insecurity.

\section{September 2001: the birth of a fear of the future - Armageddon}

The attacks have embodied a profound fear of the future, driven by a worst-case scenario, beyond the modus operandi of Al Qaida attacks, focusing on a widely used image in movies: a mushroom cloud burgeoning over a US city. It has been repeated over and over again that 'the world is no longer safe, nor will it ever be again' and 'the question is not if, but when'. As George Bush said after the attacks, 'It is my responsibility not to wait for the next bombing which could have the form of a mushroom cloud. ${ }^{10}$ And Donald Rumsfeld added, 'Next time it will not be 3,000 innocent civilians killed, but 30,000, 300,000 or even 3 million.' This view of the future has given to the neo-conservative discourse a sort of ambiguous appeal coming from their tragic argument. The scenario is voluntarist, but the fate is there. Nothing can be done against nuclear terrorism coming 
from the fanatically religious, who are impossible to deter. It is possible to save time, to 'give the future a chance', and the only solution is to eradicate all of them (terrorists and supporters) in a combat of good against evil. The born-again right interpretation of the future of the world has certainly shaped, in part, this vision of the highest civil servants in the US and has helped to convince part of the electorate. Armageddon is coming. ${ }^{11} \mathrm{We}$ are at the edge of the world. The future is known; it ends up with mass destruction of humanity or eradication of all evildoers.

These impressions, structured by the brute facts of destruction of the Twin Towers and the feelings and memories of Pearl Harbor and the first years of the Cold War, as well as the generation of catastrophic movie viewers, have been at the core of the construction of a meaning of the 'events of 9/11' as the foreshadowing of future wars or catastrophes. ${ }^{12}$ The 'impression' is fed by the attacks and all the previous movies and novels that have dealt with this 'rape' by violence of the territorial-political body of the USA. So, the Armageddon metaphor is not just a reminder of the religious feeling of the new born-again groups and their idea that the end of time is coming soon; it is perhaps a more profound secular and postmodern trend, which explains the success of this discourse about the global threat and its imminence. It is as if some people were pleased that something was happening in their lives and may happen again, as if they were finally actors (and not viewers) of their history (even as victims), as if this event of 11 September was creating some 'reality' or 'hyper reality' in relation to all these TV shows which are only for the 'others', as if now every American was really part of the spectacle of real life.

11 September 2001 is, then, to be seen as something radically new because it pre-figures the future. ${ }^{13}$ It is significant that most of the analysis and interpretations of 11 September are not oriented towards the past or even the present, but towards the future. It is less about what happened than about what next? The newness of 11 September is located in an explanation seeing it as the future of conflict and war, and as something that will happen again at an even more important scale. So, even if the prediction that the next bombing after 11 September would have many more casualties has not transpired, with Bali, Madrid or London, it suffices for the believers of this doxa to add 'not yet, not yet', with the disillusioned smile of the one who has the wisdom to know the future and who speaks to a novice.

In this doxa, no lesson from the past can be learnt. On the contrary, they are misleading. Previous experiences of terrorism are not useful. It is by checking the future and not the past that the understanding will come. Anticipation is the key word. The world goes global. The world goes with increasing possibilities of catastrophes (terrorism, global warming, nuclear accident, new viruses and, above all, a combination of these risks in a worst-case scenario). But what if one refuses the implicit consensus on the end of the state - and interstate - control, on the globalization of violence, 
on the vision of the future as a catastrophe? What if ones try to historicize and differentiate along different audiences the main narrative which leads to this idea of the merging of war and crime into a new hyperterror(ism)?

\section{Global terror or local event? Different audiences, different interpretations}

\section{The US perspective: a self-centred global perspective?}

From a US perspective, but from this perspective only, angst is there and destruction is projected as a fate. We can understand why they consider 11 September as a turning point. It was the first time since the war with English Canada and the so-called invasion of Pancho Villa of the city of El Paso for a couple of days in March 1916 that the territory of the US, part of the American continent, was under attack. Pearl Harbor was a shock but was remote from the country, and it is not surprising that the comparison that emerged spontaneously in journalists' comments was about this attack, thus creating a parallel with war. The transnational media 'Blitzkrieg', arguing the case that the attacks were not an odious crime but an act of war, was incredibly powerful and may have influenced the leaders. Furthermore, even if it was not the first time that US territory had been bombed by clandestine organizations, this time the scale was unprecedented. The idea that US territory was a 'sanctuary' was deep in the belief of the population, and even the military forces thought that only high-tech missiles or cyber threats disrupting critical infrastructures could seriously hurt the country. The artisanal work of the hijackers, combining three types of actions - hijack and destruction of a plane, vehicle hurtling into a place selected for maximum casualties, and voluntary death of the perpetrators - into one range, was below their 'radar'. For this military intelligence framed by the Revolution in Military Affairs, it was difficult to imagine that vulnerability was not related to a differential in technology and that their simulations of attacks were oblivious to the real practices of the clandestine organizations and were mimicking only their own vision of how to attack another country if necessary (Hermant and Duclos, 2006). The commission set up to understand how it had happened spoke of a 'lack of imagination', but proposed (paradoxically) to enhance technological intelligence, not to place it in doubt. So, the 'accreditation' by the highest level of state officials of the 'impression' of a radical transformation of the use of violence born that day, diffused by the mass media, has completely 'saturated', for at least six years, the sphere of communication at the interpersonal level and has blocked the possibility for other narratives to emerge.

Somehow, the gap between the idea of an absolutely new phenomenon and the very traditional response to go to an international war (without naming it that way) and reactions of anger, revenge and partly hate has 
been huge. As we will see, it has not created innovation but, on the contrary, regression to the most traditional habitus: hyperpatriotism especially (Heisler, 2001).

Nevertheless, US officials have a strong counter-argument. If, as they think, the situation of 11 September is radically new, if we live in a world under the threat of a global terror, we have to be aware not to judge it from an obsolete theory of political violence, and to adapt our knowledge to the event. They borrow the idea of Ulrich Beck, saying that the events of 11 September were not only the destruction of life but also the destruction of words and meanings (Beck, 2002a, 2002b). In a state of terror, the logic of survival obliges to revisit all together the ten commandments or the ten relations between the following: rationality and irrationality of the enemy; 'justified' fear and timing of the response; prevention as first strike and effective protection against a 'stealth' enemy; needs for emergency measures and long democratic debate; exception and rule of law; speed, secret and role of the presidency or of the administration and role of check and balance, control of proportionality of the parliament and courts; balance between security and freedom; national sovereignty and global cooperation; international law and efficient leadership at the world level; US citizenship and equality of human rights. ${ }^{14}$ The European specialists who try to compare 11 September with previous bombings are wrong. They do not understand the radical change and are 'old' Europe. They insist too much on continuity and, behind that, they want to give lessons to the US. Even if, before, the terminology of terrorism for clandestine organizations of minority groups using political violence was perhaps exaggerated, now the terminology of hyperterrorism, or at least of terrorism, makes sense to describe not all the previous actions of clandestine organizations, but this specific form of violence initiated by Al Qaida. The materiality of violence and the capacity of Al Qaida for mass killing is the proof of the future threat. War and crime have fusioned into hyperterrorism. Al Qaida did not hesitate to transform civilian planes into missiles and tried to kill the maximum number of people by mixing major crimes of innocents and techniques of war to impress and emulate other clandestine groups. ${ }^{15}$ By doing so, they knew they could not win a war, but they wanted to show the weakness of democracy concerned with the lives of innocents, to push the government to overreact through fear of mass destruction attacks, and to pursue their jihad locally by recruiting fanatical Muslims all over the world, but with two main targets - the US and Israel; Europe being marginal. ${ }^{16}$

This vision of a radically new event, merging war, terror and crime and destabilizing the old categories of what is war and what is crime, has also been largely developed in academic journals on terrorism and international relations. It seems that a cottage industry of self-proclaimed experts on $\mathrm{Al}$ Qaida and on terrorism in general (as they say) has used fear (and curiosity, a will to understand from the public) to develop a book market, 
filling the fear with even more fear to come and giving no explanation, except the propaganda of intelligence services and discourses which, in the name of protection, are playing with anxiety. More serious accounts of justification of this position 'to look forward and not backward' have been given. They have been often encapsulated into the idea of an exceptional period, justifying exceptional measures, and breaking from the rule of law and the traditional bureaucratic routines.

The question of the radical novelty of the materiality of violence is just, in my opinion, a convenient way to forget history and sociology of the clandestine organizations and their structural, strategic and logistical constraints, or do these experts, insisting on the unprecedented event of 11 September, have a point? Cornelius Castoriadis, has tried at the philosophical level, to address the question of the radically new and the possibility of a radical jump of the imaginary social significations, not derived from the past. But he was well aware that such an event is rare in history and he finds only one in Western history: the invention of democracy in Pericles' time. So, even if he considered that creation and novelty is a human specificity, he warned that, very often, this argument is de facto a strategy of power in order to declare that everything is new and then to impose new rules of the games derived from past interests. The global and the new are often there to cover the local and the old game of power, by a rhetoric trying to negate the historical context. Nevertheless, the debate about radical novelty is quite impossible to settle. Once open, it depends on specific ontology and sociohistorical framing of public culture.

\section{A non US-centred understanding of 11 September: localizing the relation of violence in space and time}

Even if I agree with the possibility of a certain form of novelty, as a European myself, I consider that the problem is nevertheless that these events were geographically and culturally localized, that to present them as global is a problem and that to present them as the birth of a doomed world, as a future of the world which cannot escape his fate, except by consenting to obey and to collaborate, is even more problematic. The attacks of 11 September spoke more to that place than to other places. The audiences were different and, if emotion was huge, it was not the same for the New Yorkers, the Californians, the Europeans, the Middle Easterners. Empathy has limits; suffering at a distance and compassion too (Boltanski, 1993). The four plane crashes were not 'global' and as such 'universally' subject to the same set of impressions and interpretations. Clearly these feelings have existed through the world coverage of the events. Messages of support came from broad swathes of governments and civil societies from other countries, including not only the future allies, but also the ones who resisted the Bush policy later on: France, Germany, Russia, Canada and many Arab countries. If the notion of 'new global threat' is still deep in the 
heart of the US citizen years on, it is not necessarily the case that it is in the heart of the European and even less for the Middle Eastern audience. They have a different sense of history and a different sense of place and duration. In their own trajectory, actions of clandestine organizations and of enemy states invading them are still strong in their memory. So, if the fear of the killing of millions of American citizens is anticipated and is repeated again and again by the neo-conservatives (but also by the democrats) and by some of the media (especially, but not only, Fox TV), this fear is quasi absent from Europe, even after Madrid and London. The narratives have diverged and, even when alliances have been set up to have the same policy, it is rare that the argumentation is the same. It is as true for those who were in favour of the Bush administration as for those who resisted it. It goes beyond ideology and policy or a so-called national culture. It has to do with this pre-crime attitude, with this belief in prediction and prevention, more accepted on one side of the Atlantic than on the other.

Tony Blair and Gordon Brown, as well as the other European leaders, have not developed such a relation with fear and prevention, even if they used the arguments. They understood how continuity in history was the way the mood of their population was framed. After the 11 March 2004 bombings in Madrid and 7 July 2005 attacks in London, life as usual was clearly the response of the population; less afraid, it seems, than their 'elites'. For Londoners, Madrilènes or Parisians, the idea of living with the possibility of being targeted by a hazardous bombing, killing 'at random', was not new at all. The Provisional IRA in London, especially in its fights against Margaret Thatcher, ETA Militar in Madrid, and the Ali Fouad Saleh network linked with Hezbollah and a faction of the Iranian government in Paris have set up a mind frame that includes the risk of this kind of violence. It is also the case in Italy, with the actions of left (BR), foreign (anti Jews) and especially far-right organizations (Ordine Nero, actions of Piazza Fontana and Bologna). ${ }^{17}$

The effects of the bombings of Madrid and London were not a 'new wave of terror', or 'of panic', as the media stated over-systematically. It was a will to resist to terror, to find the criminals and to understand their behaviour. ${ }^{18}$ These different attitudes are relevant of something more profound than a debate on terminology about novelty and globalization; it is the orientation of the response which is at stake. Is the response an effort to explain what happened or to anticipate the next case of violence in the future? And, if so, is it not a split between a criminal police and judicial approach on one side and monitoring the future through intelligence and proactive policing by military means on the other side?

In that regard, to see 11 September as the birth of a new era is then very specific to a certain strategic culture of a military elite and dependent of the historical trajectory of the US. The idea of novelty is related to previous experiences, and to a state of mind which is oriented either towards the past or towards the future. It is banal to state the obvious, but it is not 
so banal when, looking at political statements and academic works, so many of them just ignore or avoid discussing this point and jump to the conclusion that the destruction of the Twin Towers was a global event, with a global resonance and a common interpretation.

It was only a state of local fear in New York and Washington, extended through media empathy to the Western world. This state of local fear, experienced by the professionals of politics, explains better than the socalled global terror, the will of revenge, the 'wild, wild West' retaliation and the calling for a war (against evil).

Eventually, the governments were not paralyzed by terror, by the actions of Al Qaida. On the contrary, we saw a burst of anger, rage, pride and patriotism, far from the so-called interpretation of the psychological effects of terrorism, especially at that scale. The feelings on which George Bush and Donald Rumsfeld, and afterwards John Howard, Jose Aznar and Tony Blair, have played with or/and shared were not the paralysis of terror, but anger, even wrath, as if they were the fighting angels against the evildoers. In conclusion, the choice of a global war on terror on 14 September 2001 was not a necessity, or even a manufacture of fear, but a regression to the habitus of a certain group of political leaders.

The argument of global violence would not be the cause for a global counter-terrorism strategy but would be a consequence, a justification of it. The will to revenge and punish explains the argumentation, pretending that the 11 September attacks were unprecedented events for the US and the world and the date of birth of a new era.

The legacy of George Bush is suspended to the possibility of a new major attack on US soil. It may change with time. After years of success, or at least of convincing a majority of US citizens of his policy, now he is considered as one of the worst presidents ever. Assessing the relation between global violence and global 'response', global 'coercion' is certainly not straightforward. It looks too easy, either to accept any justification of policy by the argument of necessity to respond on the same scale as the violence and to reframe rule of law and habeas corpus for this reason - as well as to reframe, in an imperial way, the relations with the other states or to pretend that from the very beginning the professionals of politics in the US (and elsewhere?) were planning to extend their power and were driven by a politics of exception, as if they knew, from the beginning, the future and had the capacity to read it.

So, the discussion about the shape of the post-11 September world moves from a discussion about the attacks and their effects to the policy to counter them, to prevent new ones, seen as unavoidable, and to the effects of this policy of revenge, of punishment, of fear of the dominant actors of losing their position. Maybe the key date for an historian is, then, not 11 September, but three days later, 14 September 2001, when Congress authorized the president 'to use all necessary and appropriate force against [...] those organizations, or persons he determines planned, authorized, 
committed or aided the terrorist attacks that occurred on September 11' ${ }^{19}$ It is from this date, from the choice of this form of 'response', that the world we live in has been reframed by the dominant leaders and the professionals of security as a world under threat, as a world facing catastrophes, as a world where responsibility goes hand in hand with speedy actions, emergency powers, special powers, war powers covering the practices of both coercion and surveillance inside and outside the country. And the legacy of this period of policing insecurity by prevention is more determined by that day of 14 September than by the attacks of 11 September.

The relevant questions are then less related with the specific story of $\mathrm{Al}$ Qaida and its followers - their capacity or not to create an alliance all over the planet of the different clandestine organizations struggling against the governments in place and their capacity to build a nuclear bomb or to sneak one - than they are related with the framing process of this violence as global and justifying a policy of prevention by the most powerful actors of the world. The two faces of the problem are important, but the contemporary impact in our lives of the changes of policies - or the justifications of previous policies demanding harsher coercive measures - is as much dependent on the second face as the first one.

The logics of suspicion and exception or emergency have not been plotted by the agents in charge of security, contrary to some continuous narratives about the faking of 11 September, but these logics have emerged from a certain way of understanding the relations between war, violence, security, protection rooted in a certain vision of a world order, and a specific history of the global disorder or global insecurity largely pre-dating 11 September. The instrumentalization by some players of the opportunity to advance in the agenda some reforms has certainly been there from the beginning, and it will be demonstrated throughout this book, but it is politics as usual. So the manufacture of a politics of fear has to be distinguished from a plot or a manipulation theory. What is central is to understand if 14 September has been a great sovereign moment chosen by the Bush administration to declare a form of exception, supposedly reframing the rules of liberal democracy under emergency, as many critical authors have assessed, or if it has been, in a more mundane manner, a regression to a habitus of control and coercion of agents, who cannot accept the very idea of having to cope with hazard, violence, ambiguity of meanings, and destabilization of the images of themselves as 'rulers' that it implies.

What did the president do with these powers once they were given to him? Why did Congress delegate so much of its own power? How was it possible for the administration to read this declaration as an unconditional agreement to go to war, to detain persons internally, and later on to mock the protest of the segments of the population (or experts) that were in favour of coercive actions against Al Qaida but not in favour of a war in Afghanistan and a plan to extend it to Iraq? The rare pieces of research of 


\section{D. Bigo}

these first days and months, now that we have more access to information that was kept secret during the first mandate of George Bush, converge towards the idea that the policy was not a result of discussing rationally different options, and even less a great decisionist moment, balancing the advantages and inconveniences of declaring a state of exception. The policy was simply lead by the overwhelming fear of new attacks on that scale, by a certain vision of the future as the coming end of the civilized world, generating such angst that no response other than war was seriously discussed by the administration. As put brutally by one of the people involved in these meetings, 'It was more thinking with guts than with brain, and the brain came after to justify the initial mistakes. ${ }^{20} \mathrm{~A}$ habitus of being the dominant political actor, a strategic culture of dominance in war, a long-standing idea that violence at least from the end of the Cold War has evolved and is coming from transnational networks of individuals potentially within, the idea that technologies of surveillance exist but have been under-exploited, and the strong beliefs in both the worst-case scenario of nuclear terrorism and the solution to prevent it by anticipating and simulating this future in order to know it, if perfect information of the present is provided: these have all been played out, even without thinking about them.

Remember how the first discourses were 'Texan' and patriotic. They exalted patriotism and this patriotism was converted into a thirst for revenge to erase the shame of having been attacked in the homeland; a yen to fight which spread across the world as something not only understandable, but legitimate. The interpretations of the attacks were framed by a military spirit in search of a target against which reciprocal violence would be justified. The only possible response to such a violent deed was allegedly another act of violence to appease the suffering of the victims and the shame of the military apparatus, plus the desire to punish immediately by killing those who ordered and plotted destruction on such a level, clearly targeting civilians and third parties not directly responsible for any crucial US foreign policy-making. ${ }^{21}$ Launching immediately a territorial war against Afghanistan was a way to show the strength of the country and to restore the image of power, playing also with the feeling of taking revenge and of deterring a new attack. It was not a discussion about emergency powers, about the necessity of a Roman dictature, about a reframing of the constitution. It was about mobilising energies.

Unanimity was the response to atrocity. And unanimity was used to mobilize the country against an enemy that the military could tackle. An enemy had to be given shape beyond the bodies of the suicide bombers. It took the form of a list of 'rogue states' that sponsor terrorist networks and that are designated as enemies of the US, a list which was redrawn up in forty-eight hours to include, for the first time in twenty years, Taliban-ruled Afghanistan. But it was not so much instrumental. The great questions of the moment of decision, of the 'why' such a decision was taken, disappear as 
virtualities not realized. They were not asked. So, the philosophical questioning is at pains to give a serious account of what has been done. It is more often a pretext to reconstruct a great narrative and a shared sense with the actors of the novelty of the moment than an accurate description of their practices. If we look at these practices, it was not a choice to engage into this path of an unconventional war against an unconventional enemy; it was just evidence shared by everybody. The questions for analysts are not when, why and how a Schmittian moment of decision concerning the state of exception was taken by the Bush administration, and the possible instrumentalization of the attacks by an initial group of actors; instead, they concern the complete lack of questioning and the strength of the doxa of these groups of professionals of politics, of military, of intelligence services, of police services, of customs and immigrations services, whose differences are so striking and struggles for distinction so important, yet who shared this normality to go to war and to put large segments of the US population under surveillance and interrogations in order to prevent new attacks from happening.

That such a war and such a surveillance emerged as a solution to put an end to the transnational political violence of this so-called new age of hyperterrorism and that, initially, nobody countered this evidence by saying that it would be a way to create more problems and more violence, in these elite circles, is certainly a question which creates more unease than the one of the moment of exception; it obliges to think about consent, about the 'chains' of complicity of large segments of the population, about democracy, and cannot be restricted to a manufacture of fear by a group of neoconservatives, pushing an agenda of exception and restriction of freedom or, in a more subtle way, as a structural tendency of the contemporary democracies to decide about bare life. The question of the doxa created by the regression to habitus is also a broader question than the one on the state of exception, especially now, after the end of the Bush period and the policy of Obama to limit the exception, but to continue with the necessity of war (in Afghanistan) and of surveillance (apology of CIA) against terrorism. So, let us be clear: the choice of war has not been seen as a choice, or even as an exceptional moment driven by terror, but as the only way, as a 'necessity'. War, in that situation, has been evaluated as the 'normal' response, not as an exceptional one. The discussion set up by critical security studies as a critique of the exception certainly has to be revised.

\section{Notes}

1 On the impact of image in terms of insecuritization and the differentiation by audience, see the different communications and articles of Lene Hansen and Michael Williams in 2001. We will come back to this differentiation by audience. See also their books - Hansen (2006) and Williams (2007).

2 For a brief and precise account of what happened on 11 September 2001, see Guild (2003); Brouwer et al. (eds) (2003); National Commission on Terrorist Attacks upon the United States (2004). 
3 And, as a significant anecdote, the use of the term 9/11 or September 11 radicalizes in the writing the difference between US and EU perspectives as the databases of articles create often two different sets of articles dealing with the same event ... not to speak of the number of persons in Europe who already speak of the '9th of November'...

4 Heisbourg (2001, 2002); Delpech (2002); Adler (2002); Garwin (2002); Megret (2003); Glucksmann (2004); Allison (2004).

5 We conducted a series of interviews with US analysts from the CIA, State Department, Pentagon, FBI and White House in 2002, 2005 and 2007.

6 Aron (1958); Gardner et al. (1970); Gamson and Modigliani (1971); Poirier (1982); Cavell (2004); Catherwood and DiVanna (2008).

7 However, the relation between the anthrax scare and Al Qaida is not obvious. After four years of intensive research by the FBI, it is still highly problematic to correlate anthrax with Al Qaida and it seems that this came more from within the US military establishment in an effort to promote research budgets on this topic than from Al Qaida. A suspect has been arrested and released, but FBI agents complained about pressures. The possible trial is in a juridical limbo for the moment and it seems no one is willing to accelerate the investigations. Interviews with an FBI agent in 2004 and press releases.

8 And it is why it was so important, after the failure of the link with anthrax, to find a new link. We have seen weak explanations of Al Qaida working on atomic bombs and chemical weapons from the caves of Afghanistan and plans on computers found on Peshavar market, but nobody seriously believed this 'discovery'. And it is why the connection with Iraq was such a crucial argument, not only for the decision to go to war in Iraq, but also for all the discourse about 'global war on terrorism'. The Foreign Affairs dossier prepared to convince the UK parliament, showing inside the palace of Saddam Hussein the location of chemical plants, insisted hugely on the link. We still do not know if it was a deliberate lie - and, in that case, why - or a 'no risk policy in case of doubt', a 'shoot to kill policy' at the international level in the name of prevention. Do we still have to wait for evidence of Iraqi arms of mass destruction, or not? Time passing, it seems, at least, that we can understand why the argument before the war was not at all regime change, but to find these arms, and why it was changed afterwards with a propaganda and Newspeak resembling Orwell's novel 1984. It was certainly the beginning of the disaffection of the public for the neo-conservatives, even before Hurricane Katrina and the credit crunch.

9 Hogan (2006). See, among the most interesting, Marco Ferreri, La sémence de l'homme (1969).

10 Washington Post, 20 September 2001; Washington Post, 6 October 2001; CNN, 6 November 2001; www.cnn.com/2001/US/11/06/gen.attack.on.terror/; www.cnn.com/2001/US/09/20/gen.bush.transcript/.

11 References to Armageddon are common: Brackett (1996); Rensselaer (1998); Martin Schram and Ted Turner Documentaries (Firm) (2003). Some authors have made money from writing survival handbooks in case of mass terror or have surfed on the wave of fear with a sense of humour: Sam Scheinberg (2001); Joshua Piven and David Borgenicht (2001); Elizabeth Terry and J. Paul Oxer (2003).

12 Zaki Laidi (2002).

13 The US perspective is shared by many thinktanks, including European scholars (see supra).

14 This list of ten problems or ten new imperatives, depending on which side people were sitting, comes from the heated informal discussions between the US administration and some of the EU specialists. Quite unknown but active from the beginning of 2002, the Berlinger discussions (see Le Monde 18/06/09, email 
Colombe) have subsumed the different perspectives and insisted on the fact that many groups of NGOs and professionals inside the US were on the side of this 'European' vision, and that some key leaders of Europe and the different NATO and US networks of friends were convinced by the US administration argument of a new era. (Interviews with high-level representatives of the US administration and some EU experts.) It is important to note that often the arguments were mixed up, put in a different order and diffused only partially in other circles.

15 These arguments come from interviews of officials. They were the same in 2002 and 2005 , but not in 2007.

16 To reject this idea, which is 'globally accepted', is by itself either naive or ideologically driven by anti-Americanism and pro-violent behaviours which are anti-democratic. Democracy comes with the capacity to think radical novelty, not to repeat history.

17 It is, to a lesser degree, also the situation in Germany with Baader Meinhof, in Belgium with CCC, in Greece with 17 November, even if the population there was not a primary target of violence. It is interesting to know that the European countries that feel more like the US (the Netherlands, Sweden, Portugal, Finland, Poland and Hungary) are the ones that do not have a past of political violence by clandestine organizations.

18 Some New Yorkers felt the same, but they were not listened to by the media, who preferred to show sorrow and grief.

19 This idea comes from a discussion with Florent Blanc - Resistance in the time of unanimism in the US, Ph.D. thesis, Northwestern University, Sciences-Po Paris (2009).

20 In the same interview, the person coming from a top-level position in the political analysis circle added,

It was like in a detective story, it was a spiral where the brilliant murderer had to mask the first murder by doing other ones, and know he left behind more and more clues ... so the secret, so winning time ... many people from day one realised they were engaged in this path against the law.

21 That is why the symbol is the World Trade Center and not the attack on the Pentagon, but the interviews show how the military from the Pentagon remember well how they were also a major target. 


\title{
7 Revolution in police affairs ${ }^{1}$
}

\author{
Salvatore Palidda
}

\section{Introduction}

Over the last twenty-five years, research on the police conducted in the world's richest nations has focused on important changes to the institution and its practices. ${ }^{2}$ Among these various changes, the three most significant regard the consequences of technological innovations (and in particular socalled 'postmodern' controls), the development of the privatization of security, and the hybridization between police and military matters, which reaches the point of implicating or absorbing social prevention and assistance, in a not dissimilar way to humanitarian wars (see other chapters). However, there has yet to be an in-depth, coherent analysis of such changes at the same level as, for instance, the Revolution in Military Affairs (RMA). On the premise that changes always take place through continuity and adjustments and rarely through true breaks, in this text I propose to examine the Revolution in Police Affairs (RPA) by first discussing the main theoretical and methodological aspects indispensable for an analysis of the police forces during the transition from the democratic liberalism of the New Deal and the 'thirty glorious years' of the post-war period to the management of the neo-liberal/neo-conservative disorder of the current era. This can also be seen as the shift from the 'first' to the 'second great transformation', or from paternalist/pastoralist governmentality to a form of management that is merely interested in the bic et nunc (the here and now), the prosperity of the strongest and not in posterity - in other words, the future of society. It is in this general context that it may be possible to better understand the rise of the violent management of disorder and the concomitant weakening of a negotiated and peaceful governmentality. However, the police's apparent inability to readily adapt to the dynamics triggered by the exacerbation of fears and insecurity hinders the triumph of a 'zero tolerance' that excessively reduces the spaces for peaceful negotiation and establishes a level of security that is ultimately too unstable. Having always been accustomed to switching between the carrot and the stick, and between violence and mediation, the police are unable to abandon informal and sometimes unlawful relations with the various 
members of local society because it cannot assume the form of a military force at permanent war with a particular social group. This tendency also appears to heighten cases of violence, misconduct and corruption. This leads to disorder within the police itself that is reflected in the distance between a component that places its faith entirely in new technologies, the postmodern panopticon, and violent methods that even include torture, and hence in the myth of the asymmetry of power and strength, and another, currently minority and marginalized component that, instead, would prefer to modernize the traditional management of disorder. As I shall seek to illustrate, the apparent victory of the neo-conservative revolution in police affairs appears entirely ephemeral precisely because - unlike military forces - it is an institution that is embedded in society and cannot survive according to a logic of permanent war.

\section{The management of disorder}

During the 1960s and 1970s, various authors, including Egon Bittner (1990), who is widely regarded as the father of the sociology of the police, were convinced that social peace had been achieved and that, in the future, there would no longer be a need for the police as an armed wing of the state, and hence the holder of a legitimate monopoly of violence (see Brodeur, 2001). Moving beyond the evolutionist approach of Norbert Elias, Bittner's thesis was drawn from an interpretation of Max Weber's theory of the state as a supra-ordered, absolute and distinct entity from society.

This interpretation did not differ greatly from Foucault's analysis (especially in Discipline and Punish) where the idea of a rational, perfect power - the panopticon - is intertwined with that of biopolitics as the capability of total dominion over everyone and everything (Valverde, 2008a, 2008b). In contrast, and adopting an interpretative interactionist perspective, ${ }^{3}$ it would appear more helpful to think of the state as the political organization of society, which is the result of the interplay between a number of social institutions that cooperate, compete or are in conflict with each other. As well as private organizations (like businesses or Mafia-type associations), public institutions and others regulated by codified norms (such as the family, health service, schools, transport, justice, police and prisons) are constantly shaped by the interactions between their constituent members, the leaders of each social part and the particular social frame in which they are situated. While it is true that some institutions or certain parts of them (for example, high-ranking officials in ministries or in the administration of justice) might appear 'autonomous' or unconditioned by the interactions between the 'top' and the 'bottom', at the same time society cannot function (in other words, be governed) well or badly without the continuous experimenting and adjusting that members of each institution are forced to perform on the basis of their exchanges (peaceful 
or otherwise) and the necessary mediations with the most influential social subjects. Obviously, the latter are the strongest actors in dominant social circles that are more numerous in democratic countries. Thus, even judges, who in theory should be less influenced by interactions with the local population, remain subordinate to the game of circular interactions with politicians, moral entrepreneurs, police officers, the media, opinion leaders, representatives of professional categories as well as 'citizen' associations that are able to make themselves heard in public space (such as those that campaign around the issue of urban security).

This situation is even more evident in the case of the police, and has in fact been described by some authors as a form of street-level bureaucracy (Lipsky, 1971, 1980; Evans and Harris, 2004). While such an expression appears to distance itself from the notion of the 'armed wing of the state' with its rigid (if not dogmatic) invocation of the 'legitimate monopoly of violence', it still confirms the thesis of the structuring of a state (which is at a superior level) as something useful to penetrate society. This leads one to think of the police as synonymous with the order that characterizes a state governed by the rule of law (regardless of whether this is reactionary or democratic), and hence as an organization assigned to carry out surveillance and punishment in accordance with norms that, formally, everyone must respect. However, this idea of policing has never been effectively translated into concrete reality. This idea recalls the traditional paradigm in human sciences that, from Plato and Aristotle to Durkheim and contemporary theorists, has considered the history of society as just a series of successive phases of order and disorder. According to this model, the opposite of order is nothing more than a temporary and almost ephemeral state, for order is always destined to prevail thanks to the will, strength and ability of dominant actors, including the police, the administration of justice and, if necessary, the army.

Contrary to this linear and mechanistic vision, the history of societies reveals that there has always been a coexistence of disorder and order, war and peace, conflicts and mediations (Dal Lago, 2005). Thus, if one adopts this interpretative approach, it can be established that the survival of society depends on actors or social institutions which seek to govern the continuous coexistence of these two trends. To be more precise, this consists in repeated attempts to govern in 'the best' or 'least bad' way possible (Gleizal, 1985) through specific and continuous experimentation, even if this often meets with more failure than success, especially due to the fact that it is not undertaken with much practical sense or the utmost effort to adapt without prejudice to different situations. This is the art of governing the disorder that society never ceases to reproduce, both because human beings are all different at the same time as being characterized by irrationality and rationality (as Max Weber has shown us) and because they are always inevitably in conflict as a result of the unequal distribution of power and wealth. In reality, the government of society is not that elected 
by parliament, which seeks to administrate through the various ministries to which different institutions (schools, health service, transport, police, justice and so on) are attached.

Actual government is shaped by the outcome (successful or otherwise) of the game of interactions between these institutions and those expressed by each sector of society when such an outcome allows for the concrete government of disorder. Hence, in certain cases, the institution that appears best able to govern may in fact be the police and, on some occasions, even Mafia organizations, rather than other institutions.

A social institution's ability to participate in the concrete government of society (and, more importantly, to appear to be the key element in that activity) does not only rest upon a delegation from a higher authority or its own physical strength, but primarily on its ability to be recognized by a sizeable part of the society it governs. As Foucault argues (2004a: 341-370), power is not solely surveillance and punishment, but also paternalist or 'pastoral', in the sense that it takes care (in its own way) of people, and may even seek to provide happiness (as various theorists of police science, such as von Justi, Turquet de la Mayenne and Delamare, suggested). Thanks to Foucault (but also Garfinkel, Goffman and H. Becker), it can be better understood how, particularly for the police, this consensus translates into a sort of 'everyday plebiscite' that exists in every moment and every situation. It is as such that the need prevails on the part of the police to be recognized by a substantial part of the population as the social institution that best governs the permanent disorder produced and reproduced by society, not through the simple translation or adaptation of codified norms, but thanks to case-by-case experimentation. In doing so, police officials (who are inevitably informed by 'practical knowledge') continually re-evoke the classical theory of their institution, even though the vast majority will have never heard the names of Guillauté, Delamare, von Justi, Turquet de la Mayenne or other contemporary experts on the police. On the contrary, officers learn their trade primarily, if not solely, on the job or by partnering their elders, and continue to be subordinate to input from above: the government, the ministry, and the hierarchy in general. But it is especially the relationship with the local population that is decisive, insofar as it acts as the source of a real everyday plebiscite, which is obviously implicit, but nevertheless at times highly visible in the local and national media and in 'popularity' polls.

This is not just because the media has become powerful in democratic countries (thanks, in part, to the impact of opinion polls, the transmission of perceptions of insecurity and victimization surveys ${ }^{4}$ ), nor because the politics of fear, the exarcerbation of insecurity and the 'securitarian frenzy' has exerted considerable pressure on police forces. The 'everyday plebiscite' consists in the possibility of being able to remain on the street amidst its multiple social relations, as the social institution that is recognized by influential social actors, and as the main holder of responsibility for the 


\section{2}

\section{S. Palidda}

management of disorder. This means that members of the police force are necessarily obliged to turn a blind eye, let certain things pass, contravene norms, tolerate or even commit offences to guard over and punish those who cannot or do not intend to respect the rules of the management of disorder ('undesirables', those condemned by the majority of the included sections of society or subversives). In this sense, Foucault's pithy phrase 'la police est un coup d'Etat permanent' (2004a: 347) has to be understood in terms of a sort of continuous redefinition of the state, whereby the management of permanent disorder is indispensable for its own survival and that of the police. Hence, we are not looking at an institution structured from above (the state) that descends towards the bottom (society), but rather an institution that is situated in society and needs to continuously invent forms of mediation between this level and the higher level of the political organization of society.

As I argue below, the 'neo-conservative revolution' tends to destroy precisely the form of management that seeks a balance between the stick and the carrot, exemplary punishment and tacit mediation (letting things pass), and between tightening and loosening the web. The neo-conservative breaking of this balance arises out of the three innovations mentioned at the beginning: new technologies, the hybridization between the police and the military and the asymmetry of power, and thus the illusion of a violent method of management.

\section{The proliferation of panopticons}

In his famous article 'Postscriptum sur les sociétés de contrôle' (1990: 240-247), Giles Deleuze provides some important insights about the future of social control and sets himself the task of updating Foucault's work. This brief text has become a sort of faitiche (Latour, 1996) for those many researchers drawn to mythicizing the 'postmodern panopticon'. ${ }^{5}$ In effect, rather than developing Deleuze's valuable insights, they exalt its more questionable part. In the text, ${ }^{6}$ Deleuze recalls Foucault's vision of the history of power that, unfortunately, is quite linear and schematic:

Foucault located the disciplinary societies in the eighteenth and nineteenth centuries; they reach their height at the outset of the twentieth. [...] But what Foucault recognized as well was the transience of this model [a rather questionable term, I would argue!]: it succeeded that of the societies of sovereignty [...] But in their turn the disciplines underwent a crisis to the benefit of new forces that were gradually instituted and which accelerated after World War II: a disciplinary society was what we already no longer were, what we had ceased to be. [...] These are the societies of control, which are in the process of replacing disciplinary societies.

(Deleuze, 1992: 3) 
And this is how he described the controls:

A common language for all these places [of enclosure] exists, [but] it is analogical. One the other hand, the different control mechanisms [have a numerical] language. [...] Enclosures are moulds, distinct castings, but controls are a modulation, like a self-deforming cast that will continuously change from one moment to the other, or like a sieve [unfortunately, this too is a term that leads to believe in the 'postmodern panopticon'] whose mesh will transmute from point to point.

(Ibid.: 4)

Deleuze continued by providing some concrete examples that corresponded to the new controls of the present (although the new technologies have since developed much further, they have yet to extend to generalized social control, at least not in all European countries).

As some authors have clearly illustrated (see Heilmann), the idea of a single 'big brother' - in other words, a solitary panopticon (or Leviathan or empire) - would appear false. On the contrary, there are many 'big brothers' that correspond to different parts of the political organization of society. The enormous deployment of 'postmodern' controls can also be seen to lead to an implosion, that is, to their obstruction or might enable new forms of resistance or opposition. In other words, the idea of the disciplinarian society as a 'universal' concept does not exist (and it would seem scarcely useful to conceive any research subject in such terms). ${ }^{7}$ The changes in the various powers, controls, police practices and their consequences can be more satisfactorily understood if one thinks in terms of the interiorization of the discourse of power by the dominated parties. ${ }^{8}$ Let us therefore seek to comprehend better the changes brought about by the neo-conservative revolution in police affairs.

\section{The neo-conservative transformation of the police}

The neo-liberal/neo-conservative developments that commenced in the $1970 s^{9}$ led to a destruction (or disorganization or de-structuring) of the social set-up that was not as creative as Schumpeter and other liberal democrats, such as Keynes, Polanyi, Galbraith and Mills, imagined..$^{10}$ The dominant neo-liberal trend that neo-conservatives have managed to impose does not, in fact, aim at creating a new order such as the one envisaged (but only partly pursued) during the New Deal and, above all, the 'glorious thirty years' of the postwar period. The 'neo-conservative revolution' from the mid-1970s onwards exalted the asymmetry of power and strength between the dominant and non-dominant. This nurtured the illusion of being able to impose almost anything at any (human and social) price, without the fear of popular revolts or revolutions because the erosion of public action by non-dominant elements appeared to have been achieved. ${ }^{11}$ 


\section{S. Palidda}

Thus, the powers did not pursue the creation of a new stable and peaceful order that had been augured in the past by liberal democrats. In fact, the tendency was towards a sort of dominion of permanent disorder through force, postmodern controls and the active participation of 'zealous citizens' who identified with this mode of domination. The rule of law was eroded and dismantled, as were the rights acquired by workers and welfare in general, while privatization tended to triumph everywhere in the name of the maximization of profits. Obviously, the state did not disappear, but state institutions tended to have the same status as private ones. ${ }^{12}$ Today's state has become an actor that functions according to the same logic as any other private actor. This means seeking profit at any cost and avoiding all spending that does not procure financial benefits for the future of society. The approach to running public services (health care, transport, schools, and even the police and justice system) tends to reflect the logic underpinning the market and that of profit at any cost and above everything else. The confusion between public and private that occurred during the Bush administration (but also in almost all other so-called democratic countries) and the subordination of the public to the private sector in security matters are just some of the most striking recent examples. ${ }^{13}$

It is important to observe in the field of security management how a part of society, often a minority even if represented by the media as an unquestionable majority, has interiorized the discourse of neo-conservative power, just as the majority of judges, police officers, doctors, psychologists and teachers had always done in the past. In other terms, zealous citizens the 'included' - actively participate alongside public and private operators in the management of disorder that above all aims at a violent social surgery, to the point of turning those excluded into a sort of 'surplus humanity' (Bauman, 2004; see Rahola, 2003), which, like toxic waste, is difficult to dispose of. ${ }^{14}$ The irredeemable and rejects are those who represent the human surplus for which nobody is prepared to pay assistance and which dominant opinion asks to get rid of as far away from one's home as possible, as if they were rubbish or toxic waste. This trend is marked by a break in the balance between (public) social prevention, police prevention, repression, penal treatment, and social rehabilitation and reintegration.

One of the most flagrant examples of this is the substitution of the street educator with video-surveillance, which mirrors the more general attempt to replace social prevention with so-called police proactiveness, often by resorting to different types of police auxiliaries. All of this is accompanied by a discourse about the development of prevention that aims to reduce the 'perception of insecurity', even though what is actually produced is a continuous increase in repression and incarceration, in spite of a decrease in all forms of criminal offences (Palidda, 2009). The upshot of it all is that this does not reduce fears and insecurities, but ensures the permanent reproduction of the short circuit between fears, insecurity and securitarism that ultimately produces an erosion of political action that bolsters consent 
for zero tolerance. The reduction, elimination or subordination of social workers to police activity thus destroys the division between social prevention and police prevention with the resulting pressure for an increase in the repression of any behaviour or presence that is deemed deviant by zealous citizens.

Another example of how the neo-conservative management of street disorder leads to the creation of an imbalance between social prevention and repression/punishment that in turn favours the violent management of disorder by the police is the case of drug addicts. Social and health services that deal with addicts have been partly dismantled or reduced to a mere presence, while their staff is chiefly made up of temporary workers on miserable contracts, who are therefore forced to work predominantly for private centres that obviously only take care of addicts from families with medium-high incomes. As a result, poor drug addicts are thrown back onto the street, where the police will often ignore them, only to end up organizing periodic round-ups to try to placate the protests of zealous citizens. Meanwhile, social and health workers or street educators appear ever more compelled to become embedded - that is, to work as police auxiliaries. This gives rise to a number of social groups organized around the question of security which comprise zealous citizens, embedded social workers, officers from police forces, magistrates and journalists who are convinced that they will work their way up the professional ladder thanks to zero tolerance. These are flanked by pollsters who exacerbate the so-called 'perception of insecurity', insurance companies that sponsor them, entrepreneurs from the security business sector, private police agencies and, finally, political entrepreneurs (and various aspirants) in the government of fear who reap and nurture the consensus that is subsequently produced. The permanent social surgery and ethnic cleansing through the racist criminalization of immigrants and gypsies (or, as it is usually known, 'racial profiling', cf. Harcourt, 2008) produce a continuous overcrowding of prisons. Despite a fall in all types of offence, there has nevertheless been an increase in the number of arrests and prisoners, and in the amount of public and private spending for security and insurance policies, which further exacerbates fears and, in turn, the demands for zero tolerance (Palidda, 2009). At this point, the frame dubbed by Simon (2007) as the crime deal begins to take shape; a frame in which the enemies are not political opponents, but a sort of new 'biological threat', and which appears to justify racism as the 'condition of acceptability of putting someone to death', not 'in a society of normalization' as Foucault (1997) once argued, but rather, within the frame of permanent wars (against terrorism, rogue states, the Mafia, 'illegal' migration, insecurity and acts of urban incivility) that alternate with ephemeral truces.

The neo-conservative success has thus led to a transition from the New Deal to a management of society that tends to use violent methods themselves as a source of profit. ${ }^{15}$ There is no interest in stability, social peace, 


\section{S. Palidda}

progress and democratic development - in other words, in posterity, which, as in the case of the youths from the French banlieues or English inner cities, appears inconvenient and consigned to the impossibility of a secure future. The exacerbation of fears and insecurities, the falsification of the escalation of crime and acts of incivility, particularly by minors and youths, serves the 'tautology of fear' (and thus the consensus), and hence the (provisional) social cohesion against the enemy of the moment (Dal Lago, 1999a). The intensification of intolerance towards youths (not just in England) is perhaps the aspect that most clearly illustrates how the neoconservative management of disorder despises posterity and reveals its inability to effectively govern society, as is the case of parents and adults in general who have difficulty in their relationships with minors and adolescents and resort to violent dominion. Greater repression and penal treatment, more resources for the 'postmodern Leviathan', a greater sacrifice of liberties and rights in the name of security, for the sake of protecting the real or imagined privileges of included citizens in dominant countries: these are the recipes that are imposed, which for police forces translate into a rise in violent repressive activity (the continuous persecution of gypsies, immigrants, marginalized people, demonstrators, football fans and even gatherings of youths).

Within this frame, a constant slippage occurs from the discretionary powers of the police towards discrimination and free will, and hence the racialization of the targets of much of public and private, local and national police activity. It is in this context that there has also been a noticeable increase in the number of violent acts by the police bordering on abuses of power, corruption as well as tolerance for the same sort of violence against the excluded that is inflicted by zealous citizens, racists and neo-fascists.

The continuous reproduction of numerous unlawful conducts by police officers across Europe has been documented for several years by human rights organizations and research (among others, see the Amnesty International annual reports, Statewatch and Liste de diffusion-Etat pénal). At the same time, it should be noted that those responsible for such events often enjoy impunity or even promotion, similar to the treatment granted to perpetrators of torture in different theatres of war or police operations. ${ }^{16}$ Moreover, it is emblematic that victimization surveys never record violent crimes committed by police officers, just as there are no statistics about such offences (Palidda, 2009).

Another consequence of this shift towards the violent persecution of the excluded is that the police are removed from many of their institutional assignments and responsibilities: the fight against tax evasion and unauthorized building, checks on different economic and commercial activities, controls on waste disposal, safety in workplaces, safeness of products, and the compliance with environmental norms, as well as the fight against organized crime. ${ }^{17}$ The result is an increase in underground economies, tax evasion, work-related injuries and diseases, pollution and the production 
of dangerous goods. As such, even more real insecurity is created, only to be concealed by a dominant discourse about insecurity and fear, which is blamed on the excluded who therefore must be persecuted.

\section{Conclusions}

The strong pressures on police forces to adopt a violent approach to the management of disorder risk upsetting the role that they should exercise in the government of society. This role cannot be characterized by the logic of a permanent war, but rather by the necessary search for a social peace that is indispensable for posterity. The police's hybridization with military logic and practices, the privilege afforded to new technologies alongside the loss of traditional savoir faire, the priority for an affinity with the postmodern controls industry and the advancement of careers that are closely bound to the escalation of zero tolerance are all aspects that appear to be destined to lead the police to a serious crisis and to perhaps provoke conflicts between postmodern police officers (who are merged with soldiers and security contractors) and others who simply limit themselves to modernizing, moderately and in peaceful ways, the traditional government of disorder. The majority of officers 'drag their feet', following those in command, just as they have always done. The neo-conservative phase is probably destined at some point to end, but the repercussions will be felt for a long time. It also seems rather illusory that we may be heading towards a new New Deal (as Obama's victory seems to have led some to believe), but it likewise seems impossible that different types of power at a local, national and worldwide level can claim to govern without a search for a balance, and hence for mediation.

Translation by Yasha Maccanico and Nick Dines.

\section{Notes}

1 This text reflects and develops on the findings of research that I have carried out from the 1990s to date, particularly in the context of the Italian research and European projects (Migrinf, Elise, Challenge, Crimprev and Ramses2).

2 Among the first authors to study these changes were G.T. Marx (1984), Birnbaum (1985) and Christie (1993), as well as contributions to the magazines Cultures \& Conflits, Surveillance \&o Society, Déviance et Société, Conflitti globali (see Bibliography).

3 The main theoretical and methodological references of this interpretative and analytical perspective are Foucault's work, a number of propositions by Max Weber, as well as those put forward by Garfinkel, Cicourel, Goffman and Howard Becker.

4 Victimization surveys almost always ignore the people who are most liable to be victims of abuse, violence and offences (for example, Roma people, irregular immigrants and, in general, victims of crimes committed by members of the police force). As such, the surveyed victims are only 'included' citizens, while those identified or alleged to be 'perpetrators' are primarily the 'others' (see Palidda, (ed.) 2009, 2010). 
5 This myth seems to correspond with that of the 'pensée unique', the 'empire' and the 'multitudes'.

6 This chapter, which first appeared in L'Autre Journal, no. 1 (May, 1990), is included in the forthcoming translation of Pourparlers (Paris: Editions de Minuit, 1990), to be published by Columbia University Press.

7 Resorting to 'universals' is obviously more reassuring than agnosticism, namely, the idea that all interpretations are subjective. For the Foucauldian critique of the use of 'universaux', see Veyne (2008) and Harcourt (2008).

8 I do not intend to misrepresent the reference to Foucault and particularly his theory of biopolitics that, obviously, must not be mistaken with psychologizing approaches.

9 Obviously, this is not the same neo-liberalism that Foucault (2004a) writes about in relation to Gary Becker and others.

10 This must be distinguished from those who can be termed the grandchildren of Tocqueville, who advocated the massacre of Algerians resisting French colonization, namely, the theorists of 'postmodern' oxymorons such as 'humanitarian war' or the justification of torture. This aspect of Tocqueville is still not well known among the European mainstream, with the exception of Todorov (1988) and, more recently, Le Cour Grandmaison (2005).

11 This is in spite of the dreams of the antagonistic multitudes, 'global civil wars' or other (tragic) pleasantries espoused by a few anti-globalization activists.

12 The strength of this trend depends on the country and circumstances, and is also accompanied by counter-trends, as was visible after the financial crisis in 2008 that caused some people to shout about the return of the state and even Marx.

13 On this matter, the Italian case risks going down in history not only due to matters concerning Berlusconi (the richest man in Italy, thanks to a rather shady financial past), but particularly because of a proliferation of cases of abuse of office by private interests in the public sphere (the scandals of Banca d'Italia, Parmalat, Cirio, etc.). Among others, the most revealing is the case of Telecom's secret services that went so far as to subjugate part of the state's secret services (see Giannuli, 2007; Bigo et al. (eds), 2008). Moreover, Italy is configured as an exemplary case of 'anamorphosis rule of law', namely, the continuous transition from the legal to the illegal until the criminal and vice versa (as a picture that is moving on a distorting mirror) (see Palidda, 1992). This aspect is perhaps better understood. There is always the coexistence of war and peace, conflict and mediation, corruption and the pursuit of law.

14 Here the reference is to people who have not adapted or do not comply with the profile required by the dominant representation of neo-liberal society, to those who do not passively yield to subservience to any sort of super (and sometimes violent) exploitation, and even to those who are too worn out or wrecked (such as drug addicts or vagrants who are deemed absolutely 'irredeemable').

15 No estimate exists for security business (in terms of public and private spending), but it would not be too exaggerated to think that the figure compares with that of military expenditure. The increase of fears is also now repeatedly exploited by pharmaceutical lobbies (notoriously exemplified in the cases of avian flu and now H1N1).

16 The most striking case is that of the senior police officials and officers responsible for the serious violence and torture against demonstrators during the G8 summit in Genoa in 2001 (see Palidda, 2007a, 2008).

17 For example, the Central Directorate of the Italian police invited all the prefectures to economize on the costs of investigations, while the prefect of Palermo has set the cap for monthly expenses for Mafia investigations at 33,000 euros (Custodero, in La Repubblica, 7 March 2009). 


\title{
8 Surveillance
}

\section{From resistance to support}

\author{
Eric Heilmann
}

In a totalitarian society, the government would ideally like to see a policeman behind every individual - in other words, to turn each citizen into a policeman. In a democratic society, while this kind of total surveillance is inconceivable, the government is still expected to maintain public order and to also protect itself. Modern states have set up and organized professional police forces to act under their authority and do these jobs for them. Professionalization of the police in France only really began in the nineteenth century, when it was, and still is, inseparably linked with datagathering techniques, tantamount to a police science, that allowed them to amass specific knowledge on the population (Fijnaut, 1980; Heilmann, 1990). What is really striking about these techniques is the extraordinary economy of resources involved, especially human ones.

These written records (records, files, archives, etc.) contained detailed entries on the actions, opinions and physical characteristics of any individual considered to be a threat to social peace. The web was drawn tighter by a series of what appeared to be innocuous measures, but which had a cumulative effect on the state's relationship with its citizens. The individual's name, for example, the main way in which he/she was identified, was no longer decided by usage, as was previously the case, but by the authorities with the establishment of birth records. ${ }^{1}$ The next logical step was to oblige every individual to have a single domicile, the details of which would be entered on identity documents, such as the person's identity card, passport, livret ouvrier (work book) and others. To facilitate the process, official names were given to roads, streets and squares and their houses numbered. A wide-ranging set of regulations ensured that this meticulous organization would be applied across the whole of urban France by the end of the eighteenth century.

This economy of resources was the correlate of a new 'economy of visibility', as it was described by Michel Foucault in 1977, which became the basis for disciplinary technology: there is no need for a massive police presence to keep order in the country as they can keep watch on people through individual police records, files and archives. This gave rise to a new organization, whereby police attention focused not so much on the 
individual as on the written information which objectivized them. It was now the police archives that provided the ears and eyes for surveillance.

This being said, does the theoretical paradigm elaborated by Foucault for analysing the birth and expansion of disciplinary societies provide a relevant platform for understanding the current methods used for public order management? The development of CCTV in public areas has led, over the last few years, to considerable debate over whether Foucault's conceptual framework - in reference to Bentham's panopticon - needs to be considered within a fresh perspective to address the new ways in which social control is being exercised. A number of highly instructive papers have been published, where the authors use a variety of metaphors to describe these methods - synopticon (Mathiesen, 1997), omnicon (Groombridge, 2002), neo-panopticon (Mann et al., 2003). ${ }^{2}$ All these publications do, however, have a weakness, inasmuch as they fail to factor in public support for the deployment of CCTV and suchlike in public spaces, and this is a change of considerable significance. This chapter sets out to analyse the situation and its underlying causes.

\section{Resistance to registration}

To get a proper handle on this change, it is worth going back in time, where it is possible to see that all these regulations that set out to establish records on the population as a whole and to facilitate the identification or domicile of the individual were met with considerable resistance. Three examples show the extent of this resistance at three separate periods in French history.

In his Tableaux de Paris (1782-1788), a detailed chronicle of the morals of the period, Louis-Sébastien Mercier described how, when workmen carved road names on the sides of buildings and gave individual numbers to each house, in accordance with precisely worded regulations, they would be insulted, threatened and even struck by the local population and were therefore obliged to do their work at night. What is the explanation for this reaction? Nobody was in any doubt that, although there were certain advantages in having street names and house numbers, the main idea was to help police to more easily find people in the crowded urban sprawls. ${ }^{3}$

In the late nineteenth century, Gustave Macé, an ex-high-ranking police officer, published a book written for the general public, which contained a collection of mugshots, along with observations and stories about police work. Some of the photographs showed subjects who had had to be held down by force to have their pictures taken: some were held by the body, others by the beard or by the hair and one of the men, whose face was so contorted as to make him unrecognizable, was being forcibly restrained. Macé accused Bertillon, the initiator of mugshots in France, of using force for taking his photographs and of packing anyone who made a show of resistance away into solitary confinement. 'There was no point in doing away with the straitjacket for murderers who had been sentenced to death 
only to bring it back for a striking coachman or for individuals who were only being held in custody.' (Macé, 1890: 297). The resistance that some of the subjects put up clearly illustrates the power wielded during any kind of registration procedure. They are obliged to comply with the instructions that go with taking the photograph and they are denied, by force if necessary, any ownership of their own image.

In the twentieth century, the French law on 'informatics and liberty' illustrates another phase in people's resistance to their personal data being recorded. In an article published in Le Monde in March 1974, a journalist voiced his concerns over police intentions with regards to information technology. ${ }^{4}$ In his article, he said that the French interior ministry had just taken delivery of one of the most powerful computers on the market and he also revealed that INSEE (the French national statistics institute) was planning to set up an 'automated system for administrative files and individual records' (Safari - Système Automatisé pour les Fichiers Administratifs et le Répertoire des Individus), which would be able to link up all the files within a public administration through the use of a unique identifier. The journalist went on to say that the ministry of the interior, now that it had the technical resources it needed, 'intended to play a leading role'. The article produced an outcry, with unions, associations and political parties coming out against the government's intentions and the government was forced to set up a commission of enquiry (Vitalis, 1981), which commenced in November 1974. The commission's remit was to make recommendations to the government on actions to be taken to ensure that information technology would develop while respecting the right to privacy and public liberties.

The commission published its findings the following year and these provided the basis for the ensuing parliamentary debates, which culminated in January 1978 in a law relating to 'informatics, files and liberties'.

What is the situation today? Did anyone ever see local inhabitants insulting or threatening people installing CCTV cameras in their road? Has there been any kind of mass movement protesting against a local or national authority's plans to set up video-surveillance systems? The only possible answer is 'no'. With a few isolated and well-informed exceptions, such as the French human rights league and the national anarchists collective and their 'smile, you're being filmed' catchline, there has been virtually no opposition to the installation of CCTV cameras. The deployment of the cameras either has the support of the local population or meets with the indifference typified by the famous line 'I've done nothing wrong, so I've got nothing to be afraid of.'

\section{The growth in CCTV}

Opposition to the development of video-surveillance technologies, or at least an appeal for them to be used in a reasonable way, could have been 


\section{2}

organized along political lines, but this has never happened. The split between left and right, which divided political thinking on security issues right up to the end of the 1980s, has progressively disappeared. The fear of a massive influx of immigrants from eastern Europe after the fall of the Berlin Wall, followed by the war on terror after the events of 11 September, brought all the prevailing currents of thinking into the same camp. There are now few mayors in France who dare take a stand against having CCTV in their town ${ }^{5}$ and video surveillance has experienced substantial growth over the last few years. By 2007, 1,522 local authorities had installed CCTV in their streets and public areas, a 25 per cent increase on the 1,142 in 2006 and nearly 50 per cent compared with 2005 (812 local authorities). For the record, there were only sixty towns with CCTV at the end of the 1990s.

Much of the enthusiasm shown by local authorities for CCTV can be put down to the political drive of the interior ministry (Jouanneau, 2009), which, since summer 2007, has continually reiterated its desire to 'triple the number of cameras on public highways'. The ministry sought to boost the growth in CCTV by giving grants for local authorities, borrowing from the British Home Office's CCTV Challenge Competition system introduced in the 1990s (Norris and Armstrong, 1999). The interministerial fund for the prevention of delinquency (IFPD) gave handouts to towns that opted to install new CCTV systems or renew existing ones, although the running and maintenance charges would be paid for by the local authorities themselves. The IFPD provided funding for 314 operations in 2007 (for a total cost of $€ 13.4$ million) and 304 in 2008 (amounting to $€ 10.2$ million).

With crime prevention and urban security at a low ebb, the French interior ministry also set out a qualitative objective, which was to give the French national police and gendarmerie easy access to the images filmed by municipal police and other public operators, such as transport companies. To this end, the ministry encouraged the creation of networks between existing public CCTV systems by offering subventions to operators who were willing to renew their system to connect it up to the national police network. This policy has already had material results, with some fifty surveillance centres connected up by the end of 2007 and 120 by the end of 2008 .

Some thirty years after the outcry provoked by the Safari project, it has to be said that the government's plan for expanding CCTV coverage and encouraging public video-surveillance systems to connect up to each other has met with absolutely no reaction, either from political organizations (parties, unions and others) or from the general public. We could go further and suggest that the absence of any reaction by political organizations is due, at least in part, to the support given by the public to the installation of CCTV in urban areas.

There are only two opinion surveys known to have been conducted to find out French people's thoughts on the subject, both carried out by a survey company. ${ }^{6}$ The first one, commissioned by the French interior 
ministry, was conducted in November 2007 on a sample population of 948 people, while the second, at the behest of the national informatics and liberties commission (CNIL), involved 972 people and was carried out in March 2008.

In the 2007 survey, 78 per cent of the people questioned declared they were in favour of CCTV in public areas (13 per cent fairly unfavourable, 8 per cent very unfavourable). When the political affiliations of the subjects were taken into account, 88 per cent of people on the right were in favour, and 70 per cent of those on the left. The same question in the 2008 survey produced fairly similar responses, with 71 per cent of those questioned in favour of CCTV in public areas (15 per cent fairly unfavourable, 13 per cent very unfavourable). The data provided with the survey gave a precise picture of the social background of the people polled: 77 per cent of the over-60s and 74 per cent of women declared they were in favour of CCTV, with only 44 per cent of those with three years or more post-secondary education and 35 per cent of 18 -to-24 year-olds.

The 2007 survey also set out to assess the feeling of security given by CCTV in a public area. Of those questioned, 66 per cent said they felt safer in a public area with video surveillance, including 70 per cent of the women polled and 79 per cent of those claiming to be on the political right. The 2008 survey included a question on how people felt about the current growth in CCTV: 43 per cent of those questioned said there was 'not enough', 33 per cent said there was 'enough' and 15 per cent 'too much', with 9 per cent 'don't know's.

The information given by these surveys is obviously not on the same scale as that provided by scientific research, such as the studies conducted in the United Kingdom by E. Charman and T. Honess (1992) and J. Ditton (1998), for example. Do we know if the people questioned live in the towns or districts where the CCTV is installed? Do they know how these systems operate and what their capacity is? Are they aware of the cost and the actual effect on delinquency? None of these factors were taken into account in the surveys, which takes away some of their effectiveness. This being said, the surveys confirm, unsurprisingly, that a considerable majority of the population are in favour of CCTV systems in public areas. Only about 10 per cent of the people questioned come out strongly against CCTV (8 per cent in 2007 and 13 per cent in 2008 claimed to be 'very unfavourable').

\section{The determinants of support}

How can this support be explained? Several reasons could be put forward: the growing fear felt by the population of unknown or unidentified enemies, political action by the government, and the increasing influence of companies selling security systems with efficient marketing backing. While all of these causes have been studied in depth (Ocqueteau, 2004; Le Goff, 2008), 


\section{E. Heilmann}

we consider that there are other determining factors, which have either been neglected or underestimated, and which come down to the actual nature of a CCTV system. This is what will be examined in the this section.

By entering individual details onto a police database, the police are able to keep a constant watch on anyone they believe needs to be kept under surveillance. This means that individuals of a certain category are put on file, even if the criteria for keeping a subject under surveillance have undergone considerable change as the political and ideological context has developed. It is when details that reveal the identity or actions of an individual (such as personal details or fingerprints) are recorded in a file that fierce resistance or a gnawing anxiety is provoked. As C. Phéline (1985: 110) rightly argues with regard to mug-shots, 'By resisting a photograph being taken, an individual defends his or her personal and social identity against the power of the police.' Similarly, anyone who wants to understand the heated debate that erupted in France in the 1950s over the introduction of fingerprints on national identity cards needs to bear in mind that fingerprinting is always thought of as being one of the first steps in what Foucault called the 'penal ritual'. Does it not come down to the fact that being entered on police records is the first indication of the individual belonging (supposedly or in reality) to a deviant social category?

CCTV is not seen at all in the same way. If it were a gas, it would be carbon dioxide - colourless and odourless. The development of CCTV systems, whereby the image is core to surveillance, marks a complete break with previous systems. The cameras record a continuous stream of images and produce a vast amount of data: if a camera records, say, twenty-four images per second, it will produce about two million images in twenty-four hours and so a system with twenty cameras will capture over forty million images in a single day! The CCTV system in a public area has a dual characteristic: the images are captured without any specific target in mind and they are recorded without any criteria governing who is filmed; anyone who enters the camera's field of vision is recorded. This means that the presence of CCTV has no effect on the personal and social identity of the people filmed. It could even be said that this identity is concealed from the police by the system, as an individual could adopt a different social status according to their activities over the day. They could be seen successively as someone strolling, a consumer, a traveller or a spectator, a chameleon figure that is outside any pre-established police classification. While a police file records the past and foresees a criminal future - and the individual is considered as a potential recidivist - the video image captures the present, while putting all individual attributes aside for future consideration.

A third characteristic of a video-surveillance system is its extraordinary versatility. It can operate in any kind of location and in any part of a town to capture images of people going about their business. The images produced by CCTV are part and parcel of all aspects of daily life (such as housing, education, business, healthcare and work), while there is an 
enormous range of equipment available on the market, including fixed, swivel, analogue, digital and miniaturized cameras, cameras with zoom or with a light intensifier, and so on. The technical configurations can also take a myriad number of forms, from a single camera connected up to a computer, to a sophisticated computer system capable of displaying images from several dozen different cameras at the same time. The virtually unlimited range of applications - nowadays cameras can be seen anywhere from a nuclear reactor to the stairways in a housing block - means that the use of CCTV has now broken out of the original circle of public and private organizations responsible for maintaining public order. Video surveillance has moved away from its original purpose, which was chiefly securitybased, to operate in a much wider field, including visual assistance, flow management and decision support.

This development in the use of CCTV has become particularly marked in the arguments used by local authorities to justify expenditure on the systems they install (Heilmann, 2008). In the late 1990s, the main, almost exclusive, claim emphasized the virtues of CCTV in reducing delinquency. By 2004 and 2005, anti-terrorism was providing fresh fuel to support its use, with considerable use being made of the British example. More recently, the accent has shifted to highlighting its life-saving features (alerting the emergency services when people fall ill in the street) or providing assistance to municipal roads departments by, for example, reporting objects that might be blocking or obstructing a street. In less than a decade, the range of services offered to the community has broadened considerably. While it may well be true that this is at least partly due to skilful political and commercial manoeuvring, it also goes to show that the operators of CCTV systems have shown remarkable imagination in coming up with new ways of maximizing the use of their equipment.

\section{Conclusion}

Can the government and local authorities always rely on the backing or passivity of the population for expanding the use of CCTV?

Information and communication technology has removed the barrier that once separated private from public life and the clearest example of this is reality television, where the intimate lives of a group of people are broadcast to an audience of millions (Tisseron, 2002). Also, nowadays, anyone can have a webcam or mobile phone with which they can produce their own images, from the most banal to the most intimate, which can then be placed on a personal or community website. It could therefore be said that the presence of CCTV cameras in urban areas is the symptom of an inexorable historical process, whereby a society or an ideology of transparency and the tyranny of appearances subject individuals to permanent exhibition.

The different ways the images are produced shows that they each have their own specific features and it would be wrong to seek an all-enveloping 
explanation such as the 'dispersal of discipline' in contemporary society (Green, 1999; Lyon, 2001) to grasp the situation. If we examine the intentionality of the operators, as suggested by Lianos (2003), we understand that when an individual produces images, it is based on claiming their own identity - the individual must be able to express his or her personal identity even within the public sphere - which is the opposite to what promoters of CCTV systems on public highways set out to do.

This being so, it is possible to see what might wake people up to the use of the systems. Technological advances are now making it increasingly easy to link up in real time the anonymous images recorded by CCTV with personal digital data stored on the servers. For the police, these technologies, which were only of limited use a few years ago, have produced a significant breakthrough in identifying individuals (Norris, 2002). Ever more importantly, however, from our point of view, the use of these new systems should encourage people to consider how surveillance is affecting them. The recent survey conducted by H. Wells and D. Wills (2009) in Great Britain on drivers and their attitudes to speed cameras, shows a sea change in thinking. The authors show that the use of the cameras has produced unexpectedly fierce resistance, expressed in quite singular terms:

This resistance is not characterised by complaints of 'Big Brother' or couched in civil liberties terms. The dominant motivating narratives of drivers and drivers' groups are of challenges to identity and the perceived misrepresentation of the individual in encounters with the particular surveillance technology.

Speed cameras photograph a car if it exceeds the speed limit and then link the licence number up with its owner. The system has led to the formation of groups of drivers, all of whom describe themselves as 'normal' and 'reasonable', who are protesting against the 'inappropriateness' of this form of surveillance carried out by police officers who would be better off using their resources to catch 'real criminals'. So while the success of CCTV was based on creating a dichotomy between the respectable majority (who have nothing to fear) and a deviant minority (who should feel threatened), speed cameras have distorted the line separating the two categories. If the argument put forward here turns out to be correct, then it is possible that with this distortion, we are beginning to see the first signs of the emergence of a genuine, identity-based resistance to images produced by CCTV.

\section{Notes}

1 In the early nineteenth century, a new obligation was added to the French civil code: each citizen had to have a surname and a Christian name (or names) recorded on their birth certificate - see Lefebvre-Teillard (1990). 
2 For a summary version, see V. Francis (2009).

3 This resistance would continue for some years yet and spread to other countries. In his novel 'The Unbearable Lightness of Being' Milan Kundera described the first few days of the Prague spring: 'People in every city and town had pulled down the street signs: sign posts had disappeared. Overnight the country had become nameless. For seven days, Russian troops wandered the country, not knowing where they were' (Harper \& Row, 1984, p. 166). See also J. Koudelka's illustrated report Prague 1968 (1990).

4 Ph. Boucher, 'Safari ou la chasse aux Français', Le Monde, 21 March 1974.

5 Most of them are members of the French Communist Party.

6 Ipsos survey, carried out by phone 2-3 November 2007; representative sample of the French population, aged 18 and over; quota method: gender, age, occupation of head of family, type of urban unit, region, and Ipsos survey, conducted by interviews, 14-17 March 2008; representative sample of the French population, aged 18 and over; quota method: same as above. 


\title{
9 Enemies-criminals
}

\section{The law and courts against global terrorism $^{1}$}

\author{
Gabriella Petti
}

\section{What about global terrorism?}

Academics and legal experts have been tackling the question of global terrorism for a number of years. In fact, various conventions exist that deal with the matter in different terms. The work undertaken by these professionals, from formulating theories and identifying countermeasures to negotiating agreements and normative bricolage that accommodate the supranational level at the national level, has led to global terrorism moving beyond the limited borders of the language of international bureaucracies and has merged the actions of different political groups that sometimes employ extremely violent methods of struggle into an ideal model. ${ }^{2}$ In fact, the positions adopted by the United Nations towards 'freedom fighters' and people who are militarily defeated or oppressed by the violence of occupiers are somewhat ambiguous. ${ }^{3}$ The 'war on terror' has made it even more difficult to draw a distinction between war and peace, and has in turn blurred the separation between internal and external enemies, thus leading to a deep transformation of the idea of enemy itself. Enemies, most reassuringly personified in the figure of the terrorist criminal, ${ }^{4}$ lose 'any recognition of their status as combatants' and may be treated 'as a technical problem', in the same way as a natural disaster or epidemic (Dal Lago, 2005: 29). International consensus was built precisely on these 'operative' aspects and it was after 11 September 2001 that the need to strengthen the common struggle against terrorism asserted itself.

The attack against the Twin Towers served as the trigger that enabled the dissemination of new operative standards and legislative reforms into different national contexts, which led to the tightening of control procedures and the establishing of exceptional measures at all levels of the criminal trial, from investigations to sentencing. These reforms were introduced amidst a media-induced climate of fear and required the cooperation of several social actors, in particular experts from administrative bureaucracies, to become affirmed. ${ }^{5}$ Documents produced by international institutions have created a 'profile' of the Islamic terrorist built around the figure of the Arab and Muslim immigrant who, in turn, is identified as the quintessential object of contemporary fears. 
The European Union participated in the global offensive against terrorism but adopted an approach that was somewhat different to the one in English-speaking countries. ${ }^{6}$ However, in Italy, as in numerous other European countries, there has been growing concern among some jurists that the country's penal system may be contaminated by a "wartime logic" which would appear to confirm the assertion that there now exists a generalized state of exception or, put another way, an unceasing management of emergency. ${ }^{8}$ In effect, the efforts by the media, opinion makers, law enforcement agency officials and political leaders in Italy have been so intense and continuous in producing a common portrayal of the presence of an Islamic terrorist threat that they have managed to sway public opinion and to impose particularly repressive legislative measures. ${ }^{9}$

One consequence of the climate of moral panic was the exacerbation of measures, which included the introduction of the specific offence of international terrorism..$^{10}$ Particularly in the wake of the attacks in Madrid and London, persecution campaigns by the media and police against 'suspect communities' (Hillyard, 1993) resumed and a new cycle of reforms was set in place. ${ }^{11}$ All the laws were introduced in the form of 'urgent decrees'. Thus, the alarm around the threat of possible terrorist acts was compounded by the fear that a multiplication of norms restricting fundamental human rights could entail the obliteration of democratic principles and the constitutional state. In reality, 'emergency legislation' through the use of governmental decrees that circumvent parliamentary debate is such a consolidated instrument in Italy that it constitutes the model through which interventions on issues of security and repression are carried out (cf. Moccia, 1997).

The matters described thus far must certainly not be underestimated. However, I feel that the stories of prosecutions, imprisonment, convictions and deportations that have marked the lives of many Muslim citizens in Italy cannot be understood as merely the effect of a continual climate of moral panic, or the consequence of the exceptional measures adopted, but should also be interpreted in terms of the practices that are at work in the places where they have largely been decided: the courts. The reference to Becker in the title of this first section stands as a reminder of the risks that may incur when 'a class [is created] on the basis of how other people (judges, police officers, psychiatrists) have reacted' (Becker, 2003: 483). If one leaves aside their assumed objectivity, 'terrorists' are particularly well suited in providing a mirror image of the mechanisms that produce them.

Courtrooms are not just a place in which definitions of criminals (or terrorists) are assigned and tested, but they are also the arena in which the right to punish and the power to divide the guilty from the innocent is ritually celebrated. From this perspective, I find the court, first and foremost, interesting as the setting where discourses, forms of knowledge and practices that reproduce social images of terrorism are developed and redefined. Nonetheless, I also believe that focusing the analysis on these particular proceedings may also contribute to an understanding of some of the 
practices that are specific features of Italy's courts, but which are usually overshadowed by routine organizational practices. The court, however, must not be regarded as a homogeneous community, but as a 'field' where professionals, possessing diverse types of capital and differentially situated within this space, compete from the starting point of a set of shared preconditions. ${ }^{12}$

In short, trials tell us something about terrorism that is difficult to discern from official discourse and demonstrate how the practices and activities of courts, even the smallest of details, produce effects and influence the legal definitions of terrorism. In turn, dealing with terrorism in courts enables a better understanding of the logics that govern the trials themselves. By emphasizing the need to remain within the boundaries of law, 'even' in the fight against the terrorist criminal, means that these judicial proceedings are particularly useful in illustrating how mechanisms of exclusion, neutralization and symbolic (or material) annihilation of certain categories of individuals are enabled, not so much by a situation of legal exceptionality, but through the normal, day-to-day workings of the courts.

\section{War against the global enemy in the legal field}

The issue of international terrorism had already been tackled in Italy back in the mid-1990s. Investigations undertaken at the time targeted groups that held radical interpretations of the Islamic faith, but were clearly differentiated in terms of nationality and generally comprised opponents of governments with which Italy had agreements or economic relations. ${ }^{13}$ The trials always ended in acquittals or a modification of charges. At the time, the Italian criminal justice order was motivated by the principle of the prevalence of national sovereignty, according to which an activity was, from a legal perspective, 'subversive' or 'terrorist' only if it directly involved the Italian constitutional order.

Since 2001, investigations have generically concerned Bin Laden or the Al Qaida organization, while groups or individuals that were previously deemed to act autonomously have subsequently become alleged members. The measures used to establish whether an act is of a terrorist nature are essentially based on their pursuit of a particular cause. This involves an 'interpretation' of jihad as a 'violent strategy' that, in turn, is attributed to associations ${ }^{14}$ or individuals. ${ }^{15}$ This generalization partly results from the fact that the theoretical reference model changed after 2001, as the interpretation of global terrorism as an organization possessing a centralized command of operative divisions switched to the idea of an organizational structure based on a division of labour around territorial specializations and without a principal coordinating body. According to this vision, the various groups are unified not by their organization, but through a form of 'franchising. ${ }^{16}$ The Italian component has supposedly specialized in 'subsidiary activities', such as training, recruitment, document forgery and funding. ${ }^{17}$ 
Besides the intense media coverage of attacks that never actually took place, the activities described in trial documents have always amounted to logistical and financial support for 'terrorist' activities, even though the verified economic transactions have been far inferior to the sums internationally agreed to constitute the funding of a terrorist organization. The channels followed are those typically used for immigrants' remittances and the confiscated sums often comprise amounts in small denominations, as in the case of a suspect who had 'around five thousand euros in small coins confiscated' (Spataro, 2007).

A global version of the dominant frame that considers 'immigrants as an enemy' appears to have asserted itself (Dal Lago, 1999b). The figure of the terrorist and its associated activities have become blurred with the figure of the migrant (Arab and Muslim) and with those practices, illegal or on the margins of legality, that are related to this condition. Thus, a group of people that covertly lives in an abandoned shack or in an anonymous flat may be viewed as a likely Al Qaida base in Italy. Even the rather widespread practice of entrusting documents to friends or acquaintances can backfire. In fact, the discovery of several identity documents stored at a single place of residence - of people living in a dormitory or, in any case, of those who do not have their own home - have led, on a number of occasions, to the conjecture that this must be a terrorist base. Street maps or tourist guides of cities in the hands of these immigrants turn into possible plans for attacks. Finally, and above all else, attending a mosque and expressing one's ideas are elements that raise a great deal of suspicion. Thus, if all the suspicious conducts take place together, there is a very high risk of being considered supporters, if not members, of a terrorist organization. That such a set of circumstances might form the basis of a case history is not an exaggeration, for indeed it has surfaced in the trial documents of a number of investigations in Rome in which all the parts of the mosaic submitted by investigators were subsequently deconstructed into elements lacking particular significance or dangerousness. ${ }^{18}$

However, it is not just that terrorists are denied their national and ideological identity as a result of their social characterization, but that the very offence of terrorism has progressively lost its specificity. The package of reforms adopted after 11 September meant that the existing offence now expanded to encompass other conducts, including activities undertaken against foreign countries, and hence provided the basis for bringing charges against people. According to its new wording, any political activity characterized by violence against an established power falls within the scope of public order and hence may be prosecuted, even if it does not directly concern Italy. However, the definition is ambiguous and, as such, is often revealed too vague to lead to a conviction for international terrorism. It was precisely the difficulties encountered in trials that led to the introduction of new legislative provisions ${ }^{19}$ concerning activities that are supposedly inherent to the 'modus operandi of Italian cells' (Viganò, 2007: 42): 
recruitment of terrorists, training and supplying instructions (including through the use of video messages). ${ }^{20}$ This aspect was confirmed, to varying degrees, in many of the interviews with legal professionals. This is one example:

My first impression on reading the legislation [law 155/2005] was that in light of the trials that had already started, they had realized that certain forms of behaviour, whether or not regarded as evidence of terrorism, were in reality neutral, and could not be punished precisely because of their characteristics. But these were nevertheless seen to be a reflection of the inherent dangerousness of the people carrying out such acts and, hence, they decided to turn them into criminal norms. In other words, the legislation was certainly influenced by the outcome of the first trials. [...] We were facing such a new situation that the legislator thought they could resolve the issue with a single move by introducing new legislation [in 2001], but then, in reality, information emerged as the trials evolved that was striking for the danger it presented but which could not have any implications of a penal kind. Thus, this was a political choice, obviously in the aftermath of the events in London.

(Magistrate)

The latest modification of the criminal offence of terrorism was implicitly introduced by a sentence of the Court of Cassation (Italy's highest appeal court) in 2006 (no. 1152), which further extended its definition through the combination of different provisions from international legislation. The category of 'terrorism' was now so flexible that it enabled convictions even for people who contravened legislation on immigration or document forgery, as long as these activities fell within a programme of 'terrorist intent', which, in certain conditions, could also include actions aimed at a military target. From this moment onwards, trials have largely ended with convictions.

Subjects implicated in police operations and trials conducted during this period have been unavoidably condemned to being labelled terrorists. They were designated terrorists even before the specific offence existed, and its introduction merely ratified this status. Moreover, this condition was not simply established by the outcome of proceedings. In fact, even when they ended in acquittals, some defendants were expelled for 'public order reasons'. The same occurred to those whose trials for terrorism were pending and were released as a result of the indulto (a pardon introduced in July 2006 to ease the problem of overcrowding in prisons) and to those who had completed their sentences: all were terrorists for life, and the possibility of them mending their ways was not envisaged. Upon returning to their countries of origin, many of those expelled were arrested, sometimes subjected to torture or even disappeared. ${ }^{21}$ Finally, on occasions when 
investigations did not lead to any results or were insufficient to initiate a trial, the suspects (especially in cases involving imams) were nonetheless repatriated for 'pre-emptive reasons'. ${ }^{22}$

Overall, it is not easy to establish the number of people affected by this pre-emptive activity or those implicated in investigations, also because it is not possible to accurately reconstruct the investigations that have ended in cases being shelved, to ascertain the actual number of people expelled or acquittals. The scant information that exists regards convictions alone; and these may be deemed significant only as a measurement of the activity of the police and the system for the administration of justice (Kitsuse and Cicourel, 1963). It is also for this reason that I have chosen to carry out qualitative research on the trials held in a single court: that of Milan, the most representative court in Italy where twenty-three out of the thirty trials between 2001 and 2007 were held.

\section{De-politicization mechanisms and routes to disappearance}

The offence of international terrorism was only introduced into the penal code after the attacks in the United States, whereas a majority of the proceedings - during the period in question - concerned matters that took place before 11 September. Moreover, the conducts described in the charge sheets of trials prior to 2001 are very similar to those 'committed to trial' by investigators after the introduction of the offence of international terrorism. Often the protagonists of these judicial matters were the very same people. Finally, prior to 2001, the aggravating circumstances envisaged for internal terrorism were already being raised in the charges. In concrete terms, the introduction of a specific offence does not appear to have brought about major changes to proceedings. What did change was the atmosphere in which they were held. For everything now took place under the media spotlight.

The hypermediatization of trials is a phenomenon that is by no means new in Italian justice, especially when courtrooms become ritual venues for celebrating the fight between good and evil. Here, I wish to stress an extra characteristic that appears to set these investigations apart: a multiplication of proceedings for the same events, to the point of determining a 'judicial continuum', which, in its basic outline, is reminiscent of the period of the maxi processi. ${ }^{23}$ Here, rather than to the number of defendants, I am referring to investigative and trial practices used to tackle internal terrorism or the Mafia that were later resumed during the judicial struggle against political corruption in the early 1990s. It is worth noting that such practices are currently part of the magistrates' essential baggage, even though, for a long time, they were deemed the product of the emergency legislation, which, according to Luigi Ferrajoli's definition (1989: 844-888), operated 'under a criminal justice system of exception'. 
Considering the extent to which these practices are entrenched, one could argue that judicial practices have taken primacy over legal definitions. It is probably the combination of the technologies employed by legal professionals that enables the bringing together and blurring of different forms of behaviour, ideology and expressions of political violence into a single concept. In other terms, the hypothesis is that terrorism is more the 'resulting object' of a combination of investigative and judicial procedures that are constantly reproduced than an expression of ideological and political coherence. To be more precise, I believe that the meaning of international terrorism - in other words, its typology, characteristics and operative modes - which has increasingly prevailed during trials, may have been partly determined by the use of investigative and procedural practices inherited from the fight against internal terrorism. Likewise, it is precisely the persistence of these judicial and police practices over time ${ }^{24}$ that appears to indicate a continuity in the treatment of the issue of terrorism which, to an extent, refutes a description of the recent situation in terms of exceptionalism. Let us now briefly look at some of the technologies that have been borrowed from the judicial season of the maxi processi.

One of the most evident mechanisms is what Ferrajoli (1989: 861) defined as the 'vertical expansion' of proceedings; in other words, an increase in the offences for which each defendant is charged, which are either tautologically derived from each other - associative offences from specific offences and vice versa - or are attributed to other members of the association by way of external participation. In some measures adopted for international terrorism, especially those concerning preventative measures (Pepino, 2006: 862), the 'programme of violence' is drawn from conversations that are marked by religious radicalism, whereas the 'associative link' becomes concrete through an ideological support for jihad, which is assumed from the use of antagonistic language towards Western culture (Morosini, 2005: 411). Moreover, 'the aptness of the organizational structure for terrorist intent' is deduced from the commission of specific offences such as document forgery or the aiding and abetting of 'illegal' immigration. In turn, the 'terrorist intent' of these acts is demonstrated by the ideological adhesion to jihad or by the availability of propaganda instruments for its promotion, without direct involvement in attacks or specific knowledge about such facts being proved. Finally, the associative criminal offence is often proved using telephone contacts and a 'circularity of relations': not much, if one considers how difficult it was to prove Mafia membership or external complicity on this basis. ${ }^{25}$

Vertical expansion is also accompanied by an extension of the length of trials and of preventative imprisonment (Ferrajoli, 1989). Some proceedings have dragged on for years, with considerable intervals between the conclusion of preliminary investigations and the start of hearings. The overall periods of detention are sometimes longer than three years. A technical means employed to considerably lengthen the detention period is that 
of alleging the use of weapons as an aggravating circumstance in the charge sheet. However, in each case, weapons were never found and the aggravating circumstance was always dismissed when it came to sentencing. Nevertheless, this charge is systematically used by public prosecutors. The very charge of terrorist intent, first as an aggravating circumstance and, after 2001, as an offence has caused more than a two-fold increase in the length of detention. Furthermore, arrests often involve names that are already known, so much so that many preventative custody orders are received by people who are already in prison, turning these individuals into fixed actors in the repetition of the performance of the judicial drama. It is worth recalling that these practices are normally applied to avoid the problem of the expiry of deadlines for preventative imprisonment.

The procedures described above are supplemented by the use of criminals turned state witnesses: without their statements, the Milan prosecutors' office's hypothesis for bringing charges is often too fragile to lead to a conviction. The existence of propaganda material, the results of wiretapping and surveillance of social networks, and the finding of counterfeit documents or sums of money in defendants' homes were previously considered too weak as evidence to result in a conviction for the offence detailed in article ' 270 bis'. They have begun to take on the consistency of proof, especially after the appearance of criminals-turned-state witnesses. These are people who have been tried on different occasions by the Milan magistrates, sometimes for entirely different offences, such as drug dealing, and who, after plea-bargaining for their sentence, have started to cooperate.

Finally, proceedings comprise documents that are thousands of pages long, and this is another element that means that the defence counsel's activity is practically blocked, especially if defendants cannot count on legal aid for their defence. Only in rare instances has it been possible to appoint defence advisors or to undertake investigations for the defence. The game has largely been played out in the field of the evidence submitted by the prosecution. Moreover, the lawyers' defences are not well coordinated and it is not uncommon for them to be in conflict with each other as a result of their different trial strategies or to simply compete for visibility, clients and credibility. In effect, the outcome of the first trials was strongly influenced by the decision of the defence to attain quick solutions that were not excessively costly (largely resolved through plea-bargaining or summary procedure), due to the lawyer's difficulty in recovering the trial costs. Sentences issued on these occasions have sometimes been the basis for other convictions.

These procedures allow for an understanding of how the entire judicial institution can become a place which, rather than ascertaining the existence of a criminal offence, is directly established through the procedures that are effectively at work in the administration of justice (Sudnow, 1983: 146). A defendant ceases to be the actual subject of the trial, and instead 
turns into the 'arena of confrontation' between the different implicated actors' interpretations of facts and norms; the space where new legal definitions are reproduced or tested and the balance of elements within the judicial field are regulated.

While the mechanisms outlined so far display a continuity with procedures that are inscribed in the history of Italian courts, trials for Islamic terrorism do have some distinctive features of their own: a degree of 'fickleness' in the use of judicial interpreters and a unique lack of interest with regards the structure, opinions and political motives of the organizations that are implicated in investigations. The assistance provided by interpreters poses several difficulties in investigations involving foreign citizens, but are more marked in cases of international terrorism. It suffices to consider that the list from which they are drawn is not always based on specific cultural and linguistic competencies because the most sought-after characteristic is for the advisor to be reliable. In fact, interpreters rarely share the same nationality of the defendants, which probably arises from the assumption that, at the end of the day, they all speak the same Arabic. Rather, it seems that it is the prosecutor's office itself that recommends a shortlist of advisors 'trusted' by the magistrates who are examining the case.

We have a list. Finding someone depends on availability and on trust. I tell you this, when I did my first trial getting hold of an interpreter was a problem. And I'll tell you straight away that I can't remember the name of the interpreter on that occasion, but in any case, some time earlier the Procura della Repubblica [public prosecutor's office] had mentioned the name of someone who, in fact, you don't see around anymore. [...] He has never been charged as far as I know, I have never seen him as a defendant. 'We report that some investigations are underway, it appears as though he may be a member or a supporter of extremist circles, etc.' The public prosecutor's office indicated him to us and I didn't appoint him. So it isn't easy because there are only a few of them, but with the agreement, in any case, even with the advice of the prosecutor's office, saying 'Well, do you have any problems with this one?', it can be done, it can be done ... we have found some interpreters who are always the same ones, after all.

(Judge)

According to most of the lawyers interviewed, the same superficiality towards linguistic and cultural issues also applies to the knowledge of the political inclinations and is particularly apparent in the blurring of 'terrorist' organizations with radical organizations. Apart from a few exceptions, different groups are muddled up and placed under the same label of jihad. In this way, the radical simplification of the language used by terrorists - a unified Arabic produced in vitro by the judicial machine - is accompanied 
by a drastic reduction of the political motives of their alleged membership. More accurately, the de-politicization of terrorists is achieved by creating a split moral personality, suspended between the extremes of religious radicalism and those of personal emotional traumas, which may then sway between the suffering during childhood and the typical 'disorientation' of immigrants who do not feel welcome in the host society. These are thus individuals with weak identities, who are easy prey to indoctrinators who instruct them in a creed that, in most cases, they have never previously professed. ${ }^{26}$

In other terms, terrorists progressively slide from the political field to that of pathology. Their profile is recomposed around the compromise figure of the 'religious fanatic', lacking any social or political motivation, who is on the verge of madness and who escapes the brutality of reality by seeking refuge in the comforting space of divine justice. It amounts to a dual nonage produced by an unspecified pathology and by the flight from political maturity towards a blood-stained religious dream. Hence, whereas national subversive groups were recognized as possessing a clear and autonomous ability for political and ideological analysis, in the case of Islamic terrorists this ability is denied and becomes blurred with their 'barbaric character'. This is exemplified in the words of a public prosecutor:

So, the names of groups were found because we stumbled upon them during the investigations. In contrast to internal terrorism and the clearly defined structure of the Mafia - the Red Brigades had a Marxist-Leninist type of organization with a particular vision [...] while a Mafia family has its rules - here there are no well-defined structures. More than anything else, there are movements. So, if I want to use a category, they are movements that are based on a general readiness to kill the largest possible number of infidels. If someone is a member or in some way close to one group, this does not necessarily mean that they cannot belong to another group.

To summarize, I feel that it is precisely the formal fairness of trials that has enabled the violation of the rights of many Muslim individuals accused of membership of terrorist organizations, rather than the need for discretional or exceptional practices that delegitimate the role of the judicial system. A more effective result can, in fact, be attained by simply reproducing, through the ritual of explicit or implicit court procedures, the combination of social prejudices which reflect Foucault's definition of 'state racism', which in the case of the 'Islamic terrorist' is taken to its extreme due to their 'a priori exclusion from humankind' (Dal Lago, 2005: 30).

It does not seem to me that the 'state of exception' which is often used to describe the strategies of the fight against terrorism can be detected in these practices: the play between the sovereign's right to kill and the 
bio-power rendered through mechanisms enacted by racism is 'effectively inscribed within the functioning of every state' (Foucault, 1998: 225). In the examples discussed here, rather than causing to die, it is more a matter of leaving to die - an operation more compatible with a normalized society's techniques of government - which is aseptically applied to all those individuals who are not allowed to live. One of the acquittal sentences clarifies this mechanism well when it states:

A different treatment in trials cannot be conceived for certain categories of defendants. The notorious opinion of Günther Jakobs that 'terrorists do not have rights' can certainly not be followed, because it is in open conflict with the Italian penal system and even the Convention on human rights.

Even though the same judge fully acquitted the defendants, if one reads between the lines, it is apparent that he nevertheless considers them potentially dangerous due to their proximity to 'fundamentalist milieus'. According to the defence counsel, in fact, there is a passage written in the ruling ${ }^{27}$ that undermines the situation of its clients because it leaves open the risk of deportation 'for public order reasons'. This possibility would entail their return to a country where one of the defendants has been subjected to torture, according to the information gathered from the telephone interceptions that form part of the trial documents.

The court can therefore be understood as a space in which the enemies of society are constantly reproduced. Moreover, it is one of the symbolic places in which the social legitimation to reproduce these enemies is established. The courtroom becomes a sort of transitional space that leads towards the dark areas of administrative control, where degraded and depoliticized subjects are situated. From this viewpoint, the court, in accordance with the ceremonial procedures laid down by law, represents the possible point from which terrorists, migrants and an entire body of abnormal humanity set out on an invisible journey towards their own 'disappearance', to the general indifference of the public and without causing a stir.

Translation by Yasha Maccanico and Nick Dines.

\section{Notes}

1 This text is a synthesis of research on trials for international terrorism held in Italy, conducted in the framework of the Challenge project. As an ethnographic investigation, I have resorted to an analysis of the measures and sentences issued by courts, interviews of the actors involved (magistrates, lawyers, interpreters and journalists) and field observation of the trials.

2 Among the numerous publications in which experts from international bureaucracies provide first-hand descriptions of their activities, see Betti (2008).

3 For an analysis of the debate within the United Nations on the universal definition of terrorism, see Cassese (2005). 
4 On the 'criminalization' of terrorism, see Gilbert (1997).

5 On the mechanisms for defining political fear and its possible uses, see Robin (2005); Furedi (2005); Simon (2007). On the role of the media in spreading a 'discourse of fear' and in legitimizing the fight against terrorism, see Altheide (2002), and Maneri in this volume.

6 The European fight against terrorism has received wide-ranging criticism. On civil liberties after 11 September, see Bigo and Tsoukala (eds) (2008); Bigo, Bonelli and Deltombe (eds) (2008). On the effects of the war on terror upon the democratic order in the United States, see Cole (2005); Cole and Lobel (2007).

7 Caputo (2006). On this point, see, among others, Bartoli (2008).

8 See, for example, Ackerman (2005). On the differences between the 'state of exception' and the 'state of emergency' in the era of global terrorism, see Ciccarelli (2006).

9 Palidda (2007b). A survey published by the Financial Times in the summer of 2007 placed Italians in second place among the populations that consider Muslims a threat to national security on the basis of their direct association with terrorism (Dombey and Kuper, 'Britons "more suspicious" of Muslims', The Financial Times, 19 August 2007).

10 In the conversion law (no. 438/2001) of law decree no. 374/2001, the redrafted art. 270 bis of the penal code introduced the offence of international terrorism.

11 After the attacks in Mumbai on 26 November 2008, two suspected terrorists were arrested in Italy, controls on places of worship and mosques intensified, and a new alarmist campaign began. See 'Terrorismo, progettavano attentati due marocchini arrestati a Milano', La Repubblica, 2 December 2008; 'Islam, la Lega va all'attacco. "Moratoria su costruzione Moschee", Corriere della sera, 3 December 2008; 'Terrorismo, allerta per Natale. "Controlli in chiese e supermercati" ', Corriere della sera, 5 December 2008.

12 See Bourdieu (1986: 6), in relation to the professional aspects and conflicts that are at play in the legal (and more specifically penal) field.

13 The first groups that were investigated comprised, in turn, Algerians (Gia, Fis and Takfir w-al-Higra), Egyptians (al-Jihad and al-Gamat al-Islamiya) and Moroccans (Moroccan Group for Combat). Later, investigations also concerned Tunisian fundamentalists (Salafist Group for Call and Combat) and, more recently, Kurds alleged to be members of the Ansar Al Islam organization.

14 See the charge in sentence no. 5774/04 R.G. G.I.P. The investigation is from 2003 and concerns members of Ansar Al Islam, including Mohamed Daki.

15 This was the case of the order to apply preventative custody, issued on 29 October 2007, which affected twenty-seven people, many of whom were involved in earlier investigations.

16 Roy O., 'Al Qaeda: partito del male o etichetta per gruppi indipendenti?', Le Monde diplomatique, September 2004.

17 The possibility of interpreting entirely different sorts of offences (such as aggravated theft or falsehood in an administrative act) as assimilable to terrorism is, in reality, envisaged in the Framework Decision concerning the fight against terrorism itself.

18 Sentence of acquittal issued by the Rome assizes court (no. 8/04 reg. Inserz. Sentenz.).

19 In particular, law 155/2005.

20 Art. 270 quater and quinques of the penal code, introduced by law 155/2005.

21 On this matter, Italy has received many calls to order from the ECtHR. See the sentence on the Saadi Nassim case.

22 These are expulsions decreed directly by the interior minister (cf. law 155/05) and already envisaged by law 40/98. The most recent measure against a 'leader of the Muslim community' was issued on 22 March 2009. Cf. 'Terrorismo, blitz 
a Treviso e Udine: espulsi due immigrati vicini ad Al Qaida', in Il gazzettino.it, 23 March 2009.

23 For example, people working in the field or in the media identify investigation on Islamic terrorism by referring to the name of the relative operations, the best known of which are Al Mujairun and Bazar, Bazar bis that have since split into separate cases. This style is reminiscent of the investigations Moro-uno, Morobis, Moro-ter, Moro-quater, Rosso-uno, Rosso-due and so on. See Ramat (1985: 63-67).

24 A similar process occurred in Great Britain, where much of the legislative measures and police and judicial practices were already tested out on Irish communities. Cf. Hillyard (2005).

25 Consider the Andreotti sentence (Constitutional Court 2nd Penal Section, sentence no. 49691/2004). See Pepino (2005).

26 These problems are dealt with by Spataro (2008). The article's paragraph headings reveal how the figure of the terrorist is interpreted. Paragraph 7 is entitled 'The centrality of religious motivation is also found in the statements by terrorists arrested in Kurdistan' and paragraph 9 'The irrelevance of the pursuit of liberation in the occupied territories'. Moreover, while the title of paragraph 6 is 'The inexistence of traumas and pathologies as possible concomitant causes for terrorist choices', the presence of juvenile traumas - a violent and authoritarian father - is identified in the personal history of Mohamed Atta. In this case, the value of the example greatly outweighs that of the rule stated at the beginning, hence laying the suspicion of emotional traumas upon all terrorists.

27 The passage is:

At most, one may talk of a mere agreement between people [...] who display a clear adhesion to the fundamentalist Islamic ideology; who maintain contacts with people who operate abroad within organizations that are responsible for violent actions, documented by video tapes in their possession; that they have propaganda material in which the struggle against infidels is exalted and the violent and criminal actions of the kamikaze are acclaimed. But all of this is not sufficient, from a strictly judicial viewpoint [my italics] and in the light of a rigorous evaluation of the collection of evidence, to frame the associative offence that has been charged. 


\section{Part III}

\section{The reshaping of global society}





\title{
10 Peacetime war discourse The political economy of bellicose metaphors
}

\author{
Marcello Maneri
}

People react to fear, not love. They don't teach that in Sunday school, but it's true. ${ }^{1}$

(Richard Nixon)

A significant tradition of studies, which could be summarized by the expression 'truth (or grammar) is the first casualty of war', ${ }^{2}$ has been concerned with examining the ideological nature of political and media discourse during wartime. Rather than seeking to answer the question 'What does war do to politics' (or to the media), here I want to examine what political and media discourse does with the rhetoric and language of war, particularly in peacetime.

At a time of war, the act of violence upon words is amplified and laid bare through forms such as (self-)censorship, euphemisms, metaphors, orders and threats. Instead, during peacetime (or, to be more accurate, in the absence of wars that are explicitly recognized as such), the exercise of violence through words can pass more or less unobserved. This is a language that is often just as militarized, but one which is not forced to circumvent the close scrutiny of the consumer of the spectacle of war.

\section{War and danger in the US ideological consensus and the new European political realism}

The discourse of the War on Terror is the most recent case in which a belligerent statement in peacetime has established a sphere of intervention in order to legitimate a permanent state of low-intensity war. After 11 September 2001, the speeches made by Bush and members of his executive regarding the 'War on Terror' imposed themselves as the framework for understanding and opposing threats against the internal security of Western countries. ${ }^{3}$ As many observers have noted, the main characteristic of these speeches was the declaration of a permanent state of war, by redefining what were initially labelled as 'acts of terror' as acts of war. Rather than framing what happened as a 'crime' (which occurred in similar cases 


\section{M. Maneri}

in other countries), the US administration preferred to speak of an act of 'war' and 'combat casualties', thus clearing the way for a military response rather than recourse to police repression and the criminal justice system.

Another relevant characteristic of this discursive construction was the obsessive identification of an unprecedented threat capable of ending the American way of life, the very essence of society and world peace. The 'enemies' and 'the American people' found themselves locked into a Biblical clash between civilization and barbarianism and between good and evil. This exaggerated threat, bound up in a Manichaean morality, was preparing a devastating response on a scale that was just as great. As Jackson (2006) has documented, the US administration ended up adopting the tried and tested rhetorical, thematic and narrative arsenal used by the Reagan administration in the first war against terrorism.

Pruned of its more specific elements, in reality this rhetorical arsenal has a far wider reach. Its modern expressions stretch back at least to the origins of the North American political experience, which has always identified a threat as an indispensable premise for the nation's consolidation, be this red (the native Americans, workers' movement and Soviet bloc), brown (fascism in the 1930s), or green (Islamic terrorism) (Campbell, 1998; Jackson, 2006). In many cases, the reaction to this threat has turned into a permanent mobilization that is both rhetorical and real, and a discourse that revolves around the idea of the 'war on...' (Glover, 2002). It does not just apply to states, regimes, peoples, military actions, and, in turn, terror/ism, 'rogue states' or 'red hordes', but also, and more interestingly, to a variety of social problems and phenomena. These range from drugs (opium, alcohol, marijuana or crack, depending on the decade) to crime and in a less coherent way, as we will see, to poverty and cancer.

Two aspects can be singled out. At one level, there exists a discourse of fear that might refer to any kind of phenomena, from the political to the natural (hurricanes, earthquakes, pandemics) to the human-induced (such as satanic sects or child abuse). At another level, there is the rhetoric of war, which is normally associated with the element of fear, although this is sometimes missing (as is, in rare cases, the very figure of the enemy, like in Johnson's 'War on Poverty'). The discourse of fear and the rhetoric of war both have a long history; they have traditionally reinforced each other and most recently have reached their climax in the War on Terror.

The discourse of the 'war against ...' something often does not refer to an actual war, nor even to the basic acts of military action. It is therefore a metaphor. According to Lakoff and Johnson (1980), apart from determining the way in which a phenomenon is read, metaphors alter our conceptual structures, exalt specific elements and introduce a perspective and a set of sub-schemes. In the case of war, the metaphor includes: threats that endanger our survival, or at least state (and moral) sovereignty; extraordinary efforts and appropriate sacrifices; the existence of armies (with their heroes); hostile enemies; attacks and defences; a rational strategy assigned to our 
leaders; the expectation of victory; and the inevitability and legitimacy of bloodshed. It is not simply a matter of the use of powerful rhetoric in order to tackle a political issue; the metaphor will also shape the way in which the public will perceive, think about and believe in a phenomenon, to the point that the metaphor and the object in question become blurred. The metaphor creates a new social reality that directs our actions, which in turn strengthens the power of the metaphor itself, making it plausible and coherent. As Lakoff and Johnson note, it is a veritable self-fulfilling prophecy.

In the United States, the war metaphor resounds forcefully with the nation's founding myths, from the War of Independence and Civil War to the victory over Nazi totalitarianism in the Second World War. The flag and national anthem are only the most central of a series of symbols and narratives (from the gun-wielding borderland epic to the war heroes with their hyper-technological arsenal), which go hand-in-hand with a patriotism forged in military conflict. Practically every US president has promoted his own war, regardless of whether this was real or metaphoric, with the backing of a sprawling and gargantuan military-industrial complex.

In Europe, this metaphor is far less attractive for historical reasons, largely due to the wartime destruction experienced on its own territory. Therefore, in many cases, the rhetoric has been substituted by a pervasive agonic lexicon (such as the 'fight against' or the 'battle against') that is more or less internationally ubiquitous in cases that range from 'petty crime', 'drugs' and 'insecurity' to paedophilia, bullying and hacking. ${ }^{4}$

This does not mean that the language of war has been absent. Indeed, it has been employed insistently on various occasions (Steinert, 2003). In the United Kingdom, Blair, whose most memorable slogan was 'tough on crime, tough on the causes of crime', periodically launched 'wars on crime' and campaigns against 'anti-social behaviour'. In France, there was a shift from the Jospin government's 'fight' against insecurity (Bonelli, 2008) to Sarkozy's 'crusades against crime' and 'merciless war against drug traffickers in the banlieues' (Mucchielli, 2008). Meanwhile, in Italy, there has been obsessive and insistent talk about the 'war on urban blight' and 'illegal immigration'. In any case, even when not clad in agonic metaphors, political discourse has increasingly relied on the main ingredients of this pattern. It is not so much a question of the use of metaphors drawn from the military domain that have long been part of its 'arsenal', nor is it about the widespread use of warmongering expressions such as 'zero tolerance', 'no pity' and 'utmost firmness' that have become part of the language of representatives of every political party. Rather, what is at issue here is a particular construction of social problems.

The emergence of the discourse of enmity in Europe can be reconstructed by using the example of Italy, a country where such a development has been particularly pronounced. Shortly before the fall of the Berlin Wall, long after the post-1968 youth and worker upheavals had ended, and at the end of a decade - the 1980s - which had seen far-reaching 


\section{M. Maneri}

de-industrialization undermine the cohesion and political strength of the working class and the fight against 'red' terrorism draw to a close, Bettino Craxi ${ }^{5}$ during a visit to the United States, suddenly declared that 'drug addicts' had to be 'punished'. ${ }^{6}$ Indeed, his abrupt conversion overturned the position of lay and socialist parties, which had long championed the freedom of choice in private affairs. It followed a meeting with the Manhattan district attorney Rudolph Giuliani, whose ability for making a name for himself ${ }^{7}$ as 'accuser-in-chief' (Simon, 2007) had impressed Craxi (Sarkozy would be similarly bedazzled when he met the former mayor of New York in August 2002). A few days later, a timely poll showed that 'according to the majority of Italians, drug addicts must be punished' ${ }^{8}$

From help and rehabilitation, the emphasis thus shifted to combating the phenomenon and punishing its users and, over the following two decades of legislative changes, Italian prisons would be subsequently filled with drug addicts. ${ }^{9}$ More generally, since the late 1980s, there has been a series of campaigns targeting a host of threatening subjects inflicted with varying doses of enmity: 'hooligans', 'cowboy drivers', 'paedophiles', 'hackers', 'bullies', 'baby gangs', 'stalkers', 'wasters', ${ }^{10}$ alongside political enemies such as 'social centre youths', the 'black block', 'terrorists'. Many of these categories were the upshot of the construction of new social problems that had previously not been topical. And many of these enemies were carbon copies of analogous categories that had already been constructed or identified in the United States and, to a lesser degree, the United Kingdom, and often imported without even being translated (as in the case of 'hooligans,' 'hackers', 'bullies', 'baby gangs' and 'stalkers'). In any case, they represented the outcome of an extraordinary synergy that had arisen between a political class seeking visibility and legitimation, a media attracted by emergency situations, apparatuses of control eager to produce results in the fight against phenomena that 'arouse the greatest social alarm', various service and technology providers thrilled to gain access to new markets, and a plethora of experts ready to appear on television, publish books and publicize surveys certifying the intellectual, scientific and democratic legitimacy of the alarm. The notoriety of these various enemies did not always last for long. However, although all would be subject to laws and tailor-made measures, the investment in rules, the practical and symbolic mobilization and the attribution of danger (Douglas, 1992) would never reach the extreme level reserved for immigration, especially if this was 'illegal' - apart from the exception of 'red terrorism'. 'Immigrants' and 'terrorists' 'are considered 'total enemies'. In contrast to drug addicts, 'bullies', 'cowboy drivers' and 'wasters', they are excluded from mainstream society, the former through the denial of citizenship and the latter as a result of their radical and sometimes violent opposition to the ideological consensus. Both can therefore be subjected to acts of vicious hostility or even to systematic persecution, deportation and annihilation. 
The idea of immigrants as enemies began to spread at the beginning of the 1990s during a deep crisis of legitimacy. After occasionally being presented in the late 1980s as an 'invasion' but also as an issue that exposed the problem of racism, immigration swiftly became synonymous with petty crime. This would become central in the mid-1990s to the overarching category of 'security', which quickly became an issue that could win or lose elections. The theme of security, that like petty crime does not consider the Mafia or organized crime, encloses a series of aspects and phenomena that are partly unrelated but are nevertheless constructed as a meaningful, unitary phenomenon. At the core lies street crime against people and property, but this is encompassed by other issues, such as counterfeit goods, drug trafficking, prostitution, homelessness and decorum in public space, and it is no coincidence that, with all these concerns, immigration is seen to play a part. Even when security is presented in a moderate and constructive version, as a frame that thematizes 'us' as the victims, it nevertheless sets in motion a series of military-style responses that are very similar across the board, despite the disparate nature of its objects.

After 11 September, the alarm concerning terrorism merely deepened this fracture, providing new legitimacy and new instruments to militarystyle practices and discourses. The succession of enemies and threats that began in the late 1980s (from 'drug addicts' to 'terrorists') appears as an escalation that, on the one side, identifies opponents who are increasingly excluded or excludable from the moral community and, on the other, lays the premise for their exclusion. The more the enemy is rendered an 'Other', threatening and immoral, the more it can be targeted by a war dispositive that seeks its elimination and increasingly assumes a strategic role.

Using the experience described above as a starting point, I shall now seek to outline an ideal type of war discourse during peacetime by listing some of its principal characteristics and indicating its various functions.

\section{Characteristics and properties}

A wealth of literature has already described similar phenomena, developing concepts such as moral crusade (Gusfield, 1963), moral panic (Cohen, 2002), not to mention the much older idea of the scapegoat (Girard, 1982) and the more recent discourse/politics/culture of fear (Furedi, 2005, 2006; Altheide, 2003; Glassner, 1999; Robin, 2004; Simon, 2007). As of 11 September, there has been a lot of talk about the politics of fear and the way in which this instrumentalizes widespread anxieties and fears. The literature has perhaps paid too much attention to the society of 'fear' (Bauman, 2006), 'risk' (Beck, 1992) or 'insecurity' (Castel, 2003). The fact that these anxieties and concerns exist means that for such literature an implicit cause and effect relationship is taken for granted. However, the world is full of concerns, fears and outrage without these ever leading to a 'war' against 


\section{8}

those responsible for them. Fear (but also outrage) should rather be considered as a form of rhetoric, the sociological nature of which consists precisely in it being made public. ${ }^{11}$

Of course, the spread of uncertainty, fear about change, growing social isolation, and a sense of a loss of control over the surrounding world, all create a fertile ground for the discourse of fear. The news media's portrayal of reality plays an important role in this respect. Unlike the search for patterns and consistency that characterizes the scientific method, the journalistic representation of experience tends to select all that is atypical, exceptional and beyond norms. In this way, the media does not just willingly 'host' the emergency of the moment, but ultimately provides the impression that we are inundated with events (terrorist attacks, murders, acts of violence) that are, in reality, rather rare. People increasingly have the impression that the world is somehow 'out of control' and naturally this can have serious effects on their emotions. But what is important is not so much whether these feelings are particularly widespread or not, but whether they appear culturally plausible and are embodied by activists who have access to the public sphere ('Citizens in the trenches to obtain security'). ${ }^{12}$ The point is the ability to say 'the people are scared, so ...', ending the prospects for any other political possibility. As Robin (2004) argues, personal fears, which are a product of our mental attitudes and experiences, have scarce impact beyond ourselves. Conversely, political fear is born out of conflicts within a society and between different societies. By treating this as an apolitical feeling, but nonetheless using it as a foundation of our public life, we refuse to see the injustices and conflicts that lay at its base, and in the process create the conditions of becoming hostage to its influence.

My aim here is to sketch a model of the 'peacetime war discourse' as something that constructs its objects, their causes and solutions in a particular way. I will consider it as a discursive formation in which the use of the war metaphor in its different expressions produces relevant effects. It appears at the moment when a political centre, aided by a complex galaxy of cooperating agencies, launches itself into battle and places its seal on those themes that literature on moral crusades has often attributed to the activity of pressure groups. The process that characterizes the success of discourses of enmity has a basic underlying structure that is the same for a wide array of social and political problems:

- Through a series of repetitive and stylized statements, one or more political leaders define the principal object of collective moral fear and/ or outrage. ${ }^{13}$ In doing so, they will almost always exploit a real threat or problem. Their work consists in establishing which threats are worthy of political concern and which ones are not.

- Through an insistent action, and exploiting the privileged access to the media that their position guarantees, this political coalition, often 
entirely informal and aided by a number of allied or influenced agencies and institutions, manages to give prominence to 'its' social problem in the public sphere. This requires fear and outrage to be continuously renewed through the publicization of a series of 'facts' and the cooperation of several 'independent' agencies.

- Fear becomes a profession and a career. On the one hand, it enables the subjects who commit themselves to its proliferation to acquire status and visibility and, on the other, it redefines the tasks and priorities of the bodies that are responsible for its management. Their exploits, statistics and statements fuel the problem's status as a reality and enhance its long-term success. This success can, and in a certain sense must, feed off failures. The continuing failure to eliminate drugs, terrorism and the sources of insecurity provides an infinite number of symbolic resources for those intent on keeping tensions high, brings a continuous flow of new resources to bodies in charge of control and provides many opportunities for heroic acts against such vast threats.

The war discourse during peacetime has reached such a degree of visibility and clarity that it is perceived, used and, to an extent, consumed as a kind of format. The resemblance between discursive shifts, themes, accusations and remedies, if not actual clichés, suggests that it is considered by political and media actors, to varying degrees of awareness, as a ready-made dispositive that they merely appropriate.

From a discursive perspective, the peacetime war discourse performs a number of operations and invariably features a wide but well-defined array of elements, as follows.

\section{Production of a social object}

\section{Foregrounding/backgrounding: the Problem}

First, the war discourse during peacetime places a problem in the spotlight while radically shifting all the others into the background. This is not only a zero-sum game, in which the space occupied by the 'Problem' in the public sphere removes the visibility of competing themes, but is also a constitutive element of the discourse: war requires an exceptional effort and sacrifices for everything else. 'Security' is the 'priority of priorities'. ${ }^{14}$ In some cases, this leads to denial about the existence or seriousness of competing issues. ${ }^{15}$

\section{Framing: bringing evil into focus}

Within the Problem, a structure of relevance is established by selecting certain events and promoting them as elements that, de facto, define the Problem itself. 'Insecurity' in Italy, as in France and Great Britain, is never 
a problem about the outlook of the future or about guarantees in the present, but about threats to one's personal safety, only if these come from the street and its most visible users (and not, for instance, from organized crime), and only if they concern us, the autochthonous people. The degradation of the urban environment is part of this, but only in the form of graffiti or illegal markets, and not when it assumes the guise of unauthorized building or illegal rubbish dumps. The definition of the Problem gives rise to precise interpretations as to its causes and effects, as well as moral considerations and predetermined solutions.

The frame that imposes itself as the Problem is soon able to cannibalize all other issues, re-translating them into its own terms. As Simon (2007) shows, there are numerous examples of how the fields of schooling, family and employment are increasingly controlled and managed through the frame of crime. Another exemplary case is that of the various Wars on Drugs that have allowed a re-framing of problems caused by economic and social inequalities to be treated instead as the effects of the use and trafficking of drugs by African-Americans (Johns, 1992).

Problems defined by the peacetime war discourse tend to have recurring characteristics. The discourse targets threatening phenomena, but only if these can be traced back to a deviation from formal or informal social norms, hence, if they can be construed as an 'Other' that besieges or infiltrates the 'community'. It often prefers to disregard the causes, or to resort to more or less surreptitious explanations that implicate the nature or culture of individuals. In any case, the emphasis in the so-called Western societies is invariably placed on individual responsibilities, hardly ever on social responsibilities and even less so on state or corporate ones. ${ }^{16}$

\section{Description: opacity}

The peacetime war discourse constructs a vague object through recourse to abstraction (once again, with terms such as 'terror' and 'insecurity', but also 'drugs', which in Italy is wilfully used in the singular (droga) so as to encompass the many implicated substances under a mythical unity), the use of metaphor (the 'axis of evil') and often the deployment of terms that act as wide-ranging containers (such as 'Islamic fundamentalists' and 'Al Qaida', which are both used to refer to extremely varied elements). Overall, the object is defined by the context rather than by its own presumed features. Guerrilla fighters or acts of war are labelled terrorist when they operate against us. A substance is only a 'drug' when it is made illegal. An attack, a sexual assault or simply stealing someone's snack becomes an act of bullying, especially when it is committed in a school environment. This vagueness allows powers to be largely exempted from any sort of evaluation of their performance (Glover, 2002; Collins, 2002). It creates enemies against which it is possible to obtain significant victories, but which cannot be permanently eliminated and are therefore effective for turning panic into 
something cyclical. At the same time, the vague definition of the Problem guarantees a large degree of freedom to choose who to fight.

\section{Construction of a deep narrative structure}

\section{Complication: threat}

Naturally, and necessarily, the 'Problem' appears because something has happened and a threat to the community has emerged. The less the object is a threat, the more the war discourse is inappropriate. Identifying and continuously reviving a threat is possibly the most cumbersome, lengthy and strategic task that the fear machine has to undertake. During the 'alarm' (a good word, if ever there were one) over 'Islamic terrorism', the main element of the 'facts' reported by newspapers in Italy ${ }^{17}$ has consisted precisely in the voicing of the alarm itself: 'alarm', 'risk', 'the shadow of $\mathrm{Al}$ Qaida', 'terrorist danger', 'threat of attacks', 'beware', 'suspects', 'they were preparing', 'they wanted', 'they organized'. The alarm, which is itself a metaphor for war (originating from the battle cry 'all'arme' - 'take arms!'), is often the expectation of something that does not exist, but which nonetheless is predicted to happen. This situation of stasis is contrasted with the frantic actions of our protectors with terms such as 'blitz', 'wiped out', 'discovered', 'controlled', 'investigates', 'steps forward', 'training exercise', 'unmasking' and 'manhunt'.

A typical way of justifying an emergency (another much-loved word) is through the use of the term 'a new type of'. Hence, we often read of 'a new type of' terrorism and weapon (WMD), a 'new type of' youth deviance (baby gangs) and drug ('crack', synthetic drugs, the 'rape drug' and 'supermarijuana', claimed to be five, ten, twenty-five or even fifty times stronger than the previous variety), or a 'new type of' crime or criminal organization ('mugging', ${ }^{18}$ or the 'Chinese Triad'). If something new has happened and this something entails unprecedented threats, we do not have just an emergency but also a justification for measures that are equally unprecedented. The creative work that underpins these new threats is evident in the marketing used to transmit them. Neologisms are often coined for this purpose (the very term 'marijuana' was chosen in the 1930s by FBN (Federal Bureau of Narcotics) officials who took the name from the Mexican state of Sonora), but the discourse that coins them is so hegemonic that the objects that it constructs are subsequently perceived as objective and natural facts.

\section{Partition: us-them}

The basic operation achieved by the peacetime war discourse consists in producing entities that participate in the representation of the Problem and which are separated from each other by strict boundaries that render them internally homogenous. It is the typical opposition between us and 
them that refers to a specific layout of social relations. G.H. Mead captured this movement perfectly when he wrote:

Social organization which arises out of hostility at once emphasizes the character which is the basis of the opposition and tends to suppress all other characters in the members of the group. The cry of 'stop thief' unites us all as property owners against the robber. We all stand shoulder to shoulder as Americans against a possible invader. Just in proportion as we organize by hostility do we suppress individuality.

(Mead, 1918: 591-592)

This opposition must be continuously maintained and legitimated. Conversely, its effect as a source of identity (the creation of community and not just enmity) does not require a particular amount of effort. Speeches, rituals and calls that directly invest in 'us' and feed off an apparent 'wish for community' are common, but these are mainly a by-product of the primary opposition.

Naming and qualifying are the first linguistic tools used in this process. Those responsible for causing fear must share a common identity and the easiest way to identify such people is to name them. Through an act of symbolic violence, difference is constructed, categorized and controlled. The repeated use of stereotypical descriptions continually confirms the presumed common features that justify the existence of 'them'. On the opposite front, in the 'war against', the nation's identity is stronger than ever, although this consists, of course, in a strained unity that hides hierarchies and inequalities, conflicts between interests and different prospects. This identity is the outcome of a series of oppositions (illegality/legality, moral/ immoral, contempt/respect, dirty/clean, violent/peaceful, archaic/modern), in which the emphasis is placed more on them than on us, so that identity normally emerges through difference.

\section{Characters: the community of victims and its monsters}

The basic us-them construction is represented by figures who tend to possess recurring features. In most cases, 'us' is verbally expressed according to a range of generalities, of which the most important one in ideological terms is the embodiment of an idea of community. The nation, the city, the neighbourhood, the 'people', the 'residents' and the 'citizens' are all universals (insofar as they appear to indicate something in an abstract manner without distinctions) that conceal their discriminatory and exclusionary logic. For example, the Roma or immigrants are never referred to as 'residents', the 'city' or the 'people', but neither are drug addicts, hooligans or paedophiles. In this way, the community is construed as the community of the included, which widens or shrinks on the basis of the issue at stake. 
In the war discourse focused on the theme of crime in all its guises, a new 'testimonial' has become increasingly recurrent and central in the portrayal of fear: the real or potential victim (Robin, 2004; Furedi, 2006; Simon, 2007). This especially takes place in the United States and the United Kingdom, where this figure plays a social role that is shaped according to a precise cultural script (Altheide, 2003), while in mainland Europe this role often assumes more abstract forms. The bond between the testimonial and the community ('Everyone is a victim', as one British Labour Party policy statement announced back in 1995) performs a double function: on the one hand, it projects the agency onto the most recent scapegoat and, on the other, through the celebration of an imagined community (Anderson, 1991), it confers democratic legitimacy to even the most autocratic of war discourses. In both the 'War on Terror', with its accent on a sense of mourning and public rituals commemorating victims, and the fight for security (where insecurity has become defined as a 'popular sentiment', the concept of 'perceived insecurity' has been formulated and the overall theme has been renamed 'demand for security'), 'what people want, say or think' becomes the true means of legitimating policies of enmity.

The victims re-evoke age-old figures, such as the 'honest-father-of-thefamily' and 'housewife-dedicated-to-her-home'. They are the embodiment of the 'normal citizen', a caricature of normality that uses sentiment rather than duty as its measure. This normality has always been set against an otherness that lies outside: deviance, the fundamental cornerstone of news media discourse.

A victim requires a tormentor. But what are the characteristics of an enemy? Almost everywhere one finds the same strategies: dehumanization, sub-humanization or super-humanization. During the Reagan period (Jackson, 2006), terrorism was already being portrayed through the use of medical or disease metaphors (scourge, cancer, infection), just as fascist racism had once done and contemporary racism continues to do, seeing lumps, sores, viruses and, most importantly, the need for 'bonifiche' (decontamination and redevelopment) (Maneri, 1998). These forms of dehumanization - drug addicts advance 'like ghosts', the Roma petty thief 'climbs like a cat', immigrants 'crowd their flats like mice' - are often accompanied by 'atrocity tales' that conjure up myths of superhuman or subhuman monsters. In Italy, if a crime is defined as 'heinous', the person who committed it in the 1990 s was invariably an 'Albanian', or a 'Romanian' during the last decade (Faso, 2008). A foreigner who is arrested 'flies into a rage' and resists 'with superhuman strength'.

Dehumanization and 'monsterfication' are functional to the creation of the threatening figure and to the construction of an irrational, unknown and dangerous 'Other'. As several observers have noted, 'barbarians' (the enemies) can be equated with the Freudian $I d$ : irrational, violent and dangerous, and often libidinous. Thanks to this projected image, we can 'orientalize the Other' and construct our Western identity (Said, 1978). 
Orientalizing the Other, any other, is attractive because it provides us with the screen on which to project all unspeakable evils; unspeakable not only in the sense that they are extremely complex but because they are much closer to home than we are willing to acknowledge. As Escobar (1997) claims, dehumanization is necessary to turn the Other into a mirror image of our demons: it is the return to our threatened humanity.

The enemies targeted by peacetime war discourse are inevitably weak ones. As a discourse of power, the war discourse never grapples with itself. In Italy, during Tangentopoli (the great crisis during the early 1990s that wiped out an entire political class involved in a widespread system of political corruption), 'emergency' and 'alarm' would have seemed almost sober definitions, yet nobody used them. Similarly, no one ever considered waging a 'war on corruption' or treating the individuals responsible as enemies. Enemies lack a voice, and this is never the case for a corrupt politician.

In many cases, policies of enmity have devastating effects on their recipients. In others, they are limited to a sort of announcement-effect, in which war mainly consists in its declaration while, apart from the cultural sphere, the concrete effects are largely irrelevant for those on the receiving end. Whether a matter of inflicting heavy defeats on the enemy class, or simply announcing a firm response, what is often most important for the leaders is to convince voters that they are the only ones who can be trusted. During periods of rapid change in which certain social groups are unsettled and their status is threatened by the arrival or emancipation of other groups, minorities or populations, being perceived as the last bulwark against these dangers may be the only objective that entrepreneurs of fear set themselves. It is difficult for them to wage a direct attack because this runs the risk of accusations of cynicism or, worse still, racism. Rather, it is easier to identify certain issues (drugs, petty crime, the oppression of Muslim women) that can be readily associated to the true target of hostility. War on opium! ('Finally someone does something against the Chinese'). Ban marijuana! ('It's the Mexicans' turn'). Let's prohibit the veil, female genital mutilation, the mosque and even minarets! ('If it weren't for them, there would be no one standing up against the invasion of Islam and immigration...'). These are all symbolic fronts that voters effortlessly recognize. ${ }^{19}$

\section{Agency: reacting, with sharp reflexes}

Just as wars often begin with a real or deliberately provoked incident that may justify a reaction, the narrative in peacetime war discourse starts with an entirely external agency (we have been attacked, infiltrated, poisoned, besieged, threatened and groped, hence we must react). The rhetorical dispositive of defence is necessary to justify hostile and violent speeches and actions, by shifting the initiative onto the bearers of threats through an 
often carefully prepared strategy. In contemporary society, increasingly dominated by the media, this dynamic has been increasingly exasperated. In situations where the media tends to construct emergencies in order to strengthen the impact of a news item, politics expresses itself by producing responses to the previous day's emergency. A lady was killed and the murderer's nationality was Romanian? 'Easier expulsions for Romanians!' or, better still, '200,000 foreigners will be kicked out.'20

\section{Positioning: I am above you - I am like you}

So far, we have encountered characters from Manichaean accounts. A speaker, however, ambiguously overlaps with the story and its actors (the victims and tormentors). When Maroni, the Italian interior minister who took office in 2008 following the centre-right's electoral victory around the issue of 'security', decided to deploy Italian army units in four cities, he was finally able to declare that 'the time for firmness has come, let's get rid of fear'. ${ }^{21}$ Maroni constructs the rulers and the ruled as a single unit that possesses common feelings ('let $u s$ get rid'). He also calls on the community to pull together, while simultaneously carving out his role as its protector. Here, the figure of the protector is both different and the same as the victim (Maroni is scared, while the faces of a thousand presidents enter into our homes embodying the feelings experienced by victims). This is able to happen because the protector is both in the story and on the outside as its narrator. At the level of énonciation, as developed by Émile Benveniste, the substantial and foundational ambiguity of the peacetime war discourse basically lies in superimposing a 'me-you' onto the 'us-them' dichotomy, producing a 'meyou-us' versus 'them'. This vertical unity, in which the 'community' is treated as an infant and sheltered under the protective umbrella of its leaders with whom it simultaneously identifies, is precisely what politicians strive for. Fear, as Robin (2004) recalls, is also a feeling of the powerful towards the weak. Hobbes said that 'the end of Obedience is Protection', but he might as well have said 'the end of Protection is Obedience'.

The dialogic-rational confrontation is terminated because the imagined community resulting from the mobilization of war holds no love for those who are not patriotic. Dissent is delegitimized in the name of a necessary unity and is replaced by a carte blanche for those in power. Rather, citizens have to all become informers. ${ }^{22}$

\section{Valorization and emotions}

\section{The morals of fear}

War discourse during peacetime brings a dimension of passion into the core of policies and their accompanying discourses, which are otherwise ideally considered the reign of practical rationality. Alongside fear, feelings such as 
compassion and solidarity for victims (even love in the case of abused children) play an important role. At the same time, the identification of a peril is projected onto a system of values that classifies problematic behaviour as an offence against morality. Outrage is one of the feelings that is most often represented in the discourse of enmity, which overflows with a highly moralistic vocabulary. As with the classic reactionary discourse, insistent references are made to traditions, customs and values that are idealized and caricatured in response and retaliation to some kind of change. This explains why the theme of 'decorum' in public spaces has played such a key role in the discourse and policies on security. With apparently little bearing on the alarm about threats to personal safety, the well-kept state of a small neighbourhood park comes to symbolize the threshold of civility and society as a moral value. The need for decorum is also about a need for mental hygiene and for the maintenance of the boundaries between the inside and outside, us and them. More generally, the peacetime war discourse is about establishing a unity with clear boundaries: between the centre and the margins, the legitimate and the illegitimate, dirt and cleanliness, attraction and repulsion, the known and the unknown, order and disorder, and, last but not least, the human and the inhuman.

\section{Performativity}

\section{First and foremost, mobilization}

Drawing on passion and moral outrage and invoking threats all aim at encouraging involvement while preparing a call to action. As a myth about rebirth and regeneration, war always presupposes a mobilization, an active attack and a strong position against something. This is another reason why politics is so attracted to its discourse: 'now we will act'. As it is a process that legitimates, requires and produces bloodshed ('to counter illegal immigration and all the ills it brings, we have to be nasty not conciliatory'), ${ }^{23}$ the action that this discourse invokes must assume a belligerent dimension, which automatically excludes or ridicules any solution that seeks to understand the social and political conditions that lie at the roots of threatening behaviour. As Mead stated, 'to understand is to forgive' (1918: 592), and the immorality and dehumanization of the bearers of threats does not allow this to occur. On the other hand, the time scale of the war discourse is the present. This enables the dehistoricization and decontextualization of the causes of problematic behaviour, which, in turn, is naturalized.

\section{A disciplinary regime: loved by politics, welcomed by the media}

It would seem that the resort to militarized metaphors started to spread through Europe after the disappearance of the traditional enemy personified 
by the Soviet bloc and 'communism' and, over the last few years, has experienced a powerful acceleration. Some medium- and long-term factors have assisted its rise.

For a number of decades, there has been talk of the crisis of politics in societies increasingly conditioned by the action of supranational bodies, organized capital and various pressure groups, and of its subsequent difficulty in creating long-term legislative programmes that channel the specific and diversified interests present in society. Thus, the need arises for legitimation, visibility and consensus, which is most readily achieved by resorting to populist policies that give prominence to situations of crisis, stir up fears and allow specific differences to become unified. The war discourse provides the necessary simplification for this populist and Manichaean management of the crisis and, in many ways, leads us back to the Europe of the 1930s. It is a perfect distraction that covers up the evasion of more complex social problems that produce conflict and damage powerful interests, and which cannot or do not want to be tackled.

A second revealing element regards the enemies of the war discourse. If we consider internal enemies, it appears evident that they are selected from the sorts of social problems for which states do not want to take responsibility. It is plausible that there exists a very close relationship between the retreat of the welfare state - interlinked with the tax revenue crisis of states and the competitive pressure that comes with the globalization of the economy - and the construction of a discourse that portrays recipients of public welfare policies as enemies of society. While the mainland European left, in particular, had tended to pinpoint the social causes to problems, these are redefined by neo-liberal thought, which instead places the stress on individual responsibility as the cause, linchpin and resource to tackle them. On both sides of the Atlantic, those considered responsible for and creators of their own problems are derided, stigmatized and often criminalized. They include 'Welfare scroungers' (Hall, 1980), 'single' and 'teenage' mothers (Sidel, 1996; Glassner, 1999), drug addicts, the unemployed, the homeless, mental patients, beggars, street hawkers and Roma people, all of whom have been removed, in varying degrees according to each case, from the protection of the welfare state and have above all been treated - some to a greater and others to a lesser extent - as menaces to society and as problems that they have brought $u s$.

The war against immigration clearly appears to be a strategic question. In the light of the conflicts between capital and labour during the 1960s and the 1970s, the welfare state represented a class compromise. Once the native working class has disappeared or has been rendered innocuous, it is no longer necessary to make compromises with the new labour force in the unqualified service sector, industrial and agricultural production and construction: it is enough to strip it of its rights. As such, the new international division of labour produces a class of non-persons (Dal Lago, 1999b). However, the shift from class compromise to exclusion requires that 


\section{8}

certain human beings be permanently removed from society: a removal that must be continuously legitimated. Hence, they are no longer class enemies, but a class of enemies situated outside society. The centrality of the contemporary bellicose discourse is therefore bound to this strategy. However, it rests on far broader foundations. Relations between the global North and South, characterized by growing inequalities, an ultra-colonial plundering of natural and environmental resources and political and military interference that is no longer partially contained and legitimized by the division of the world into two conflicting blocs, produce two sorts of relevant consequences. On the one hand, they trigger migratory movements that are not even deterred by the militarized management of borders and, on the other, they provoke resentment and public disorder that arouse greater fear the less they are channelled through institutional and controllable forms.

These two effects of the neo-liberal global order have been tackled in two distinct ways. The first can be defined, without exaggeration, as a war on migration (Palidda, 1996b). Patrols, camps, deportations, round-ups, detention centres, hyper-technological surveillance mechanisms and databases are just a few of the military-style instruments used to control migrants. The second has been confronted by a series of ordinary military intervention operations that are ambiguously indicated by well-known oxymorons: peace keeping, international policing, pre-emptive war and humanitarian war. 11 September represented the fusion between the internal and external fronts, because from this moment on - and starting from the logical premise that a majority of 'terrorists' were immigrants every immigrant became a potential terrorist (all the more so if they came from an 'Islamic' country).

The two fronts of intervention are interesting because, in both cases, the metaphor of war is continuously corroborated in public experience. Terrorism, which originates (or rather, must originate) ${ }^{24}$ from the outside, is perfect to bring the military inside..$^{25}$ Bars, walls, guards and checkpoints disseminate a military and prison aesthetic to a greater extent than ever before, especially in the United States and the United Kingdom. ${ }^{26}$ Migrants, Roma people, refugees and asylum seekers are increasingly present in public and media discourse as a result of the images and language produced by the institutions that directly deal with them, such as police forces, border guards, customs, the navy and Frontex. It is a vocabulary that speaks of countermeasures and controls and that reflects the respective outlooks and priorities of these agencies, foisting them upon the public, together with the objects that they handle, modify, produce and define (Maneri, 2010). These media sources are the oligopolists of a linguistic production that confers meaning to the 'problem of the moment'. Against the backdrop of this iconic, verbal and physical landscape, declarations regarding the 'war against', despite the repeated failures, appear culturally plausible. Indeed, they seem paradoxically to be the only discourses that make any sense. 
This discourse regime is a powerful instrument of social control. Freedoms acquired through struggle and otherwise untouchable have, with a few strokes of the pen, been sacrificed on the altar of the discourse's objectives. Wars around crime, drugs, terrorism and security have released military personnel and police forces from the binds of red tape and exempted them from any accountability. Entire categories of individuals are normalized by repressive apparatuses deployed for this specific purpose. At an international level, as the 'war against narcoterrorism' during the 1980s demonstrated, the old imperial policy of gunboat diplomacy finds its present-day justification in the metaphor of war. In all these forms, the peacetime war discourse appears to us like a disciplinary regime (Foucault, 1975) founded upon the use of force and useful to govern violence so as to guide its effects.

\section{Notes}

1 This famous statement was attributed to Nixon by one of his confidants.

2 Widely used, this phrase dates back at least to the time of Aeschylus.

3 The 'War on Terror' became a global emergency thanks also to the ability of the networks among the various countries' secret services to spread their predictions of imminent (and often non-existent) threats, which in turn were presented almost in unison as 'facts' by media around the world.

4 This is also the effect of the growing mediatization of political discourse. The media appreciates momentum, dramatization, excitement, personification, simplification, and the agonic discourse delivers them in abundance. War terminology itself is one of the main components of media jargon, whereby a criticism is an 'attack', a police operation is a 'blitz', immigrants are an 'army' and their movement an 'invasion', a protest is a 'revolt' or 'crusade', and so on. In a certain sense, war has forged the language of the media and the latter, in turn, has told politics how to speak.

5 Craxi was the secretary of the Partito Socialista Italiano (Italian Socialist Party) and head of the government in the 1980s.

6 This was reported in La Repubblica, 25 October 1988, under the title 'Let's punish drug addicts'.

7 This is how La Repubblica introduced the figure of the district attorney:

The Manhattan district attorney, Rudolph Giuliani, is one of the most prominent representatives of this new society. His name is a synonym of intransigence, strictness and tenacity. Here in America, when one talks of the fight against the Mafia, corruption and dirty deals, one is talking about Giuliani.

(Repubblica, 25 October 1988)

8 This poll was conducted by the SWG Institute and reported in La Repubblica, 30 October 1988.

9 It is estimated that those entering prison for drug-related offences amount to 47 per cent of all prisoners (Scandurra, 2009).

10 The Italian term 'fannulloni', meaning people who work very little or not at all, was used as a negative epithet by the minister for the civil service of the current Italian government to refer to employees of the public administration who were, in fact, accused of not working enough. 
11 Along similar lines Dal Lago (1999a: 9) defines fear as 'the interpretation and collective legitimation of generally arbitrary signs of danger as irrefutable evidence of the threat to the stability and existence of a society'.

12 Il Corriere della Sera, 25 November 2009, p. 21.

13 In the alarms about epidemics or environmental catastrophes, such as the case of bird flu, the initiative came from representatives of the scientific community. But these are discourses of fear, not of a 'war against'.

14 This slogan - like the more philosophical 'security is the fundamental right upon which all the others rest', voiced initially by 'left-wing' philosophers - has been used in Italy, as in France, on countless occasions.

15 It is not a frequent case because it is usually enough not to talk about it. However, during the 2008 elections, Berlusconi displayed his notorious optimism when he went as far as to deny the economic crisis.

16 As Johns (1992) recalls, the cases of overdoses from legal drugs in the USA, home of the War on Drugs, were three times more than those from heroin at the start of the 1990s. Likewise, while all methods were used to persecute people suspected of 'aiding terrorists', important companies were allowed to continue doing business with countries suspected of terrorism.

17 I have analysed the articles about international terrorism that appeared in the daily newspapers Il Corriere della Sera, La Repubblica and La Stampa between 2002 and 2006.

18 On the 'arrival' of 'mugging' in England, see Hall et al. (1978).

19 For a subtle analysis of the stakes involved in symbolic policies in the case of 'cultural crimes', see Brion (2010).

20 I refer here to the urgent meeting of the Council of Ministers of the Italian government on 1 November 2007 that approved a decree for expulsions. The exact number was proposed by Fini, the current president of the Chamber of Deputies (the lower house of parliament), but who at the time was in opposition.

21 This was the title of the online edition of the Corriere della Sera on 16 May 2008.

22 The citizen informer is not just expressly encouraged by police forces and authorities of all countries, but is also often placed in a position of not being able to refuse to do so (Simon, 2007). In Italy, landlords who do not report their 'illegal' immigrant tenant risk between six months and three years in prison, and a similar penalty is also envisaged in France.

23 These are the words of interior minister Maroni, reported in La Stampa, 3 February 2009 , p. 5.

24 Consider, for instance, the loss of interest in the investigation into the anthrax attacks once it became clear that the likely culprit was an American biological defence expert.

25 This is so much the case that, for the first time, the US now has a military command for North America.

26 See Graham (2009). It had already become widespread with the war on crime, for example, with measures such as curfews in hundreds of cities. In 2008 and 2009 in Italy, a state of emergency was declared in five regions 'in relation to the settlements of nomadic communities'. The neighbourhood watch programmes and ronde (citizen patrols), which were introduced in Italy in 2009 with a law called the 'security package', and which despite the enormous public hype actually saw a very low level of participation, are based on the presumption that criminals come from outside. Here the affinity with war itself is at its most striking. 


\title{
11 Global bureaucracy
}

\section{Irresponsible but not indifferent ${ }^{1}$}

\author{
Mariella Pandolfi and Laurence McFalls
}

The United Nations once dealt only with governments. By now we know that peace and prosperity cannot be achieved without partnership involving governments, international organizations, the business community and civil society. In today's world, we depend on each other.

$(\text { Kofi Annan })^{2}$

\section{'The party is over'}

New York, Vienna, Geneva, Washington, Paris, Rome: the offices and meeting rooms in buildings that belong to the United Nations, to other intergovernmental organizations or to major non-governmental organizations (NGOs) all seem to resemble one another, their etiquette, architecture and social urbanity gravitating around the perennial duet of cosmopolitan utopia and anxiety. Men and women, chosen on the basis of quotas allocated to each donor country, move along the corridors, interact in meeting rooms designed with identical egalitarian table arrangements in mind, with ample room provided for simultaneous interpreters: each movement is dictated by time constraints and incorporates an 'international' sense of urgency. Employees and functionaries with forward contracts for periods that normally range between six months and two years and identified by means of designations like P2, P3, P4, P5, or D1 and D2, which represent ascending hierarchical levels at the UN, but the designations themselves can also be adopted and understood by other international organizations. These abbreviations are emblematic of the UN's autonomy in shaping its bureaucracy; a great deal of attention is paid to these codes because, as of the 1990s, no job can be considered permanent, and therefore each abbreviation reveals an employee's position and status: the cosmopolitan denizens of this transnational galaxy are very sensitive to the duration and renewal of these coveted contracts.

The stress between the end of one contract and the beginning of the next, both at headquarters and at the local offices handling emergencies and crises, is palpable: 'I was in Macedonia, will they send me to Darfur?', 'I 
“did" East Timor; maybe they'll send me to Afghanistan?', 'I have problems with my boss, perhaps they'll move me from New York to Nairobi.' In the multiethnic corridors, gossip follows dangerous paths: undercutting a colleague or a boss by revealing confidential or unofficial information is not an unusual strategy among these cosmopolites. The indiscretions and scoops that bounce from these corridors to the media, making use of real or alleged secret reports, are just another tool for lateral negotiations within the network of power relations that rule this international galaxy.

These petty intrigues call into question the technocratic rationality upon which the global bureaucracy bases its legitimacy. Michael Herzfeld in The Social Production of Indifference (Herzfeld, 1992) provides an interesting interpretation of the symbolic roots of modern Western bureaucracy, which, he argues, is not the result of a process of rationalization. Bureaucracy, so central to contemporary societies, seems to Herzfeld to be quite distant from, and almost stand in contradiction to, the apparent foundations of our contemporary world. He shows how, contrary to common opinion, bureaucracy does not create responsibility through clear hierarchies of command, but rather indifference and irresponsibility. The circle of irresponsibility becomes a fatalist theology, where bureaucracy turns into a system that constantly legitimizes its behaviour by shifting blame from one part of itself to another in a Kafkaesque manner that calls for bureaucracy's reinforcement as an antidote to its own failings. Bureaucrats can always shift criticism onto their boss, onto those of inferior rank, or onto the system itself and can therefore protect themselves through a mechanism that produces distance and indifference.

While Herzfeld's dystopian analysis may hold for the modern bureaucratic state, our own experiences of contemporary global bureaucracies have shown that we must distinguish between irresponsibility and indifference. By projecting onto bosses whose careers are rising or falling, onto the locales in which they operate, onto experts who create distrust and suspicion, cosmopolitan bureaucrats resort to a strategy of personal irresponsibility, but not to indifference. In fact, they enter a cycle of passions, fear, envy and rage that become tools that feed the bureaucratic mechanisms themselves. They are sincere about their objectives and in their frustrations with their failures. The bureaucrats in the international community's 'cosmopolis' feed on information and mandates for action on a global scale and are therefore not constrained by a closed system of values and practices, which could indeed lead to indifference. Precisely because they are not indifferent to the outcome of their missions, their passions become the embers that constantly rekindle the flame of a mechanism of projection of responsibility onto others. Paradoxically, the continuous accumulation of information, to which their actions contribute, draws on the logic of modernity but produces a virtual rationality: the more they learn, the more they can blame others in an ultimately irrational cycle of scapegoating. This endless projection of blame is possible, however, only because the 
global bureaucracy has, since the end of the Cold War stalemate, become but one facet of an extremely slippery configuration or network of cosmopolitan actors that includes independent experts, public and private subcontractors, and an exponentially growing army of NGOs. In this chapter, we propose to explore this cosmopolis (Zolo, 1997), both ethnographically and theoretically, first describing the mechanisms and logics of global bureaucracies and their symbioses with expert consultants and NGOs and then characterizing the peculiar form of legitimate authority exercised by this complex, tentacular apparatus of global government. We shall argue that the diverse and diffuse practices, techniques and logics at work within this cosmopolitan nebulous constitute a new form of domination on a global scale.

\section{Global bureaucrats}

We can see the logic of this irresponsible but not indifferent apparatus at work in the career trajectories of permanent functionaries, hired consultants and volunteers. Meeting in circumstances marked by war and a sense of urgency, during dinners attended by experts, project coordinators, journalists, peace keepers and reporters, young volunteers freshly adorned with their ID badges and enjoying their first international experiences hear stories about the rollercoaster fortunes of upper- and mid-level functionaries at international headquarters, fortunes which swing between ascent to the highest reaches and to crushing losses of power. Alongside the Ps and the Ds, another army summoned by urgency energizes the international community: a multitude of experts recruited to complete ad hoc projects is gathered, one might almost say compressed, by the pressures of emergencies. The contracts regulating the experts' career brief and term of duty, often issued for one single project, are called L contracts. Resorting to contractual employees is an indication/admission of a state of paralysis or inefficiency in offices that should be capable of dealing independently with most of the tasks that they end up subcontracting.

Contracts issued to experts belong to a ritual regulated by the 'TOR', or terms of reference. The TOR present the task to be performed; they constitute a document halfway between a schematic and bureaucratic description of what has to be done and a more technical plan dealing with where and how to proceed. 'To implement', i.e. to carry out a mandate whose technical correctness does not itself come into question, is the key phrase in the experts' jargon, and they will use it repeatedly while drafting their TOR. Both the mission's stated goals and agenda must be outlined in the TOR, which becomes a map of the project's different phases. After each mission, a report is drafted upon the contract's completion, which will subsequently authorize and legitimize the experts for their next missions.

The TOR is a vital document, which in principle ought to distinguish the hired expert from the permanent bureaucrat, but which instead 
becomes the first step towards the contracted expert's normalization. One needs to think, plan and operate in a manner that not only follows contractual obligations but, above all, follows procedures already routine to the programme or project into which the expert has been recruited. The formal, bureaucratic network and the implicit demands that gave rise to the request for the expert's services shape, control and surround the experts' plans with informal barriers and often succeed in having these experts join the ranks of the 'innocent and innocuous', conforming to these international organizations' common-sense logic. The operations for drafting and accepting the TOR thus tend to reproduce, though not explicitly, pre-existing procedures: from formatting rules to the adoption of a formalized style, to practicality as the essential requisite; the path from the first drafting of the TOR to the completion of the assignment and finally to the submission of the final report is one that allows little deviation from the existing institutional norm.

Indeed, the experts' roles themselves are subject to ambiguous logics: were experts called upon only because a specific programme or office was not able to achieve the result which the competence of the individuals involved would have led one to expect? Or were experts enrolled to corroborate or reconfirm the programme's or office's conclusions? Indeed, if project coordinators bolster their legitimacy by resorting to the experts' professional competence within their organization, they are also extremely anxious about the work these experts perform and the final product they deliver. Anxiety, unfortunately, although useful and legitimate in the context of achieving one's objectives, is rarely useful for a serene evaluation of the work accomplished: it instead leads to situations in which experts enjoy little autonomy. The experts' work becomes bureaucratized and subjected to control micro-mechanisms and to standardized performance-based evaluation criteria so that they ultimately lose all critical sense. Furthermore, co-optation, whether through friendship or political networks, often determines who can become part of the circle of experts, even for only six-month renewable contracts. Experience and professionalism are, to be sure, extremely important but ancillary virtues: personal connections come first; individual expertise will become a determining factor for career ascendancy only later.

Pandolfi, as an expert for several projects under the auspices of the UN and other international organizations between 1999 and 2001, found it extremely difficult to sidestep the bureaucratic negotiations that characterized the different phases of her work. The drafting of her TOR was extremely complicated, involving several practical issues, the first being her ability to preserve a degree of autonomy and avoid the bureaucratic constraints inherent to the TOR. The second, even more alarming, at least from the point of view of an anthropologist who does not conceive of the mission as a 'cut and run' operation, was the need to confront the logic of scheduled meetings on location. After all, one can easily travel 
through countries, meet many people and still continue to have a partial and conformist view of the places one has visited, especially if one adheres to a standard agenda that has been assembled in an office by others. The presumptuousness of experts who claim to have understood a country or a crisis area by going to dinners in diplomatic circles or events sponsored by international organizations is disconcerting. At other times, the 'unscheduled' but predictable discovery of local cultural practices by experts often accelerates processes of exoticization or essentialization of the 'other,' particularly in places such as the post-communist Balkans, where the terror and excesses of totalitarian rule lead the expert to expect to 'discover' the worst pathologies of a traumatized society. The need to meet local social actors is often reduced, within the schedules prepared by the secretaries of the local offices, to a series of encounters within a circuit that generates its own information, and which therefore tends to marginalize and exclude other points of view. Pandolfi remembers telling a particularly zealous secretary assigned to organizing the operational details of her mission that she had not come to Albania to immerse herself in society life and that, above all, as an anthropologist, she wanted to choose her informants, and therefore her information, on her own, or at least with a limited level of support from institutional actors. The secretary could not understand Pandolfi's reaction, and her disappointment was obvious: she had put great effort into organizing a 'prestigious' and, one should add, rather standard series of meetings with authorities whose analyses complemented those that were circulating on Albanian soil - albeit only within the international community.

As a hired consultant, Pandolfi met with ministers, ambassadors and representatives of international organizations who invited her for coffee, breakfast or lunch. After initially allowing herself to be subjected to this preordained ritual, she finally balked. War in Kosovo seemed inevitable and attempting to understand the social fragility of the areas of Albania that would soon have to support an extraordinary influx of refugees was her priority for her first professional assignment with the UN, and yet her requests to freely move around the country, and especially to meet noninstitutional social actors, were perceived as eccentricities that were difficult to comprehend. Pandolfi decided first to talk to the project coordinator and then to the programme director in a tug of war that would last several days until she was finally granted full autonomy in her work. Meanwhile, the diligent secretary saw her castle of prestigious meetings crumble to the ground, with every change to the planned schedule being perceived by her as an obstacle or a threat to her contract renewal. In actual fact, most experts end up accepting the bureaucratic agenda that has been prepared for them and passively integrate it, as a marginal detail, into the mission's results. The habit of not meeting non-institutional actors, or in any case actors who are outside the international circuit, is part of the normal state of affairs in most missions. 
The final phase of most missions is the drafting of a confidential report. Indeed, countless reports circulate between offices, reports requested from various experts and used to produce other ad hoc reports; and so the reports multiply and accumulate. Their language is invariably English, a simplified English however, a pidgin that mechanically uses categories and definitions that hide both local violence and the violence of universal utopia: words such as implementation, building democracy, power-sharing, law enforcement... Usually these reports simply accumulate on shelves in the offices of the various organizations and join the list of innumerable descriptions of the evils of the world and the equally numerous facile utopias for their solution. The reports are usually drafted at the headquarters of the organization that drew up the initial TOR: each TOR authorizes one contract, and it in turn shapes the mission's coordination and support at the crisis location. It thus also predetermines and frames the first evaluation report as well as the final report, in which the overall success of the mission is analysed and accounted for, but always from the perspective that had generated the mission in the first place ... At this point, however, the report can follow two distinct logics and take two different paths. If the contract was signed in New York, Vienna, Washington or Geneva, the report will have fulfilled its task, and it will be added to the countless others that have accumulated in the offices of the various $\mathrm{P} 2 \mathrm{~s}, \mathrm{P} 3 \mathrm{~s}, \mathrm{P} 4 \mathrm{~s}$ and $\mathrm{P} 5 \mathrm{~s}$, or perhaps passages, those that confirm the organization's mission or testify to its success, will be integrated into an annual report. The report may, however, be more or less officially put back into circulation and arrive at some local office that belongs to the galaxy of the mission's partners, yet if it does arrive at one of these local offices, it will now obey the rules of a second logic. By this point, the reports have often attained confidential status. They may then be given to you by the local elite as a sign that you, like they, have been accepted, that you, too, are part of this cosmopolitan community, that you have entered the circles of global civil society. Above all, they wish to show that those who have access to confidential reports have superior bargaining and negotiating powers in a society in which humanitarian crises, political transitions and regional conflicts have in reality blocked all autonomous forms of bargaining power. The group of people with access to these reports is undoubtedly small, but the relative power generated by control of this type of information, especially in areas of crisis, transition or international tutelage, is significant because those who share this information can claim membership in, and the incumbent privileges of, a transnational network which, to be sure, depends on the resources of the global bureaucracy but surpasses the reach of its formal procedures and hierarchies of command.

Indeed, the novelty of contemporary global politics resides not in the fact that the global bureaucracies, be they associated with the UN, the Bretton-Woods institutions or other intergovernmental organizations, 
can, now that they are finally freed from the constraints of the bipolar Cold War order, promote 'global governance', but rather in the fact that they do so as but one element within a complex apparatus whose governmental logic we shall attempt to define after briefly describing the other predominant institutional mechanism of the contemporary global order: the NGO.

\section{The symbiosis between global bureaucracy and non- governmental organizations}

Within the complex galaxy of global authority, a new type of political actor plays a pivotal role, its centrality distinguishing contemporary global power relations from past imperial or colonial forms. Although nongovernmental organizations derive from charitable groups whose emergence paralleled and accompanied the imperialist projects of the nineteenth century (Duffield, 2007), their explosion in numbers and in mission types since the 1990s have made them an integral part of the global apparatus that manages populations in (potential) crisis zones. Despite their label and their pretensions to autonomy, NGOs are intimately linked to governmental and intergovernmental organizations, operating internationally through their personnel, their sources of expertise and knowledge, their normative claims to legitimacy and their funding. They are the institutionalized subcontractors who implement the global bureaucracy's programmes, and in so doing they accentuate the cycle of irresponsibility while reinforcing the moral imperatives that sustain the bureaucracy's constant, roaming action. At the same time, NGOs reconfirm the global bureaucracy's utopian belief that the implementation of its expert programmes will entail its own withering away as societies become self-governing, albeit in conformity with the programmes the global bureaucracy (re)produces and propagates.

This illusion is particularly predominant in the post-communist societies of central and eastern Europe where confusion between NGOs and the concept of civil society reigns. The proliferation of NGOs has arisen from contradictory demands as they are expected both to substitute for fragile political institutions in the wake of communism and to present themselves as the kernel of a true, autonomous civil society. While the NGO boom has indeed permitted the emergence of new polyglot social actors, capable of constructing networks that have been granted recognition both locally and internationally, thus erasing the image of individuals tied to or oppressed by paralyzing pasts, their pursuit of mechanical, uncritical, forms of imitation of arrangements established by international organizations, as if these were the only acceptable logic of adaptation, has also had unintended consequences. As Hilhorst (2003) notes, the various dimensions of NGOs' strategies need to be examined, since they simultaneously provide services, erect ideological fortresses, respond to bureaucratic plans and attempt to legitimize their work by 
following a universal logic of accountability. The NGOs' thousand faces vary depending on whether their interlocutors are local populations, donors, colleagues, their own staff or other international organizations. Works that analyse NGOs' procedures, ideologies and practices show that the discursive practices intrinsic to the hegemonic nature of development exercise a constant and non-negotiable form of control on relations between the universalizing rhetoric of aid and development and the strategies that emerge from the local context (Ferguson, 1990; Hobart, 1993; Escobar, 1995). Obviously negotiation is fragile in contexts that were subjected to authoritarian forms of government. In postcommunist Europe, the most frequent strategy established special, hybrid tutelage/laboratory combinations that encouraged the proliferation of local NGOs in the midst of the growing administrative and bureaucratic confusion of the new democracies, while international NGOs operated in parallel.

This complex layering of interventions, of policy implementation and of authority involving international (inter)governmental organizations, international NGOs and local, allegedly autonomous, indigenous NGOs in networks of organizational, personal, financial and epistemic interdependence such as we have observed in Albania or Kosovo makes it possible for all actors to avoid responsibilities (Pandolfi, 2002, 2003, 2005, 2008). NGOs, however, can in particular claim their innocence, even as they vaunt their flexibility, adaptability to circumstances and moral commitment to whatever their particular cause may be. To be sure, the unlimited and uncritical power/right/duty to intervene has given way in the last decade to a chorus of criticisms, doubts and public confessions by both military and civilian protagonists. Once again, a savvy use of the media has shown that this sector is capable of recognizing its mistakes, rethinking its operational frameworks and reviewing its intervention strategies - that is, simultaneously to shirk responsibility and to reinforce its mandate (Yala, 2005; Brauman, 1996/2002: 42). To short-circuit criticism, the NGOS have first articulated eyewitness testimony of their own action, then offered an ethical and operational self-criticism, and finally proposed their own professionalization in a move that distances them from their role of ethical witnessing. Paradoxically, they operate on a global level, in the accelerated temporality of the need for action, in a universalistic ethical perspective, but they are answerable only to internal and self-referential criteria. If there are management problems, they are resolved by means of verification procedures that are internal to the NGO itself; if there are abuses of power, once again internal procedures, flexible and fast-tracked, determine whether any of the individuals involved should be expelled or moved; if there are criminal acts, they are often covered up by the reports' lack of transparency, since they occurred in a location whose jurisdiction lies in an ambiguous no man's land between international law and the local or national law. 


\section{Migrant sovereignty and therapeutic domination}

Motivated by its mission to save the planet, to save the sick, to save the poor and to save the warring from each other and themselves, the cosmopolitan community of global bureaucrats, experts-without-borders and NGO operatives perpetuates both its bottomless benevolence and ultimate irresponsibility through a novel form of authority that we characterize with the concepts of migrant sovereignty and therapeutic domination. Quite literally, the cosmopolitan community is migrant, its primum mobile being urgency. In emergency situations, it assumes a strong and authoritative identity, and is able to act invoking norms and strategies that are so independent of the locations in which it operates that it is able to impose itself, under the pressures of the need to inform and help, by adopting a new form of domination. The group composing this community has become progressively homogenized, both at the level of the protocols of the imagination and at the level of discursive practices, though differences in power relationships within the community itself remain significant. We contend that the category of 'migrant sovereignty' is particularly suited to describe the peculiarities of the phenomenon as a whole. This category defining the complex and heterogeneous world of the 'internationals' in crisis areas (soldiers, civilians, bureaucrats) is not metaphoric: it refers to a network of actors, actions and discourses that legitimizes its presence by invoking ethical-temporal rules and a meta-historical category that can be defined as the 'culture of emergency'.

The migrant and deterritorialized community that constitutes the cosmopolitan apparatus operates through the practices of social actors who recognize one another though they belong to different nationalities. This community arrives upon a location, occupies it logistically, suspends existing norms, imposes others, insinuates its own lifestyles and strings barbed wire to protect the individuals and things that belong to it. Paradoxically, the multiplicity of cultures displayed by individuals who belong to the migrant sovereign become progressively marginal under the pressure exercised by the culture of emergency action, be it military, humanitarian or developmental. The standardization of procedures applied, the protocols expected for each type of action, the technology of practices that require experts' certification and the ideology of actions that consider themselves both necessary and redemptive define a community that identifies reflexively with the project of belonging itself and which, apparently united only at the moment action is required, actually shares a common utopia at a deeper level.

This migrant sovereignty suffers precisely from the problem that it does not view itself as a cosmopolis, i.e. as a coherent community at home wherever it operates. Instead, its members view their respective actions as fragmented and autonomous and, in the cycle of irresponsibility, they can blame one another for the failure of their implicitly shared utopia to come 
to fruition. They create a permanent dissociation anxiety and hence practise a false self-representation. Despite this lack of self-recognition, the concept of migrant sovereignty identifies the elements that bind this community. The definition of sovereignty includes not only the element of legitimacy but also that of legality; it describes a form of authority that is both political and moral. The global bureaucracy today thus evokes not only a 'duty to intervene' or a 'right to intervene' but a 'responsibility to protect' in the name of an emergent transnational rule of law that would exercise control and sometimes replace national legal systems since these can justify the destruction of citizens and minorities. Sovereignty also includes a socio-anthropological dimension that cannot be overlooked: it is tied to the behaviour of actors, organizations and programmes that arrive, occupy and manage a specific territory. We qualify this sovereignty as migrant because this cosmopolis is deterritorialized; it is a mobile, flexible, exportable form of government, capable of moving individuals, logistical infrastructures and manufactured goods rapidly, always following the same standardized procedures.

The international community today is very different from that of the colonial period, though references to direct and indirect forms of rule abound in discourses and strategies critical of these contemporary forms of intervention. It is precisely the idea of intervention - an extraordinary action that pretends to restore order as opposed to the ordinary instauration of colonial or imperial order - that creates a divide between the occupations of the past and the more recent ones that appeal to the right/duty to interfere and the responsibility to protect. To understand the legitimacy claimed by this new, migrant sovereign, we turn to Max Weber's sociology of domination (Weber, 1978: vol. 1, ch. 3). According to Weber's Herrschaftssoziologie, any social order relies, at the micro-social level, on dominant actors' particular claims to legitimate authority. Weber (1978) identifies three 'pure', or ideal-typical, forms such claims can take: the traditional, the charismatic and the legal rational. Weber's typology implies a fourth, unnamed form. To explain this fourth form, we must recall that Weber's three modes of legitimation do not describe the normative contents of the claims rulers make to justify obedience to their commands but derive from the form of relationship between rulers and subordinates. Thus, traditional authority refers to a relationship in which the norm for obedience is inherent to the ruler's person embodying (a) value(s) in a 'timeless' regime of continuity, whereas charismatic authority emanates from the person of the ruler in an extraordinary, revolutionary regime of rupture. By contrast, legal-rational authority is literally disembodied in that the ruler appeals to an impersonal norm or procedure necessarily in a regime of continuity, the validity of the norm depending on its personal and temporal decontextualization.

This formal typology logically suggests a fourth mode of legitimation, namely one in which a ruler makes an impersonal claim to authority in a 
context of rupture with existing norms. By metonymic analogy to medical knowledge, we call this fourth pure form therapeutic domination (McFalls, 2010), for, as in the doctor-patient relationship of command, the ruler claims obedience by virtue of the application of a scientifically valid, impersonal procedure - a treatment protocol - in the extraordinary context of crisis. The concept of therapeutic domination can make sense of power relations on sites of military and humanitarian interventions in political and medical crisis zones, where an international corps of experts, the migrant sovereign, arrives with a panoply of standard operating procedures to cure social and physical ills with varying degrees of success but also with paradoxical side effects, including a self-defeating form of resistance to therapeutic domination that we label iatrogenic ('physicianinduced') violence. Analogous to patient non-compliance or refusal of treatment, iatrogenic resistance further pathologizes the targets of expert intervention in a self-perpetuating cycle so that intervention begets more intervention as the provision of food and shelter, for example, quickly necessitates not only the establishment of physical infrastructures but ultimately legal, political, economic, social and cultural reforms to make lifesaving measures effective, efficient and enduring. Therapeutic domination can thus spill over from the context of crisis management to become a generalized mode of government, just as preventive medicine can take over every aspect of a (potential) patient's life.

The technical correctness of therapeutic domination exercised by international humanitarian and development NGOs and intergovernmental global bureaucracies thus expands and perpetuates an order of domination that pretends to be localized, temporary and restorative. What is more, by provoking the futile resistance of iatrogenic violence, it prolongs and relegitimates itself in a manner that frees interveners from responsibility for failure and reconfirms their normative engagement, or non-indifference. To be sure, critiques of their own power (abuses) have arisen within the ranks of international NGOs, and they do not draw on the formal logic of our concept of therapeutic domination; but the concept sheds light on a global political order in which a host of technical experts exercise authority around the globe and over the heads of traditional state institutions in the name of human development, human rights, human security and human survival. The question remains, however, how and when this new governmental apparatus came to fruition.

\section{The birth of a new biopolitics}

This new form of sovereignty, suspended somewhere between the discourse of universal human rights and the technical practices of therapeutic domination, emerged fully with the Kosovo crisis. In the wake of the political-humanitarian catastrophes of Somalia, Rwanda, and Bosnia, crises that constituted laboratories for the technical perfection of the 
military-humanitarian-development complex, the intensifying ethnicized political conflict in the Serbian province of Kosovo provided the liminal occasion for the therapeutic apparatus to congeal as a coherent global governmentality. Proclaimed as the first 'humanitarian war', the NATO bombardment of Belgrade in the spring of 2009 was accompanied by the simultaneous deployment of a huge army of global bureaucrats, NGOs, and their incumbent independent experts and consultants set to save lives, to manage refugee flows and heteronomously to establish the political, juridical, economic and social conditions necessary for Kosovo's future 'autonomy'. As with the oxymoron 'humanitarian war', conventional language has had difficulty expressing the novelty of the political entity that Kosovo has become. Thus, for example, the Independent International Commission on Kosovo concluded, in 2000, that the NATO-led intervention was 'illegal but legitimate' and that 'Kosovo now exists regardless, for better or for worse'.

Kosovo, we contend, is not anomalous but paradigmatic for the new global therapeutic order. On the discursive level, from the first campaigns to legitimate intervention in the name of prevention of 'another genocide', down to current campaigns to market Europe's poorest territory as a beacon of hope for self-sustainability within a globalized economy, Kosovo has illustrated the rhetorical efficacy of an appeal to the ultimate value of human life. It has contributed to the construction of a political space in which global information admits only those appeals capable of producing emotions, passions and the desire to defeat the evils of the world. The emergencies that provoke indignation and compassion are expertly exposed by international organizations. While the institutional machinery and the articulation of messages of global solidarity grind forward in both the donor and recipient countries, the cosmopolis shows it is ready for action, that it is able to collect funds and launch appeals in a short period of time, not only to individual nations, but above all to the entire planet's population. The media present us with the world's tragedies and simultaneously tell us that we have to be present, intervene, provide assistance: and it is not the world's powerful who are called upon but instead all the 'fortunate' human beings who inhabit the planet. Religion, culture, power seem to be of no consequence in these appeals to fight the world's evils. We thus face what seems to be a democratically constructed information mechanism: a space that appeals to the need for interventions or the prevention of catastrophes and appears democratically irreprehensible. Next to this passive form of participatory democracy - that is, one that receives information but cannot manage it, except by sharing the gist of the message itself, making donations and considering the intervention itself as absolutely necessary - we find intervention itself, which, once activated, becomes impossible to control. We thus confront the paradox of the coexistence of the noblest will to share information and of the most opaque procedures implemented in zones of intervention. The combination 
of the mobility of the cosmopolis, of the urgent need for action in face of real (or feared) emergencies and of the undeniable social utility of many interventions makes it nearly impossible to establish any global democratic mechanism for controlling interventions, despite their appeal to a certain democratic legitimacy.

On the practical level, Kosovo testifies to the enduring nature of an authority that claims to be exceptional. The past decade there has exposed the dangers of managing crises by freezing them at the political level and creating a growing 'grey area', in which compassion, the rhetoric of human rights and the idea that one can fight with weapons to export markets and democracy all came together in a moral and practical swamp. Today this situation of the 'protected' unilateral independence of Kosovo is an emblematic example that can show us how fragile the management of post-bipolar crises really is. But this situation of fragility could be extended to the propaganda with which the mission in Afghanistan is managed, where a strategy of confusion conflates the protection of women's rights with the war on terrorism. The history of international relations and of politics in general offers no precedent, namely, where the alleged objective of political normalization draws on such an ambiguous confusion of political and military strategies. Whatever the original strategy might have been, it seems to have become lost in the rivulets of long-term emergency economic assistance, of UN missions, in which UN forces gradually militarize areas of long-term crisis, and of humanitarian goodwill gone awry in the micro-management of daily life.

Be it in Kosovo, Afghanistan or elsewhere, the idea of managing crises in the grey zone that calls itself humanitarian not only pathologizes intervention zones, it also pathologizes any peace accord; it pathologizes development; it pathologizes a democratization process that is staged with endless rhetoric but with little promise; just as it has pathologized the independence that Kosovo proclaimed in February 2008. The urgency/ emergency is permanent: a paradigmatic oxymoron of our contemporaneousness. The emergency's duration is transformed into an endless state of control and tutelage on the part of the complex machinery of the international community. The experts exhort us to be patient: getting used to living with the idea that 'there is still a lot to accomplish' has become the leitmotif in the corridors of New York, Vienna, Geneva, Brussels, Washington, Paris and Rome.

\section{Notes}

1 This chapter provides an overview of the various trajectories that our work on humanitarian intervention has taken in recent years. This research has been funded by grants from the Fonds Québecois de Recherche sur la Société et la Culture and from the Social Sciences and the Humanities Research Council of Canada. Our research has benefited from fruitful interactions with friends and colleagues, including those at Byron Good and Mary-Jo Del Vecchio Good's 


\section{M. Pandolfi and L. McFalls}

Friday Morning Seminar at Harvard University, at seminars at the École des Hautes Études en Sciences Sociales in Paris directed by Marc Abélès, Dider Fassin and Michel Agier, and at workshops that we have organized on the topic over the last few years at Université de Montréal in the framework of our Groupe de recherche sur les interventions militaires et humanitaires (GRIMH). We are grateful to Gil Anidjar, Vincent Crapanzano, Mark Duffield, Alessandro Dal Lago, Ugo Mattei, Michael Fischer and Salvatore Palidda for many rich exchanges. We would also like to extend our thanks to the graduate student members of our research group, GRIMH.

2 This quotation is taken from UN General Secretary (1997-2007) Kofi Annan's remarks at the World Economic Forum in Davos, Switzerland on 31 January 1999.

3 'The party is over' was the curt expression with which an academic and intellectual who took over the management of a major UN programme in the late 1990s terminated hundreds of contracts with experts that were significantly impacting on the programme's budget. 


\title{
12 The space of camps \\ Towards a genealogy of places of internment in the present
}

\author{
Federico Rabola
}

Our age - with its modern warfare, imperialism, and the quasi-theological ambitions of totalitarian rulers - is indeed the age of the refugee, the displaced person, mass immigration.

(Edward Said, Reflections on Exile)

\section{Definitions}

The passage cited above comes from an impassioned essay by Edward Said dedicated to the form of displacement that gets defined, in a slightly elegiac tone, as exile (Said, 2002: 174). Said's words allude to a point of no return where exile, as a specifically individual experience, reveals something that we no longer are. In fact, today the status of 'out of place' individuals is captured in political language through a series of totalizing categories and truisms: 'internally displaced people' and 'asylum seekers' (depending on whether the dispersal takes place inside or outside a state's boundaries), 'temporary refugees' or 'prima facie refugees' (persecuted individuals assigned temporary humanitarian status) and migrants, who may be 'economic' and 'regular'. One might well argue that these naming exercises amount to little more than words. In reality, such definitions end up producing exactly what they indicate by branding individuals whose existence reflects a condition that exceeds univocal forms of belonging. The only way to define this 'excess', therefore, consists in cancelling out all its discrete elements, attributing it with cumulative categories and, on the basis of these classifications, making choices and decisions about the fate of the individuals in question. Two further considerations, however, need to be borne in mind.

The first consideration regards the arbitrariness of such distinctions and how these can overlap in the story of a single life. In other words, after being forced to leave (and therefore falling under the definition of the 'internally displaced'), it is possible that an individual manages to cross national boundaries and to apply for asylum in a third country (hence becoming an 'asylum seeker'). What can then happen, although the 
chances are extremely reduced, is that the application for asylum is accepted, even if only temporarily (thus the individual becomes a 'prima facie refugee'). It should be remembered that applications made to consulates or the border police nearly always remain dead letters, and the rejection takes the form of a decree which prohibits a reapplication in other countries, thus leading to practical banishment (Valluy, 2005). In any case, the right to asylum, redefined as a generic form of humanitarian protection, is today conceived as a temporary instrument that presupposes the eventual normalization of the situation in the land of origin (UNHCR, 2006). Once the asylum status expires, it is presumed that the person will spontaneously return to his or her own country of origin. Otherwise, they will be threatened with a deportation order that, in most cases, will remain unexecuted, but which will nevertheless subsume their prior existence as internally displaced, 'asylum seekers' and 'temporary refugees' under a situation of precarity and blackmail that hastens their advance towards a definition of 'illegality'. The point, then, does not concern the commonly presumed 'objective' differences between individuals that share a condition of displacement, but rather the arbitrariness of such definitions and the political effects that these generate.

The second consideration directly regards the focus of analysis in this chapter. Each stage of the 'moral career' of these individuals in fact corresponds to a camp or temporary centre that is more or less equipped for the purpose of detention. Here, the official language also abounds with euphemistic formulae. Besides the various play on words accentuating either a detention or humanitarian aspect, there are a series of definitions that obsessively stress the transitory nature of such places: 'emergency temporary locations' or 'temporary protected areas' for the 'internally displaced'; 'transit processing centres' or 'identification centres' (depending on whether they are located in transit or destination countries) for 'asylum seekers'; the more uninspired term 'temporary reception centres' for 'temporary refugees'; and, lastly, detention centres or, in the case of Italy, 'centres of temporary stay' (which were renamed more explicitly as 'centres of identification and deportation') for undocumented migrants.

Thinking in less euphemistic terms, if it is theoretically possible that an individual passes through all the definitions discussed above, it is also politically constant that each of these definitions corresponds to one of these 'centres' or, put another way, definitively temporary zones. The absolute temporariness of these places of transit clashes with their equally peremptory relentlessness, as material epiphanies of the deterritorialized borders of the present.

\section{The camp as form}

It is from this constancy - the permanent transit through temporary places - that the hypothesis of a 'camp-form' takes shape: a common matrix able 
to account for the various manifestations in which camps inhabit the present (Rahola, 2003). Camps represent, first and foremost, the only 'possible' territory that reattaches a humanity in movement to borders and a univocal sense of belonging. The impression, in other words, is that it is the insufficient status of individuals which gives a 'sense' to camps. They exist as 'wasted' places for 'wasted' subjects, responses which exceed for subjects who exceed. Yet, this thesis is too mechanical and formal, and ultimately removes the 'dynamic' dimension of camps. For this reason, it is essential to consider not just the status of individuals but also the 'lives' of those who are forced to transit through a camp, including the forms of action and rebellion that take place there. From this perspective, for example, Michel Agier identifies a political space in camps that is in permanent tension and, in many ways, 'open' (Agier, 2008). Recovering the dynamic nature of camps, nonetheless, also means taking into account the sinister complementariness that welds places and individuals together, and hence the particular 'productive' dimension which permeates such dispositives. The way in which camps bear down on displaced individuals as a spectral possibility, defining their living conditions in time (in terms of precarity) and space (in terms of confinement), does not mean that camps can be dismissed as simply 'wasted' places. Any serious reflection on the issue must rather wrestle with a series of questions: what does it mean to be marked out as subjects whose fate is overshadowed by a camp? What role does a dispositive like the camp play in producing this condition? What dimension of power and what political space does this lead to?

The idea of a camp-form emerges out of the responses to such questions. It underlines the importance of taking into consideration all types of camps in the present, but also indicates an approach for rereading the history of this dispositive of confinement. A starting point is offered by Hannah Arendt, who defines camps as 'substitutes for a nonexistent homeland', where individuals who do not belong are interned:

Every attempt by International conferences to establish some legal status for stateless people failed because no agreement could possibly replace the territory to which an alien, within the framework of existing law, must be deportable. [...] [T] he only practical substitute for a nonexistent homeland was an internment camp. Indeed, as early as the thirties this was the only "country" the world had to offer the stateless [italics added].

(Arendt, 1958: 284)

The impression in just these few lines is that Arendt intended to assume the internment camp as a matrix in order to reconstruct a general historical narrative able to shed light also on its most extreme examples. It is this very 'matrix' that should become the focus of our attention and which needs to be brought up to date. The fact that camps represent a looming 
prospect for a range of 'out-of-place' individuals continues to appear a decisive element. Migrants and refugees share a condition of displacement that is primarily an act: that of transgressing the political imperative which attaches an individual to a place and of claiming other forms of (non)membership. This nonetheless regards an 'excess' that is also an evident (qualitative rather than quantitative) symptom of a point of no return, which throws all that is still considered 'in its place' into crisis. Stephen Castles and Alistair Davidson capture the sense of implosion of the forms around which political membership has been organized during the course of modernity:

Millions of people are disenfranchised because they cannot become citizens in their country of residence. Even more people, however, have formal membership of the nation-state yet lack many of the rights that are meant to go with this. [...] There are increasing numbers of citizens who do not belong. This in turn undermines the basis of the nation-state as the central site of democracy.

(Castles and Davidson, 2000: viii)

These words pinpoint the overall crisis of an inclusive system and of the dialectical relationship between inclusion and exclusion, whereby the latter is absorbed into the idea of a democratic state and of the rule of law. Here, I advance the hypothesis that the existence of camps is at times the most immediate sign of such a crisis, in the way that it alludes to an 'other' space that exceeds the borders of the state itself. ${ }^{1}$

There exists a substantial literature which describes camps in terms of exception. Through a rereading of modern sovereignty around the dialectical pairing of biopower and bare life, Giorgio Agamben (1998; 2005), for example, sees the camp as a paradigmatic place where sovereign power and life confront each other, leading to a suspension of every mediation and right. Agamben attempts to reflect upon that which is produced as an 'outside' in relation to a given legal system, and which can be captured and 'taken outside' (or, to use the Latin term, excipere; Agamben, 1998: 92), by suspending ordinary legal instruments and appealing to a transcendent idea of sovereignty, as the instance that decides the state of exception. In a perspective closer to the Foucaultian idea of governmentality, I believe that it is necessary to focus above all on the meaning of places and practices that define and govern subjects without necessarily referring to the transcendence of a sovereign decision, which on the contrary proves true on an immanent level, in the gestures and in the immediate effects produced by such places and practices (Foucault, 2007). Put in other terms, this means assuming the dispositive of the 'camp' for its specific 'positive' and therefore productive capacity. From this 'positiveness' originates the idea of the camp-form. Here, form is not understood in its immediate sense as a neutral frame devoid of signs and direction, but rather in its dialectic 
meaning of a 'principle that concretizes', a 'strange factor of attraction that distorts and prejudges' and which 'colors the entire field in question' (Žižek, 2002b: 29). This idea of form, associated with the matrix of the camp identified by Arendt, captures something that 'produces a difference': in other words, by superseding every experience of exclusion, it ratifies a radical difference. This idea is connected with an excess and determines the existence of individuals who 'exceed' the meaning of a place.

Camps 'give form' and 'produce a difference'. Their 'productiveness' is the ability to decree the existence of individuals liable to internment, over and above individual responsibility and biographical factors. Given the absolute temporary dimension in which they pass judgment and the transitoriness that they ratify, camps are not simply the only territory for displaced individuals, but, as a looming possibility, differentially define human beings who exceed borders and forms of belonging as 'detainable' and 'deportable' (De Genova, 2002). This appears to me to be the governmental character of camps: places where power is produced; dispositives through which a 'difference' is established.

It could be argued that every form of sovereignty endows itself with instruments capable of producing differences, and that power (in all its expressions, from its sovereign variant to the more microphysical power of an institution) is concretized through the act of establishing a minimal but incommensurable difference. Similarly, a sovereign decision is at stake in the case of the camp. However, this is a sovereignty that, instead of being presupposed, is produced and produces; that rather than decreeing exceptions on its inside, emanates from and acts upon a space that transcends the specific borders in which the concept of sovereignty derived its domain of enforcement. In other words, rather than being situated in a space marked by a suspension which takes exception to the legal system, camps seem to be governed by a logic that exceeds that space. And if they also reflect a performative decision, this is done in a way that exceeds every univocal dimension of sovereignty, being rearticulated in a multiplicity of anonymous powers and in a proliferation (rather than a suspension) of the normative sphere. Camps are therefore governmental dispositives that act, nonetheless, on individuals and impinge on a space in radical discontinuity with the national order.

The question therefore shifts to the political quality of this space and the type of power that it exerts. If such a space exceeds every idea of border founded upon a dialectical relationship between the inside and outside, and is invested without ever being absorbed back into such borders, it follows that the form of sovereignty subsequently produced will always be something that exceeds every conventional representation and acts upon and through a series of subjects who, rather than taking exception to forms of state and national power, will continue to exceed those as well.

I shall return to this matter later. Here, I want to simply suggest that camps delineate a separate history, which transcends every dichotomy 
between the inside and outside. The idea of a 'separate' history does not mean denying a rapport with the national order. Rather, this is something that is qualitatively incommensurable with a disciplinary dispositive that operates in a specific territory and system (all those institutions that, following the work of Michel Foucault or Erwing Goffman, are called 'total'): a rapport where there is no osmosis; in which every 'dialectic' between an inside and outside is transcended. In other words, camps exceed national space and allude to a different scale, but one which does not simply clash with the national scale. On the contrary, this scale both invests and is invested by the national scale in an increasingly destabilizing way. For this reason, the space of camps is not even qualifiable as a simple surface, nor is their action assimilable to a gesture that ratifies a form of exclusion. Rather, camps are the symptom of an overlap and imbrication in which the global and the national interpenetrate each other. Abandoning the idea of a straightforward contrast, it is necessary to realize that the meaning of camps is inscribed, first and foremost, in the act of decreeing differences of status in an intricate, multi-scalar dimension, where working out the distinction between an inside and outside becomes increasingly arduous, and where the global violently impacts upon the national, generating new solid concretions of borders (such as camps). ${ }^{2}$

\section{Excess}

This indication, among other things, allows us to return to a controversial issue which, since Arendt, has characterized many reflections on camps: the idea of superfluity that unites the places and the human beings destined to be interned there. The Arendtian hypothesis in fact betrays a certain aversion towards all that is not situated along the absolute political border that separates those who belong from those who do not, the citizen from the stateless person. Not belonging, though, does not mean not producing, nor is it true that camps are necessarily unproductive places. Their productivity, however, does not respond to an immediate economic logic (with the exception of the forced labour camp), nor to 'functional' criteria (if one considers the fact, for example, that most migrants held in detention centres are not deported but are released as illegals). This productivity is instead inscribed in the act of ratifying a radical difference: decreeing the existence of subjects liable to internment and managing their bodies; that is, governing them, disciplining them and making them illegal. The productivity of camps, in other words, is reflected in the particular excess condition of those who are interned in them, as well as in the specific productivity that characterizes such excess. Certainly, defining the condition of a refugee as 'productive' would appear far-fetched. Excluding the various 'humanitarian' economies, the drama of deportation and forced movement seems, on the contrary, to suggest the desolate sense of something 'beyond all calculations', which Arif Dirlik invites us to extend globally: 
Those who do not respond, or the 'basket cases' that are not essential to those operations - four-fifths of the global population by the managers' count - need not be colonized; they are simply marginalized. What the new flexible production has made possible is that it is no longer necessary to utilize explicit coercion against labor at home or in colonies abroad. Those peoples or places that are not responsive to the needs (or demands) of capital [...] simply find themselves out of its pathways.

(Dirlik, 1994: 351)

These words suggest an absolute waste. For example, the human condition that crowds a refugee camp can appear along these lines; therefore it is not even worthy of the common language of exploitation. However, I do not think that the dramatic reality of the 'basket cases' continually produced by global capital allows for the excess to be read exclusively as superfluous because of its unproductiveness. Moreover, the new 'flexible' production resorts to forms of coercion of living labour which inundate both the (ex) colonies and metropolitan cities, leading to the overlapping of maquiladoras and sweatshops, immaterial and slave labour, formal and real subsumption. And contemporary migration responds to a decidedly productive logic by representing a humanity as exploited because unrecognized (or recognized on a strictly differential basis), because rendered illegal and because in excess. Distinguishing between a productive excess and a 'residual' and abstractly political excess in fact sanctions the arbitrary differences and partages inherent in government strategies (for instance, between forced and economic migration or between migrants, refugees and evacuees) and, as a result, loses a continuum (even biographical, as I have tried to demonstrate) which is the underlying cipher of the contemporary excess, insofar as this comes under the more general circuit of mobility. I believe that the significance of excess, as a condition that claims a right to mobility and is situated beyond every exclusive form of membership, is materially defined in the spectral possibility of labour separated from all rights, and blurs every distinction between productivity and unproductiveness, exploitation and abandonment. In other words, it is around the deep rift between labour and rights and between life and its contingent surroundings that the true boundary of excess is constructed: a political border that is at the same time economic and which rearticulates every relation between the economic and political. Out of this emerges, like a common thread, a distorted image of precarity that defines the existence of today's non-persons and stateless people, as well as the millions of 'citizens who do not belong' or whose membership is a shadow without substance.

The spectre of a camp looms over this humanity in excess as the 'only possible territory'. Camps, as such, indicate the way in which new differences of status, class and 'race' are rearticulated globally. They are the material and territorial residue of the increasingly abstract and 
deterritorialized borders of the present. The differences they produce confirm a human condition that exceeds every idea of exclusion, and is instead 'included', according to a radically differential logic tantamount to apartheid, as confinable and deportable. ${ }^{3}$

\section{A genealogy}

If camps delineate a separate history, the roots of this history are located outside the West. Various works (from that drafted by Arendt, through to the 'resentful' study by Andrzej Kaminski, up to the more recent and contentious work by Kotek and Rigoulot) (Kaminski, 1982; Kotek and Rigoulot, 2000) have highlighted how the recourse to administrative detention of 'civilians' originated in colonies, first in Cuba after the 1894 insurrection and then in South Africa six years later. The origins could be dated back even further to the time of the first reserves where Native North Americans were interned. Yet, if the idea of colonialism is conceived along Gramscian lines, the colonial matrix of camps seems to be confirmed in all these cases. A lacuna, however, exists, only partially attributable to Arendt, who in fact forcefully denounced the 'administrative massacres' of colonialism, but one which is more serious in successive work: this regards the capacity to interrogate the sense of this origin, without simply acknowledging it as a historic fact.

Needless to say, camps are not the only dispositive that came into existence in the colonies only to then move towards the centre, and in doing so overturn the narrative according to which history has always occurred first in Europe. Carlo Ginzburg has reconstructed the Bengali origins of fingerprints as a practice used by the population to locate individuals in a family system, which was later transformed by the Raj into an instrument of identification (Ginzburg, 1989). On being imported into the heart of the Western metropolis, fingerprints would preside over a fundamental internal border between the 'labouring' and 'dangerous' classes, at the convergence between disciplinary and control techniques. A similar denouement occurred in the case of the machine gun which, after the American Civil War, was banned in the wars that took place in the 'West', only to take on a key role in the Scramble for Africa, although it continued to be used in the United States in the final campaigns against the Native Peoples and in order to repress the strikes at the end of the nineteenth century. When the same weapon was deployed in the trenches of the First World War, a decisive qualitative leap had occurred: the 'total war' already practised in the colonial campaigns now began to expand across the European continent itself. The idea of the return of the margins to the centre as essential to an understanding of 'metropolitan' matters is relayed in Aimé Césaire's call for a reading of totalitarianism as the importation of colonial practices into the heart of Europe once the 'living space' of the overseas territories appeared to be running out. He went one step further, suggest- 
ing that the taboo shattered by Nazism consisted (also) in the fact of applying directly to European 'citizens' what had once only been conceivable for colonial subjects - in other words, the rendering of life and death as equally straightforward, practicable options (Césaire, 1972; Du Bois, 1992). This particular kind of transgression that locates the Holocaust in an already 'postcolonial' dimension forces us to rethink the absolute violence of colonialism and, above all, to see how the condition of the colonial subject is vital to understanding the significance of the camp-form in its modern evolution. Ultimately, a genealogy of camps is necessarily a genealogy of excess, in which the figure of the colonial subject represents the matrix or, put another way, the point of no return. ${ }^{4}$

The trajectories of the camp-form delineate a movement that, from the colonies, is destined to move towards the centre, 'provincializing' Europe in the process, prior to its culmination in a problematic postcolonial scenario. Camps would be imported into the West during the First World War, as detention and labour facilities for war prisoners, as well as places to intern civilians of 'foreign' nationality and colonial subjects. They would then spread in the 1930s in a Europe saturated with borders and in a geopolitical situation that continued to be colonial but which was on the verge of catastrophe. After the abyss of the Shoah, their presence dissipated but did not disappear: as a reinforcement of the bipolar borders after the Second World War, they plunged into the hell of the Soviet gulags and forced labour camps of China and Eastern Europe, and continued to overshadow an entire world in the process of decolonization. The tally of administrative dispositives and spectral 'substitutes for a homeland' would be reaffirmed at the end of the 1980 s and scattered across the apparently smooth surface of the present. These represent the principal junctures in the specific history of camps (Rahola, 2003: 61-113), and the basis from which I want to now single out three closely interrelated points for reflection.

\section{From the colonies to the world}

The first point is a question of method and regards the implications of a genealogical approach. Following Foucault, this consists in a nonchronological, retrospective method in which the unweaving of the present is weighed down, redefined and complicated by the shadow of the past (Foucault, 1984). Through such an approach, it is possible to recover the 'separate history' of camps. While this history does not entirely explain what happened in camps, it nevertheless reiterates the fact that one day in history it was decided that these should exist and that human beings could be interned in them, and thus they surely turned into something new. Now, the fact that this day is geographically located in the colonies and that the 'first' confinable and deportable individual is associated with the figure of the colonial subject means that any discourse on camps is situated in a specific timespace order and within the Border upon which this order is based. 
At the end of Culture and Imperialism, Edward Said called for the entire colonial project to be reread according to a more general 'principle of confinement' which constitutes its compass and underlying matrix (Said, 1994). The effect was that of a dichotomous world divided along the 'physical and epistemic' Border that separated the metropolis from the colonies and sanctioned the coexistence of subjects and citizens in a unified time and a polarized geography. The colonies, in other words, represented a space in excess, which evaded and questioned dialectical images of national boundaries and an inside-outside logic, and for this reason were governed by a colonial law that 'exceeded' (rather than took exception to) the legal system of each colonial power. ${ }^{5}$ It is in this very dimension of excess - the discursive translation of which converged with the idea of an invested but distinct 'living space' - that the principle of confinement operated: the artifice under which colonial space could coexist at a distance from the metropolis in a synchronic and 'modern' time. Whether the space-time of the colonies and the Border upon which it was based have both been definitely overcome is an issue that does not cease to provoke debate. Without denying the persistence of relations of domination, and the ongoing existence of occupations and protectorates that are the corollary of contemporary wars of prevention or intervention, I nevertheless think that it is reductive to represent the present in reiterative and (neo) colonial terms. Before anything else, this would overlook the disruptions which, from the struggles for independence onwards, have redrawn an entire geography and forced capital to establish itself at another, necessarily global, level. Drawing on the area of studies known as 'postcolonialism', it is thus useful to recover the sense of a transition having taken place but one which has by no means been resolved, which inevitably problematizes the very significance of the prefix 'post' (Hall, 1996; Mezzadra and Rahola, 2006). In short, this entails detecting the continuing traces of a past of domination and exploitation in the present, but without being able to still situate them within a polarized geography and an absolute Border. This is the particular 'backward' movement imposed by a genealogy: while the past looms over the present, the present continues to disturb the linear thread of that same past. This means, among other things, that the Border is today virtually displaced across the globe to the point that it separates the centre of the metropolis from its banlieues and the enclosure of 'gated communities' from that experienced in slums and favelas. More importantly, it means that the shadow of this border continues to be cast on the subjects who today exceed it: namely, migrants, refugees and asylum seekers. These individuals, like the colonial subjects of yesterday, appear perennially 'out of place' as they continue to overreach, violate and transgress the shattered border. Finally, returning to the focus of this chapter, it is also in the shadow of this shattered border that the campform spreads across the apparently smooth surface of the present, populating the ex-metropolises and ex-colonies with camps. 


\section{Camps and war}

The second element that needs to be considered regards the relation between the recourse to camps, as dispositives legitimized by security measures, and the 'state of war'. This war is neither declared nor recognized, and is, above all, radically asymmetrical because it unfolds beyond the borders that provide the basis for its organization and configuration. In tracing a history of camps, one continually encounters insurrections, revolts and violated borders. Indeed, camps came into existence for the first time as a response to struggles or the simple trespass of borders and based on a logic that radicalized the borders that had been infringed: in Cuba, following the insurrection against Spanish rule, in South Africa during the Boer Wars (without getting embroiled in that other internal border constructed along the 'colour line'), in Namibia, where the Herero people were putatively concentrated and exterminated by the German Imperial Army because their sheer presence exceeded the aberrant Lebensraum, and later in Libya, Vietnam, Algeria and Kenya. The 'uncounted' (Rancière, 1999) masses who populated the Europe of the 1920s and 1930s, the same Europe that would later be crowded with camps, conveyed an analogous 'subversive' potential in the way they contested the principle of inclusion founded on peremptory boundaries of race, nation and class, or, more prosaically, because they crossed borders in flight from the ghettos where they had been confined for centuries. In both cases, these 'impossible' presences indicated the irreversible crisis of an inclusive model based on their 'difference' and would provoke a reaction that radicalized this difference through the resort to a dispositive of detention, which did not derive out of a national legal system but from a colonial space that exceeded the reach of this system. That is why the introduction of camps in the West, rather than pointing to the possible suspension of the rule of law, was the symptom of a condition that, as previously for colonial subjects, went beyond exclusion because it alluded to a space that exceeded every 'inside-outside' logic and specific form of border. This, ultimately, was a space in which peace and war appeared absolutely reversible options.

The use of chemical weapons and the first planned exterminations (such as those by the Germans in Namibia, the Italians in Libya and the French at Sètif), the first so-called 'random' civilian victims and the use of torture as a practice for unidentified enemies are all elements which enable us to deduce the colonial matrix underlying today's asymmetrical conflicts, but without the binary geography of the past. In a certain sense, behind the unclassifiable figure of the 'terrorist' or dehumanized enemy liable to extraordinary rendition and torture hides the situated figure of the colonial subject that rebels: a subject whose act of violence, by definition asymmetric, will always be labelled with the disqualifying category of 'illegal enemy combatant'. This implies that places like Abu Ghraib, 
Bagram or Guantanamo are not exceptions but instead appear to totally reflect the (post)colonial matrix of the camp-form, in that space that exceeds every legal system and specific dimension of borders. They represent the distorted and global projection of those various special places where 'differential' colonial subjects were concentrated and tortured. Guantanamo, Abu Ghraib and Bagram are metonyms of the politics of security and the deterritorialized geography of the war on terror. The analysis needs to focus on the very specificity of this geography. Exactly what sort of space determines such places?

\section{The space of camps}

The hypothesis advanced here is that an answer to these extreme dispositives - considered by many to be places of exception and beyond the law lies in the 'serial nature' of detention centres for 'irregular' migrants or identification centres for asylum seekers. It is the distinctive space of the camp-form with its origins in colonialism which determines the specificity of Guantanamo. The third and final question we need to consider, therefore, regards the very 'quality' of this space.

The point has been raised that, in an exceptionalist logic, camps are the dispositive through which sovereignty can capture the outside on its inside. So, for example, it would be possible to explain how detention centres for migrants operate inside a specific legal system, while suspending that same system. But besides the 'formal' question about the presumed suspension of the legal system, and hence the elements of alegality typical in the institution of camps (and undeniable if one reasons in terms of normalized spaces and their internal exceptions), I believe it is necessary to concentrate upon their specific geography and, above all, upon the material effects produced by the deployment of such dispositives. Furthermore, the same axiom that the space of camps is always and only a suspension of rights (and, in turn, the outcome of a sovereign decision) proves to be questionable. Even an extreme place like Guantanamo, continuously evoked as a 'black hole' and legal abyss, given its institution as an emergency measure (Weber would term it a 'substantial legitimation'), appears if anything to be characterized by a normative proliferation. The volume of government decrees and administrative acts on Guantanamo might not remove the burden of a sovereign decision, but it certainly blurs it and, above all, reinflects it in a multiplicity of different subjects, 'sovereigns' to varying degrees, who manage and command the extreme measures adopted in such a place. As Fleur Johns affirms, 'the detention camps of Guantánamo Bay are above all works of legal representation and classification. They are spaces where law and liberal proceduralism speak and operate in excess' (Johns, 2005: 615). The 'excess' here regards the normative proliferation that invests Guantanamo, and the law which, rather than being suspended, operates beyond itself and its own limits. But its significance can also be 
extended to comprehend the statuses of the interned subjects (who exceed the figure of the enemy and every form of membership), the multiplicity of anonymous powers and new 'legalities' that are produced (and which exceed univocal ideas about sovereignty ${ }^{6}$ ), as well as the very extraterritoriality of Guantanamo, which reproduces colonial forms beyond the geography of colonialism. The same character of excess, as already explained, applies at varying degrees for 'more specific' and serial manifestations of the camp. Rather than an exception and suspension of law, the existence of camps should hence be interpreted as something that bends the law, and creates new legal figures, new statuses and, at most, new acts and forms of sovereignty. ${ }^{7}$ In other words, it is the sign of something that exceeds insofar as it produces 'differences'. In this case, it amounts to a radical difference which is determined when an individual becomes 'confinable', and therefore to the material institution of a differential regime through camps.

Put another way and coming closer to a Foucaultian idea of governmentality, when considering power, it needs to be remembered that its effects are often more important than its causes, to the same extent that sovereignty itself is not presupposed but is rather conceived as something that is produced and, by being produced, establishes differences. Thus I believe that an exceptionalist reading - which tends to always put the power that establishes places ahead of the effects of power upon individuals - ultimately situates the institution of camps within a history destined to revolve around itself, which in turn continually reconfirms a logic of a steady, indestructible, omnivorous sovereignty. This is a logic that, first and foremost, persists and 'rebounds' within definite national boundaries, and therefore within the binary dialectic - the inside-outside - around which the idea of sovereignty developed.

With regard to this development, camps seem instead to indicate a different spatiality: they are deterritorialized places, as demonstrated by the tendency to locate them far away from national boundaries into an increasingly pronounced extraterritorial dimension. This is the case of Guantanamo or Bagram, but also the hundreds of 'preventive' centres of detention and identification that are scattered thousands of kilometres from the borders that they are supposed to preside over; and the 'humanitarian' camps that, by preventively confining the displaced in situ, deny the possibility of applying for asylum in a third country. What, then, are the definite borders that can be associated with these 'forms' of camp? What type of sovereignty institutes them and is exerted over them? Is the answer really to be found by resorting to traditional borders and exceptions within them, and to decisions that revert to a unitary sovereign subject? Or is it rather necessary to turn elsewhere, towards a space that exceeds such borders and towards figures who exceed such a univocal dimension?

In this chapter, as should now be clear, my suggestion has been to look elsewhere. This is the reason why, instead of the storyline that sees camps as the reflection of a principle of sovereignty that decrees the state of 
exception (and therefore as something that is included 'through exclusion'), a different interpretative thread has been preferred, which questions the borders in which camps are supposed to have been instituted and where exclusion is included. Moreover, Cèsaire's idea that totalitarian regimes imported into Europe what had been 'normal' in the colonies does not only indicate the possibility of detecting continuity in a history, but more radically the necessity of decentring that history and reading it according to a different set of criteria. Certainly, it could always be objected that the exception was the rule in the colonies. But a different 'quality' of political space (and, with it, a different form of sovereignty) emerges out of the colonies, and it would be reductive, to say the least, to revert back to national sovereignty through the passe-partout category of 'exception'.

The space of colonies has always exceeded and challenged forms of binary logic (such as inside-outside and friend-enemy) and conventional representations of borders. ${ }^{8}$ At most, it was a space characterized by a 'permanent war' and 'low-intensity conflict' and therefore by security policies intent on compartmentalizing a territory and population. ${ }^{9}$ As such, the colonies were extraordinary 'governmental laboratories' that implemented techniques of government which reflected the more general division of status between colonists and subjects (Chatterjee, 2004). Thus they are not areas of 'waste' or a suspension of the law, but excessive places: in the sense that they are spaces which exceed the reach of the 'national' legal system but nonetheless are invested with a proliferation of administrative decrees and security policies. It is in this governmentalized territory, where security becomes the ultimate goal of government action, that camps belong.

The colonial origins of the camp-form therefore point to a different and more 'distant' trajectory. It is not a question about how camps can be captured in a legal system by taking exception to it (eccependolo), but rather understanding how they sanction the limit of the reach of that system by exceeding it (eccedendolo), and signalling at a more mundane level a border between exclusion and inclusion, and between an inside and an outside that no longer exist. To completely accept this matrix, and therefore to write a genealogy of camps, thus means to relocate camps in a territory that exceeds every representation of modern national borders while indicating its spectral artificiality and intrinsic weakness. From this perspective, camps are the symptom of a space that has always transcended the specific space of nations, within which it has been historically colonized, plundered and racialized, but never totally absorbed. It is a space (and this is the postcolonial sense of the global present) that, whenever it penetrates the specific space of states, violating its borders and subverting distinctions between an inside and outside, produces holes and abysses. And in each of these holes, there sits a camp.

Translation by Nick Dines. 


\section{Notes}

1 For an analogous interpretation of camps as the symptom of a more general process of the multiplication and autonomization of borders, see Mezzadra and Neilson (2008).

2 Saskia Sassen (2007) insists on the multiscalar character of globalization, where the national and the global intersect, generating new kinds of borders.

3 For Etienne Balibar (2005), the process of European integration is based on a logic of apartheid, due to the presence of a subcategory of 'citizens-subjects' composed of migrants.

4 Gayatry Spivak (1988) has demonstrated how the 'biopolitical' status of the citizen, vested with the care and control of the state, is unthinkable without considering the material costs of such a transition (a history that Foucault 'wrote only halfway') in the colonies.

5 The double standard between colonial law and the national legal system is theorized, for example, by the Italian jurist Santi Romano (1918: 14-123).

6 Judith Butler (2004b: 50-100) interprets Guantanamo as the expression of a hybrid form that superimposes sovereign instances and governmental strategies, recreating instrumentally the former on the strength of the immanent logic of the latter.

7 The hypothesis of a transformation of law rather than its suspension is advanced by Claudia Aradau (2007) who, on the basis of the colonial geography implicit in the Schmittian nòmos, interprets Guantanamo as the expression of an 'other' exception, no longer attributable to a sovereign decision but instead bowed to the needs by the government of space and society under the imperative of security.

8 The otherness of colonial space partly coincides with what Robert J. Walker (1993) defines as outside of the modern inside-outside, to the extent that such exteriority transcends any absolute dichotomy between inside and outside.

9 For an analysis of the continuum of violence that characterizes the colonies, see R.J. Young (2001: 329-335). The hard and fast spatial dichotomy of the colonies is described by F. Fanon (1963). 


\section{Bibliography}

Ackerman, B. (2005) La costituzione di emergenza. Come salvaguardare libertà e diritti civili di fronte al pericolo del terrorismo, Rome: Meltemi ['The Emergency Constitution', Yale Law Journal, 113, 5 (2004): 1029-1091].

Ackerman, B. (2006) The Failure of the Founding Fathers. Jefferson, Marshall, and the Rise of Presidential Democracy, Harvard: Harvard University Press.

Adler, A. (2002) J'ai Vu Finir le Monde Ancien, Paris: Grasset.

Agamben, G. (1995) Homo sacer. Il potere sovrano e la nuda vita, Torino: Einaudi.

Agamben, G. (1998) Homo Sacer: Sovereign Power and Bare Life, Stanford, CA: Stanford University Press.

Agamben, G. (2003) Stato di Eccezione. Homo sacer, 2/1, Torino: Bollati Boringhieri, trans. (2005) State of Exception, Chicago: University of Chicago Press.

Agier, M. (2008) Gérer les Indesiderables, Paris: Flammarion.

Alberts, D.S., Garstka, J.J. and Stein, F.P. (1999) Network Centric Warfare. Developing and Leveraging Information Superiority, Washington, DC: CCRP (2nd edn).

Allison, G. (2004) Nuclear Terrorism: The Ultimate Preventable Catastrophe, New York: Times Book-Henry Holt and Company.

Altheide, D.L. (2002) Creating Fear, Aldine: Transaction.

Altheide, D.L. (2003) 'Notes Towards a Politics of Fear', Journal for Crime, Conflict and the Media, 1, 1: 37-54.

Anderson, B. (1991) Imagined Communities: Reflections on the Origin and Spread of Nationalism, London: Verso.

Anonymous (2002) Through Our Enemies' Eyes. Osama Bin Laden, Radical Islam, and the Future of America, Washington, DC: Brassey's (1st edn).

Aradau, C. (2007) 'Law Transformed: Guantànamo and the "other” Exception', Third World Quarterly, 28, 3: 489-501.

Arendt. H. (1958) The Origins of Totalitarianism, New York: Meridian (2nd edn).

Arendt, H. (2006) Eichmann in Jerusalem. A Report on the Banality of Evil, New York: Penguin Books.

Aron, R. (1958) On War: Atomic Weapons and Global Diplomacy, London: Secker \& Warburg.

Aron, R. (1966) Peace and War. A Theory of International Relations, Garden City, NY: Doubleday \& Company. 
Aron, R. (1983) Clausewitz: Philosopher of War, London: Routledge and Kegan Paul.

Arquilla, J. and Ronfeldt, D. (eds) (1997) In Athena's Camp: Preparing for Conflict in the Information Age, Santa Monica: Rand.

Arquilla, J. and Ronfeldt, D. (2000) Swarming and the Future of Conflict, Santa Monica: Rand.

Asad, T. (2007) On Suicide Bombing, New York: Columbia University Press.

Balibar, E. (2005) 'Europe, pays des frontières', in E. Balibar, Europe, Constitution Frontière, Paris: Éditions du Passant.

Barber, B. (2001) Jihad vs. Mcworld, New York: Ballantine Books (2nd edn).

Barber, B. (2003) Fear's Empire: War, Terrorism, and Democracy in an Age of Interdependence, New York: W.W. Norton.

Bartoli, R. (2008) Lotta al terrorismo internazionale. Tra diritto penale del nemico jus in bello del criminale e annientamento del nemico assoluto, Torino: Giappichelli.

Bauman, Z. (2004) Wasted Lives. Modernity and its Outcasts, Cambridge: Polity Press.

Bauman, Z. (2006) Liquid Fear, Cambridge: Polity Press.

Beck, U. (1992) Risk Society. Towards a New Modernity, London: Sage (original edn, 1986).

Beck, U. (2002a) 'The Cosmopolitan Society and its Enemies', Theory, Culture \&o Society, 19, 1-2: 17-44.

Beck, U. (2002b) 'The Terrorist Threat: World Risk Society Revisited', Theory, Culture \&o Society, 19: 39-55.

Beck, U. (2003) 'The Silence of Words: On Terror and War', Security Dialogue, 34, 3: 255-267.

Becker, H. (2003) 'E di Mozart che mi dici? E dell'omicidio?', Rassegna italiana di sociologia, 44, 4: 483-492.

Benjamin, W. (1962) 'Per la critica della violenza', in W. Benjamin, Angelus Novus, Turin: Einaudi, pp. 5-30 (original: 'Zur Kritik der Gewalt' ['Critique of Violence'], 1921).

Bennet, C. and Lyon, D. (eds) (2008) Playing the Identity Card. Surveillance, Security and Identification in Global Perspective, London: Routledge.

Benveniste, E. (1971) 'Civilization. Contribution to the History of the Word', in Problems in General Linguistics, Coral Gable, FL: University of Miami Press (2 vols).

Berkowitz, B. (2003) The New Face of War. How War will be Fought in the 21st Century, New York: The Free Press.

Berman, P. (2003) Terror and Liberalism, New York: W.W. Norton.

Betti, S. (2008) Le armi del diritto contro il terrorismo. Un esperto ONU fra diplomazia codici e assistenza legale, Milan: Franco Angeli.

Bigo, D. (2005) 'La mondialisation de l'(in)sécurité', in 'Suspicion et exception', Cultures \& Conflits, 58: 53-101.

Bigo, D. (2007) 'Al bando. Sicurezza, eccezione e sorveglianza', in 'Un mondo di controlli', Conflitti globali, 5: 52-75.

Bigo, D. and Tsoukala, A. (eds) (2008) Terror, Insecurity and Liberty: Illiberal Practices of Liberal Regimes after 9/11, London: Routledge.

Bigo, D., Bonelli, L. and Deltombe T. (eds) (2008) Au nom du 11 Septembre, les démocraties à l'épreuve de l'antiterrorisme, Paris: La Découverte.

Birnbaum, P. (1985) 'La rivincita di Bentham: l'ascesa dell'autoritarismo in Gran Bretagna', in R. Scartezzini, L. Germani and R. Gritti (eds), I limiti della 


\section{Bibliography}

democrazia. Autoritarismo e democrazia nella società moderna, Napoli: Liguori, pp. 262-279.

Bittner, E. (1990) Aspects of Police Work, Boston: Northeastern University Press.

Blanc, F. (2009) 'Resistance in time of unanimism in the US', Ph.D thesis, Northwestern University, Sciences-Po Paris.

Boltanski, L. (1993) La Souffrance à Distance: Morale Humanitaire, Médias et Politique, Paris: Éditions Métailié, trans. (1999) Distant Suffering: Morality, Media, and Politics, New York: Cambridge University Press.

Bonelli, L. (2008) La France a peur. Une histoire social de l'insécurité, Paris: La Découverte.

Boot, M. (2006) War Made New. Weapons, Warriors, and the Making of the Modern World, New York: Gotham Books.

Bourdieu, P. (1986) 'La force du droit', Actes de la recherche en sciences sociales, 64, 1: 3-19.

Bourdieu, P. and Passeron, J.C. (1970) La Reproduction. Éléments d'une théorie du système d'enseignement, Paris: Minuit.

Brackett, D.W. (1996) Holy Terror. Armageddon in Tokyo, New York: Weatherhill (1st edn).

Brauman, R. (2002) Humanitaire, le dilemme: entretien avec Philippe Petit, Paris: Textuel (1st edn, 1996).

Bréhier, L. (1949) Le monde byzantine, vol. II, 'Les institutions de l'Empire byzantine'. Paris: Albin Michel.

Brion, F. (2010) 'User du genre pour faire la différence? La doctrine des délits culturels et de la défense culturelle', in S. Palidda (ed.), Les mobilités humaines en Méditerranée au XXI siècle, Le Fennec-Karthala (forthcoming).

Brodeur, J.P. (2001) 'Le travail d'Egon Bittner: une introduction à la sociologie de la force institutionnalisée', Déviance et Société, 25, 3: 307-323.

Brodeur, J.P. (2003) Les visages de la police. Pratiques et perceptions, Montréal: Les Presses de l'Université de Montréal.

Brodeur, J.P. (2005) 'Force policière et force militaire', in F. Lemieux and B. Dupont (eds), La militarisation des appareils policiers, Laval: Les Presses de l'Université Laval, pp. 41-56.

Brodeur, J.P. (ed.) (2006) 'La police en pièces détachées', in Crimonologie, 38, 2: n.p.

Brodeur, J.P. and Leman-Langlois, S. (2004) 'Surveillance totale ou surveillancefiction?', Les Cabiers de la sécurité intérieure, 55: 61-90.

Brodeur, J.P. and Monjardet, D. (2003) 'Sécurité intérieure et sécurité extérieure: recompositions et métamorphoses', Les Cahiers de la sécurité intérieure, 53: 157-169.

Brouwer, E., Catz, P. and Guild, E. (eds) (2003) Immigration, Asylum and Terrorism. A Changing Dynamic in European Law, Nijmegen: Recht and Samenleving.

Brunner, O. (1939) Land und Herrschaft. Grundfragen der territorialen Verfassungsgeschichte Südost-Deutschland im Mittelalter, Baden-Wien: Roher.

Buchanan, M. (2001) Ubiquity: The Science of History ... or Why the World Is Simpler Than We Think, New York: Random House.

Bull, H. (1977) The Anarchical Society. A Study of Order in World Politics, New York: Columbia University Press (2nd edn (1995) London: Macmillan).

Burke, J. (2004) Al Quaeda: The True story of Radicalism, London: I.B. Tauris.

Butler, J. (2004a) 'Indefinite Detention', in J. Butler, Precarious Life. The Powers of Mourning and Violence, London and New York: Verso. 
Butler, J. (2004b) Precarious Life. The Powers of Mourning and Violence, London: Verso.

Butler, J. and Spivak, G. (2007) Who Sings for the Nation-State? Language, Politics, Belonging, London: Seagull Books.

Campbell, D. (1998) Writing Security. United States Foreign Policy and the Politics of Identity, Minneapolis, MN: University of Minnesota Press (revised edn).

Campbell, D. (2000) Inside Echelon: The History, Structure and Function of the Global Surveillance System Known as Echelon, available at www.heise.de/tp/r4/ artikel/6/6929/1.html.

Caputo, A. (2006) 'Introduzione. Verso un diritto penale del nemico?', Questione Giustizia, 4: 623-649.

Carter, A.B. and Perry, W.J. (1999) Preventive Defense. A New Security Strategy for America, Washington, DC: Brookings Institution Press.

Cartuyvels, Y. and Mary, Ph. (eds) (1999) L'Etat face à l'insécurité. Dérives politiques des années 90, Bruxelles: Labor.

Cassese, A. (2005) Lineamenti di diritto internazionale penale, Bologna: Il Mulino.

Castel, R. (2003) L'insécurité sociale. Qu'est-ce qu'être protégé?, Paris: Éditions du Seuil.

Castles, S. and Davidson, A. (2000) Citizenship and Migration, London: Macmillan.

Catherwood, C. and DiVanna, J.A. (2008) The Merchants of Fear: Why They Want Us to be Afraid, Guilford, CT: Lyons Press.

Cavell, R. (2004) Love, Hate, and Fear in Canada's Cold War, Toronto: University of Toronto Press.

Cebrowski, A. and Garstka, J. (1998) 'Network Centric Warfare: Its Origin and Future', United States Naval Institute Proceedings, 124, 1: 28-35.

Césaire, A. (1972) Discourse on Colonialism, New York: Monthly Review Press (1st edn, 1955).

Chaliand, G. (ed.) (1990) Anthologie mondiale de la stratégie. Des origines au nucléaire, Paris: Laffont.

Charman, E. and Honess, T. (1992) 'CCTV in Public Places. Its Acceptability and Perceived Effectiveness', Crime Prevention Unit Series, paper no. 35, London: Home Office.

Chatterjee, P. (2004) The Politics of the Governed, New York: Columbia University Press.

Chilton, P. (1987) 'Metaphor, Euphemism, and the Militarization of Language', Current Research on Peace and Violence, 10, 1: 7-19.

Christie, N. (1993) Crime Control as Industry. Towards GULAGs, Western Style?, London and New York: Routledge.

Ciccarelli, R. (2006) 'Guerra ai pirati del XXI secolo', Conflitti globali, 4: 97-106.

Ciccarelli, R. (2008) Immanenza. Filosofia, diritto e politica della vita dal XIX al XX secolo, Bologna: Il Mulino.

Ciccarelli, R. (2009) 'Terrorisme', in Lexique de biopolitique. Les pouvoirs sur la vie, Toulouse: Erès, pp. 183-188.

Clarke, R.A. (2004) Against All Enemies, New York: RAC.

Clausewitz, K. (1976) On War, Princeton: Princeton University Press.

Cohen, S. (2002) Folk Devils and Moral Panics, London: Routledge (3rd edn).

Cole, D. (2005) Enemy Aliens, New York and London: The New Press.

Cole, D. and Lobel, J. (2007) Less Safe. Less Free. Why America is Losing the War on Terror, New York and London: The New Press. 


\section{Bibliography}

Collins, J. (2002) 'Terrorism', in J. Collins and R. Glover (eds) Collateral Language. A User's Guide to America's New War, New York: New York University Press.

Cook, R. (2005) 'The Struggle Against Terrorism Cannot be Won by Military Means', Guardian, 8 July.

Cowan, R.S. (1997) A Social History of American Technology, New York and Oxford: Oxford University Press.

Dal Lago, A. (1999a) 'La tautologia della paura', Rassegna Italiana di Sociologia, 1: $5-41$.

Dal Lago, A. (1999b) Non-persone. L'esclusione dei migranti nella società globale, Milan: Feltrinelli [Non-persons. The Exclusion of Migrants in a Global Society, Milan: Ipoc Press, 2009].

Dal Lago, A. (2003) Polizia globale. Guerra e conflitti dopo l'11 settembre, Verona: Ombre Corte.

Dal Lago, A. (2005) 'La guerra mondo', Conflitti Globali, 1: 11-31.

Dal Lago, A. (2006a) 'Esistono davvero i conflitti tra culture? Una riflessione storico-metodologica', in C. Galli (ed.) Multiculturalismo, Bologna: Il Mulino.

Dal Lago, A. (2006b) 'Il problema del contesto nell'analisi dei conflitti contemporanei (ovvero, quando il terrorismo è un feticcio)', in Questione Giustizia, 4.

Dal Lago, A. (2006c) 'Introduction to global conflicts: a special section', Ephemera. Theory and Politics in Organisation, 6, 1: 5-8.

Dal Lago, A. (2008) 'La police globale, état de conflit permanent du capitalisme globalisé', in D. Bigo, L. Bonelli and T. Deltombe (eds), Au nom du 11 Septembre. Les démocraties à l'épreuve de l'antiterrorisme, Paris: La Découverte, pp. 36-48.

Dal Lago, A. (2010) Le guerre in cui viviamo. Filosofia e sociologia dei conflitti armati, Rome: Manifestolibri.

Dal Lago, A. and Quadrelli, E. (2003) La città e le ombre, Crimini, criminali, cittadini, Milan: Feltrinelli.

Dal Lago, A. and Rahola, F. (2009) 'Il nuovo mestiere delle armi. Identità e legittimità professionale dei mercenari contemporanei', Etnografia e ricerca qualitativa, III, 3.

Davis, M. (1990) City of Quartz. Excavating the Future of Los Angeles, New York: Vintage.

Davis, M. (1998) Ecology of Fear: Los Angeles and the Imagination of Disaster, New York: Metropolitan Books.

De Genova, N. (2002) 'Migrant “Illegality” and Deportability in Everyday Life', Annual Review of Anthropology, 31: 419-447.

De Landa, M. (1991) War in the Age of Intelligent Machines, New York: Zone Books.

Deleuze, G. (1990) 'Postscriptum sur les sociétés de contrôle', in Deleuze (ed.), Pourparlers, Paris: Editions de Minuit, pp. 240-247

Deleuze, G. (1992) Postscript on the Societies of Control, Cambridge, MA: MIT Press, pp. 3-7, available at www.n5m.org/n5m2/media/texts/deleuze.htm.

Deleuze, G. and Guattari, F. (1977) Anti-Oedipus. Capitalism and Schizofrenia, New York: Viking.

Deleuze, G. and Guattari, F. (1987) A Thousand Plateaus: Capitalism and Schizophrenia, Minneapolis: University of Minnesota Press.

Delpech, T. (2002) Politique du Chaos. L'autre Face de la Mondialisation, Paris: Seuil.

Derrida, J. (1994a) Force de Loi. Le 'fondement mystique de l'autorité', Paris: Galilée. 
Derrida, J. (1994b) Politiques de l'amitié, Paris: Galilée.

Derrida, J. (2003) Voyous. Deux essais sur la raison, Paris: Galilée, trans. (2005) Rogues: Two Essays on Reason, Stanford, CA: Stanford University Press.

Derrida, J. (2008) La bête et le souverain, volume 1, Paris: Galilée.

Desh, M.C. (2001) Soldiers in Cities. Military Operations on Urban Terrain, Carlisle, PA: Strategic Studies Institute, US Army War College, available at www. strategicstudiesinstitute.army.mil/pdffiles/PUB294.pdf.

Desportes, V. (2009) 'Armées. “technologisme” ou "juste technologie”?', Politique Étrangère, 2: 403-418.

Dillon, M. and Neal, A.N. (2009) The Liberal Way of War. Killing to Make Life Live, London: Routledge.

Dirlik, A. (1994) 'The Postcolonial Aura', Critical Inquiry, autumn: 351.

Ditton, J. (1998) 'Public Support for Town Centre CCTV Schemes: Myth or Reality?', in C. Norris, J. Moran and G. Armstrong (eds), Surveillance, CCTV and Social Control, Aldershot: Ashgate Publishing, pp. 221-228.

Douglas, M. (1992) Risk and Blame. Essays in Cultural Theory, London: Routledge.

Du Bois, W.E. (1992) The Modern World and Africa, New York: International Publishers.

Duffield, M. (2007) Development, Security and Unending War, Cambridge: Polity Press.

Dumont, L. (1986) Essays on Individualism. Modern Ideology in Anthropological Perspective, Chicago and London: Chicago University Press.

Duso, G. (ed.) (1993) Il contratto nella filosofia politica moderna, Milan: Franco Angeli.

Edwards, J.A. (2000) Swarming on the Battlefield. Past, Present and Future, Santa Monica: Rand.

Eribon, D. (1991) Michel Foucault (1926-1984), Paris: Flammarion.

Escobar, A. (1995) Encountering Development. The Making and Unmaking of the Third World, Princeton: Princeton University Press.

Escobar, R. (1997) Metamorfosi della paura, Bologna: Il Mulino.

Evans, T. and Harris, J. (2004) 'Street-Level Bureaucracy, Social Work and the (Exaggerated) Death of Discretion', British Journal of Social Work, 34, 6: 871-895.

Fanon, F. (1961) Les damnés de la terre, Paris: François Maspéro.

Faso, G. (2008) Lessico del razzismo democratico. Le parole che escludono, Roma: DeriveApprodi.

Fassin, D. and Pandolfi, M. (eds) (2009) Contemporary States of Emergency. The Politics of Military and Humanitarian Intervention, Cambridge, MA: MIT Press.

Ferguson, J. (1990) The Anti-Politics Machine: 'Development,' Depoliticization, and Bureaucratic Power in Lesotho, Cambridge: Cambridge University Press.

Ferguson, N. (2006) The War of the World. Twentieth-Century Conflict and the Descent of the West, New York: Penguin.

Ferrajoli, L. (1984) 'Delitto politico, ragion di stato e stato di diritto', in 'Il delitto politico dalla fine dell'Ottocento ai giorni nostri', Quaderni di Critica del diritto: 49-65.

Ferrajoli L. (1989) Diritto e ragione. Teoria del garantismo penale, Rome and Bari: Laterza.

Ferrajoli, L. (2006) 'Il diritto penale del nemico e la dissoluzione del diritto penale', Questione Giustizia, 4: 21-44. 


\section{Bibliography}

Ferreri, M. (1969) La sémence de l'homme, film.

Fijnaut, C. (1980) 'Les origines de l'appareil policier moderne en Europe de l'Ouest continentale', Déviance et Société, 4, 1: 19-41.

Fisk, R. (2006) The Great War For Civilisation: The Conquest of the Middle East, New York: Alfred Knopf.

Forman, P. (1987) 'Behind Quantum Electronics. National Security as Basis for Physical Research in the United States, 1940-1960', Historical Studies in the Physical and Biological Sciences, 18, 1: 149-229.

Foucault, M. (1975) Surveiller et punir, Paris: PUF.

Foucault, M. (1981) 'The Order of Discourse' in R. Young (ed.), Untying the Text. A Poststructuralist Reader, Boston: Routledge and Kegan Paul, pp. 48-78.

Foucault, M. (1984) 'Nietzsche, History, Genealogy,' in P. Rabinow (ed.) The Foucault Reader, New York: Pantheon Books.

Foucault, M. (1994) Dits et Écrits, III, Paris: Gallimard.

Foucault, M. (1995) Discipline and Punish. The Birth of the Prison, New York: Vintage Books.

Foucault, M. (1997) II faut défendre la société, Cours du Collège de France 1975-1976, Paris: Hautes Études, trans. (2003) Society Must Be Defended, Lectures at the Collège de France, 1975-1976, London: Allen Lane, an imprint of Penguin Books, trans. (1998) Bisogna difendere la società, Milano: Feltrinelli.

Foucault, M. (2000) Power, New York: New Press.

Foucault, M. (2001) 'Va-t-on extrader Klaus Croissant?', in Foucault, Dits et Écrits, Paris: Gallimard, vol. II, pp. 361-366.

Foucault, M. (2004a) Sécurité, territoire, population. Cours au Collège de France, 1977-1978, Paris: Gallimard/Seuil, trans. (2007) Security, Territory, Population. Lectures at the College De France, Basingstoke: Palgrave MacMillan.

Foucault, M. (2004b) Naissance de la biopolitique. Cours au Collège de France, 1978-1979, Paris: Gallimard/Seuil, trans. (2008) The Birth of Biopolitics. Lectures at the College de France, 1978-1979, New York: Palgrave MacMillan.

Foucault, M. (2008) Le gouvernement de soi et des autres, Paris: Hautes Etudes/ Gallimard/Seuil.

Foucault, M. (2009) Le gouvernement de soi et des autres - tome 2, Le courage de la vérité. Cours au Collège de France (1983-1984), Paris: Seuil-Gallimard.

Fournell, J.L. (1988) Avertissements politiques de Guicciardini, Paris: Editions du Cerf.

Fraenkel, E. (1941) The Dual State. A Contribution to the Theory of Dictatorship, New York: Oxford University Press.

Francis, V. (2009) 'Du Panopticon à la New Surveillance', Revue de Droit Pénal et de Criminologie, 88, 11: 1025-1046.

Freeman, C. (1974) 'Aspects of Public Policy for Innovation', in C. Freeman and L. Soete, The Economics of Industrial Innovation, Harmondsworth: Penguin.

Fukuyama, F. (1992) The End of History and the Last Man, New York: The Free Press.

Fukuyama, F. (2006) Nation-Building. Beyond Afghanistan and Iraq, Baltimore: The Johns Hopkins University Press.

Furedi, F. (2005) Politics of Fear. Beyond Left and Right, New York: Continuum International Publishing Group.

Furedi, F. (2006) Culture of Fear Revisited. Risk-taking and the Morality of Low Expectation, London: Continuum (revised edn). 
Galli, G. (2008) La democrazia e il pensiero militare, Gorizia: LEG.

Gamson, W.A. and Modigliani, A. (1971) Untangling the Cold War. A Strategy for Testing Rival Theories, Boston: Little.

Gardner L.C., Schlesinger, A.M. and Morgenthau, H.J. (1970) The Origins of the Cold War, Waltham, MA: Ginn-Blaisdell.

Garlan, Y. (1975) War in the Ancient World, New York: W.W. Norton.

Garland, D. (2001) The Culture of Control, Oxford: Oxford University Press.

Garwin, R.L. (2002) 'The Technology of Megaterror', MIT Technology Review, September, available at www.technologyreview.com/energy/12925.

Giannuli, A. (2007) 'Guerra finanziaria e intelligence', in 'Un mondo di controlli', Conflitti globali, 5: 114-129.

Giannuli, A. (2008) 'Les services de renseignement italiens après le 11 septembre', in D. Bigo, L. Bonelli and T. Deltombe (eds), Au nom du 11 septembre. Les démocraties à l'épreuve de l'antiterrorisme, Paris: La Découverte, pp. 234-245.

Giglioli, P.P., Cavicchioli, S. and Fele, G. (1997) Rituali di degradazione. Anatomia del processo Cusani, Bologna: Il Mulino.

Gilbert, P. (1997) Il dilemma del terrorismo, Milan: Feltrinelli [Terrorism, Security and Nationality, London: Routledge, 1994].

Ginzburg, C. (1989) 'Clues. Roots of an Evidential Paradigm', in C. Ginzburg, Clues, Myths and the Historical Method, Baltimore: Johns Hopkins University Press, pp. 96-125.

Girard, R. (1982) Le bouc émissaire, Paris: Grasset et Fasquelle.

Girard, R. (2007) Achever Clausewitz, Paris: Carnets Nord.

Glassner, B. (1999) The Culture of Fear. Why Americans are Afraid of the Wrong Things, New York: Basic Books.

Gleizal, J.J. (1985) Le désordre policier, Paris: PUF.

Glover, R. (2002) 'The War on -', in J. Collins and R. Glover (eds.) Collateral Language. A User's Guide to America's New War, New York: New York University Press.

Glucksmann, A. (2004) 'The World of Megaterrorism: Mad Is the European Who Thinks Himself Immune to Terror for Having Opposed Saddam's Overthrow', Wall Street Journal, 21 March.

Goode, E. and Ben-Yehuda, N. (2009) Moral Panics. The Social Construction of Deviance, Chichester: Wiley-Blackwell.

Gnoli, A. and Volpi, F. (1997) I prossimi titani. Conversazioni con Ernst Jünger, Milan: Adelphi.

Graham, P., Keenan, T. and Dowd, A.M. (2004) 'A Call to Arms at the End of History: A Discourse-Historical Analysis of George W. Bush's Declaration of War on Terror', Discourse \& Society, 15, 2-3: 199-221.

Graham, S. (2009) 'Cities as Battlespace. The New Military Urbanism', City, 13, 4: 383-402.

Gray, C.S. (1999) Modern Strategy, Oxford and New York: Oxford University Press.

Gray, C.S. (2005) Recognizing and Understanding Revolutionary Change in Warfare, The Sovereignty of Context, Carlisle, PA: Strategic Studies Institute.

Green, S. (1999) 'A Plague on the Panopticon: Surveillance and Power in the Global Information Economy', Information, Communication and Society, 2: 26-44.

Greenberg, D. (1967) The Politics of Pure Science. An Inquiry into the Relationship between Science and Government in the United States, New York: Plume Books. 


\section{Bibliography}

Groombridge, N. (2002) 'Crime Control or Crime Culture TV', Surveillance \& Society, 1: 30-46.

Guareschi, M. (1999) 'Dal modello istituzionale-giuridico all'analitica del potere: Michel Foucault', in G. Duso (a cura di), Il potere. Per la storia della filosofia politica moderna, Rome: Carocci, pp. 469-476.

Guareschi, M. (2005) 'Ribaltare Clausewitz. La guerra in Michel Foucault e Deleuze-Guattari', Conflitti globali, 1: 52-68.

Guild, E. (2003) 'Introduction', in E. Brouwer, P. Catz and E. Guild (eds), Immigration, Asylum and Terrorism: A Changing Dynamic in European Law, Nijmegen: Instituut voor Rechtssociologie, Centrum voor Migratierecht.

Gusfield, J.R. (1963) Symbolic Crusade. Status Politics and the American Temperance Movement, Urbana and Chicago, Illinois: University of Illinois Press.

Gusterson, H. (1996) 'Nuclear Weapons Testing: Scientific Experiment as Political Ritual', in L. Nader (ed.) Naked Science. Anthropological Inquiry into Boundaries, Power, and Knowledge, New York and London: Routledge.

Habermas, J., Derrida, J. and Borradori, G. (2004) Philosophy in a Time of Terror. Dialogues with Jurgen Habermas and Jacques Derrida, Chicago: University of Chicago Press.

Hacker, B.C. (2006) American Military Technology. The Life Story of a Technology, Santa Barbara, CA: Greenwood Press.

Halberstam, D. (2001) War in Time of Peace. Bush, Clinton and the Generals, New York: Scribner.

Hall, S. (1980) Drifting into a Law and Order Society, London: Cobden Trust.

Hall, S. (1996) 'When was the Post-colonial?', in I. Chambers and L. Curti (eds), The Post-colonial Question, London: Routledge.

Hall, S., Critcher, C., Jefferson, T., Clarke, J. and Roberts, B. (1978) Policing the Crisis. Mugging, the State and Law and Order, London: Macmillan.

Hammes, T.X. (2006) The Sling and the Stone. On War in the 21st Century, Minneapolis, MN: MBI Publishing Company and the Zenith Press.

Hansen, L. (2006) Security as Practice. Discourse Analysis and the Bosnian War, London: Routledge.

Hanson, V.D. (2001) Why the West Has Won. Carnage and Culture from Salamis to Vietnam, London: Faber.

Hanson, V.D. (2009) Obama's Bad War, available at www.victorhanson.com/articles/hanson121109B.html.

Harcourt, B.E. (2001) Illusion of Order. The False Promise of Broken Windows Policing, Cambridge, MA: Harvard University Press.

Harcourt, B.E. (2007a) Against Prediction. Profiling, Policing, and Punishing in an Actuarial Age, Chicago: Chicago University Press.

Harcourt, B.E. (2007b) 'Sulla svolta attuariale in criminologia', in 'Un mondo di controlli', Conflitti globali, 5: 87-102.

Harcourt, B.E. (ed.) (2008) 'Discipline, Security and Beyond', The Carceral Notebooks, vol. 4.

Hardt, M. and Negri, A. (2004) Multitude: War and Democracy in the Age of Empire, New York: The Penguin Press.

Harvey, D. (2005) A Brief History of Neoliberalism, Oxford and New York: Oxford University Press.

Heilmann, E. (1990) 'Le policier, l'ordinateur et le citoyen', Culture Technique, 21: 174-184. 
Heilmann, E. (2007) 'Sorvegliare (a distanza) e prevenire. Verso una nuova economia della visibilità', in 'Un mondo di controlli', Conflitti globali, 5: 24-35.

Heilmann, E. (2008) 'La vidéosurveillance, un mirage technologique et politique', in L. Mucchielli (ed.), La frénésie sécuritaire, Paris: La Découverte, pp. 113-124.

Heisbourg, F. (2001) 'De l'après-guerre froide à l'hyperterrorisme,' Le Monde, 12 September.

Heisbourg, F. (2002) Hyperterrorisme, la nouvelle guerre, Paris: Odile Jacob.

Heisler, M. (2001) 'Democratic dilemmas compounded' (round table of the 6 December 2001), Fondation Franco-Américaine, Paris.

Henrotin, J. (2009) La technologie militaire en question: le cas américain, Paris: Economica.

Hermant, D. and Duclos, L.J. (eds) (2006) 'Mort Volontaire Combattante: Sacrifices Et Stratégies', Cultures \& Conflits, 63.

Herzfeld, M., (1992) The Social Production of Indifference. Exploring the Symbolic Roots of Western Bureaucracy, Chicago: University of Chicago Press.

Hilhorst, D. (2003) The Real World of NGOs. Discourse, Diversity and Development, London: Zed Books.

Hill, D.L. (1995) 'Negotiating Nuclear Testing Treaties', in G.E. Marcus (ed.) Technoscientific Imaginaries, Chicago and London: University of Chicago Press.

Hillyard, P. (1993) Suspect Communities. People's Experience of the Prevention of Terrorism Acts in Britain, London: Pluto Press.

Hillyard, P. (2005) 'The "war on terror": Lessons from Ireland', in T. Bunyan (ed.) The War on Freedom amd Democracy, London: ECLN.

Hobart, M. (ed.) (1993) An Anthropological Critique of Development. The Growth of Ignorance, London: Routledge.

Hogan, D.J. (ed.) (2006) Science Fiction America: Essays on SF Cinema, Jefferson, NC: McFarland, pp. 166-175.

Holland, J. (2009) 'From September 11th, 2001 to 9-11: From Void to Crisis', International Political Sociology, 3, 3: 275-292.

Hosenball, M., Isikoff, M. and Thomas, E. (2003) 'Cheney's Long Path to War', Newsweek, 17 November.

Huizinga, J. (2004) Lo scempio del mondo, Milan: Bruno Mondadori.

Huntington, S.P. (1996) The Clash of Civilizations and the Remaking of World Order, New York: Simon \& Schuster.

Jackson, R. (2006) 'Genealogy, Ideology, and Counter-terrorism. Writing Wars on Terrorism from Ronald Reagan to George W. Bush Jr.', Studies in Language \& Capitalism, 1: 163-193.

James, A.D. (2009) 'Reevaluating the Role of Military Research in Innovation Systems: Introduction to the Symposium', Journal of Technological Transfer, 34: 449-454.

Jenkins, R. (1999) Synthetic Panics. The Symbolic Politics of Designer Drugs, New York: New York University Press.

Jobard, F. (2006) 'Police, justice et discriminations raciales', in D. Fassin and E. Fassin (eds), De la question sociale à la question raciale? Représenter la société française, Paris: La Découverte, pp. 211-229.

Jobard, F. (2006) 'Sociologie politique de la racaille. Les formes de passage au politique des 'jeunes bien connus des services de police', in H. Lagrange and M. Oberti, Émeutes urbaines et protestations. Une singularité française, Paris: Presses de Sciences-Po, pp. 59-79. 


\section{Bibliography}

Jobard, F. (2008) 'La militarisation du maintien de l'ordre, entre sociologie et histoire', Déviance et Société, 32, 1: 101-109.

Johns, C.J. (1992) Power, Ideology, and the War on Drugs. Nothing Succeeds Like Failure, New York: Praeger.

Johns, F. (2005) 'Guantanamo Bay and the Annihilation of the Exception', The European Journal of International Law, 16, 4: 613-635.

Jouanneau, H. (2009) 'Vidéosurveillance, le débat continu', Gazette des communes, dossier spécial, 23 March, pp. 24-31.

Joxe, A. (1990) Le cycle de la dissuasion 1945-1990. Essai de stratégie critique, Paris: La Découverte.

Joxe, A. (1991) Aux sources de la guerre, Paris: PUF.

Joxe, A. (1992) L’Amérique mercenaire, Paris: Stock.

Joxe, A. (2002) Empire of Disorder, Cambridge, MA: MIT/Semiotext(e) (French: L'empire du chaos. Paris: La Découverte \& Syros).

Joxe, A. (2004) 'Barbarisation moderne des guerres dans l'empire global. le paradigme de la guerre de banlieue', Asterion, July 2004, 'Revue électronique' de l'ENS Texte intégral.

Joxe, A. (2005) 'Il lavoro dell'Impero e la regolazione democratica della violenza globale', in Conflitti globali, 1: 70-79.

Kagan, R. (2003) 'The United States Is, and Should Be, an Empire', American Enterprise Institute for Public Policy Research, 5 March, available at www.aei. org/event/428.

Kagan, R. and Kristol, W. (2005) 'The Right War for the Right Reasons', in G. Rosen (ed.), The Right War? The Conservative Debate on Iraq, New York: Cambridge University Press.

Kaldor, M. (2000) 'Cosmopolitanism and Organised Violence', paper prepared for conference on 'Conceiving Cosmopolitanism', Warwick, 27-29 April, available at www.theglobalsite.ac.uk/press/010kaldor.htm.

Kaldor, M. (2007a) New and Old Wars: Organized Violence in a Global Era, Stanford, CA: Stanford University Press (2nd edn).

Kaldor, M. (2007b) Human Security: Reflections on Globalization and Intervention, London: Polity Press.

Kaldor, M., (2008) 'La stratégie militaire américaine, nuovelle doctrine, nuoveaux problèmes', www.laviedesidees.fr/La-strategie-militaire-americaine.html; in English: www.opendemocracy.net, 'New Thinking Needs New Direction', 25 September.

Kaminski, A. (1982) Konzentrantionslager 1896 bis heute, Stuttgart: Kohlhammer.

Kaplan, R.D. (2000) The Coming Anarchy: Shattering the Dreams of the Post Cold War, New York: Random House.

Keegan, J. (1994) A History of Warfare, New York: Vintage Books.

Kepel, G. (2004) The War for Muslim Minds: Islam and the West, Cambridge, MA and London: Belknap Press.

Kevles, D.J. (1978) The Physicists. The History of a Scientific Community in Modern America, New York: Knopf.

Kilcullen, D. (2008) 'My View on Iraq', Small Wars Journal, 29 July.

Kitsuse, J.I. and Cicourel, A.V. (1963) 'A note on the uses of official statistics', Social Problems, 11, 2: 131-139.

Knox, M. and Murray, W. (eds) (2001) The Dynamics of Military Revolution, 1300-2050, Cambridge: Cambridge University Press. 
Kotek, J. and Rigoulot, P. (2000) Le siècle des camps. Détention, Concentration, Extermination. 100 ans de mal radical, Paris: Lattès.

Koudelka, J. (1990) Prague 1968, Paris: Centre National de la Photographie.

Kurtenbach, S.E and Lock, P. (eds) (2004) Kriege als [Über]Lebenswelten: Schattenglobalisierung, Kriegsökonomien und Inseln der Zivilität, Bonn: Dietz.

Lakoff, G. and Johnson, M. (1980) Metaphors We Live By, Chicago: University of Chicago Press.

Landes, D.S. (1998) The Wealth and Poverty of Nations: Why Are Some So Rich and Others So Poor?, New York: W.W. Norton.

Latour, B. (1996) Petite réflexion sur le culte moderne des dieux faitiches, Paris: Synthélabo.

Le Cour Grandmaison, O. (2005) Coloniser. Exterminer. Sur la guerre et l'Etat colonial, Paris: Fayard.

Lefebvre-Teillard, A. (1990) Le nom. Droit et histoire, Paris: PUF.

Le Goff, T. (2008) Vidéosurveillance et espaces publics, Rapport, Paris: IAURIF.

Lens, S. (1970) The Military-Industrial Complex, New York: Kahn \& Averill.

Leone, R.C. and Anrig, G. Jr. (eds) (2003) The War on our Freedoms: Civil Liberties in an Age of Terrorism, New York: Public Affairs.

Leslie, S.W. (1993) The Cold War and American Science. The Military-IndustrialAcademic Complex at MIT and Stanford, New York: Columbia University Press.

Levy, S. (1984) Hackers. Heroes of the Computer Revolution, New York: Doubleday.

Liang, Q. and Xiangsui, W. (2002) Unrestricted Warfare: China's Master Plan to Destroy America, New York: Pan American Publishing Company.

Lianos, M. (2003) 'Le contrôle social après Foucault', Surveillance \& Society, 1, 3: 431-448, available at www.surveillance-and-society.org/journalv1i3.htm.

Lind, W.S., Keith, N., Schmitt, J.F., Sutton, J.W. and Wilson, G.I. (1989) 'The Changing Face of War: Into the Fourth Generation', Marine Corps Gazette, October: 22-26.

Lipsky, M. (1971) 'Street-Level Bureaucracy and the Analysis of Urban Reform', Urban Affairs Review, 6 April: 391.

Lipsky, M. (1980) Street-level Bureancracy. Dilemmas of the Individual, New York: Russell Sage Foundation.

Lonsdale, D.J. (2004) The Nature of War in the Information Age, London and New York: Frank Cass.

Ludendorff, E. (1922) Kriegführung und Politik, Berlin: Mittler.

Lydersen, K. (2003) 'US Plan for Global Domination Tops Project Censored's Annual List', AlterNet, 16 September.

Lyon, D. (1994) The Electronic Eye. The Rise of Surveillance Society, Cambridge: Polity Press.

Lyon, D. (2001) Surveillance Society. Monitoring Everyday Life, Buckingham: Open University Press.

MacArthur, J. (1992) The Second Front. Censorship and Propaganda in the Gulf War, Berkeley: University of California Press.

Macé, G. (1890) Mon musée criminel, Paris: Charpentier.

Mackenzie, D. (1990) Inventing Accuracy. A Historical Sociology of Nuclear Missile Guidance, Cambridge, MA: MIT Press.

Maneri, M. (1995) 'Stampa quotidiana e senso comune nella costruzione sociale dell'immigrato', unpublished thesis, Università di Trento. 


\section{Bibliography}

Maneri, M. (1998) 'Lo straniero consensuale. La devianza degli immigrati come circolarità di pratiche e discorsi', in A. Dal Lago (ed.), Lo straniero e il nemico. Materiali per l'etnografia contemporanea, Genova: Costa \& Nolan.

Maneri, M. (2009) I media e la guerra alle migrazioni, in S. Palidda (ed.), Razzismo democratico. La persecuzione degli stranieri in Europa, Milan: Agenzia X, pp. 66-88.

Maneri, M. (2010) 'Media discourse on immigration. Control practices and the language we live by', in S. Palidda (ed.) Racial Criminalisation of Migrants, Farnham: Ashgate (forthcoming).

Mann, S., Nolan, J. and Wellman, B. (2003) 'Surveillance. Inventing and Using Wearable Computing Devices for Data Collection in Surveillance Environments', Surveillance \& Society, 1, 3: 331-355, available at www.surveillance-andsociety.org/journalv1i3.htm.

Margalit, A. (2009) 'Bombe viventi. La ragioneria politica del terrorismo', interview by R. Ciccarelli, published in il Manifesto, 22 September, pp. 11-12.

Marx, G.T. (1984) Undercover: Police Surveillance in America, Berkley and Los Angeles: University of California Press.

Marx, G.T. (2007) 'Sorveglianza soft. Come cresce la voglia di regalare informazioni personali', in 'Un mondo di controlli', Conflitti globali, 5: 37-50.

Mathiesen, T. (1997) 'The Viewer Society: Michel Foucault's Panopticon Revisited', Theoretical Criminology, 1-2: 215-234.

McFalls, L. (2010) 'Benevolent Dictatorship. The Formal Logic of Humanitarian Government', in D. Fassin and M. Pandolfi (eds), Contemporary States of Emergency, New York: Zone.

Mead, G.H. (1918) 'The Psychology of Punitive Justice', The American Journal of Sociology, 23, 5: 577-602.

Megret, F. (2003) 'Justice in Times of Violence', European Journal of International Law, 14, 2: 327-345.

Metz, S. (1997) 'Strategic Asymmetry', Military Review, July-August, 4.

Meyers, P.A. (2008) Civic War and the Corruption of the Citizen, Chicago: University of Chicago Press.

Mezzadra, S. and Neilson, B. (2008) 'Border as Method, or the Multiplication of Labor', Transversal, 6, available at www.edu-factory.org/index.php?option=com_ content\&task=view\&id=83\&Itemid=41.

Mezzadra, S. and Rahola, F. (2006) 'The Postcolonial Condition', Postcolonial Text, 2, 1, available at http://postcolonial.org/index.php/pct/article/view/393/819.

Michaud, Y. (1978) Violence et Politique, Paris: Gallimard.

Military Order, 13 November 2001, in Federal Register, 16 November 2001, 66, 222.

Miller, M. and Soeffner, H.-G. (eds) (1996) Modernität und Barbarei. Soziologische Zeitdiagnose am Ende des 20. Jahrhunderts, Frankfurt am Main: Suhrkamp.

Miller, R.L. (1988) Heritage of Fear. Illusion and Reality in the Cold War. A Review, New York: Walker.

Miller, T.C. (2007) 'Contractors Outnumber Troops in Iraq', Los Angeles Times, 4 July 2007, available at http://articles.latimes.com/2007/jul/04/nation/na-private4.

Minc, A. (1997) La Mondialisation Heureuse, Paris: Plon.

Mir Puig, S. and Corcoy Bidasolo, M. (eds) (2004) La politica criminal en Europa, Barcelona: Atelier.

Moccia, S. (1997) La perenne emergenza. Tendenze nel sistema penale, Napoli: Esi. 
Morosini, M. (2005) 'Jihad e giustizia penale', Questioni giustizia, 2: 409-420.

Mucchielli, L. (2002), Violences et insécurité. Fantasmes et réalités dans le débat français, Paris: La Découverte.

Mucchielli, L. (ed.) (2008) La frénésie sécuritaire. Retour à l'ordre et nouveau contrôle social, Paris: La Découverte.

Munkler, H. (2004) Die Neuen Kriege, Reinbek bei, Hamburg: Rowohlt Taschenbuch Verlag.

Murray Li, T. (2007) The Will to Improve. Governmentality, Development and the Practice of Politics, Durham and London: Duke University Press.

National Commission on Terrorist Attacks upon the United States (2004) The 9/11 Commission Report. Final Report of the National Commission on Terrorist Attacks Upon the United States, authorized edn, New York: Norton.

Nation Intelligence Council (2004) Mapping the Global Future: Report of the National Intelligence Council's 2020 Project, Based on Consultations with Nongovernamental Experts around the World, Government Printing Office, Pittsburgh (PA), December, available at www.foia.cia.gov/2020/2020.pdf.

Neal, A.N. (2008) 'Goodbye War on Terror? Foucault and Butler on Discourses of Law, War and Exceptionalism', in M. Dillon and A.W. Neal (eds), Foucault on Politics, Security and War, London: Palgrave Macmillan.

Neal, A.N. (2009) Exceptionalism and the Politics of Counter-terrorism, London: Routledge.

Norris, C. (2002) 'From Personal to Digital: CCTV, the Panopticon and the Technological Mediation of Suspicion and Social Control', in D. Lyon (ed.), Surveillance as Social Sorting. Privacy, Risk and Digital Discrimination, London: Routledge, pp. 249-281.

Norris, C. and Armstrong, G. (1999) The Maximum Surveillance Society. The Rise of CCTV, Oxford: Berg.

O'Hanlon, M. (2000) Technological Change and the Future of Warfare, Washington, DC: The Brookings Institution.

Ocqueteau, F. (1997) Les défis de la sécurité privée: protection et surveillance dans la France d'aujourd'hui, Paris: L'Harmattan.

Ocqueteau, F. (2004) Polices entre Etat et marché, Paris: Presses de Science-Po.

Ong, A. and Collier, S. (2005) Global Assemblages. Technology, Politics and Ethics as Anthropological Problems, London: Blackwell Publishing.

Ong, A. (2006) Neoliberalism as Exception: Mutations in Citizenship and Sovereignty, Durham and London: Duke University Press.

Palidda, S. (1992) 'L'anamorphose de l'Etat-Nation: le cas italien', Cahiers Internationaux de Sociologie, 93: 269-298.

Palidda, S. (1996a) 'Verso il fascismo democratico?', Aut Aut, 276: 143-168.

Palidda, S. (ed.) (1996b) Délit d'immigration. La construction sociale de la déviance et de la criminalité parmi les immigrés en Europe, Bruxelles: COSTCommunauté Européenne.

Palidda, S. (1998) 'La conversione poliziesca delle politiche migratorie', in A. Dal Lago (a cura di), Lo straniero e il nemico. Materiali per l'etnografia contemporanea, Genoa: Costa \& Nolan, pp. 209-235.

Palidda, S. (2000) Polizia postmoderna. Etnografia del nuovo controllo sociale, Milano: Feltrinelli.

Palidda, S. (2007a) 'Missions militaires italiennes à l'étranger: la prolifération des hybrides', Cultures \& Conflits, 67, available at www.conflits.org/index3126.html. 


\section{Bibliography}

Palidda, S. (2007b) 'Politiche della paura e declino dell'agire pubblico', in 'Un mondo di controlli', Conflitti globali, 5: 13-22.

Palidda, S. (2008) 'Appunti di ricerca sulle violenze delle polizie al G8 di Genova', Studi sulla questione criminale, 3, 1: 33-50.

Palidda, S. (ed.) (2009) Razzismo democratico. La persecuzione degli stranieri in Europa, Milan: Agenzia X.

Palidda, S. (2010) 'Violences policières et violences des pouvoirs en Italie', in X. Crettiez and L. Mucchielli (eds), La violence politique en Europe, La Découverte (forthcoming).

Palidda, S. (ed.) (2010) Racial Criminalization of Immigrants in the 21st Century. London: Ashgate (forthcoming).

Pandolfi, M. (2000) 'Une souveraineté mouvante et supracoloniale. L'industrie humanitaire dans les Balkans', Multitudes, 3: 97-105.

Pandolfi, M. (2002) 'Moral Entrepreneurs, souverainetés mouvantes et barbelé. Le bio politique dans les Balkans post-communistes', Anthropologie et Sociétés, special issue, M. Pandolfi and M. Abélès (eds), Politiques jeux d'espaces, 26, 1: 29-50.

Pandolfi, M. (2003) 'Contract of Mutual (In)difference. Governance and Humanitarian Apparatus in Albania and Kosovo', Indiana Journal of Global Legal Studies, 10, 1: 369-381.

Pandolfi, M. (2005) 'Sovranità mobile e derive umanitarie: emergenza, urgenza, ingerenza', in R. Malighetti (ed.) Oltre lo sviluppo: una prospettiva antropologica, Rome: Meltemi, pp. 151-185.

Pandolfi, M. (2008) 'Laboratory of Intervention. The Humanitarian Governance of the Postcommunist Balkan Territories', in M.-J. Del Vecchio Good, S.T. Hyde, B.J. Good and S. Pinto (eds), Postcolonial Disorders, Berkeley: University of California Press, pp. 157-186.

Papa, M. and Donini, M. (eds) (2007) Diritto penale del nemico, Milan: Giuffré.

Pape, R.A. (2005) Dying to Win. The Strategic Logic of Suicide Terrorism, New York: Random House.

Parker, G. (1996) The Military Revolution, 1500-1800: Military Innovation and the Rise of the West, Cambridge: Cambridge University Press (2nd edn).

Paye, J.-C. (2007) Global War on Liberty, New York: Telos Press Publishing.

Pepino, L. (2005), Andreotti - La mafia - I processi. Analisi e materiali giudiziari, Torino: EGA.

Pepino, L. (2006) 'La giustizia, i giudici e il paradigma del nemico', Questione giustizia, 4: 844-877.

Peters, R., Comm. (1997) 'Constant Conflict', Parameters, summer: 4-14.

Petraeus, General (2008) 'Counterinsurgency Guidance', available at http://usacac. army.mil/CAC2/MilitaryReview/repository/MilitaryReview_200810310001MD.xml.

Petti, G. (2004) Il male minore. La tutela dei minori stranieri come esclusione, Verona: Ombre Corte.

Petti, G. (2008) Nemici di comodo. Pratiche di esclusione nei processi per terrorismo internazionale, Milan: Libreria Clup.

Phéline, Ch. (1985) L'image accusatrice, Paris: Les Cahiers de la Photographie.

Pick, D. (1996) War Machine. The Rationalisation of Slaughter in the Modern Age, New Haven: Yale University Press.

Piven, J. and Borgenicht, D. (2001) The Worst-Case Scenario Survival Handbook. Travel. Pop Culture, San Francisco: Chronicle Books. 
Poirier, L. (1982) Essais de stratégie théorique, Paris: Fondation pour les Etudes de Défense Nationale.

Preston, R.A., Werner, H.O. and Wise, S.F. (1956) Men in Arms. A History of Warfare and Its Interrelationships with Western Society, New York: Praeger.

Price, D.K. (1965) The Scientific Estate, Cambridge, MA: Harvard University Press.

Rahola, F. (2003) Zone definitivamente temporanee, Verona: Ombre Corte.

Rahola, F. (2005) 'La parte delle vittime. Note sull'umanitarismo tra guerre di ingerenza, politiche di sicurezza e controllo dell'eccedenza', Conflitti globali, 1: 80-95.

Ramat, M. (1985) 'Il maxi processo', Questioni giustizia, 2: 259-75.

Rancière, J. (1999) Disagreement. Politics and Philosophy, Minneapolis: University of Minnesota Press.

Record, J. (2003a) 'The Bush Doctrine and War with Iraq', Parameters, spring: 4-21, available at www.usamhi.army.mil/USAWC/Parameters/03spring/record.htm.

Record, J. (2003b) 'Bounding the Global War on Terrorism', Carlisle, PA: Strategic Studies Institute, Army War College, available at www.iwar.org.uk/cyberterror/ resources/gwot/bounding-ssi.htm.

Reid, J. (2006) The Biopolitics of the War on Terror. Life Struggles, Liberal Modernity, and the Defence of Logistical Societies, Manchester: Manchester University Press.

Rensselaer W. Lee (1998) Smuggling Armageddon: The Nuclear Black Market in the Former Soviet Union and Europe, New York: St. Martin's Press (1st edn).

Ricks, T.E. (2006) Fiasco: The American Military Adventure in Iraq, New York: Penguin Press.

Robin, C. (2004) Fear: The History of a Political Idea, New York and London: Oxford University Press.

Romano, S. (1918) Corso di diritto coloniale, Roma: Athenaeum.

Rossiter, C.L. (1948) Constitutional Dictatorship. Crisis Government in the Modern Democracy, New York: Brace\&World.

Said, E. (1978) Orientalism, New York: Pantheon Books.

Said, E. (1994) Culture and Imperialism, New York: Vintage Books.

Said, E. (2002) Reflections on Exile and Other Essays, Harvard: Harvard University Press.

Saint-Bonnet, F. (2001) L'état d'exception, Paris: PUF.

Sassen, S. (2007) A Sociology of Globalization, New York: Norton \& Company.

Sassen, S. (2008) Territory, Authority, Rights. From Medieval to Global Assemblages, Princeton: Princeton University Press.

Scandurra, A. (2009) 'Libro bianco sulla legge Fini-Giovanardi', unpublished report.

Scheinberg, S. (2001) Survive Bio-Terrorism. A Basic Handbook, Newport, OR: CYA Publications.

Schmitt, C. (2003) The Nomos of Earth in the International Law of Jus Publicum Europaeum, New York: Telos Press.

Schmitt, C. (2006) Political Theology. Four Chapters on the Concept of Sovereignty, Chicago: Chicago University Press.

Schmitt, C. (2007) The Concept of the Political, Chicago: University of Chicago Press, (2nd edn).

Schram M. and Ted Turner Documentaries (Firm) (2003) Avoiding Armageddon. 


\section{Bibliography}

Our Future, Our Choice. Companion to the PBS Series from Ted Turner Documentaries, New York: Basic Books.

Schwartz, N.D. (2003) 'The War Business', Fortune, 3, March.

Sebesta, L. and Pigliacelli, F. (2008) La terra vista dall'alto. Breve storia della militarizzazione dello spazio, Roma: Carocci.

Senellart, M. (1995) Les arts de gouverner. Du regimen medieval au concept de gouvernement, Paris: Editions du Seuil.

Sheehan, J.J. (2008) Where Have All the Soldiers Gone?: The Transformation of Modern Europe, Boston and New York: Houghton Mifflin Company.

Sidel, R. (1996) 'The Enemy Within. A Commentary on the Demonization of Difference', American Journal of Orthopsychiatry, 66, 4: 490-495.

Simon, J. (2007) Governing Through Crime. How the War on Crime Transformed American Democracy and Created a Culture of Fear, Oxford and New York: Oxford University Press.

Singer, P. (2004) Corporate Warriors. The Rise of the Privatized Military Industry, Ithaca: Cornell University Press.

Singer, P.W. (2009) Wired for War. The Robotics Revolution and Conflict in the 21st Century, New York: Penguin Press.

Sloterdijk, P. (2004) Schäume, Frankfurt am Main: Suhrkamp.

Soros, G. (1998) La Crise du Capitalisme Mondial: l'intégrisme des marchés, Paris: Plon, trans. (1998) The Crisis of Global Capitalism, LLC: Perseus Books.

Sorrentino, V. (2008) Il pensiero politico di Foucault, Rome: Meltemi.

Spataro A. (2007) 'Le forme attuali di manifestazione del terrorismo nella esperienza giudiziaria: implicazioni etniche, religiose e tutela dei diritti umani.', available at http://appinter.csm.it/incontri/ele_relat_inc.php?\&id=Mjg4MA\%3D\%3D.

Spataro A. (2008) 'Why Do People Become Terrorists? A Prosecutor's Experience', Journal of International Criminal Justice, 6, 3: 507-524.

Spivak, G. Ch. (1988) 'Can the subaltern speak?', in L. Grossberg and C. Nelson (eds), Marxism and the Interpretation of Culture, Urbana: University of Illinois Press.

Steinberger, J. (2005) 'Social Responsibility of the Scientist: The Future of Nuclear Weapons in NATO', in G. Luzzatto and L. Guzzetti (eds) I rapporti tra scienza e società. I valori e le responsabilità, la ricerca e lo sviluppo, l'informazione, Roma: Carocci.

Steinert, H. (2003) 'The Indispensable Metaphor of War. On Populist Politics and the Contradictions of the State's Monopoly of Force', Theoretical Criminology, 7, 3: 265-291.

Sudnow, D.N. (1983) 'Reati normali: aspetti sociologici del codice penale nella difesa d'ufficio', in P.P. Giglioli and A. Dal Lago, Etnometodologia, Bologna: Il Mulino. [original.: 'Normal Crimes: Sociological Features of the Penal Code in a Public Defender Office', Social Problems, 12, 3: 255-276.)

Terry, E. and Oxer, J.P. (2003) Survival Handbook for Chemical, Biological, and Radiological Terrorism, Philadelphia, PA: Xlibris.

Tisseron, S. (2002) L'intimité surexposée, Paris: Hachette.

Todorov T. (1988) De la colonisation en Algérie, Bruxelles: Complexe.

Toffler, A. and H. (1997) 'Foreword: The New Intangibles', in J. Arquilla and D. Ronfeldt, In Athena's Camp: Preparing for Conflict in the Information Age, Santa Monica, CA: Rand.

Traynor, I. (2003) 'The Privatisation of War', Guardian, 10 December. 
UNHCR (2006) 'Draft Directive on Temporary Protection in the Event of a Mass Influx', Geneva, September.

Valluy, J. (2005) 'La nouvelle Europe politique des camps d'exilés', Cultures \& Conflits, 57.

Valverde, M. (2008a) 'Analyzing the Governance of Security. Jurisdiction and Scale. Police, Sovereignty, and Law. Foucaultian Reflections', Behemoth, 1, 1: 3-15.

Valverde, M. (2008b) 'Beyond Discipline and Punish: Foucault's Challenge to Criminology', Carceral Notebooks, 4/2008: 201-223, available at http:// foucaultblog.wordpress.com/2010/01/19/carceral-notebooks.

Veyne, P. (2008) Foucault, sa pensée, sa personne, Paris: Albin Michel.

Viganò, F. (2007) 'La legislazione nazionale negli anni del terrorismo globale anche nei rapporti con la normativa comunitaria', available at http://appinter.csm.it/ incontri/ele_relat_inc.php?\&id=Mjg4MA\%3D\%3D.

Villatte, S. (1999) 'Les philosophes devant la guerre', in P. Brun (ed.) Guerres et societés dans les mondes grecs (490-322), Paris: Editions du temps.

Virilio, P. (2002) Ground Zero, London: Verso.

Virilio, P. (2006) Speed and Politics, Los Angeles: SemioTexte.

Vitalis, A. (1981) Informatique, pouvoir et libertés, Paris: Economica.

von Trotha, T. (ed.) (1997) Soziologie der Gewalt, Opladen/Wiesbaden: Westdeutscher Verlag (special issue of Kölner Zeitschrift für Soziologie und Sozialpsychologie).

von Trotha, T. (2005) 'Globalizzazione violenta, violenza globalizzata e mercato della violenza', Conflitti globali, 1: 97-110.

Wacquant, L. (1999) Les prisons de la misère, Paris: Raisons d'Agir.

Waddington, D., Jobard, F. and King, M. (eds) (2009) Rioting in the UK and France. A Comparative Analysis, Cullompton: Willan.

Walker, R.J. (1993) Inside/Outside: International Relations as Political Theory, Cambridge: Cambridge University Press.

Walzer, M. (2006) Just and Unjust War, New York: Basic Books (4th edn).

Weber, M. (1978) Economy and Society, Berkeley: University of California Press (vol. 1, ch. 3).

Weber, M. (1988) 'Zwischen zwi Gesetzen', in J. Winckelmann (ed.), Gesammelte politische Schriften, Tübingen: J.C.B. Mohr, p. 146.

Weinberger, C. (1984) 'The Uses of Military Power', 28 November, available at www.pbs.org/wgbh/pages/frontline/shows/military/force/weinberger.html.

Wells, C. (1984) The Roman Empire, Stanford: Stanford University Press.

Wells, H. and Wills, D. (2009), 'Individualism and Identity: Resistance to Speed Cameras in the UK', Surveillance \& Society, 6, 3: 259-274, available at www. surveillance-and-society.org/ojs/index.php/journal.

White, M. (2005) The Fruits of War. How Military Conflict Accelerates Technology, London: Simon \& Schuster.

Williams, M.C. (2007) Culture and Security. Symbolic Power and the Politics of International Security, Abingdon, Oxon and New York: Routledge.

Yala, A. (2005) Volontaire en ONG: l'aventure ambiguë, Paris: ECLM.

Young, R.J. (2001) Postcolonialism. An Historical Introduction, Blackwell, Oxford.

Zaki Laidi (2002) 'World Time as a Global Event', Geopolitics, 5, 2.

Zarka, Y.C. (2001) 'De la guerre', in Hobbes et la pensée politique moderne, Paris: PUF. 


\section{Bibliography}

Žižek, S. (2002a) Welcome to the Desert of the Real, London: Verso.

Žižek, S. (2002b) Repeating Lenin, Zagreb: Arkzin.

Zolo, D. (1997) Cosmopolis. Prospects for World Government, Cambridge, Polity Press.

Zolo, D. (2000) Chi dice umanità, Torino: Einaudi

Zolo, D. (2002) Invoking Humanity. War, Law and Global Order, New York: Continuum Books.

Zolo, D. (2009) Terrorismo umanitario. Dalla guerra del Golfo alla strage di Gaza, Reggio Emilia: Diabasis.

\section{Documents}

CNN, 'Bush Warns of Potential "Evil Weapons”, 6 November 2001, available at http://archives.cnn.com/2001/US/11/06/bush.terror.

CNN, 'Transcript of President Bush's Address', 21 September 2001, available at www.cnn.com/2001/US/09/20/gen.bush.transcript.

CNN, 'You Are Either With Us or Against Us', 6 November 2001, available at www.cnn.com/2001/US/11/06/gen.attack.on.terror.

Eurostat, Statistics in Focus, 46/2009, available at http://ec.europa.eu/health-eu/ newsletter/14/newsletter_it.htm.

FP7 in Brief. 'How to get Involved in the EU 7th Framework Programme for Research', available at http://ec.europa.eu/research/fp7/understanding/fp7inbrief/ home_en.html.

'Towards a More Secure Society and Increased Industrial Competitiveness', Security Research Projects under the 7th Framework Programme for Research, May 2009, available at ftp://ftp.cordis.europa.eu/pub/fp7/security/docs/towards-amore-secure_en.pdf.

Washington Post, 'President Bush Addresses the Nation', 20 September 2001, available at www.washingtonpost.com/wp-srv/nation/specials/attacked/transcripts/ bushaddress_092001.html. 


\section{Index}

9/11 22, 27-8, 29; as birth of fear of the future 106-8; as epitome of the fall of state system 103; as global event of violence 104-5; non-US understanding of 110-15; as turning point for radically new era 105-6; US perspective on 108-10

\section{Abu Ghraib 195-6}

academic participation, military research 86-7, 89-90, 94-5

academic perception on 9/11 109-10 ad hoc alliances 23

ADABTS, (Automatic Detection of Abnormal Behaviour and Threats in crowded Spaces) 9

administrative detention 192-3

Afghanistan 3, 6, 21, 23, 28, 31, 42, 44, 54, 65, 95, 100, 114, 183

Agamben, Giorgio 32, 188

Agier, Michel 187

Al Qaida 27-8, 104, 109, 112, 113-14, $140,141,160$

Albania, international agencies in 175

Algeria 3

Ali Fouad Saleh network 111

Altheide, D.L.163

Anderson, B. 3

Annan, Kofi 171

anthrax attacks 106

Anti-Oedipus (Deleuze/Guattari) 74

Arendt, H. 187, 189, 192

Aristotle 44

Armageddon 106-8

armed decision, primacy of 22-3

Armstrong, G. 132

Aron, Raymond 12, 79-81, 82-3, 105

ARPA (Advanced Research Project Agency) 87, 89-90, 91
Asad, T. 65

asylum seekers 185-6

asymmetrical conflicts 27-8, 31; and internment 195-6

atomic bomb 84-5, 87, 105

Atomic Energy Commission 87

authority: intergovernmental organizations/NGOs 179-81; international experts $174-5$

Aznar, Jose 112

Bagram 196, 197

balkanization 40, 42

Baltic States 2, 21, 23

Bauman, Z. 10, 124, 157

Beck, U. 105, 109, 157

Becker, H. 121, 139

Benjamin, W. 59

Benveniste, Émile 165

'big brother' 123

Bigo, Didier 4, 13, 103-15

biopolitics, birth of new 181-3

Bittner, Egon 119

Blair, Tony 111, 112

Boltanski, L. 110

Bonelli, L. 155

book overview 11-15

Boot, M. 94

Borradori, Giovanna 104

Bosnia, international intervention in 181-3

Bourdieu, P. 80

Brauman, R. 178

Brodeur, J.-P. 119

Brown, Gordon 111

Brunner, O. 73

Bull, H. 73

bureaucratic negotiations 174-5

Burke, J. 27 
Bush, George W. 5, 21, 23, 46, 53, 57, $60,96,106,112,114,153-4$

Bush, Vannevar 86

Campbell, D. 154

camps 185-98; as form 186-90; space of 196-8

carrot and stick approach 118-19, 122

Castel, R. 157

Castles, Stephen 188

Castoriadis, Cornelius 110

CCTV 124-5, 130; determinants of public support 133-5; growth in 131-3; public support for $132-5$

Cebrowski, A. 92

Central and Eastern Europe, NGOs 177-8

Césaire, Aimé 192-3, 198

charismatic authority 180

Charman, E. 133

Chatterjee, P. 198

China 40, 41; technological capability 98-9

Ciccarelli, Roberto 12, 57-69

Cicourel, A.V. 143

civil liberties, France 131

civilianization of war 5

Clark, General Wesley 28

'clash of civilizations' $2-3,5,30$

Clausewitz, K. 1, 5, 13, 24, 92; and global policymaking 46-8; on politics and war 70-83

Clausewitz: philosopher of war (Aron) 79

Clinton, Bill 60

Cohen, S. 157

Cold War 39, 77, 79, 80-1; arms race 85-90, 96; defense spending during 84 ; memories of 105,107

collateral damage $27,30-1$

Collier, S. 67

Collins, J. 160

colonial origin of camp-form 192-4, 198

colonialism 38-9

communication technologies 91-5

confidential reports, international agencies 176

conflict, distinguishing from war 80-1

conquest, end of imperial strategies of 38-9

contemporary war as global enforcement 21-32

conventional warfare 27
Cook, R. 3

Court of Cassation, Italy 142

Craxi, Bettino 156

crematistic economy, disproportion of 45-6

criminal trials: de-politicization of terrorists 143-8; and global terrorism 138-40; legal war against global enemy 140-3

criminals-turned-state witnesses 145

crisis management 171-83

cultural conflict 64-7

Culture and imperialism (Said) 194

culture, influence of war on 29-30

cyberwars 42,93

Dal Lago, Alessandro 1-15, 21-32, 69, 97, 120, 126, 138, 141, 147, 167

danger, in war discourse 153-7

DARPA (Defense Advanced Research Project Agency) 87, 91

Davidson, Alistair 188

Davis, M. 10

De Genova, N. 189

De Landa, M. 27, 76

de-humanisation 163-4

de-politicization mechanisms 143-8

de-territorialized spaces 196-8

deep narrative structure construction: agency 164-5; characters 162-4; complication 161; partition 161-2; positioning 165

defense advisors, terrorism trials 145

defense, rhetorical dispositive of 164-5

Defense News 84

defense spending $84,87,94$

Deleuze, Giles 12, 13, 74-9, 82, 122-3

deregulated market economy, spread of 40

Derrida, Jacques 30, 104

Desportes, V. 95

difference: characterisation of 162-4; construction of 161-2; production of 189-90, 197

Dirlik, Arif 190-1

disciplinary regimes $166-9$

disorder: management of 119-22; violent management of 118-19, 123-7

Ditton, J. 133

dominant classes, barbarization of 48

Douglas, M. 156

drug addicts 125, 156, 160

Du Bois, W.E. 193 
dual-use technologies 88-90

Duclos, L.J. 108

Duffield, M. 177

Duso, G. 72

economic deregulation 44, 50 economic dominion 38-40 economic globalization 40-1 economic migrants 190-2 Eisenhower, Dwight D. 85-6, 87 electronic revolution 42,44 emergency, justification for 161 enemy: characteristics of 162-4; changing face of 1-4; debasing 30-1; identification of 114-15; internal/ unlawful 60-1

\section{ENIAC (Electronic Numerical} Integrator and Computer) 91

enmity, discourse of 155-7

Eribon, D. 74

Escobar, A. 164, 178

ETA Militar 111

Europe: construction of difference 163; discourse of enmity 155-6; liberation of 39 ; perspective on $9 / 11109,111$; political realism 153-7, 167; rapid intervention military force 23 ; shift towards barbarism 52-3; special laws 60-1

European Union (EU): research policies $7-11$; security policy 53 ; and sovereignty 40

Evans, T. 120

evil, framing of 159-60

exceptionalism 31 ; and authority 183 ; in current governmentality 67-9; decisions concerning 111-15; and internment 188-9, 196-8; and the norm 59-60; terrorist trials 139 , $147-8$

excluded, violent persecution of 123-7 exclusion and inclusion 188

experimental wars $42-3$

external enemies $62,167-8$

Fallaci, Oriana 30

fascism 77-8

Faso, G. 163

Fassin, D. 2

fear: discourse of 157-9; of future 106-8; morals of 165-6

Ferguson, J. 178

Ferrajoli, Luigi 58, 143-4

Fijnaut, C. 129 financial crisis: crimes of 51-2; as revealer of actual powers 50-1

financial forces, political disproportion of doctrines for use of 44

financial support, terrorist activities 141

fingerprinting, origins of 192

Fisk, R. 5

flexible production 191

forced labour camps 193

forcible abduction 60

Forman, P. 86, 88, 91

Foucault, Michel 1, 7, 12, 13, 24, 62, $65,67,68,70-4,82,119,121$, 122-3, 125, 129-30, 134, 147-8, 169, 188, 190, 193, 197

founding myths, US 155

Fourth-Generation Warfare (4GW) 97-8

France: insecurity 159-60; surveillance 129-36

Freeman, C. 89

Fulbright, Senator J. William 89

Furedi, F. 157, 163

Galli, G. 96

Gamson, W.A. 105

Garstka, J. 92

Gaullism 39

Geneva Conventions 60

Giap, V.N. 97

Ginzburg, Carlo 192

Girard, R. 157

Giuliani, Rudolph 156

Glassner, B. 10, 157, 167

Gleizal, J.J. 120

global act of violence, $9 / 11$ as 104-5

global bureaucracy: birth of new biopolitics 181-3; global bureaucrats 173-7; migrant sovereignty and therapeutic domination 179-81; symbiosis with non-governmental organizations $177-8$

global confrontation, disproportion of religiousness in 45

global empire, barbarisation of means of 41-3

global enforcement 21-32

global interconnection, armed groups 3-4

global leadership, de-Americanization of 43-4

global 'nobility' 48

global policies, clandestinity of 41 
global policy-making, maintenance of Clausewitzian template 46-8

Global Positioning System (GPS) 94

global society, war in transformation of 5-11

global standardization 5-6

global terrorism $138-40 ; 9 / 11$ as

108-10; de-politicization of terrorists 143-8; legal war against 140-3

Glover, R. 154, 160

Gnoli, A. 70

Goffman, Erwing 190

government of technique 64

governmental prospects, and political theology 57-69

governmentality, norm/exception in 67-9

Green, S. 136

Greenberg, D. 86

Groombridge, N. 130

Guantanamo 196-7

Guareschi, Massimiliano 12-13, 70-83

Guattari, Felix 12, 13, 74-9, 82

guerrilla warfare $27,97-8$

Gulf Wars 3, 27, 41, 94

Gusfield, J.R. 157

Gusterson, H. 89

Guzzetti, Luca 4, 13, 84-100

Habbash, George 66-7

Habermas, J. 104

Hacker, B.C. 88, 93, 94, 96, 100

Hall, S. 167, 194

Hammes, T.X. 97, 99, 100

Hanson, L. 1

Harcourt, B.E. 125

Harris, J. 120

Heilmann, Eric 14, 123, 129-36

Heisbourg, F. 104

Heisler, M. 109

Henrotin, J. 98

Hermant, D. 108

Herzfeld, Michael 172

Hezbollah 111

Hilhorst, D. 177

Hill, D.L. 89

Hillyard, P. 139

Hiroshima 105

historical context of 9/11 109-10

historical discourse on war 71-4

Ho Chi Minh 97

Hobart, M. 178

Hobbes, Thomas 24, 38, 71-2

Holland, J. 104
Honess, T. 133

Howard, John 112

Huizinga, Johan 70

human rights, disregard for 30-1

humanitarian interventions 6

humanitarian law 65, 67

Huntington, S.P. 2-3, 5, 30

Hussein, Saddam 6

hyper-modern conformity 44

hyper-modern imperial hubris 41

hyperterrorism 104-5, 109, 115

iatrogenic (physician-induced) violence 181

ideal type of war discourse 157-66

ideological consensus, US 153-7

illegal combatants, internment of 195-6

immigrants, as the enemy $141,156-7$

immigration, war against $167-8$

imperialism, US 38-40, 41-3

income, nobility of 48-50

Independent International Commission on Kosovo 182

industrial military research $88,94-5$

information technologies 91-5

insecurity: causes of $10-11$; rise of 105-8

INSEE, France 131

intergovernmental organizations

171-83; authority of 179-81

internal enemy 60-1, 62, 167

international experts $173-5$

international interventions 171-83

internment 22; camp as form 186-90; camps and war 195-6; definitions

185-6; from colonies to world

193-4; excess 190-2; genealogy

192-3; space of camps 196-8; terrorist offences 144-5

interpreters, terrorist trials 146

intolerance, intensification of 126

investigative practices, terrorist trials 143-8

Iraq 3, 6, 21, 23, 29, 30, 42, 44, 65, 93-4, 99, 100

Islam 2-3, 29-30

Islamic fundamentalism $65-7$

Italy: construction of difference 164; insecurity 159-60; terrorism trials 139-48; war metaphor 155-6

Jackson, R. 154, 163

Jakobs, Günther 148

James, A.D. 84 
Japanese Red Army 66-7

jihad 140, 144, 146

Johns, C.J. 160

Johns, F. 196

Johnson, M. 154

Jouanneau, H. 132

Joxe, Alain 2, 12, 37-54

Jünger, Ernst 70

Kagan, R. 31

Kaldor, Mary 21, 53

Kamikaze, phenomenology of 64-7

Kaminski, A. 192

Kevles, D.J. 87-8

Kistiakowsky, George B. 86

Kitsuse, J.I. 143

Kosovo 21, 23, 27, 29, 175, 181-3

Kotek, J. 192

Kristol, W. 31

Kuipers, Benjamin 90

Kuwait 3, 6, 21, 27

Lakoff, G. 154

Latour, B. 122

Latin American paradigm 39-40

law: nexus with space 63-4; of war 38 ; violation of 73

Lawrence Livermore Laboratory 86

Le Goff, T. 133

legal order 59-60; origin of 63

legal status, unlawful enemy combatants 60-1

legal-rational authority 180

legitimate authority, forms of 180-1

Lenin 74,83

Lens, S. 85

Leslie, S.W. 88,89

Leviathan (Hobbes) 71

Levy, S. 90

Liang, Q. 98

Lianos, M. 136

life and death, reversal of value of 65-6

Lincoln Laboratory 86

Lind, W.S. 97

Lipsky, M. 120

lobbying power 46,52

local authorities, use of CCTV 132, 135

local event, $9 / 11$ as $110-15$

local NGOs 178

London bombings 22, 111

Ludendorff, Erich 70, 74

Lyon, D. 136

Macé, Gustave 130-1
McFalls, Laurence 15, 171-83

Machiavelli 37

machine guns 192

Mackenzie, D. 87, 91

Madrid bombings 22, 111

Maneri, Marcello 14-15, 153-69

Manhattan Project 84, 96

Mann, S. 130

Mao Tse-Tung 97, 98

Margalit, A. 67

market economy, deregulation in 40

market fundamentalism 45, 48

martyrdom 65

Marxism 71, 73-4

'materialized war' 77-9

Mathiesen, T. 130

Mead, G.H. 162, 166

media: at war 153-69; embedded journalists 29 ; perspective on $9 / 11$ 108, 111, 112; US/Europe 153-7

mediation 118-19, 122

mercenary power, US 41

Mercier, Louis-Sébastien 130

metaphors 154-5, 158-9, 166-9

Metz, S. 31

Mezzadra, S. 194

Michaud, Yves 104

micromachines 94

migrant sovereignty $179-81$

Milan, terrorist trials 143-8

militarized metaphors 166-9

military transformation 41-3

military research, outsourcing 84-90

military transformation 41-3, 44

military superiority 96-100

military-industrial-academic complex 84-90

Moccia, S. 139

moral panic 139, 157-9

morals of fear 165-6

Morosini, M. 144

Mucchielli, L. 155

mug-shots 130-1, 134

Munkler, H. 21

Murray Li, T. 67

Napoleonic wars 76-7

National Center for Defense Robotics 95

National Defense Education Act, US 87-8

national identity cards 134

National Intelligence Council 4

NATO 2, 22, 23, 27, 182 
Nazism 39

neo-colonialism 39-40

neo-conservative transformation:

barbarisation of dominant classes 48;

barbarization of means of global

empire 41-3; barbarization of aims

38; crimes of crisis and crimes of war

51-2; de-Americanization of strategies 43-4; deregulated market economy 40; disproportion of crematistic economy 45-6;

disproportion of religiousness in

global confrontation 45;

disproportion of technological

modernity and power of lobbies 46;

financial crisis as revealer of actual

powers 50-1; hyper-modern

conformity and political

disproportion of doctrines 44;

imperial strategies of conquest/

protection 38-9; Latin American

paradigm 39-40; maintenance of

Clausewitzian template in global

policy-making 46-8; mercenary

power 41 ; new nobility of income

48-50; non-democratic barbarisms

52-3; of police 119-27

neo-liberalism, effects of 167-8

neologisms 161

network organizational model 99

network-centric warfare (NCW) 92-4, 96-7

New Deal 118, 123, 125, 127

nomadic war machine 74-9

Nomos of the earth (Schmitt) 62-4

non-democratic barbarisms 52-3

non-governmental organizations

(NGOs) 171-83; authority of

179-81; symbiosis with global

bureaucracy $177-8$

non-institutional actors, and

bureaucracy 173-7

non-US perspective on 9/11 110-15

norm: in current governmentality 67-9;

and exception 59-60

Norris, C. 132, 136

North-South relations 168

Northern Alliance 28

nuclear terrorism 106-8

nuclear weapons 96, 98

O'Hanlon, M. 26

Obama, Barack 1, 28, 44, 46, 49, 53

Ocqueteau, F. 133
Odyssey (Homer) 96

Okamoto, Közö 66-7

Ong, A. 67

order and disorder 120-1

'Other': characteristics of 162-4; construction of $157,160,161-2$

outsourcing, research $84-90$

Pakistan 44, 54

Palidda, Salvatore 1-15, 118-27, 168

Pandolfi, Mariella 2, 15, 171-83

panopticons, proliferation of 122-3

Pape, R.A. 31

Passeron, J.C. 80

paternalistic power 121

Patraeus, General 43, 54

patriotism 114

Pax Romana 38

Peace and war: a theory of international relations (Aron) 83

peace processes 43

peace: barbarization of 37-54;

distinguishing from war 79-81

peacetime war discourse: characteristics and properties of 157-66;

disciplinary regime 166-9; war and danger in the US 153-7

Pearl Harbor 107, 108

Pepino, L. 144

personal fear 158

petty crime and immigration 157

Petti, Gabriella 14, 138-48

Phéline, C. 134

phenomenology of the kamikaze 64-7

Pigliacelli, F. 85

Poirier, L. 105

police: access to CCTV images 132; databases 134; management of disorder 119-22; neo-conservative transformation of 123-7;

professionalization of 129-30;

proliferation of panopticons 122-3

policies of enmity 164-5

policy-making institutions, lack of 46-8

political crime, definition of 60-1

political fear 158

political inclinations, knowledge of 146-7

political realism, Europe 153-7

political recomposition 54

political theology, exceptionalism and

governmental prospects in 57-69

political-economic hegemony 6 
politics and war 24-5; Aron on 79-81;

Deleuze and Guattari on 74-9;

Foucault on 70-4; reversing

Clausewitz 82-3

politics of war 61-4

politics, crisis of 167

Popular Front for the Liberation of

Palestine 67-8

positioning 165

postcolonialism 194-6

Postcriptum sur les sociétés de contrôle

(Deleuze) 122

power relations $70-4$

pre-emptive war 57-8

Price, D.K. 86, 87, 90

'private warfare' 72-3

productive capacity, camps 188-90

productive excess 190-2

Prometheus, myth of 96-100

protection, end of imperial strategies of 38-9

Provisional IRA 111

public support: CCTV 132-5;

registration 130-1

racial profiling 125

racism 74

Rahola, Federico 6, 15, 124, 185-98

Rancière, J. 195

RAND Corporation 88

Reagan, Ronald 40

refugee camps 185-6, 190-3

regional subglobalizations 54

registration, resistance to 130-1

religiousness, in global confrontation 45

research policies, EU 7-11

revenge, thirst for 114

Revolution in Military Affairs (RMA) 4, 8, 26-8, 41-3, 92-3, 108

Revolution in Police Affairs (RPA) 118-27

rhetoric of war 154-5

Rigoulot, P. 192

Robin, C. 157, 158, 163, 165

robotics $94-5$

rule of law 58-9

Rumsfeld, Donald 42, 44, 53, 106, 112

Russia: Cold War relations with US 80-1; labour camps 193; technological capability $87,89,91$, 96

Rwanda, international intervention in 181-2
Safari system, France 131

Said, Edward 163, 185, 194

Sassen, S. 68

Schmitt, Carl 24, 32, 48, 58, 59, 61, $62-4,73,81$

scientific education $87-8$

Sebesta, L. 85

security technologies $8-10$

security, primacy of 22

self-centred perspective of 9/11 108-10

Senellart, M. 7

Serbia 22

Seventh Framework Programme for Research (FP7) 2007-2013, EU 7-8, 11

'shock and awe' 95

Sidel, R. 167

Simon, J. 125, 156, 157, 160, 163

Singer, P.W. 6, 87, 90, 91, 94, 95

'smart bombs' 94

social characterization, terrorist suspects 141

social control: agencies of 10 ; militarization of 22; and war discourse 168-9

social injustice $48-50$

social life, pacification of 62

social object production: description 160-1; foregrounding/backgrounding 159; framing 159-60

social peace $119-20$

social problems: construction of 155-7; re-framing of 159-60, 167-8

Social production of indifference

(Herzfeld) 172

'social system of thought', war as 24

socializing relation of violence $110-15$

societies of control 122-3

societies, transformation of 5-11

Society must be defended (Foucault) 70, 73-4

Somalia 21, 181-2

Soros, George 45

Sorrentino, Vincenzo 74

sovereignty: crisis of 58-9; loss of 52-3, 62-3; migrants 179-81; principle of $38-9$

Soviet Union see Russia

Spataro, A. 141

speed cameras 136

Standard Research Institute 86

Star Wars 89

state of emergency 61-4

'state of war' 71-2, 195-6 
state system, fall of 103

state, incorporation of war function 74-9

Steinberger, J. 89

Steinert, H. 155

strategic globalization, deconstruction of process of 38

street-level bureaucracy 120

subprime crisis 50

Sudnow, D.N. 145

suicide bombings 64-7

'suicide state' 78

surveillance: determinants of support 133-5; growth in CCTV 131-3; resistance to registration 130-1; technologies for 8-10

suspicion, logic of 113-14

symbolic war 80

\section{Tableau de Paris (Mercier) 130}

Taliban 28

technical education $87-8$

technological modernity, disproportion of 46

technological superiority 96-100

technoscience: information and communication technologies for war 91-5; military-industrial-academic complex 84-90; myth of Prometheus 96-100

terms of reference (TOR) 123-5, 176, 181

terrorism: nature of 2-4; offence of 141-2, 143

terrorist-criminals 138-48

terrorists, as enemy 156-7

Thatcher, Margaret 40

therapeutic dominion 179-83

Thousand Plateaus (Deleuze/Guattari) 74,82

threat, identifying and reviving 161-5

Tisseron, S. 135

Toffler, A. \& H. 92

'total war' 76-9, 192

Totale krieg (Ludendorff) 70

traditional authority 180

transnational rule of law 180

Traynor, I. 6

trial practices $143-8$

Turing, Alan 91

UK: construction of difference 163; discourse of enmity 156 ; insecurity 159-60; strategic alignment 39; surveillance $132,133,135,136$; war metaphor 155

United Nations (UN): embargo against Iraq 30; and global bureaucracy 171-83; position of freedom fighters 138; UNHCR 186

unlawful enemy combatants 60-1

unmanned aerial vehicles 93, 95, 98

Unrestricted warfare (Liang/Xiangsui) 98

US Patriot Act 22, 60, 61

US: Cold War relations with Russia 80-1; construction of difference 163; global leadership 43-4; ideological consensus 153-7; imperial module 39-40; mercenary power 41 ; military strategies 43-4; military transformation 41-3; neo-colonialism 37-54; perspectives on 9/11 108-10; response to $9 / 11$ 111-15; RMA 4, 8, 26-8, 41-3, 92-3, 108; shift to barbarism 52-3; strategic culture 4; as super-armed mercenary power 41 ; technological superiority 96-100; technoscience 84-95; at turning point before Obama 53-4

Valluy, J. 186

Valverde, M. 119

vertical expansion, trial proceedings 144-5

victims, characteristics of 162-4

Vietnam War 93, 96

Viganò, F. 141

violent management of disorder 118-19, 123-7

Virilio, P. 78, 104

Vitalis, A. 131

Volpi, F. 70

Vom kriege (Clausewitz) 75, 82

von Moltke, Helmuth 92

Wal-Mart 92

Walker, R.J. 4

Walzer, M. 1

'war as action'/'war as state' 81

war crimes 42, 51-2

war metaphor 154-5, 158-9

War on Terror: discourse on 153-4; onset of 111-15

war: and changing face of the enemy 1-4; future form of $97-8$; as global enforcement 21-32; information and communication technologies for 
91-5; and internment 195-6; media discourse 153-69; military-

industrial-academic complex 84-90; myth of Prometheus 96-100; neoconservative transformation of 37-54; in peacetime war discourse 153-7; and politics 70-83; politics of 24-5, 61-4; role in transformation of global society 5-11; and technoscience 84-100

weapons of mass destruction (WMDs) 106-8

Weber, M. 32, 120, 180, 196

Wells, H. 136

Western hegemony 28-9

Westernization 5-6
Westphalian war objectives 37-8

White, M. 94

Wills, D. 136

World War I 193

World War II 39-40, 84

Xiangsui, W. 98

Yala, A. 178

youth, intolerance towards 126

'zero losses' ideology 27

zero tolerance approach 118-19, 127

Žižek, S. 104, 189

Zolo, D. 173

Zuse, Konrad 91 